\title{
NELSON QUIM
}

\section{DESENVOLVIMENTO DE UMA METODOLOGIA DE SIMULAÇÃO APLICADA AO SISTEMA DE ARREFECIMENTO VEICULAR.}

Dissertação apresentada à Escola Politécnica da Universidade de São Paulo para obtenção do Título de Mestre em Engenharia. 


\section{NELSON QUIM}

\section{DESENVOLVIMENTO DE UMA METODOLOGIA DE SIMULAÇÃO APLICADA AO SISTEMA DE ARREFECIMENTO VEICULAR.}

Dissertação apresentada à Escola Politécnica da Universidade de São Paulo para obtenção do Título de Mestre em Engenharia.

Área de Concentração:

Engenharia Mecânica

Orientador:

Prof. Dr. Marcos de Mattos Pimenta

São Paulo 


\section{FICHA CATALOGRÁFICA}

Quim, Nelson

Desenvolvimento de uma Metodologia de Simulação Aplicada ao Sistema de Arrefecimento Veicular. São Paulo, 2007 $149 \mathrm{p}$.

Dissertação (Mestrado) - Escola Politécnica da Universidade de São Paulo. Departamento de Engenharia Mecânica.

1. Sistema de Arrefecimento 2. Trocadores de Calor 3. Método dos Volumes Finitos CFD 4. Compartimento do Motor 5. Engenharia Automotiva. I. Universidade de São Paulo. Escola Politécnica Departamento de Engenharia Mecânica II. t. 
A minha esposa Sandra

e a minha filha Letícia com muito carinho. 


\section{AGRADECIMENTOS}

Em primeiro lugar agradeço a minha esposa Sandra Yumi, que sempre me apoiou e esteve ao meu lado nos momentos mais difíceis.

Ao amigo e orientador Prof. Dr. Marcos de Mattos Pimenta pela amizade e diretrizes seguras sem as quais este trabalho não se realizaria.

Aos amigos do Departamento de Engenharia de Produto da Behr e Delphi e ao engenheiro Fábio Panzetti do Campo de Provas da GMB, pelas contribuições que ajudaram no enriquecimento deste trabalho.

À GENERAL MOTORS DO BRASIL, representada pelo seu Gerente do departamento de Cálculo Estrutural - CAE da Engenharia do Produto, Engenheiro Roberto Pereira Ramos, pela oportunidade de desenvolver um trabalho de pesquisa relacionado aos assuntos da empresa e pelo apoio que me possibilitou concluir o mestrado paralelamente às atividades da empresa.

A todos que, direta ou indiretamente, colaboraram na execução deste trabalho. 


\section{SUMÁRIO}

SUMÁRIO .............................................................................................. iv

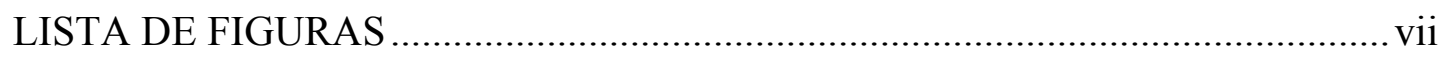

LISTA DE SÍMBOLOS .................................................................................

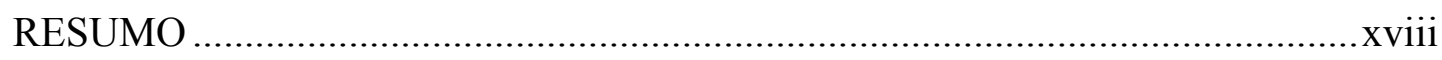

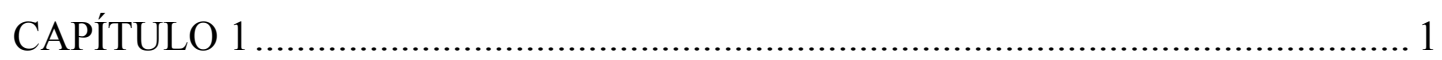

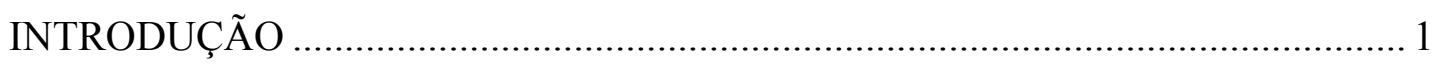

1.1 Objetivos e Motivação ............................................................................ 1

1.3 Descrição do Tema..................................................................................... 7

1.3.1 Requisitos de Projeto do Sistema de Arrefecimento................................. 10

1.3.2 Itens que Afetam a Entrada de Ar no Compartimento do Motor.............. 11

1.3.3 Circuito de Arrefecimento do Motor ......................................................... 16

1.3.4 Circuito de Arrefecimento da Cabine ..................................................... 17

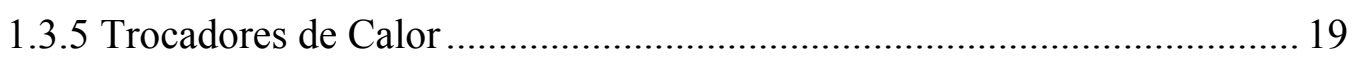

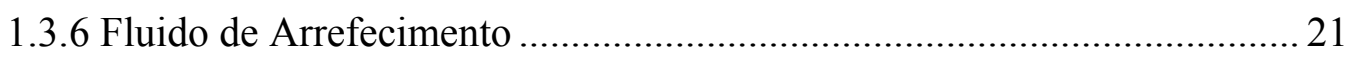

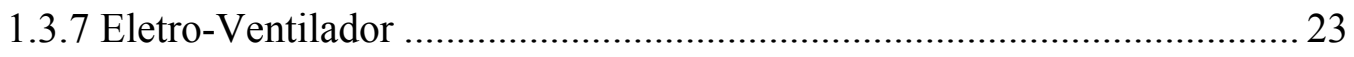

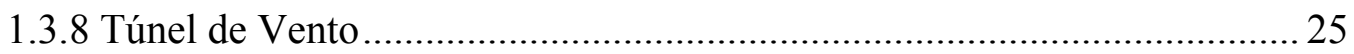

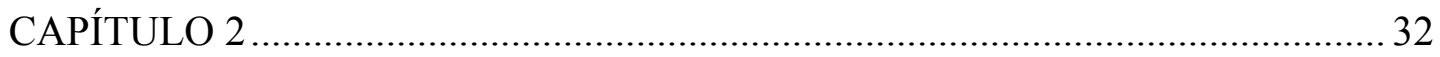

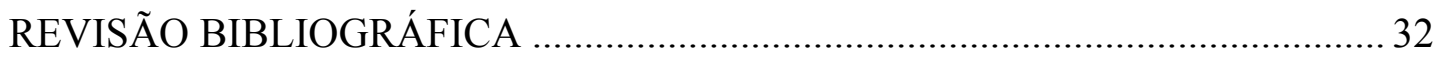

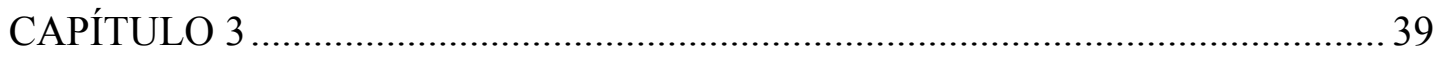

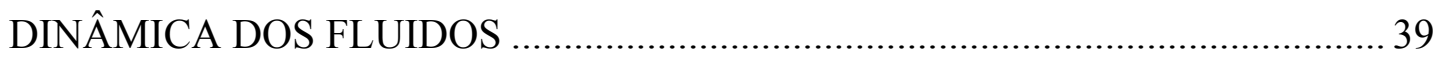

3.1 Equações de Conservação de Massa, Quantidade de Movimento e Energia... 39

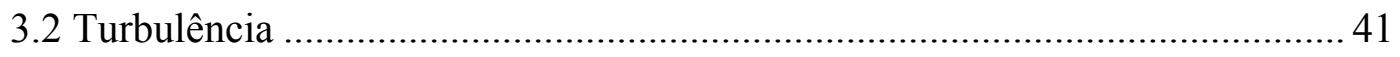

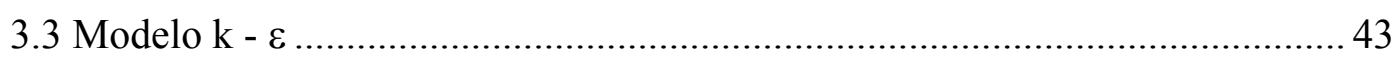

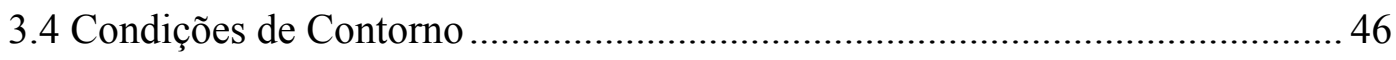

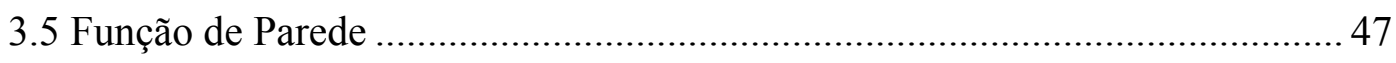

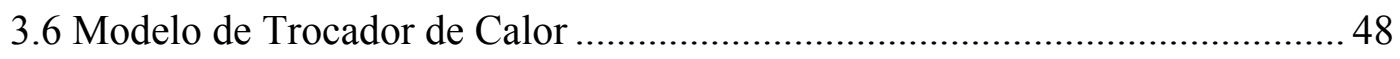

3.6.1 Modelo de Troca Térmica (Trocador de Fluxo Contracorrente) .............. 49

3.6.2 Algoritmo de Simulação Numérica para a Determinação da Curva NUT 52

3.6.3 Modelo de Perda de Carga (Trocador de Fluxo Contracorrente).............. 54

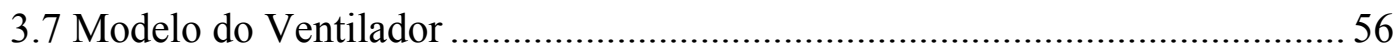


CAPÍTULO 4 60

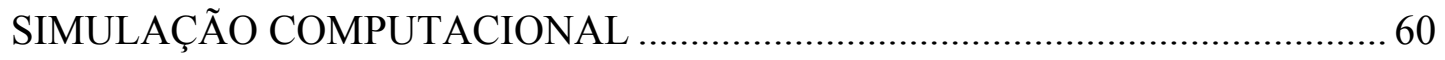

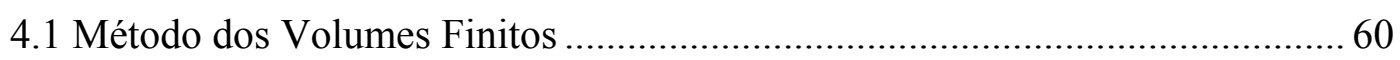

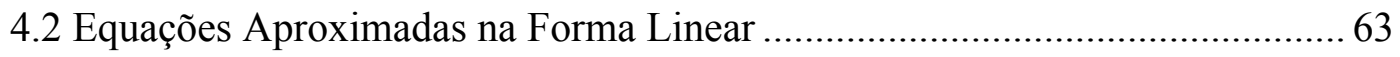

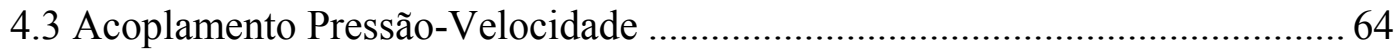

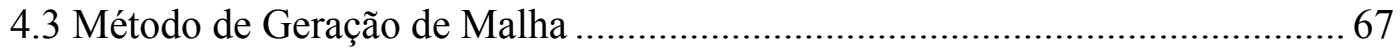

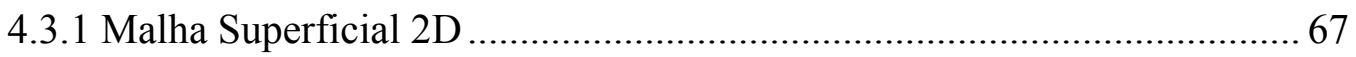

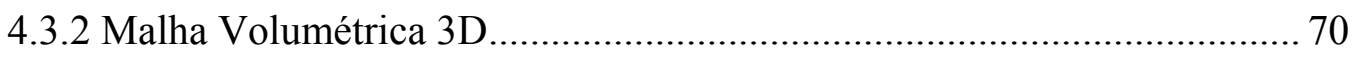

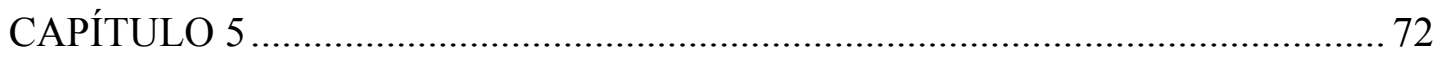

VALIDAÇÃO E VERIFICAÇÃO DOS MODELOS NUMÉRICOS ....................... 72

5.1 Validação de Modelo Numérico do Sistema de Arrefecimento........................ 73

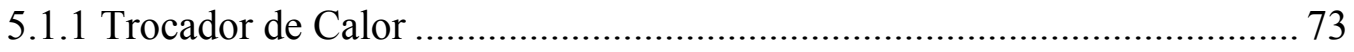

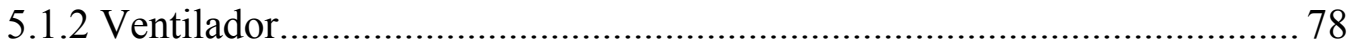

5.1.3 Conclusões Preliminares das Validações Numéricas dos Itens Isolados do

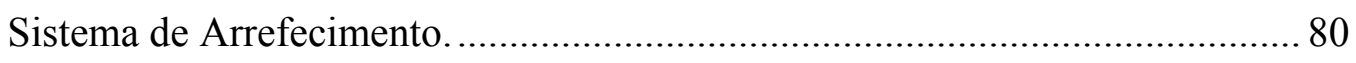

5.2 Estudo da Influência de Malha no Fluxo de Ar no Compartimento do Motor

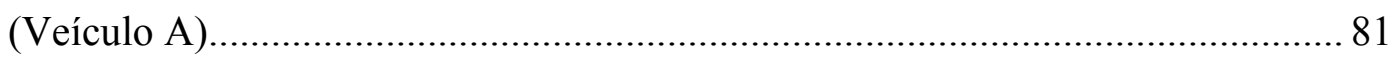

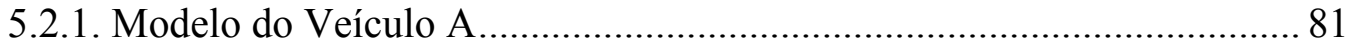

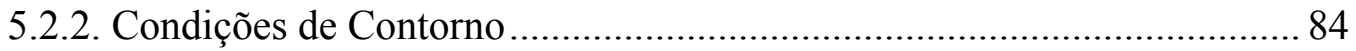

5.2.3. Resultados do Estudo da Influência de Malha da Grade no Fluxo de Ar no

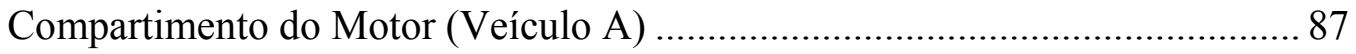

5.2.4 Estudo da Influência de Malha Externa no Fluxo de Ar no Trocador de Calor (Veículo A) .89

5.3. Estudo da Influência do Modelo Simplificado no Fluxo de Ar no Trocador de

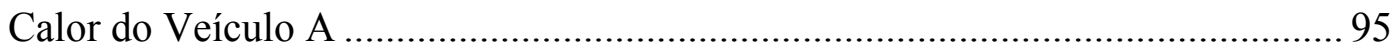

5.4. Conclusões Preliminares do Estudo de Refinamento de Malha...................... 98

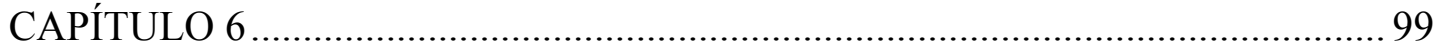

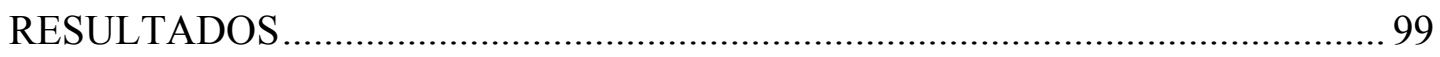

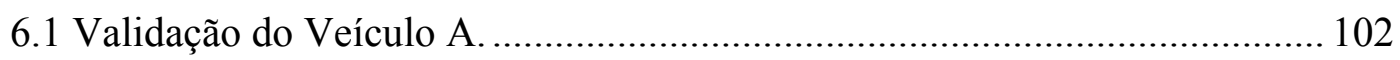

6.2 Validação do Veículo B ........................................................................... 110

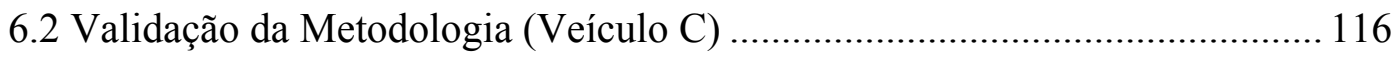

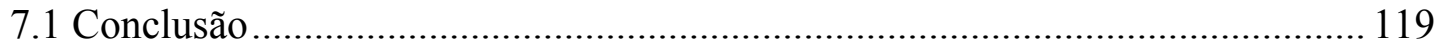


7.2 Recomendações para trabalhos posteriores.................................................. 121

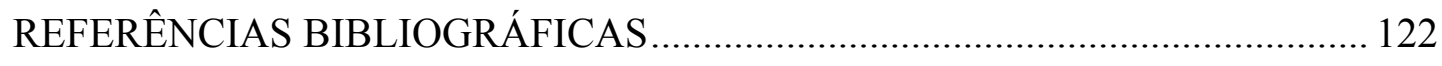

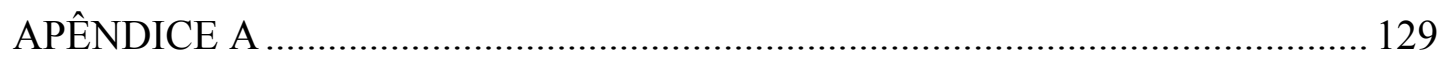

ANÁLISE COMPARATIVA DE PERDA DE CARGA EM GRADES

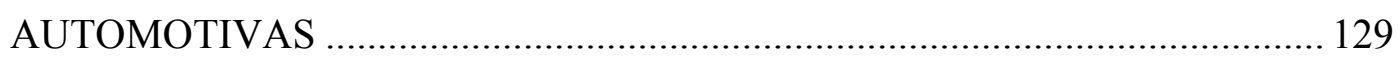

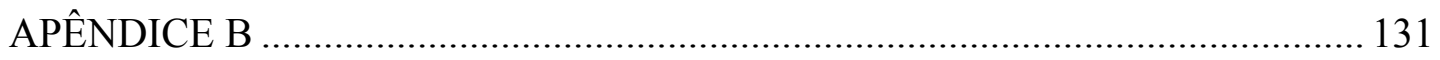

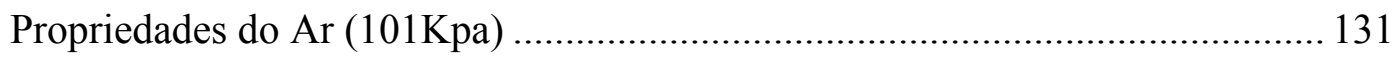

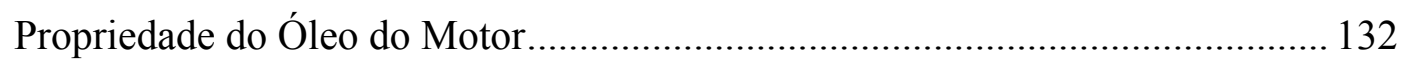

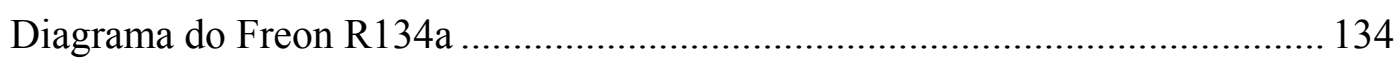

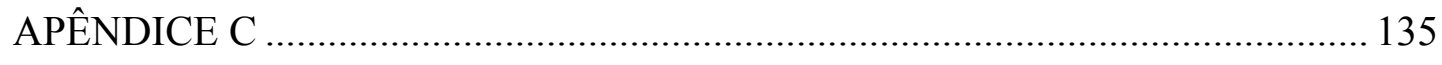

PROGRAMA DE CÁLCULO DAS CURVAS NUT EM TROCADORES DE

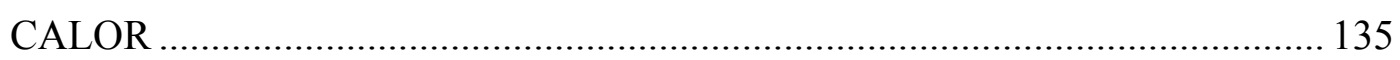

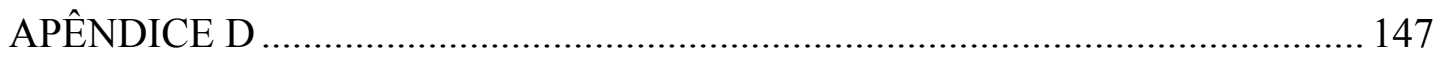

SUB-ROTINA PARA VENTILADORES - FAN.f .......................................... 147 


\section{LISTA DE FIGURAS}

Figura 1.1 - Etapas da metodologia de avaliação do sistema de arrefecimento............ 3

Figura 1.2 - Escoamento típico de ar pelo compartimento do motor em altas

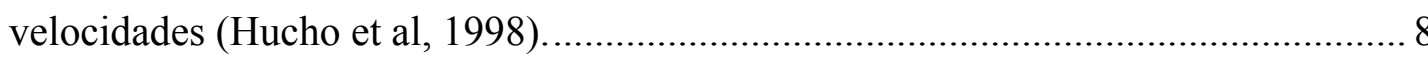

Figura 1.3 - Escoamento típico de ar pelo compartimento do motor na condição parada (Hucho et al, 1998).

Figura 1.4 - Componentes do sistema de arrefecimento do veículo (Hucho et al 1998).

Figura 1.5 - a) Grades convencionais perfilado ou tipo friso. b) Grade tipo tela com

prolongamento.

Figura 1.6 - Alteração do coeficiente de arrasto para diferentes tipos de disposição do radiador (Buchheim R.,1983.).

Figura 1.7 - Coeficiente de arrasto de um carro sedan esporte com e sem aberturas frontais (Renn e Gilhaus, 1986.).

Figura 1.8 - Teste de impacto em pedestre (baixa velocidade).

Figura 1.9 - Componentes do compartimento do motor. a) Kadett A, b) Kadett E GSi.

Figura 1.10 - Sistema de arrefecimento do motor.

Figura 1.11 - Diagrama do Ciclo de Refrigeração HFC-134a.................................. 18

Figura 1.12 - Sistema de arrefecimento da cabine................................................. 19

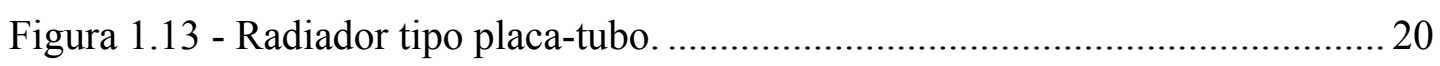

Figura 1.14 - a) Pontos de ebulição de várias concentrações de etileglicol (Mercer, A. D.,1995) b) Ponto de ebulição de soluções aquosas de etanodiol (Maes e Armstrong, 1992). 23

Figura 1.15 - Ventilador de alto desempenho Lohmann (1995)............................... 25

Figura 1.16 - Os objetivos da aerodinâmica veicular................................................. 26

Figura 1.17 - Comparação de perfis de velocidade (Hucho et al,1998).................... 27

Figura 1.18 - Túnel de Vento da General Motors para testes aerodinâmicos em escala natural de veículos (Hucho et al, 1998). 28

Figura 1.19 - Figura ilustrativa dos componentes internos do túnel de vento de circuito fechado para ensaio aerodinâmico em veículos automotivos. 29 
Figura 1.20 - Efeito da fronteira lateral no campo de escoamento: a) efeito de contração em um túnel fechado b) expansão em um túnel aberto.

Figura 1.21 - Figura ilustrativa com detalhes do túnel de vento com sistema de esteira móvel.

Figura 1.22 - a) Separação de fluxo e formação do vórtice de ferradura para rodas em condição estacionária Elofsson (2002) b) Deslocamento do ponto de estagnação e alteração da esteira de vórtices devido à rotação da roda Cogotti (1983). c) Redução do coeficiente aerodinâmico para roda em movimento Cogotti (1983)....

Figura 1.23 - Veículo montado sob sistema de esteira e cilindros rotativos para teste do sistema de arrefecimento.

Figura 3.1 - Condições de contornos aplicadas a um perfil de asa no túnel de vento.

Figura 3.2 - Trocador de calor tipo tubos aletados com os dois fluidos nãomisturados (Incropera e Dewitt,1998) 49

Figura 3.3 - Desenho esquemático do trocador de calor de fluxo cruzado .................50

Figura 3.4 - Curva de rejeição térmica do radiador (curva de desempenho)............. 52

Figura 3.5 - Curva típica da unidade de troca térmica NUT em função das vazões de ar e do líquido de arrefecimento de radiadores.

Figura 3.6 - Discretização do núcleo em células de 10 x 6 .

Figura 3.7 - Exemplo de curva de perda de carga externa de um trocador de calor. . 56

Figura 3.8 - Curva característica de um ventilador automotivo.

Figura 4.1 - Volume de Controle para ilustrar a discretização das equações do transporte escalar.

Figura 4.2 - Algoritmo do Método de Solução Segregado.

Figura 5.1 - Condições de contorno da câmara para validação do trocador de calor. 74

Figura 5.2 - Modelo do trocador de calor contendo 36 × 26 células. 74

Figura 5.3 - Curva típica de Perda de carga externa do ar obtida em teste. 75

Figura 5.4 - Curva comparativa de perda de carga entre teste e simulação numérica. 76

Figura 5.5 - Curvas típicas de rejeição térmica de um radiador.................................. 76

Figura 5.6 - Curva de NUT para vazão do líquido de arrefecimento de $0.4 \mathrm{~kg} / \mathrm{s}$. ...... 77 
Figura 5.7 - Curva comparativa de rejeição térmica entre teste físico e simulação numérica

Figura 5.8 - Condições de contorno do duto para validação do ventilador.. 79

Figura 5.9 - Curva comparativa de perda de carga entre teste e simulação numérica.

Figura 5.10 - Linhas de corrente mostrando o efeito "swirl". 80

Figura 5.11 - Distribuição de velocidade $[\mathrm{m} / \mathrm{s}]$ no plano central longitudinal.. 80

Figura 5.12 - Malha triangular do compartimento do motor do Veículo A. 83

Figura 5.13 - Malha triangular do sistema de arrefecimento (CRFM).

Figura 5.14 - Malha volumétrica do veículo A (corte no plano central na longitudinal).

Figura 5.15 - Condições de contorno do túnel de vento. 84

Figura 5.16 - Níveis de refino de malha superficial da grade do pára-choque. 87

Figura 5.17 - Estudo da Influência de malha da grade no fluxo de ar no radiador. a) Tamanho do modelo. b) Vazão de ar no radiador.

Figura 5.18 - Estudo da Influência de malha da grade no fluxo de ar no radiador. a) Tempo de processamento. b) Coeficiente aerodinâmico. 88

Figura 5.19 - Modelo do veículo A como refinamento de malha $10 \mathrm{~mm}$ na região da grade. 89

Figura 5.20 - Efeito das forças viscosas sob a superfície do veículo 89

Figura 5.21 - Gráfico de contribuição dos principais componentes no coeficiente aerodinâmico

Figura 5.22 - Refinamento da malha externa do veículo A e consideração das rodas em detalhes com a condição de parede deslizante .

Figura 5.23 - Gráfico de convergência do coeficiente aerodinâmico para diferentes ordens de discretização. 92

Figura 5.24 - Contorno de $y^{+}$na superfície da carroceria do veículo .93

Figura 5.25 - a) Linha de corrente sob roda estacionária com formação do vórtice ferradura. b) Linha de corrente sob roda em movimento resultando o desprendimento de vórtice na região superior.

Figura 5.26 - Distribuição de pressão na superfície e linhas de corrente com contorno de velocidade no veículo completo. 
Figura 5.27 - Gráfico comparativo da vazão de ar no trocador de calor e do tempo de processamento

Figura 5.28 - Simplificações no modelo com a exclusão da parte traseira e os retrovisores laterais do veículo. 95

Figura 5.29 - Condições de contorno do modelo parcial simplificado. 96

Figura 5.30 - Contorno de velocidade $[\mathrm{m} / \mathrm{s}]$ entre o modelo completo e modelo parcial (plano $\mathrm{Y}=00$ ). 96

Figura 5.31 - Contorno de pressão [Pa] entre o modelo completo e o modelo parcial (plano $\mathrm{Y}=00$ ).

Figura 5.32 - Gráfico comparativo da vazão de ar no trocador de calor e do tempo de processamento. .97

Figura 6.1 - Procedimento de Simulação CFD. 101

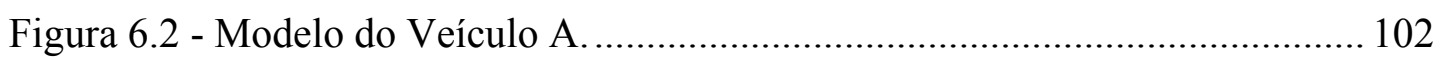

Figura 6.3 - Sistema de Arrefecimento do Modelo A .............................................. 103

Figura 6.4 - Pontos instrumentados do circuito de refrigeração do veículo A......... 105

Figura 6.5 - Diagrama R134a para o cálculo da carga térmica do condensador na condição de $20 \mathrm{~km} / \mathrm{h}$.

Figura 6.6 - Distribuição térmica da linha de escapamento obtido em teste físico.. 107

Figura 6.7 - Distribuição térmica do bloco do motor obtido em teste físico. 107

Figura 6.8 - Gráfico comparativo da temperatura do líquido de arrefecimento na entrada do radiador (Veículo A).

Figura 6.9 - Diferença de temperatura do líquido de arrefecimento na entrada $\left(\mathrm{T}_{1 \mathrm{e}}\right) \mathrm{e}$ saída $\left(\mathrm{T}_{1 \mathrm{~s}}\right)$ do radiador (Veículo $\left.\mathrm{A}\right)$. 109

Figura 6.10 - Distribuição térmica da seção transversal do Veículo A. 109

Figura 6.11 - Vetor de velocidade na seção longitudinal ( $Y=00$ ) para a condição de $20 \mathrm{~km} / \mathrm{h}$. 110

Figura 6.12 - Malha superficial do veículo B.

Figura 6.13 - Malha superficial dos componentes do motor.

Figura 6.14 - Modelo do sistema de arrefecimento do veículo B.

Figura 6.15 - Distribuição térmica da linha de escapamento e do bloco obtidos em teste físico. 
Figura 6.16 - Gráfico comparativo da temperatura do líquido de arrefecimento na entrada do radiador (Veículo B)

Figura 6.17 - Diferença de temperatura do líquido de arrefecimento na entrada e saída do radiador (Veículo B).

Figura 618 - Distribuição térmica do compartimento do motor com linhas de trajetórias de partículas.

Figura 6.19 - Modelo do Veículo C.

Figura 6.20 - a) Modelo do sistema de arrefecimento do veículo C. b) Motor do veículo A montado sob o veículo C

Figura 6.21 - Temperatura do líquido de arrefecimento na entrada do radiador (Veículo C).

Figura 6.22 - Diferença de temperatura do líquido de arrefecimento na entrada e saída do radiador (Veículo C). 


\section{LISTA DE TABELAS}

Tabela 1.1 - Propriedades físicas típicas de compostos de sistema de refrigeração (Maes e Armstrong., 1992).

Tabela 3.1 - Equações de escoamento turbulento para fluido compressível (Versteeg

e Malalasekera, 1995 p53). 43

Tabela 3.2 - Coeficientes do modelo $k-\varepsilon$ de Turbulência........................................... 46

Tabela 3.3 - Coeficientes empíricos da função de parede........................................... 48

Tabela 6.1 - Dados obtidos em túnel de vento e utilizado como condições de

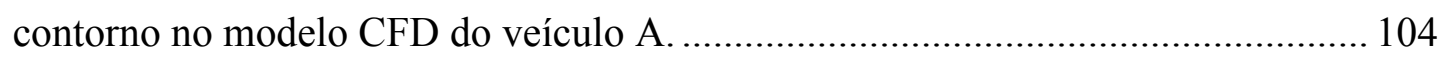

Tabela 6.2 - Cálculo da Rejeição Térmica do Condensador do Veículo A. ............. 106

Tabela 6.3 - Cálculo da Rejeição Térmica do Radiador do Veículo A...................... 106

Tabela 64 - Resultados da Simulação do Veículo A................................................ 108

Tabela 6.5 - Dados obtidos em túnel de vento e utilizado como condições de

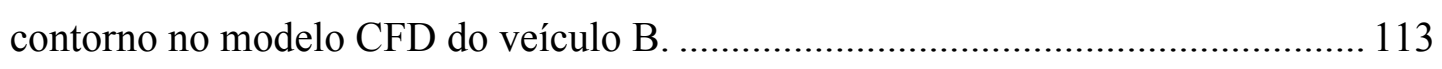

Tabela 6.6 - Resultados da Simulação do Veículo B............................................... 114 


\begin{tabular}{|c|c|}
\hline CAC & Charge Air Cooler ( Trocador de Ar) \\
\hline CAD & Computer Aided Design \\
\hline CAE & Computer Aided Engineering \\
\hline CAM & Computer Aided Manufacturing \\
\hline CFD & Computational Fluid Dynamics \\
\hline CRFM & Condenser-Radiator-Fan Module \\
\hline EG & Etilenoglicol \\
\hline FA & Fluido de Arrefecimento \\
\hline GM & General Motors \\
\hline GMB & General Motors do Brasil \\
\hline GMNA & General Motors of North America \\
\hline $\mathrm{HPC}$ & High Performance Computing \\
\hline HVAC & Heating, Ventilation and Air Conditioning \\
\hline LMDT & Média Logarítmica das Diferenças de Temperatura \\
\hline MEF & Método de Elementos Finitos \\
\hline $\mathrm{MRF}$ & Multiple Reference Frame \\
\hline MVF & Método dos Volumes Finitos \\
\hline NREL & National Renewable Energy Laboratory \\
\hline NS & Navier Stokes \\
\hline NUT & Número de Unidade de Transferência de Calor \\
\hline SA & Sistema de Arrefecimento \\
\hline SIMPLE & Semi-Implicity Method for Pressure-Linked Equation \\
\hline SUV & Sport Utility Vehicle \\
\hline UDF & User Defined Functions \\
\hline $\mathrm{UG}$ & Unigraphics \\
\hline $2 \mathrm{D}$ & Duas Dimensões \\
\hline $3 \mathrm{D}$ & Três Dimensões \\
\hline
\end{tabular}




\section{LISTA DE SÍMBOLOS}

A

$a_{i, j}$

C

$C_{a}$

$C_{d}$

$C_{\text {min }}$

$C_{\max }$

$C_{1}$

$C_{1 \varepsilon}$

$\mathrm{C}_{2}$

$C_{2 \varepsilon}$

$C_{\mu}$

$c p$

D

Dh

$d_{f}$

E

$E_{i j}$

$E_{w}$

$e_{i j}$

F

$f_{n}$

$h$

$I_{i j}$

$J_{f}$

$K_{i}$

$K_{t}$

$k$ área $\left[\mathrm{m}^{2}\right]$

coeficientes lineares convectivos

capacidade térmica $[\mathrm{J} / \mathrm{kg} . \mathrm{s}]$

constante

coeficiente aerodinâmico

mínima capacidade térmica $[\mathrm{J} / \mathrm{kg} . \mathrm{s}$ ]

máxima capacidade térmica [ $\mathrm{J} / \mathrm{kg} . \mathrm{s}$ ]

capacidade térmica do fluido quente [ $\mathrm{J} / \mathrm{kg} . \mathrm{s}$ ]

coeficiente empírico do modelo $k$ - $\varepsilon$ de turbulência

capacidade térmica do fluido frio

coeficiente empírico do modelo $k-\varepsilon$ de turbulência

coeficiente empírico do modelo $k-\varepsilon$ de turbulência

calor específico

diâmetro [m]

diâmetro hidráulico [m]

função da razão da área pelo coeficiente $a_{i, j}$

energia [N.m]

componentes da deformação cisalhante média

parâmetro de rugosidade da parede

componente da deformação cisalhante

força $[\mathrm{N}]$

coeficiente de pressão do ventilador

entalpia $[\mathrm{kJ} / \mathrm{kg}]$

matriz de perda de carga inercial

função de fluxo de massa

função de permeabilidade

coeficiente de transferência de calor total $\left[\mathrm{m}^{2} \mathrm{~K} / \mathrm{W}\right]$

energia cinética turbulenta $\left[\mathrm{m}^{2} / \mathrm{s}^{2}\right]$ 


\begin{tabular}{|c|c|}
\hline$k_{t}$ & coeficiente de condução térmica $\left[\mathrm{m}^{2} \mathrm{~K} / \mathrm{W}\right]$ \\
\hline$k_{v}$ & constante empírica de Von Kármám \\
\hline$L$ & comprimento $[\mathrm{m}]$ \\
\hline$\ell$ & escala de comprimento \\
\hline$\dot{m}$ & vazão mássica $[\mathrm{kg} / \mathrm{s}]$ \\
\hline$\dot{m}_{c}$ & vazão mássica de freon no condensador $[\mathrm{kg} / \mathrm{s}]$ \\
\hline$\dot{m}_{r}$ & vazão mássica de líquido de arrefecimento $[\mathrm{kg} / \mathrm{s}]$ \\
\hline$N$ & rotação $[\mathrm{rad} / \mathrm{s}]$ \\
\hline$N_{s}$ & número de divisões \\
\hline NUT & número de unidade de transferência de calor \\
\hline$p$ & pressão $[\mathrm{Pa}]$ \\
\hline $\bar{p}$ & pressão média $[\mathrm{Pa}]$ \\
\hline$p^{\prime}$ & flutuação da pressão [Pa] \\
\hline$\dot{Q}_{C}$ & fluxo de calor no condensador [W] \\
\hline$\dot{Q}_{\max }$ & máxima fluxo de calor [W] \\
\hline$\dot{Q}_{R}$ & fluxo de calor no evaporador [W] \\
\hline$\dot{Q}_{T C}$ & fluxo de calor no trocador de calor [W] \\
\hline$\dot{q}_{\text {celula }}$ & fluxo de calor na célula computacional [W] \\
\hline$\dot{q}_{\text {total }}$ & fluxo de calor total [W] \\
\hline$R$ & raio $[\mathrm{m}]$ \\
\hline $\operatorname{Re}$ & número de Reynolds \\
\hline $\operatorname{Re}_{\text {crit }}$ & número de Reynolds crítico \\
\hline$R e_{t r}$ & número de Reynolds de transição \\
\hline$S$ & fonte de energia [W] \\
\hline$T$ & temperatura $\left[{ }^{\circ} \mathrm{C}\right]$ \\
\hline$T_{\text {celula }}$ & temperatura da célula $\left[{ }^{\circ} \mathrm{C}\right]$ \\
\hline$T_{1 e}$ & temperatura de entrada do fluido quente $\left[{ }^{\circ} \mathrm{C}\right]$ \\
\hline$T_{1 s}$ & temperatura de saída do fluido quente $\left[{ }^{\circ} \mathrm{C}\right]$ \\
\hline$T_{2 e}$ & temperatura de entrada do fluido frio $\left[{ }^{\circ} \mathrm{C}\right]$ \\
\hline$T_{2 s}$ & temperatura de saída do fluido frio $\left[{ }^{\circ} \mathrm{C}\right]$ \\
\hline
\end{tabular}




\begin{tabular}{|c|c|}
\hline$t$ & tempo $[\mathrm{s}]$ \\
\hline$U$ & velocidade $[\mathrm{m} / \mathrm{s}]$ \\
\hline$U_{c}$ & velocidade característica $[\mathrm{m} / \mathrm{s}]$ \\
\hline$u$ & componente da velocidade na direção $x[\mathrm{~m} / \mathrm{s}]$ \\
\hline$u_{r}$ & velocidade relativa entre o fluido e a velocidade do sistema de \\
\hline \multicolumn{2}{|c|}{ coordenadas $[\mathrm{m} / \mathrm{s}]$} \\
\hline$u^{\prime}$ & flutuação da velocidade na direção $\mathrm{x}[\mathrm{m} / \mathrm{s}]$ \\
\hline $\bar{u}$ & velocidade média na direção $\mathrm{x}[\mathrm{m} / \mathrm{s}]$ \\
\hline $\bar{u}_{r}$ & campo de velocidade relativa média $[\mathrm{m} / \mathrm{s}]$ \\
\hline$\overline{u_{r}^{\prime}}$ & flutuação do campo de velocidade relativa $[\mathrm{m} / \mathrm{s}]$ \\
\hline$u_{\tau}$ & velocidade de atrito na parede $[\mathrm{m} / \mathrm{s}]$ \\
\hline$u^{+}$ & velocidade na subcamada viscosa da parede \\
\hline$V$ & volume $\left[\mathrm{m}^{3}\right]$ \\
\hline$V_{i j}$ & matriz de perda de carga viscosa \\
\hline$v$ & componente da velocidade na direção y $[\mathrm{m} / \mathrm{s}]$ \\
\hline $\bar{v}$ & velocidade média na direção y $[\mathrm{m} / \mathrm{s}]$ \\
\hline$v^{\prime}$ & flutuação da velocidade na direção y $[\mathrm{m} / \mathrm{s}]$ \\
\hline $\mathrm{Z}$ & razão das capacidades térmicas \\
\hline$w$ & componente da velocidade na direção $\mathrm{z}[\mathrm{m} / \mathrm{s}]$ \\
\hline$w^{\prime}$ & flutuação da velocidade na direção $\mathrm{z}[\mathrm{m} / \mathrm{s}]$ \\
\hline $\bar{w}$ & velocidade média na direção $\mathrm{z}[\mathrm{m} / \mathrm{s}]$ \\
\hline $\mathrm{y}$ & medida de distância em relação à parede $[\mathrm{m}]$ \\
\hline$y^{+}$ & coordenada na subcamada viscosa da parede \\
\hline
\end{tabular}




\section{Símbolos Gregos}

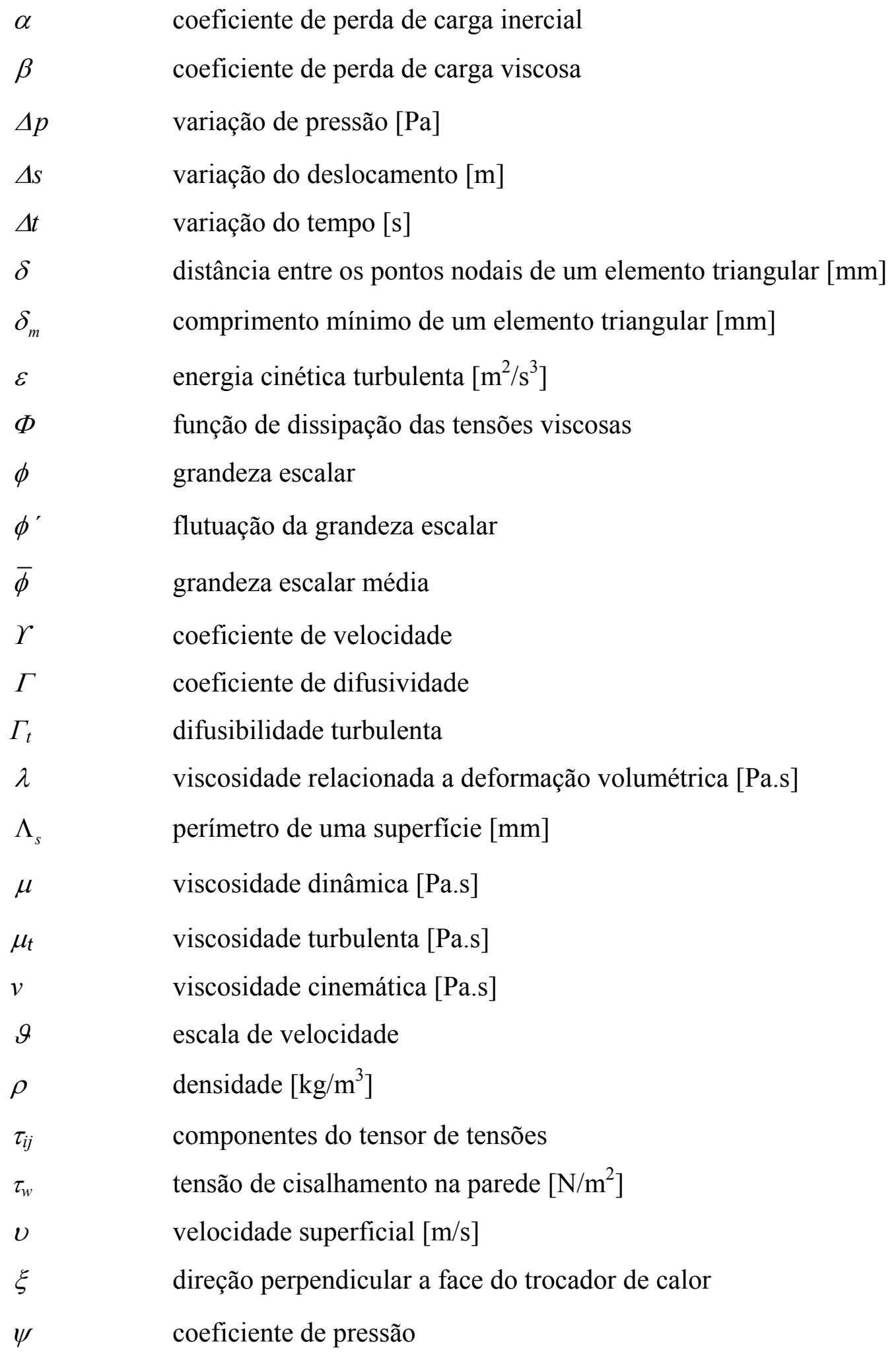




\section{RESUMO}

Este trabalho visa o estudo de uma metodologia de simulação numérica aplicada ao processo de troca térmica do motor de um veículo de passeio. O processo de troca térmica é essencial para evitar o superaquecimento do motor, que provoca $o$ rompimento do filme de óleo lubrificante dos pistões e, conseqüentemente, o seu travamento. Essa metodologia será útil nos estudos preliminares do sistema de arrefecimento de um veículo na fase inicial de projeto por meio de simulações virtuais, o que possibilitará a redução de protótipos, além de proporcionar um ganho em tempo de resposta. A metodologia utiliza um programa comercial de CFD para a simulação do processo de troca térmica no interior do compartimento do motor do veículo. As simulações foram realizadas com base nos testes físicos em túnel de vento que fazem parte do desenvolvimento e projeto de automóveis em condições de operação que representam situações críticas integrantes da vida operacional. Essas condições operacionais de teste, tais como a velocidade do veículo, as cargas térmicas, a potência dos ventiladores e outros parâmetros foram utilizadas como condições de contorno na validação do modelo do veículo. O processo de validação de modelos é composto por: validações de itens isolados do sistema de arrefecimento, avaliação do efeito da densidade de malha computacional de um modelo completo na vazão de ar nos trocadores de calor e simplificações no modelo para a redução do tempo de processamento. Neste trabalho três modelos distintos de veículos foram utilizados, sendo que dois deles para a validação na comparação com os resultados de túnel vento, enquanto o terceiro modelo foi utilizado para a validação da metodologia através de comparações com os dados obtidos nos testes em pista circular. Os resultados das simulações mostraram variações máximas de $5,5 \%$ na temperatura do líquido de arrefecimento na entrada do radiador em relação aos testes. A metodologia de simulação mostrou ser uma poderosa ferramenta de otimização durante a fase de desenvolvimento do projeto e complementando os testes físicos para o sistema de arrefecimento veicular. 


\begin{abstract}
The present work is applied to a development of a numerical simulation methodology for a passenger vehicle engine cooling process. The heat exchange process is essential to avoid the engine overheat which may result in the piston oil film separation and consequently its halt. This methodology will be useful for the preliminary studies of the cooling system at the initial phase through the virtual simulations which can reduce the number of prototypes and save proposals' time response. The methodology uses commercial CFD software for airflow simulation and the thermal process at under hood. The simulations were based on the physical wind tunnel tests that are part of the automotive development, with operational conditions representing critical situations experienced by a vehicle in its operating life. The test conditions, such as vehicle speed, thermal loads, fan power and other parameters were used as the boundary conditions for the model validation.

The validation process is based on the following phases: validation of the isolated cooling system components, the effect of mesh density at cooling airflow using a complete vehicle model and model simplification in order to improve the processing time. In this work development, three different models were used; two of them for validation with test tunnel data and the third, was used for methodology validation through the circular road test. The simulation results for tunnel and circular road showed $5.5 \%$ of differences for the radiator coolant inlet temperature when compared with physical tests. The methodology of the simulation is a powerful tool for optimization during the development phase and complementing the physical tests for the vehicle cooling systems.
\end{abstract}




\section{CAPÍTULO 1}

\section{INTRODUÇÃO}

\subsection{Objetivos e Motivação}

Sabe-se que mais de um terço da energia térmica produzida pela combustão interna do motor é dissipada no sistema de arrefecimento. Segundo a Agência Nacional de Energias Renováveis dos Estados Unidos - NREL, um litro de gasolina produz aproximadamente $1,6 \mathrm{~kW} . \mathrm{h}$ de energia no processo de combustão, quantia esta suficiente para ferver mais de 400 litros de água. Diante de tal constatação é que o sistema de arrefecimento do motor automotivo deve ser eficiente a ponto de evitar o superaquecimento do líquido de arrefecimento, sob pena de comprometimento do sistema operacional do veículo.

Nesse sentido, um sistema de arrefecimento eficiente deve atender os seguintes requisitos:

- Uma vazão adequada de líquido de arrefecimento no motor;

- Um radiador eficiente para retirar o calor proveniente do motor;

- Um eletro-ventilador potente acoplado ao radiador para garantir a troca térmica na condição de baixa velocidade do veículo, proporcionando temperaturas adequadas aos componentes do motor;

- Um termostato para regular a temperatura operacional do motor de modo a garantir um bom desempenho no aspecto de consumo e emissões.

O líquido de arrefecimento do motor deve ter aditivos adequados para a proteção em ambientes expostos às mais variadas temperaturas (baixas/altas), além do uso de inibidores de corrosão para evitar a deposição de óxidos nas paredes, reduzindo-se assim a troca térmica.

Normalmente as máximas temperaturas no sistema de arrefecimento e nos componentes adjacentes ao motor ocorrem quando este é submetido à máxima potência ou torque, sob uma condição crítica de fluxo de ar no compartimento.

O veículo em uma situação de baixa velocidade associada ao máximo torque de seu motor resulta em uma rejeição elevada de calor no sistema, que por sua vez, 
deverá ser removida por meio de convecção forçada através do acionamento de eletro-ventilador acoplado ao sistema de arrefecimento. Desta forma, além da importância do escoamento de ar no compartimento do motor, os projetos visam otimizar as dimensões do sistema de arrefecimento e maximizar o potencial de troca térmica com um menor consumo de energia possível.

Nos projetos automotivos convencionais, em geral, são utilizadas plataformas preexistentes as quais incluem motor, chassis, suspensão e o sistema de arrefecimento, montadas sob uma nova estrutura externa. Nesse caso será necessário somente o redimensionamento das aberturas de tomada de ar da nova carroceria de forma a se obter as mesmas vazões de ar de um veículo do modelo anterior. $\mathrm{O}$ trabalho desenvolvido por Laurence (2003) mostra o estudo do escoamento de ar no compartimento do motor com adição de direcionadores de ar para maximizar o fluxo, validando, assim, o sistema de arrefecimento.

Por outro lado, como é sabido, cada vez mais crescente é a exigência do mercado consumidor no que se refere à aparência, segurança, potência do motor e o custo do veículo, sendo certo que, referidos itens se mostram decisivos ao sucesso de venda, daí o desafio de se projetar um sistema de arrefecimento compacto e eficiente que se coadune às expectativas dos consumidores.

Quando um novo veículo for projetado sem a utilização das plataformas preexistentes, somente os valores de vazões de ar nos trocadores de calor obtidos em simulação não serão suficientes para predizer a eficiência de um sistema de arrefecimento. Desta forma, para a avaliação da eficiência do sistema de arrefecimento será necessária, além da vazão de ar, a capacidade de troca térmica do trocador de calor com o ar externo.

O presente trabalho tem como escopo o desenvolvimento de uma nova metodologia de avaliação do sistema de arrefecimento independente da configuração da plataforma através da utilização de um programa comercial de CFD.

A simulação numérica computacional permitirá, além da obtenção dos valores de vazão de ar nos trocadores de calor, a visualização do escoamento e a identificação das possíveis regiões de recirculação. A simulação possibilitará determinar o desempenho do sistema de arrefecimento através da temperatura do fluido de arrefecimento na entrada do radiador. Através desta variável aliada à 
pressão de projeto do radiador é que se permitirá predizer com antecedência se o veículo entrará ou não em superaquecimento.

As validações de protótipos são feitas normalmente em testes de pista ou em túnel de vento, implicando-se em um custo elevado ao término do projeto. Com o intuito de reduzir o custo de protótipos somado à necessidade de uma resposta rápida na avaliação de desempenho do sistema de arrefecimento, tem-se que a simulação numérica é a ferramenta que atende concomitantemente estes requisitos, especialmente nas fases iniciais do desenvolvimento do projeto.

Assim, a Dinâmica dos Fluidos Computacional (CFD) é uma ferramenta eficaz ao estudo de fenômenos de troca térmica com transferência de massa e que viabilizará o auxílio no entendimento dos fenômenos físicos dentro do compartimento do motor.

Para que a ferramenta de CFD seja aplicável a qualquer tipo de veículo automotivo, será necessário o estabelecimento de uma metodologia de simulação de modo a obter resultados confiáveis e correlacionados com os testes físicos. Mencionada metodologia foi desenvolvida em duas fases, conforme pode-se observar na figura 1.1 abaixo:

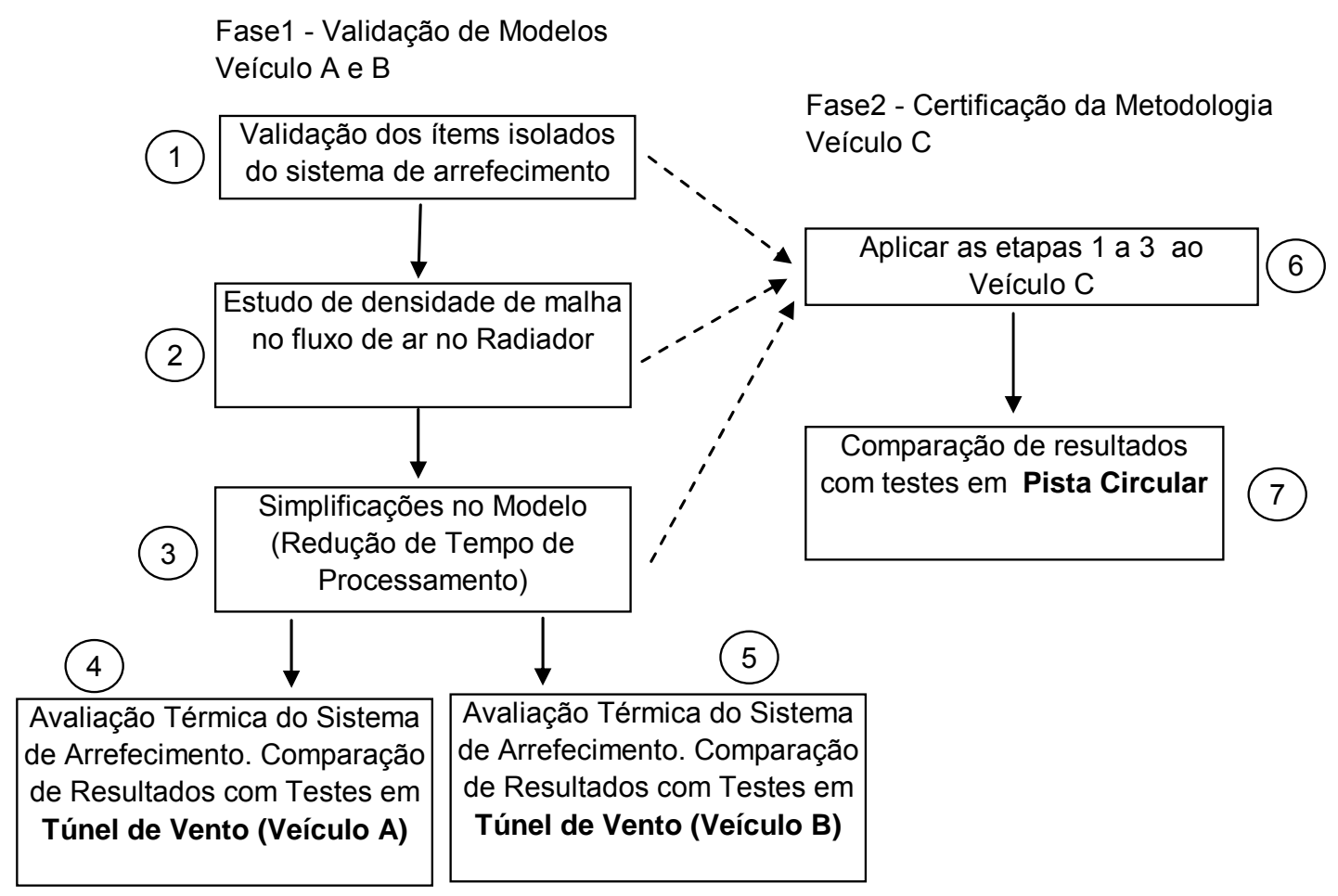

Figura 1.1 - Etapas da metodologia de avaliação do sistema de arrefecimento. 
A validação da metodologia (fig. 1.1) foi feita com base nos resultados obtidos no túnel de vento da GMNA situado em Detroit, nos Estados Unidos e na pista circular da GMB situado em Indaiatuba, São Paulo, através das seguintes etapas:

1- Validação de componentes isolados do sistema de arrefecimento.

Os componentes isolados do sistema de arrefecimento são considerados componentes essenciais para o mecanismo de troca térmica do sistema de arrefecimento. Para que a simulação numérica do veículo apresente resultados confiáveis, as validações numéricas dos itens isolados do sistema de arrefecimento, como o trocador de calor e o ventilador, foram simulados e comparados com os resultados de testes físicos de desempenho obtidos pelo fabricante.

2- Avaliação do efeito da densidade da malha computacional de um veículo completo com enfoque na vazão de ar dos trocadores de calor.

Como o parâmetro principal na troca térmica dos trocadores de calor é a vazão de ar, o estudo de refino de malha foi avaliado nas regiões das grades do veículo de forma a capturar os efeitos de desprendimento de vórtices ou mesmo os efeitos de recirculações que normalmente ocorrem nessas regiões.

3- Simplificações no modelo.

A utilização de modelo completo permite a determinação da distribuição da pressão ao longo do veículo e conseqüentemente, o valor do seu coeficiente aerodinâmico $(\mathrm{Cd})$. Quanto menor a discrepância do $\mathrm{Cd}$ simulado em relação ao valor de teste, poder-se-á certificar que a distribuição de velocidade e pressão no veículo estará suficientemente próximo ao do caso real.

A utilização de modelos completos e refinados requer um elevado tempo de processamento. Desta forma, simplificações no modelo se revelam necessárias em regiões que não afetam o escoamento do ar nos trocadores de calor, pois a metodologia só será eficaz quando apresentar resultados confiáveis com baixo tempo de resposta. 
4 e 5- Validação de modelos térmicos (Veículo A e B).

Com o modelo já simplificado, a equação de energia de troca térmica será considerada de forma a obter valores de temperatura do líquido de arrefecimento na entrada do radiador em condições críticas operacionais do veículo onde estes resultados serão confrontados com os obtidos em teste em túnel de vento.

6- Com os modelos dos "Veículos A e B" validados, temos todas as informações relativas às cargas térmicas além do conhecimento do grau de refinamento necessário em cada região do veículo.

Com o intuito de mostrar a aplicabilidade do método para veículos que independem dos itens da plataforma, utilizou-se um terceiro veículo de geometrias distintas (Veículo C) para a avaliação do sistema de arrefecimento. Este veículo utiliza a mesma motorização do "Veículo A" porém, com um novo módulo de arrefecimento construído com base nas informações adquiridas durante a validação do veículo A.(etapas de 1 a 3 ).

7 - Como o "Veículo C" se trata se de um veículo em desenvolvimento com limitações no custo do projeto, a validação do modelo só foi possível através de resultados obtidos em uma pista circular com o uso de um protótipo.

Nas simulações dos veículos de passeio foram utilizadas as seguintes condições operacionais de túnel de vento:

- condição de baixa velocidade $\left(20 \mathrm{~km} / \mathrm{h}\right.$ à $2^{\mathrm{a}}$ Marcha) com a utilização de reboque sob uma rampa com inclinação de seis graus;

- condição de $80 \mathrm{~km} / \mathrm{h}$ com máximo torque (4 Marcha);

- condição de $100 \mathrm{~km} / \mathrm{h}$ com máxima aceleração (4a Marcha);

- condição de máxima velocidade (160km/h a $5^{\mathrm{a}}$ Marcha).

Em todos os casos o eletro-ventilador encontrava-se ligado na máxima rotação, sob as condições de regime permanente e temperatura ambiente controlada de $38^{\circ} \mathrm{C}$. 


\subsection{Estrutura da Dissertação}

No primeiro capítulo introdutório será apresentada uma abordagem dos requisitos de projeto de um sistema de arrefecimento, bem como a descrição dos itens que o compõem. Ainda nesse capítulo serão demonstradas as considerações do túnel de vento utilizado na validação do procedimento. No segundo, apresentar-se-á uma revisão bibliográfica acerca dos assuntos relativos às simulações de arrefecimento de compartimento de motor com abordagem das técnicas de simulações e os programas existentes no mercado atual.

No terceiro e quarto capítulos serão apresentadas as formulações matemáticas para soluções do escoamento e a troca térmica do compartimento do motor assim como o método de volumes finitos e considerações aplicadas aos modelos matemáticos de trocadores de calor, do ventilador e a metodologia de construção dos modelos computacionais.

No quinto capítulo se demonstrará a validação numérica dos itens isolados do sistema de arrefecimento, como o trocador de calor e o ventilador por meio de comparação de resultados de testes físicos e de desempenho obtidos pelo fabricante. Também será apresentado o estudo da influência de malha no escoamento no compartimento do motor e de simplificações no modelo na redução do tempo de resposta.

O sexto capítulo mostrará a validação numérica do sistema de arrefecimento comparando a temperatura do líquido de arrefecimento na entrada do radiador com os resultados de teste em túnel de vento para os veículos distintos denominados neste trabalho como A, B e C.

No capítulo final serão apresentadas as conclusões do trabalho com base nos resultados obtidos, os quais avaliaram a aplicabilidade da metodologia e as suas contribuições no desenvolvimento de um projeto. Serão também apresentadas sugestões de novas avaliações e considerações no sentido de complementar a metodologia. 


\subsection{Descrição do Tema}

As relações entre o arrasto aerodinâmico veicular e o sistema de arrefecimento do motor estão interligadas pela busca da redução de níveis de consumo de combustíveis, necessidade esta que se tornou importante no final da década de 70 com a crise do petróleo.

Na primeira reunião realizada no "Clube de Roma" em 1968, ficou claro que a disponibilidade do material fóssil era limitada a um curto espaço de tempo, pelo que, desde então, a conscientização ambiental tem crescido de forma considerável. Esses fatos motivaram à implantação de legislações rígidas nas indústrias automobilísticas com vistas a reduzir o nível de consumo de combustíveis nos veículos.

A redução do arrasto representa a maior contribuição na economia do combustível. Estudos feitos por Emmelmann e Berebur (1990) mostram que, excluídas as perdas internas do motor, $40 \%$ das perdas são relativas ao arrasto aerodinâmico, $23 \%$ devido à resistência ao rolamento, $15 \%$ devido ao efeito peso e o restante às perdas de componentes e da transmissão. Dados fornecidos pela OPEL ${ }^{2}$ mostram que a melhoria aerodinâmica sucessiva do Vectra desde 1979 resultou em uma redução de 26\% no consumo de combustível em 1988.

Durante mais de 20 anos tem se focado na redução do coeficiente de arrasto de veículos na economia de consumo. Exemplo clássico é o "Kadett City" de 1975 com Cd de 0.51 e o "Kadett GSi" 1985 de 0.30, donde se observou uma redução de $41 \%$ alcançada graças a otimização e redução da entrada de ar pelo compartimento do motor. Não obstante a redução do coeficiente de arrasto, verificou-se o surgimento de um novo problema, qual seja, o superaquecimento do sistema de arrefecimento.

Atualmente um dos maiores obstáculos em aerodinâmica veicular é o projeto do sistema de arrefecimento do motor. Este problema pode ser observado, inclusive, nos carros de passeios modernos, onde o projeto da estrutura frontal do veículo tem

\footnotetext{
${ }^{1}$ É uma organização Internacional cuja missão é "Agir como um catalisador de mudanças globais, livre de quaisquer interesses políticos, econômicos, ou ideológicos".

${ }^{2}$ Subsidiária da General Motors na Alemanha.
} 
uma influência decisiva no comportamento térmico do compartimento na qual está diretamente ligada ao conforto e dirigibilidade.

Estudos conduzidos por Crook, R. F., (1995) da Associação Nacional de Radiadores Automotivos a NARSA (National Automotive Radiator Association), mostram que um terço da energia do combustível é transformado em energia mecânica, outro terço é perdido no sistema de exaustão do escapamento e o restante é transferido no sistema de arrefecimento do motor.

Em um motor em regime permanente, a sua carga térmica é transferida de forma direta para o sistema de arrefecimento não importando a sua eficiência. Diante disso indaga-se: como é possível identificar se o radiador do sistema de arrefecimento é eficiente?

Em regime permanente, um radiador eficiente à temperatura de entrada do fluido quente será estável e operando com pressões abaixo do valor especificado para tampa do radiador na qual foi projetado, enquanto em um radiador ineficiente ocorrerá um superaquecimento do fluido e conseqüentemente, o seu vazamento comprometerá o funcionamento do motor. Desta forma, a eficiência de um radiador está associada à quantidade de ar externo que se escoa para o compartimento.

Segundo Hucho et al (1998), o escoamento de ar pelo compartimento do motor em um veículo em alta velocidade é movido pela diferença de pressão entre a região de alta pressão estática localizada na frente do pára-choque e a região de baixa pressão localizada posteriormente ao protetor de cárter. Este efeito é denominado de efeito "ram" e pode ser compreendido através da ilustração abaixo:

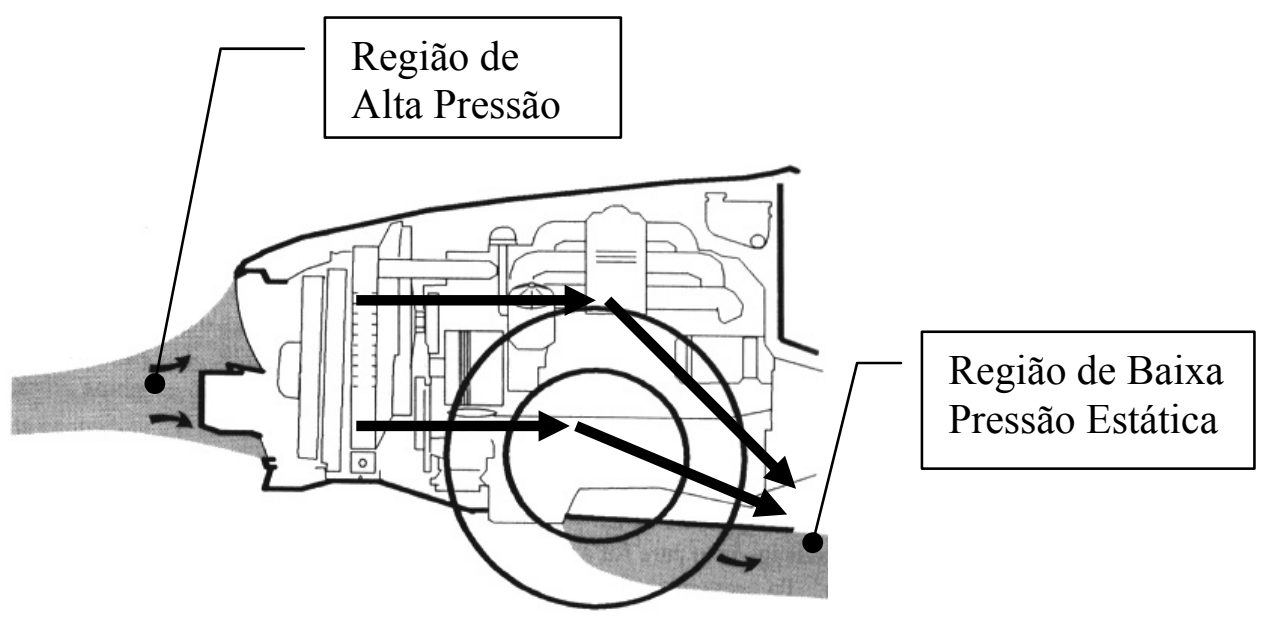

Figura 1.2 - Escoamento típico de ar pelo compartimento do motor em altas velocidades (Hucho et al, 1998). 
Quando o efeito " $\mathrm{ram}^{3 "}$ " não é suficiente, ou seja, quando o veículo se encontra em baixa velocidade, os ventiladores auxiliares entram em ação para aumentar a vazão de ar pelos trocadores de calor como ilustrado na figura 1.3. Desta forma, para baixas velocidades, o efeito dos ventiladores é predominante, enquanto em altas velocidades o efeito "ram" predomina.

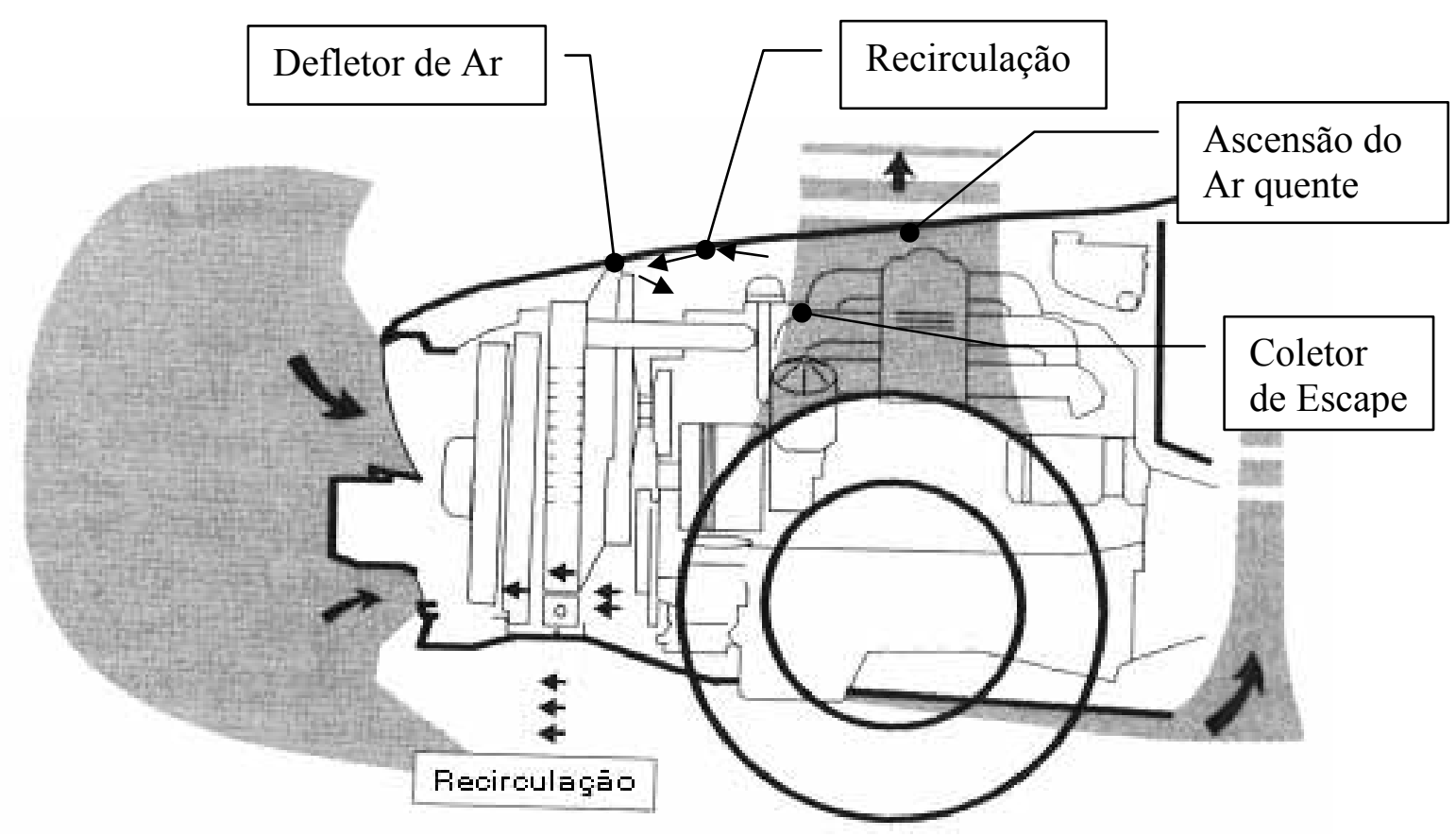

Figura 1.3 - Escoamento típico de ar pelo compartimento do motor na condição parada (Hucho et al, 1998).

A figura acima mostra o escoamento de ar quando o veículo se encontra na condição do veículo parado e em marcha lenta. Nessa condição, o escoamento é movido pelos ventiladores e pela convecção natural. $\mathrm{O}$ ar externo é aspirado pelos ventiladores por meio das aberturas superiores e inferiores, e as linhas de corrente na frente do veículo se contraem e o escoamento é acelerado ao passar pelo ventilador. Devido à disposição compacta dos componentes adjacentes ao motor e a ausência do efeito "ram", a pressão do ar diminui devido à perda de carga e apenas uma pequena parte do ar quente é eliminada através da região inferior do motor.

\footnotetext{
${ }^{3}$ Escoamento do ar movido pelo diferencial de pressão.
} 
Como decorrência, o ar quente passa pelo coletor de escape com temperatura aproximada de $600^{\circ} \mathrm{C}$ submetendo-se a um reaquecimento e diante da convecção, mostra-se inevitável o surgimento do efeito indesejável denominado de recirculação. No efeito da recirculação, o ar quente tende a voltar nos trocadores de calor diminuindo assim a eficiência do radiador.

A maioria dos projetos atuais inclui a adição de defletores de forma a evitar o retorno do ar quente proveniente do efeito da recirculação.

\subsubsection{Requisitos de Projeto do Sistema de Arrefecimento}

O requerimento básico para o sistema de arrefecimento é certificar que os componentes do motor sejam adequadamente resfriados sob todas as condições operacionais do veículo.

Em veículos automotivos, o módulo de arrefecimento é normalmente denominado de CRFM composto pelos seguintes elementos ilustrados na figura 1.4, a saber:

- Dois ventiladores auxiliares externos com finalidades de "empurrar" e "puxar" o ar através dos módulos;

- Condensador para proporcionar o conforto térmico da cabine;

- Radiador para o arrefecimento do motor;

- Defletor de ar do radiador para direcionar e otimizar o escoamento;

- Trocador de calor do óleo para arrefecimento da caixa de transmissão automática.

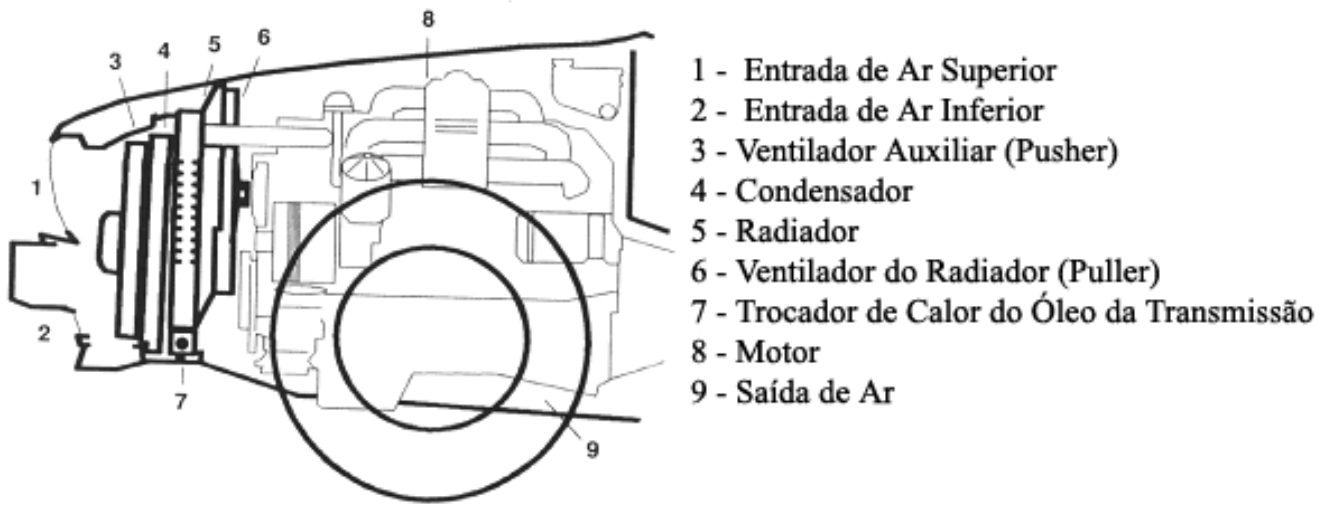

Figura 1.4 - Componentes do sistema de arrefecimento do veículo (Hucho et al 1998). 
No sistema convencional de resfriamento por água, cuidados devem ser adotados para que o líquido de arrefecimento do motor não tenha superaquecimento, pois caso contrário levará ao rompimento do filme de óleo causando a perda das propriedades de lubrificação e finalmente, ao travamento dos pistões.

Um sistema de arrefecimento inadequado altera também os níveis de poluentes emitidos pelo motor e com isso a sobra do combustível irá se depositar no catalisador, ocasionando-lhe a corrosão e a perda da sua funcionalidade.

Há que se compatibilizar, entretanto, a necessidade de um sistema de arrefecimento eficiente às novas tendências dos mercados nacionais e internacionais que indicam a predileção por um carro potente, seguro e de baixo consumo e com design moderno e arrojado.

Contudo, o aumento da potência do veículo exige uma grande quantidade de vazão de ar externo no compartimento do motor. Desta forma, para que se viabilize a crescente busca de conforto e segurança houve a necessidade de incremento no número de componentes do compartimento do motor como demonstrado por Emmelmann e Bernebur (1990). Esses fatores aliados às novas tendências de projeto e ao conceito de um motor compacto têm reduzido, de forma drástica, a passagem de ar no sistema de resfriamento do motor, o qual exigirá um sistema de arrefecimento de alta eficiência e com dimensões reduzidas

\subsubsection{Itens que Afetam a Entrada de Ar no Compartimento do Motor.}

Durante a fase inicial do projeto, faz-se necessária a análise de determinados itens que podem influir na vazão de ar no compartimento do motor, como abaixo identificados:

- Tipos de grades nas aberturas frontais;

- Redução da abertura de tomada de ar na melhoria do coeficiente de arrasto;

- Introdução de viga de segurança e o posicionamento inadequado da placa de licença;

- Aumento de número de componentes para conforto e segurança. 


\subsubsection{Tipos de Grades nas Aberturas de Tomada de Ar}

A introdução de grades prolongadas tipo "tela" nas aberturas frontais do veículo, em substituição das tradicionais grades tipo perfilados, restringe o escoamento do ar pelo compartimento como ficou evidenciado com o estudo apresentado no Apêndice A. Essas novas grades têm funções meramente estéticas, pois são projetadas de forma que o seu prolongamento tenha uma pequena angulação que quando instaladas não permitam a visualização dos componentes internos do compartimento do motor.

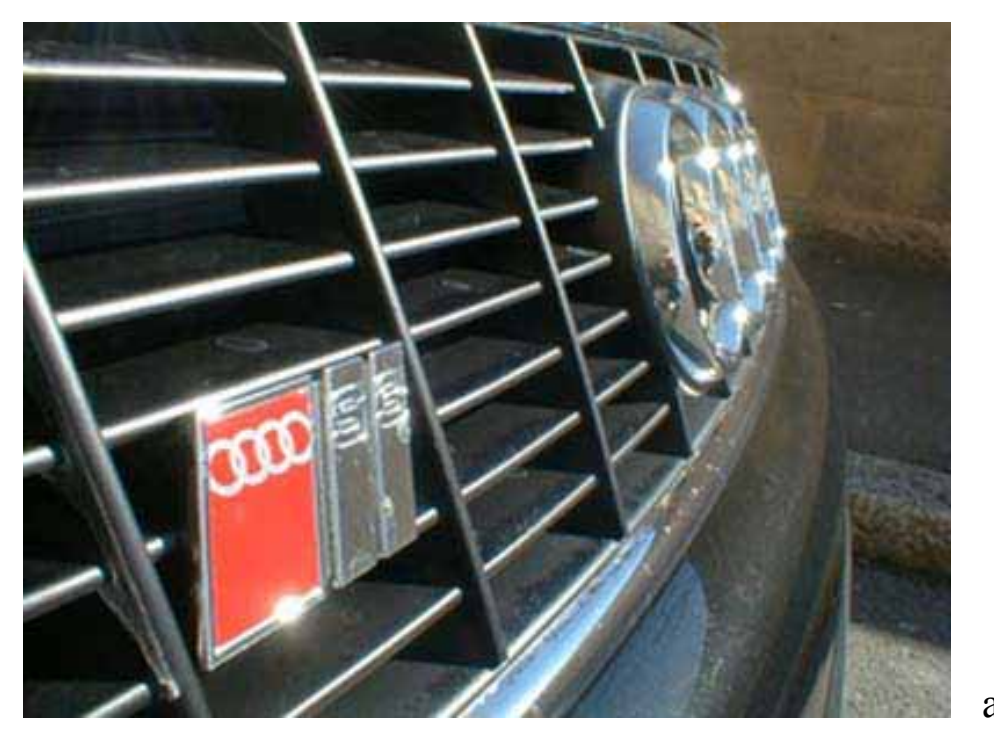

a)

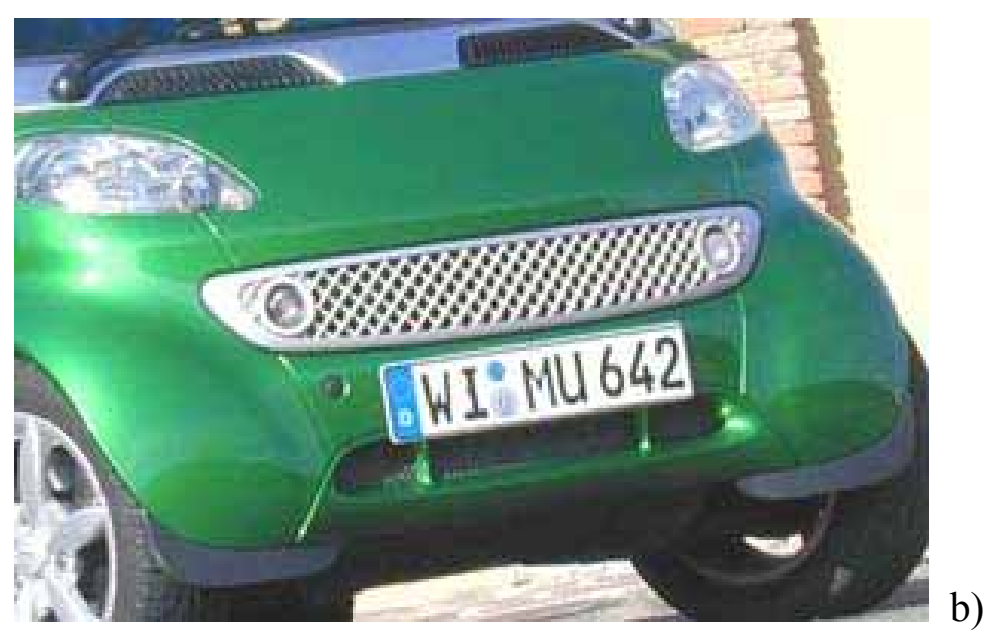

Figura 1.5 - a) Grades convencionais perfilado ou tipo friso. b) Grade tipo tela com prolongamento. 


\subsubsection{Redução da Abertura de Tomada de Ar na Melhoria do Coeficiente de Arrasto}

Em projetos modernos, a busca do baixo coeficiente de arrasto é um fator relevante para se obter um veículo de baixo consumo. Estudos realizados por Buchheim (1983) e Renn e Gilhaus (1986) mostram que o coeficiente de arrasto é menor nos veículos em que o ar não percorre pelos componentes internos do compartimento, como demonstradas nas figuras 1.6 e 1.7 .
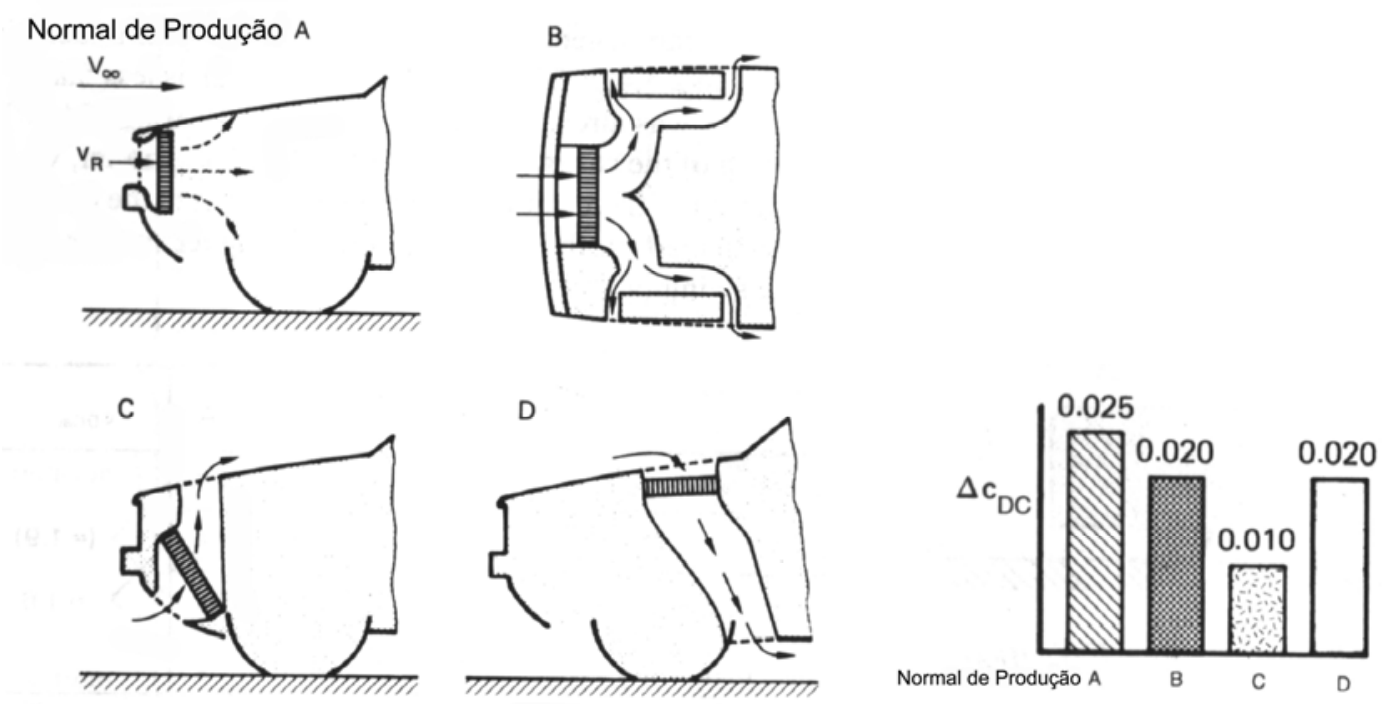

Figura 1.6 - Alteração do coeficiente de arrasto para diferentes tipos de disposição do radiador (Buchheim R.,1983.).
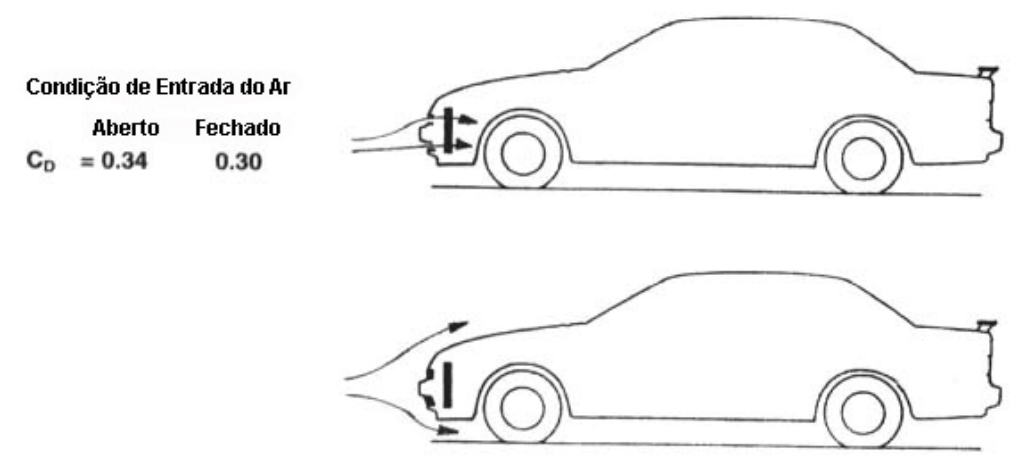

Figura 1.7 - Coeficiente de arrasto de um carro sedan esporte com e sem aberturas frontais (Renn e Gilhaus, 1986.). 


\subsubsection{Introdução de Viga de Segurança e o Posicionamento Inadequado da Placa de Licença.}

Dados levantados por Schmitt (2004), do centro de bioengenharia da Universidade de Wayne, indicam que anualmente no mundo mais de 140 mil pessoas sofrem acidentes automotivos, dentre as quais 3 mil se tornam vítimas fatais e outras 15 mil sofrem seqüelas permanentes. De acordo com estudos realizados, extrai-se que na maioria dos atropelamentos com vítimas fatais, estas apresentavam fraturas cranianas e nos membros inferiores. Outro dado apontado consiste no fato de que na maioria desses casos as vítimas encontravam-se alojadas sob o veículo.

A introdução da viga de proteção tem a finalidade de aumentar a rigidez da área inferior da capa do pára-choque, de modo que em uma colisão de baixa velocidade de até $40 \mathrm{~km} / \mathrm{h}$, a vítima é lançada e amortecida sobre o capô do veículo.

No caso de veículos utilitários esportivos os "SUVs" em que a carroceria é mais alta, o posicionamento do pára-choque é limitado à altura de um carro de passeio para que possa maximizar a energia de deformação durante um impacto frontal. A altura da viga de impacto deve, nos termos das normas de segurança, atuar como um sistema de alavanca. Como a região do pára-choque tem alta pressão estática para o efeito "ram", essas restrições de posicionamento aliadas à presença da placa de licença, resultam em uma abertura de tomada de ar ineficiente. Estudos conduzidos por Nishimura et al (1993) mostram que uma variação de $23 \mathrm{~mm}$ no posicionamento da placa de licença pode reduzir em 3.4\% o valor do fluxo de ar.
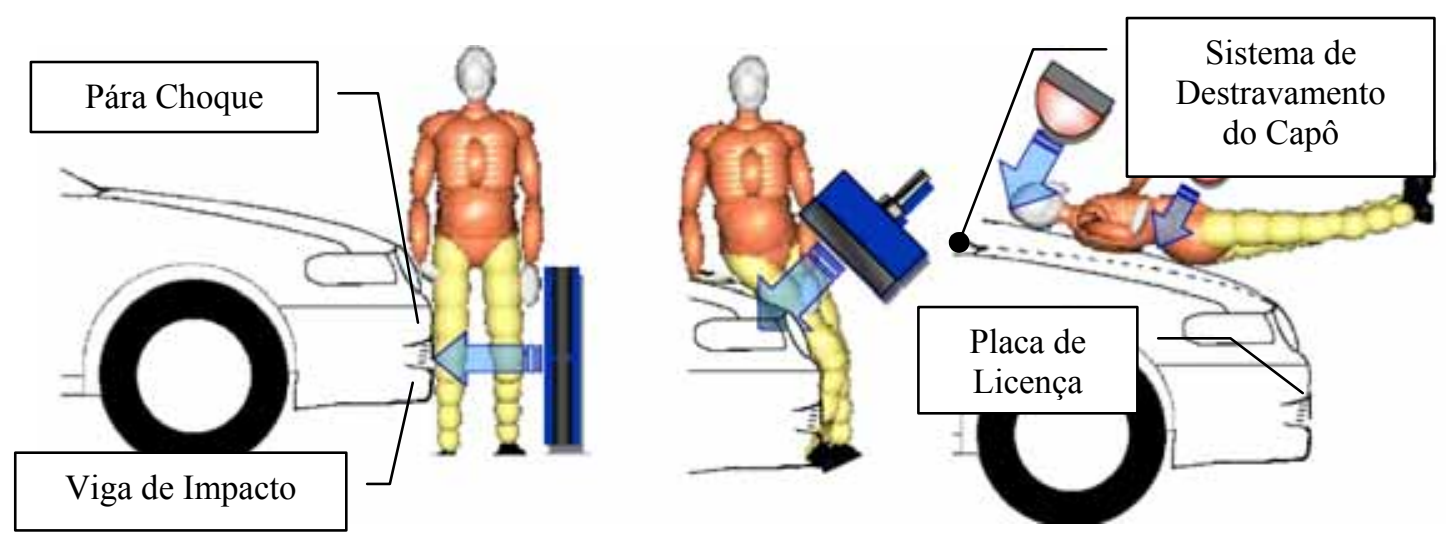

Figura 1.8 - Teste de impacto em pedestre (baixa velocidade). 


\subsubsection{Aumento de Números de Componentes de Conforto e de Segurança no Compartimento do Motor}

Como já sublinhado em linhas anteriores, a contínua busca de desempenho, segurança e conforto dos veículos resultaram em um aumento de número de componentes auxiliares no compartimento dos motores tais como:

- Transmissão Automática (grande número de engrenagens);

- Sistema de ABS;

- Bomba de Direção Hidráulica;

- Compressor do Ar Condicionado / Condensador;

- Filtro de Ar / Ressoador (Motorização / Ruído);

- Tanque de Combustível de partida a frio.

Esses componentes resultaram em um aumento no "bloqueio" do fluxo de ar através do motor; em muitos casos, esses componentes são fontes adicionais de calor tais como o caso de compressores e bombas. Esse fenômeno pode ser verificado pela comparação do veículo Kadett E GSi de 1985 com o Kadett A de 1965. O compartimento do motor do "Kadett GSi" $16 \mathrm{~V}$ mostra uma alta compactação de componentes auxiliares em relação ao "Kadett $A$ " que apresenta espaços livres para a circulação de ar.

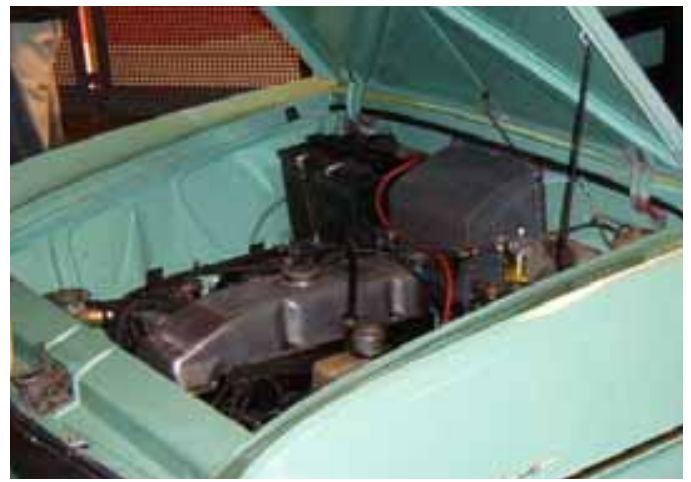

a) Kadett $A$ (1965)

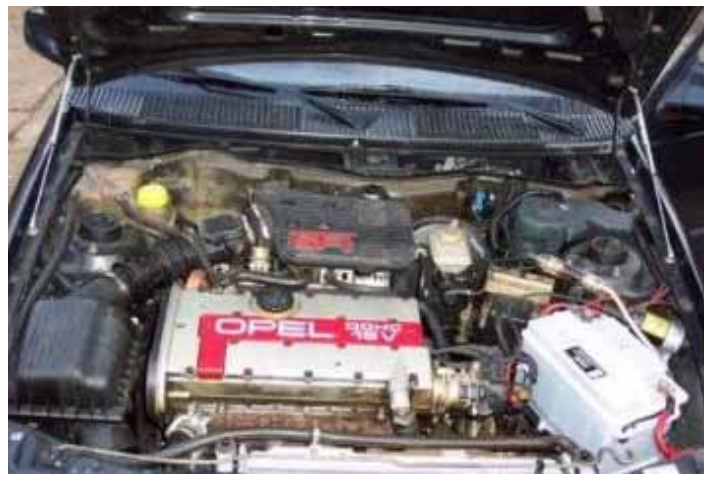

b) Kadett E GSi 16V(1985)

Figura 1.9 - Componentes do compartimento do motor. a) Kadett A, b) Kadett E GSi. 
A busca de conforto, novos estilos e segurança têm contribuído na redução do fluxo de ar pelo compartimento do motor, tornando-se um desafio o projeto de um sistema de arrefecimento compacto, eficiente e de baixo custo (Shah et al, 1990). Desta forma, novas tecnologias têm sido incorporadas aos projetos do sistema de arrefecimento dentre os quais podemos citar:

- A utilização de materiais termo-plásticos de alta resistência nos componentes agregados aos trocadores de calor na redução do peso;

- Ventiladores de alta eficiência e de baixo nível de ruído com anel direcionador de fluxo para a redução do efeito da recirculação;

- Trocadores de calor com sistema de "Turbilhonador" no interior dos tubos para aumentar o número de Reynolds e conseqüentemente, a troca térmica;

- A utilização de tubos de geometrias elípticas alongadas cuja superfície da parte interna apresenta pequenas saliências com finalidades de reduzir a área frontal do trocador de calor.

\subsubsection{Circuito de Arrefecimento do Motor}

A transferência da energia térmica do motor para o radiador é feita por meio do sistema de arrefecimento do motor com recirculação de água, onde o fluido de arrefecimento sai quente do motor, passa pela válvula termostática e segue para o radiador onde então o calor é rejeitado ao meio ambiente. A bomba de água opera tanto para o circuito do aquecedor do sistema de ar condicionado quanto para o circuito do arrefecimento do motor. Se a válvula termostática encontrar-se fechada, a água circulará internamente no motor até atingir a temperatura operacional próximo a faixa de $110^{\circ} \mathrm{C}$. Com a elevação da temperatura, a válvula termostática é aberta e o fluido quente será então liberado para o circuito de recirculação. Dependendo da temperatura do fluido quente, a válvula termostática poderá acionar o eletroventilador, de modo a aumentar a eficiência de troca térmica.

Como a bomba de água está ligada ao eixo da manivela por meio de uma correia dentada, operando em sincronia com a rotação do motor, pode-se dizer que a energia térmica rejeitada ao sistema de arrefecimento é proporcional à rotação do motor. 


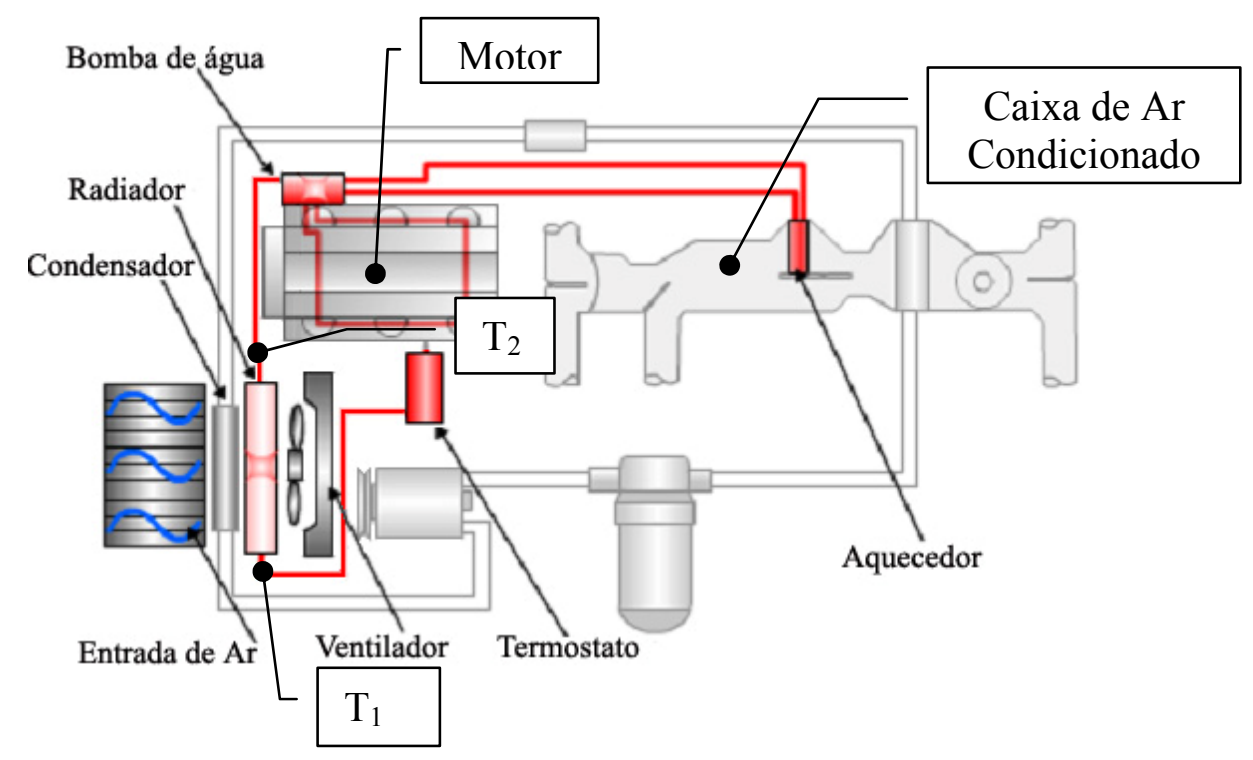

Figura 1.10 - Sistema de arrefecimento do motor.

Como pode ser verificado, o sistema de recirculação do líquido de arrefecimento do motor tem grande impacto no desempenho do veículo. Uma bomba de água ou uma válvula termostática inadequada ou com defeito poderá reduzir a transferência de calor para o radiador, promovendo um superaquecimento no bloco do motor. A carga térmica no radiador pode ser expressa pelo produto da variação da temperatura do líquido de arrefecimento na entrada e saída pela capacidade térmica como abaixo equacionado (1.1):

$$
\dot{Q}_{R}=\dot{m}_{r} \cdot c p \cdot\left(T_{2}-T_{1}\right)
$$

\subsubsection{Circuito de Arrefecimento da Cabine}

O conforto térmico de ocupantes é um item valorizado nos projetos atuais. Contudo, as tendências de estilos na utilização de grandes áreas cobertas com vidros e o sistema de teto solar são cada vez mais freqüentes, favorecendo, assim, a retenção do calor devido à radiação solar, das fontes de calor proveniente do assoalho, de equipamentos internos a cabine (aparelho de som) e de ocupantes. Toda essa energia acumulada deverá ser retirada através do sistema de arrefecimento por meio do evaporador do ar condicionado. 
O sistema de climatização para aplicações automotivas tem características particulares que se diferencia de um sistema de climatização para ambientes de escritórios. Em uma aplicação automotiva, a variação de condições de conforto é de grande relevância, como por exemplo:

- O nível de carga solar, a velocidade do veículo;

- A umidade relativa do ar;

- As temperaturas internas e externas da cabine;

- O número de ocupantes e a disposição no interior do veículo;

- Regime de rotação e carga do motor.

Diante dessa variabilidade, o sistema deve ser projetado para funcionar sob todas essas condições, propiciando condições de conforto térmico com o menor consumo de energia. Desta forma, o sistema de arrefecimento, além de retirar a grande parcela da carga térmica do motor, deverá também retirar uma parcela significativa da carga térmica proveniente da cabine através do condensador.

O sistema de arrefecimento da cabine funciona pelo princípio de alteração de fase do fluido como ilustra a figura 1.11.

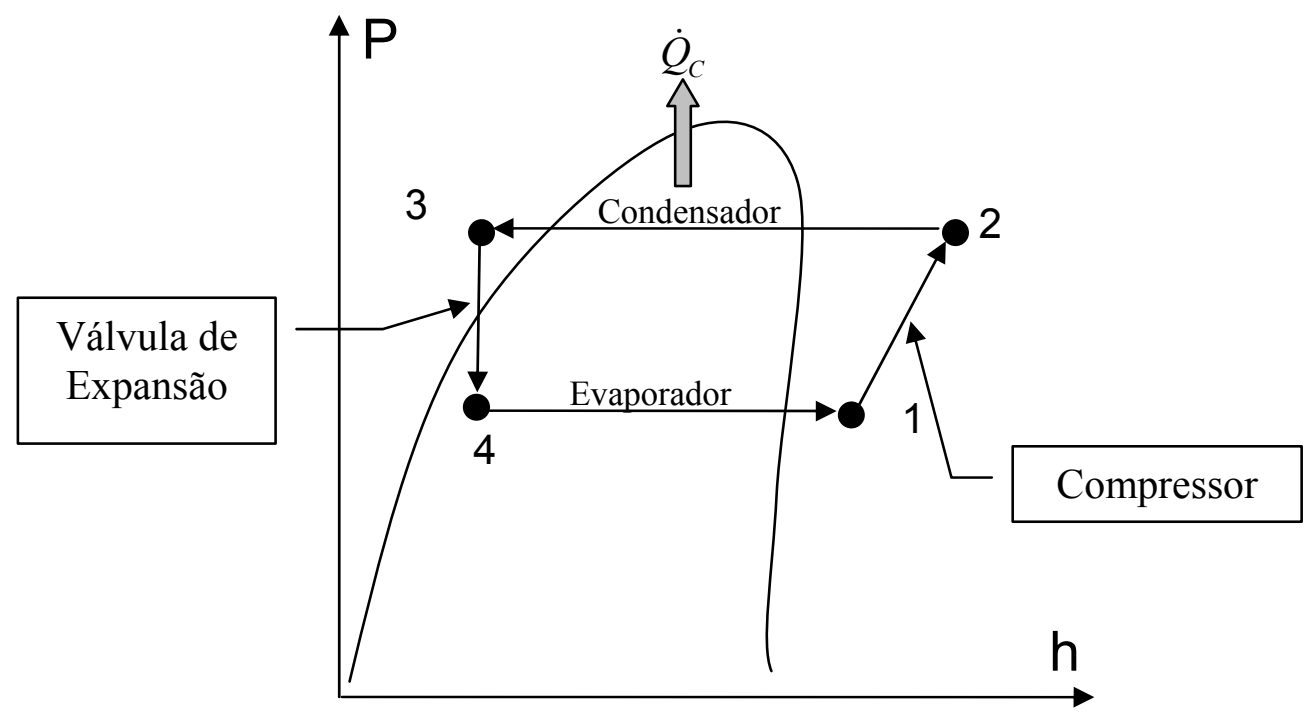

Figura 1.11 - Diagrama do Ciclo de Refrigeração HFC-134a.

Para um volume de controle envolvendo o lado do refrigerante do condensador, o calor rejeitado para o reservatório quente $\dot{Q}_{C}$ ( Condensador) é dada pela diferença de entalpias $h 2-h 3$ denominada de rejeição térmica do condensador (Ávila ,2002). 
$\dot{Q}_{C}=\dot{m}_{c}\left(h_{3}-h_{2}\right)$

A expansão adiabática que ocorre no dispositivo de expansão é modelada como sendo isoentálpica, de tal maneira que:

$h_{4}=h_{3}$

Detalhe de cálculo da rejeição térmica em cabines pode ser visto nos trabalhos de Santos E. (2005).

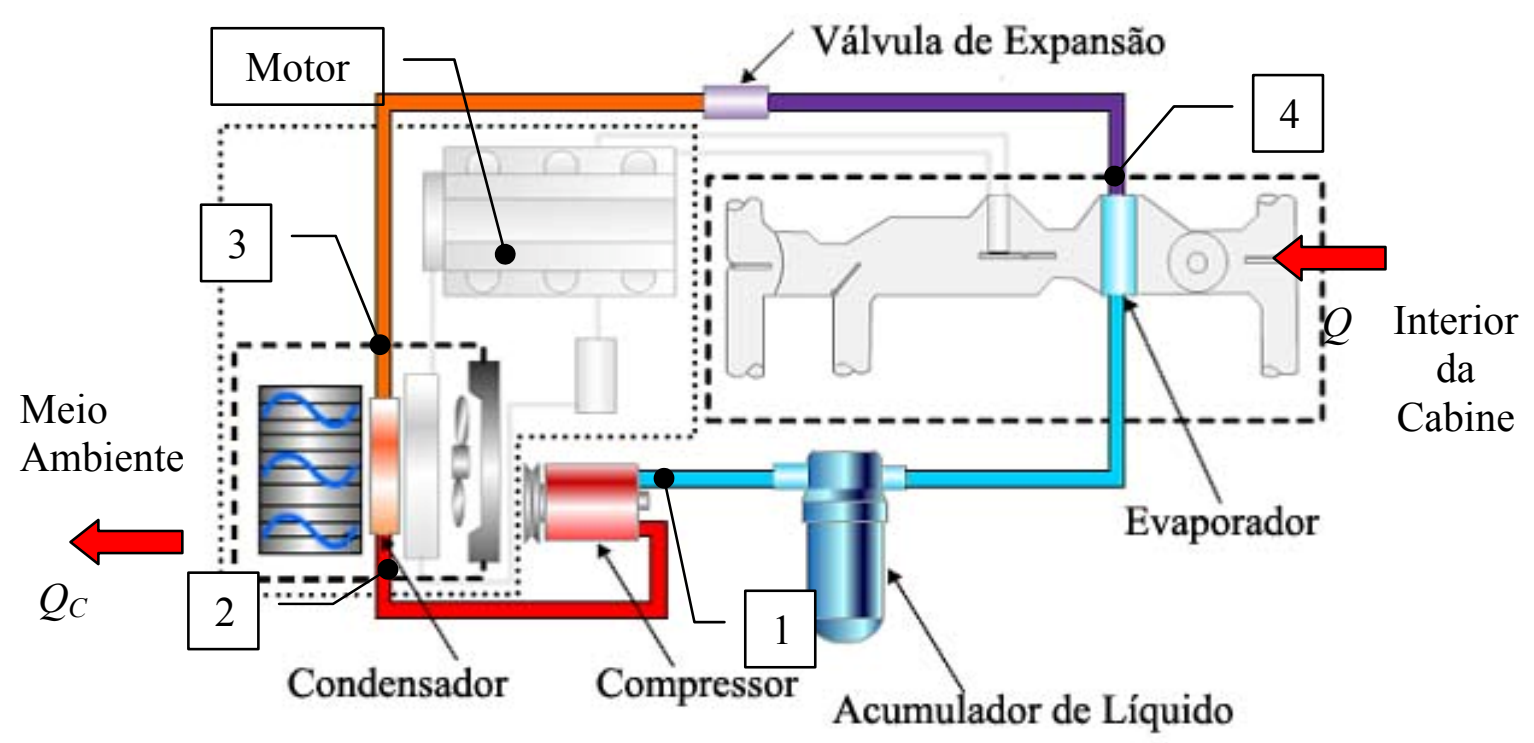

Figura 1.12 - Sistema de arrefecimento da cabine.

\subsubsection{Trocadores de Calor}

Denominam-se trocadores de calor os dispositivos utilizados para transferir a energia térmica (entalpia) entre dois ou mais fluidos, ou entre superfícies sólidas e o fluido, em temperaturas diferentes e geralmente sem a presença de trabalho externo.

De acordo com as definições de Kays e London (1984), tanto o condensador ou radiador de um sistema de refrigeração automotivo são considerados trocadores de calor compactos, sendo que ambos utilizam o ar como um dos fluidos para a troca térmica. Devido ao baixo calor específico, grandes quantidades de ar são necessárias para que se possa remover a quantidade de calor necessária do trocador de calor. A 
limitação da área de troca térmica, característica da aplicação automotiva, faz com que as velocidades de ar sejam elevadas. O crescente número de itens auxiliares no compartimento do motor resultou em uma limitação na área dos trocadores de calor, exigindo, assim, a utilização de trocadores compactos.

Os trocadores compactos têm a característica de apresentar alta densidade de aletas (figura 1.13) as quais são consideradas de área primária ou superfície direta de troca térmica. Além das áreas primárias existem também as áreas secundárias ou indiretas que são as frestas de ventilação "louvers" interligadas às aletas.

Esses conjuntos de características fazem com que os trocadores de calor tenham alta relação de área de troca térmica por unidade de volume numa ordem de $3300 \mathrm{~m}^{2} / \mathrm{m}^{3}$ (Rohsenow, Hartnett e Cho 1998). Devido à sua alta eficiência de troca térmica, a configuração de trocadores tipo placa-tubo ainda é a mais utilizada na área automotiva. Os tubos de alumínio são ligados com interferência nas placas aletadas e soldadas ao tanque pelo processo de brasagem.

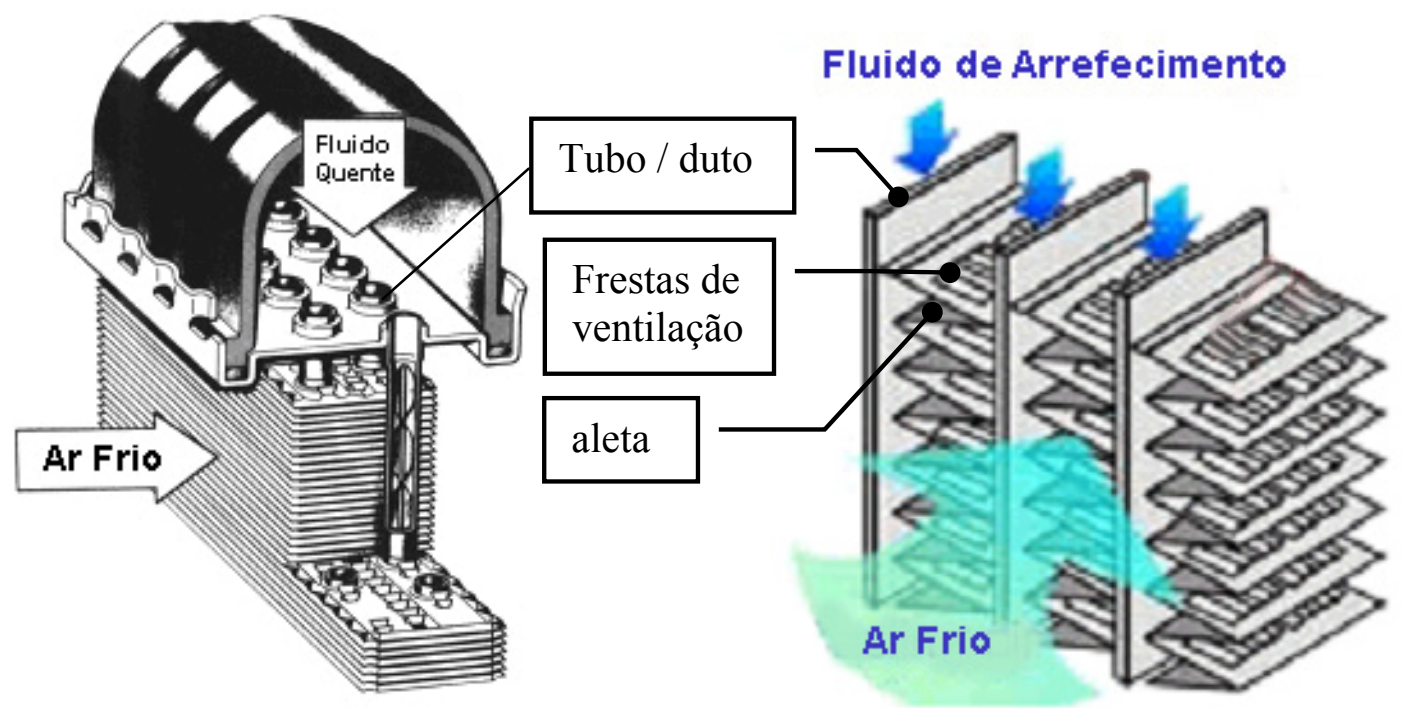

Figura 1.13 - Radiador tipo placa-tubo.

O ângulo das frestas de ventilação possui grande influência na troca térmica dos radiadores, pois tem a finalidade de evitar a formação da camada limite de escoamento do ar aumentando, assim, o número de Reynolds e conseqüentemente, a troca térmica. 


\subsubsection{Fluido de Arrefecimento}

$\mathrm{Na}$ definição popular, o anticongelante é um aditivo que impede o congelamento quando misturado com água no sistema de arrefecimento automotivo. Houve época em que essa definição era bastante adequada, entretanto, o anticongelante moderno não se limita à apenas esta função. Ele proporciona a proteção ao sistema de arrefecimento para temperaturas adversas, impedindo-se que este congele no inverno e ferva no verão (especialmente nos carros com ar condicionado). Oferece, ademais, proteção contra ferrugem e corrosão sem prejudicar as mangueiras de borracha e as peças plásticas. Cite-se ainda o anticongelante à base de etilenoglicol que é quimicamente estável e com um custo relativamente baixo. Normalmente o anticongelante é denominado de "Fluído de Arrefecimento" (FA).

Os requisitos de desempenho do " $F A$ " tornaram-se mais rigorosos na década de 80 , isto porque, o que antes era um produto simples destinado basicamente para proteger o sistema de arrefecimento dos motores de combustão interna tornou-se um produto complexo contendo um equilíbrio de aditivos desenvolvidos para cumprir muitos requisitos severos. A necessidade do aumento da importância do " $F A "$ foi induzida pelo surgimento de motores mais eficientes e potentes, operando em altas temperaturas, pelo uso de materiais de liga leve e plástico no sistema de arrefecimento e pela crescente preocupação com o aspecto toxicológico do próprio "FA".

Devido à redução da massa dos veículos a fim de melhorar a economia de combustível, o volume de " $F A$ " usado também foi drasticamente reduzido, para a contribuição na redução do peso, submetendo o " $F A$ " a elevados regimes de fluxo, altas temperaturas e significativos fluxos de calor entre metal e o " $F A$ ". Para uma troca de calor eficiente é necessário que o " $F A$ " mantenha a propriedade anticorrosiva e com alta condutividade térmica.

Segundo Maes e Armstrong (1992), os requisitos e especificações dos fabricantes de veículos para os fluidos de refrigeração exigem os seguintes requisitos do fluido:

- ter alta capacidade de troca térmica; 
- ser capaz de proporcionar proteção contra congelamento e ebulição;

- ter propriedade anticorrosiva e ser compatível com plásticos, elastômeros e água;

- ser quimicamente estável em qualquer temperatura operacional;

- ter baixa formação de espuma;

- ser ecológica e toxicamente aceitável.

Atualmente, as formulações de água-etilenoglicol (EG) são os " $F A$ " preferidos, pois, além do seu baixo custo, se mostrou como o mais eficiente na proteção térmica do motor como pode ser comprovada pela tabela comparativa (1.1) com o álcool metílico $\left(\mathrm{CH}_{3} \mathrm{OH}\right)$, propilenoglicol $(\mathrm{PG})$ e água pura.

Tabela 1.1 - Propriedades físicas típicas de compostos de sistema de refrigeração (Maes e Armstrong., 1992).

\begin{tabular}{|c|c|c|c|c|}
\hline PROPRIEDADE & ÁGUA & $\mathrm{CH}_{3} \mathrm{OH}$ & EG & $P G$ \\
\hline Peso específico $20 / 20^{\circ} \mathrm{C}$ & 1,0000 & 0,7924 & 1,1155 & 1,0381 \\
\hline Calor Específico, cal $/ \mathrm{g} .{ }^{\circ} \mathrm{C}$ & 0,998 & 0,600 & 0,574 & 0,600 \\
\hline \multicolumn{5}{|l|}{ Ponto de Congelamento ${ }^{\circ} \mathrm{C}$} \\
\hline Puro & 0 & $-97,7$ & $-13,3$ & - \\
\hline Solução com $50 \%$ de água & - & $-7,9$ & $-36,6$ & $-33,0$ \\
\hline Ponto de Ebulição, ${ }^{\circ} \mathrm{C}$ & 100,0 & 64,50 & 197,30 & 187,20 \\
\hline Pressão de valor, $20^{\circ} \mathrm{C}, \mathrm{mm} \mathrm{Hg}$ & 17,5 & 96,1 & 0,12 & 0,18 \\
\hline Ponto de fulgor, vaso aberto, ${ }^{\circ} \mathrm{C}$ & - & 15,6 & 115,6 & 107,2 \\
\hline \multicolumn{5}{|l|}{ Viscosidade $\mathrm{cp}$} \\
\hline $20^{\circ} \mathrm{C}$ & 1,00 & 0,60 & 20,9 & 60,5 \\
\hline $40^{\circ} \mathrm{C}$ & 0,65 & 0,46 & 9,1 & 19,3 \\
\hline $100^{\circ} \mathrm{C}$ & 0,28 & - & 1,8 & 2,6 \\
\hline
\end{tabular}

No passado era comum a utilização de água como fluido de arrefecimento do motor a combustão interna. Entretanto, o seu ponto de congelamento é relativamente alto, o que resulta em sérios danos ao motor e ao sistema de arrefecimento, haja vista que a água sofre uma mudança de expansão de cerca de $9 \%$ do seu volume quando congelada, suficiente para causar trincas no bloco do motor ou no radiador. 
À medida que se aumenta a eficiência do motor, em parte aumentando a temperatura do motor, tem-se uma maior quantidade de calor rejeitado pelo sistema de arrefecimento. Pode-se proporcionar um arrefecimento adicional com o aumento da pressão do sistema de refrigeração e permitindo-se com isso que o " $F A$ " circule a uma temperatura máxima mais alta. O ponto de ebulição elevado do " $F A$ ", à base de EG (Etilenoglicol) com relação à água, é importante porque reduz as perdas por evaporação, cavitação da bomba de água causada por vaporização "instantânea" no lado de sucção da bomba e ebulição causada pelo calor residual de um motor desligado. A figura 1.14 mostra os pontos de ebulição de EG com a variação da sua concentração.

\begin{tabular}{|c|c|c|}
\hline \multirow[b]{2}{*}{$\begin{array}{l}\text { Concentraçäo } \\
\text { de EG } \\
\text { (\% em volume) }\end{array}$} & \multicolumn{2}{|c|}{ PONTO DE EBUUÇÃO } \\
\hline & $\begin{array}{l}\text { Pressāo } \\
\text { atmostérica }\end{array}$ & $\begin{array}{l}\text { Pressaāo do } \\
\text { sistema } 103 \\
\mathrm{kPa}(15 \mathrm{psig})\end{array}$ \\
\hline 33 & $104^{\circ} \mathrm{C}\left(219^{\circ} \mathrm{F}\right)$ & $125^{\circ} \mathrm{C}\left(257^{\circ} \mathrm{F}\right)$ \\
\hline 44 & $107^{\circ} \mathrm{C}\left(224^{\circ} \mathrm{F}\right)$ & $128^{\circ} \mathrm{C}\left(262^{\circ} \mathrm{F}\right)$ \\
\hline 50 & $108^{\circ} \mathrm{C}\left(227^{\circ} \mathrm{F}\right)$ & $129^{\circ} \mathrm{C}\left(265^{\circ} \mathrm{F}\right)$ \\
\hline 60 & $111^{\circ} \mathrm{C}\left(232^{\circ} \mathrm{F}\right)$ & $132^{\circ} \mathrm{C}\left(270^{\circ} \mathrm{F}\right)$ \\
\hline 70 & $114^{\circ} \mathrm{C}$ (238॰ $)$ & $136^{\circ} \mathrm{C}\left(276^{\circ} \mathrm{F}\right)$ \\
\hline \multicolumn{3}{|c|}{$\begin{array}{l}\text { Concentraçōes superiores a } 70 \text { por cento năo săo reco } \\
\text { mendadas; } 68 \text { por cento oferecem a máxima proteçă } \\
\text { contra congelamento, cerca de }-69^{\circ} \mathrm{C}\left(-92^{\circ} \mathrm{F}\right) \text {. }\end{array}$} \\
\hline
\end{tabular}

a)

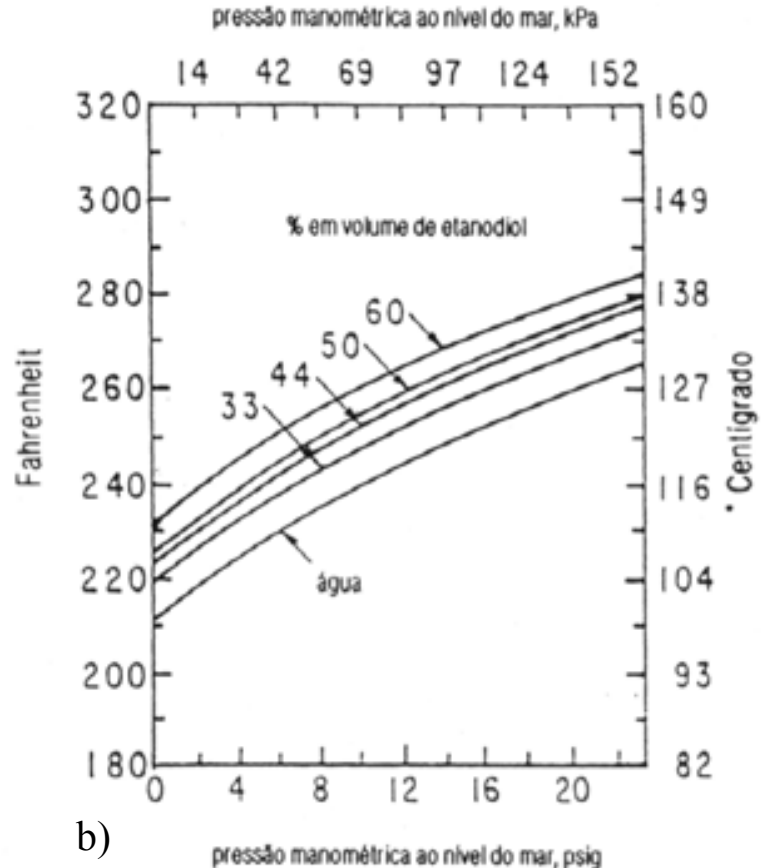

b)

Figura 1.14 - a) Pontos de ebulição de várias concentrações de etileglicol (Mercer, A. D.,1995) b) Ponto de ebulição de soluções aquosas de etanodiol (Maes e Armstrong, 1992).

\subsubsection{Eletro-Ventilador}

Como já visto no item 1.3 em veículos em baixa velocidade o efeito "ram" é ausente. Para garantir a troca térmica, eletros-ventiladores serão necessários para impor a vazão de ar através dos trocadores de calor. 
Basicamente, o eletro-ventilador pode ser definido como sendo um dispositivo que impõe uma corrente de ar por meio da movimentação controlada de uma superfície. A principal diferença entre um ventilador e uma bomba está no fato de que o primeiro trabalha com movimentação de um fluido gasoso, e o segundo de um líquido. Já no caso do compressor, apesar de trabalhar também com gases, esse tipo de turbomáquina eleva a pressão do sistema a partir da compressão do fluido de trabalho, reduzindo, assim, seu volume específico. Portanto, é de esperar que o ventilador trabalhe com incrementos de pressão bem mais baixos do que o compressor.

Um ventilador, na sua configuração mais simples, é composto basicamente de um rotor propulsor com certo número de pás ligadas ao cubo. Quando o rotor entra em movimento giratório através do motor elétrico, as pás transferem energia ao fluido, e assim, o fluxo de ar é estabelecido. Essa ação causa um aumento de pressão dentro da carcaça (ou voluta) do ventilador que é então repassada ao fluxo.

A classificação de ventiladores é feita com base na direção do fluxo através das pás. Os dois principais tipos são: os centrífugos e os axiais.

$O$ ventilador centrífugo tem seu fluxo axial de entrada expulsado radialmente pelas suas pás propulsoras. Dentro da voluta é desenvolvido um componente tangencial que define a velocidade da saída do ventilador. Esse tipo de máquina costuma ser operada em baixas vazões e altas cargas.

O ventilador axial, por sua vez, é caracterizado pelo seu fluxo de ar aproximadamente paralelo ao eixo do rotor. Esse fluxo, no entanto, não é exatamente axial devido a um componente tangencial "swirl" que é gerado devido ao torque aplicado pela hélice propulsora ao fluxo. Diferentemente do ventilador centrífugo, o axial tende a trabalhar em baixas cargas e altas pressões, o que atende os requisitos para o uso automobilístico a fim de garantir o processo de troca térmica.

A escolha de um eletro-ventilador axial baseia-se nas suas curvas de desempenho obtido em testes físicos. Normalmente são caracterizadas por três fatores: a carga ou pressão manométrica, o rendimento e a potência do rotor em função do escoamento.

As simulações computacionais tornaram-se mais eficientes na área da dinâmica dos fluidos, possibilitando a análise e otimização de pás de ventiladores 
com geometrias complexas em termos de eficiência e nível sonoro. Um exemplo de desenvolvimento tem sido descrito por Lohmann (1995), Lakshmikantha (1999) e recentemente por Henner (2003).

A figura 1.15 mostra as pás de um ventilador no formato de uma foice em comparação com o ventilador axial convencional. Devido ao seu alto desempenho, o uso destes ventiladores tem se tornado mais freqüente na área automobilística.
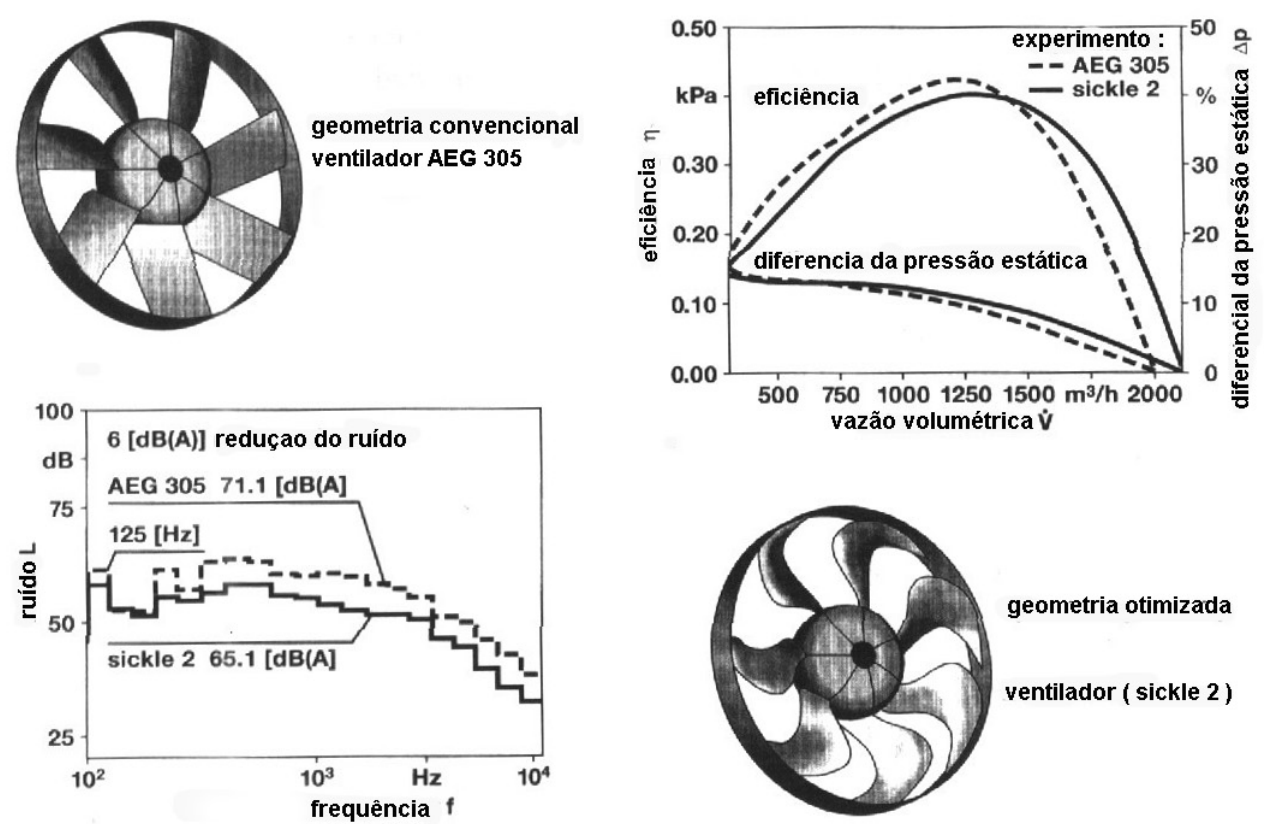

Figura 1.15 - Ventilador de alto desempenho Lohmann (1995).

\subsubsection{Túnel de Vento}

Atualmente a maioria das avaliações do sistema de arrefecimento é feita em teste de pista. Porém a repetividade e a discrepância dos resultados desses testes são afetadas pela variação do clima, principalmente o efeito do vento e a temperatura ambiente. Dessa forma, o teste em túnel é preferível pela conveniência, precisão e repetividade dos resultados.

Assim, muitos testes para avaliação do efeito aerodinâmico ou térmico, em que certas condições operacionais devem ser estabelecidas para a certificação ou aprovação do veículo, são realizados em túneis de vento. Tais testes envolvem os seguintes tipos de avaliação: 
- Coeficiente de arrasto (estudo da redução de consumo de combustível);

- Coeficiente de sustentação (estabilidade veicular em altas velocidades);

- Carga lateral (estabilidade veicular devido aos ventos cruzados);

- Deposição de partículas (visibilidade);

- Conforto térmico de passageiros (distribuição térmica na cabine);

- Aeroacústico (estudo do nível sonoro devido ao efeito de desprendimento de vórtices);

- Desempenho térmico do sistema de arrefecimento do motor.

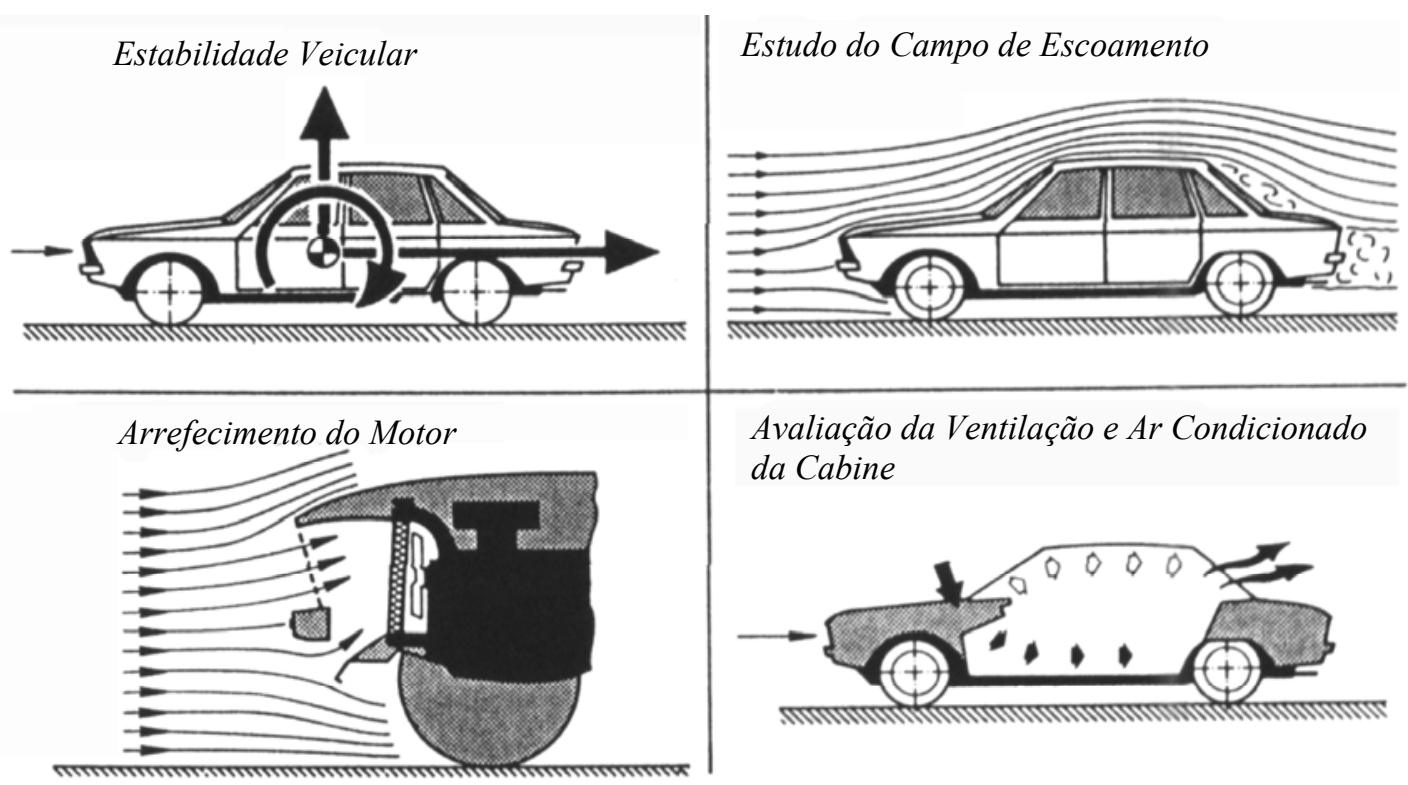

Figura 1.16 - Os objetivos da aerodinâmica veicular.

Geralmente, os resultados de túnel são utilizados para aferição de modelo de simulação. Apesar do túnel não representar perfeitamente as condições de pista, os veículos são submetidos às condições simplificadas onde os perfis de velocidades do vento não são considerados. 


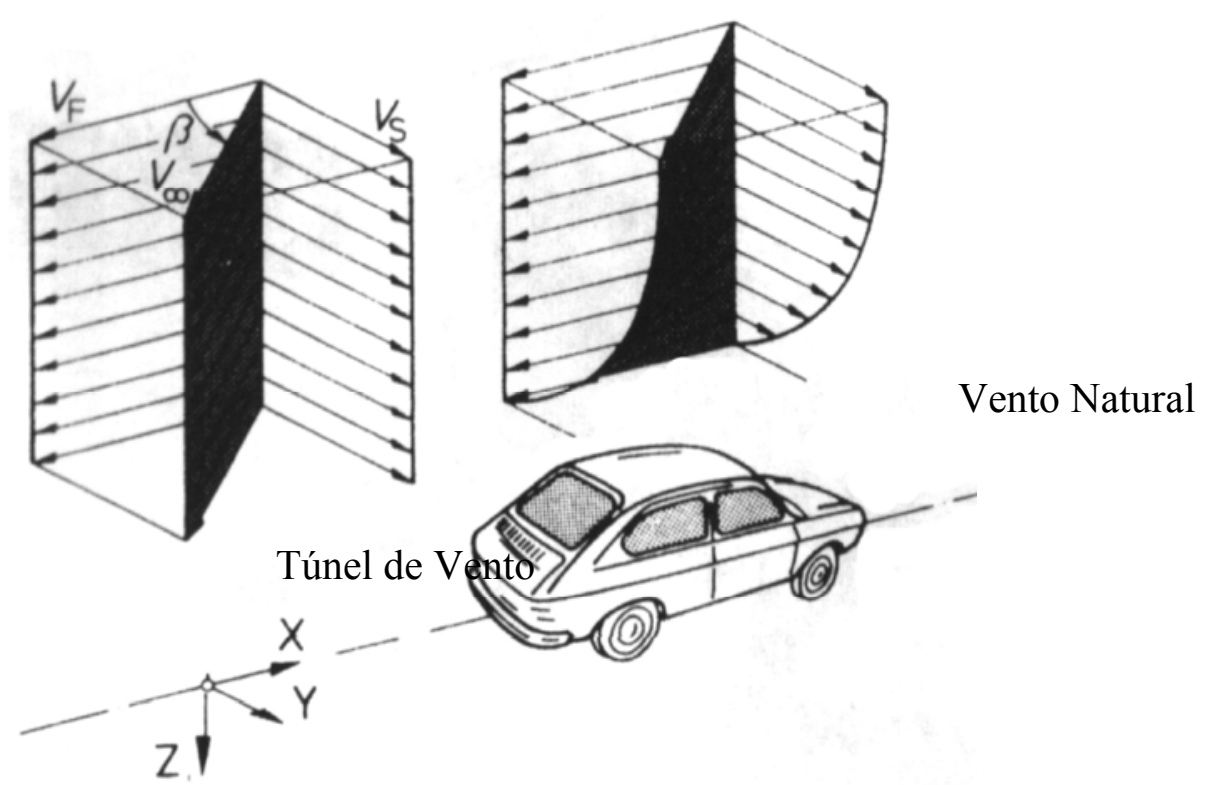

Figura 1.17 - Comparação de perfis de velocidade (Hucho et al,1998).

O túnel de vento para testes de arrefecimento em automóveis deve ser capaz de reproduzir as condições similares às de campo (pista) com a utilização de veículo em escala natural. Deve ainda permitir o controle da temperatura, umidade e velocidade do ar além da carga solar. É necessário também o uso de um dinamômetro para submeter ao veículo às condições operacionais como uma subida de serra onde o torque do motor é exigido ao máximo.

Inicialmente, os testes aerodinâmicos em veículos automotivos eram realizados em pequenos túneis especialmente construídos para ensaios de maquetes de aeronaves com escalas de 1:10, entretanto, a transferência de resultados para a escala real apresentava um risco considerável devido aos seguintes fatores:

1) Falta de Similaridade Geométrica.

Devido aos detalhes, as maquetes não conseguiam representar a geometria real do veículo, simplificando assim por uma superfície em que se ignorava uma possível região geradora de vórtices.

2) Falta de Similaridade Cinemática.

O número de Reynolds pode ser alterado com a exclusão de um detalhe. Em maquetes o efeito da camada limite do solo no veículo tem grande impacto nos resultados. As maquetes não apresentavam aberturas frontais de entrada de ar pelo 
compartimento do motor o que representa uma variação significativa no coeficiente de arrasto como mostrado na figura 1.7.

Um dos mais antigos túneis em escala natural dedicado ao testes de veículos está localizado em Stuttgart-Untertürkheim na Alemanha, construído em 1939 com a façanha de atingir a máxima velocidade de $270 \mathrm{~km} / \mathrm{h}$.

Um dos maiores túneis de vento aplicado aos veículos automotivos em escala natural, atualmente, é o da General Motors situado em Detroit (Estados Unidos), dotado de um sistema de circuito fechado e climatizado para avaliação de desempenho aerodinâmico, estabilidade direcional e conforto térmico em veículos de passeio e de médio porte como as "Pick Ups" e os veículos esportivos "SUVs" (Sport Utility Vehicle) em escala natural.

Segundo Kelly e Schenkel, (1982), este túnel apresenta uma seção transversal do cone de contração "nozzle" de $56,16 \mathrm{~m}^{2}$ e com comprimento aproximado de $21,3 \mathrm{~m}$ construído em metal revestido com uma espessa camada de $600 \mathrm{~mm}$ de concreto para evitar a propagação de onda sonora. O fluxo de ar é proveniente de um potente ventilador com hélice de $13 \mathrm{~m}$ de diâmetro e uma potência de $2238 \mathrm{~kW}$ contínua e $2984 \mathrm{~kW}$ intermitente apta a gerar uma velocidade da ordem de $250 \mathrm{~km} / \mathrm{h}$ (com 15 min de duração).

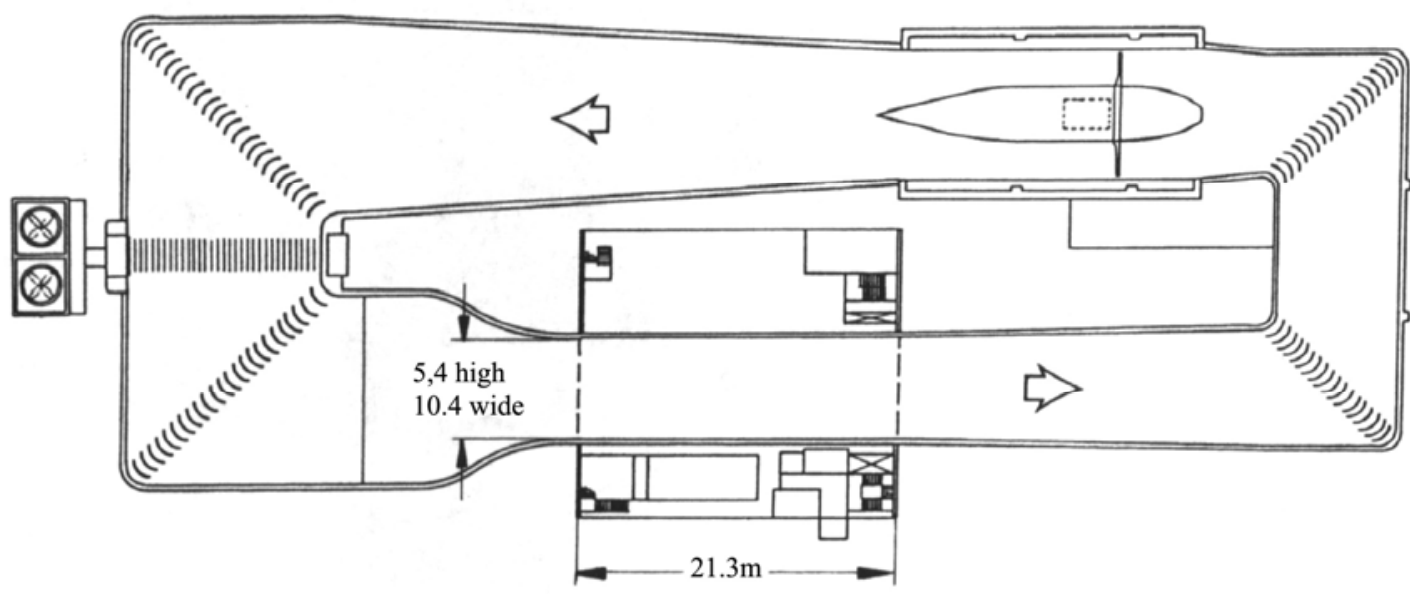

Figura 1.18 - Túnel de Vento da General Motors para testes aerodinâmicos em escala natural de veículos (Hucho et al, 1998).

Existem basicamente dois tipos de túneis de vento classificados de acordo com o tipo de fluxo de ar. O tipo "circuito aberto" ou tipo "Eiffel" em que o ar do 
túnel é puxado através de um ventilador e expelido ao meio ambiente, enquanto no de "circuito fechado" ou tipo "Göttingen", o ar é reaproveitado para realimentação do sistema. A vantagem do circuito aberto sobre o fechado é o custo de instalação, na medida em que no circuito fechado, o custo operacional é menor devido ao baixo consumo de energia, mas por outro lado, exige alto custo de investimento em dutos e sistema de isolamento térmico.

A figura 1.19 ilustra o esquema de um túnel de circuito fechado similar ao utilizado no levantamento de resultados de ensaio de arrefecimento do motor do presente trabalho.

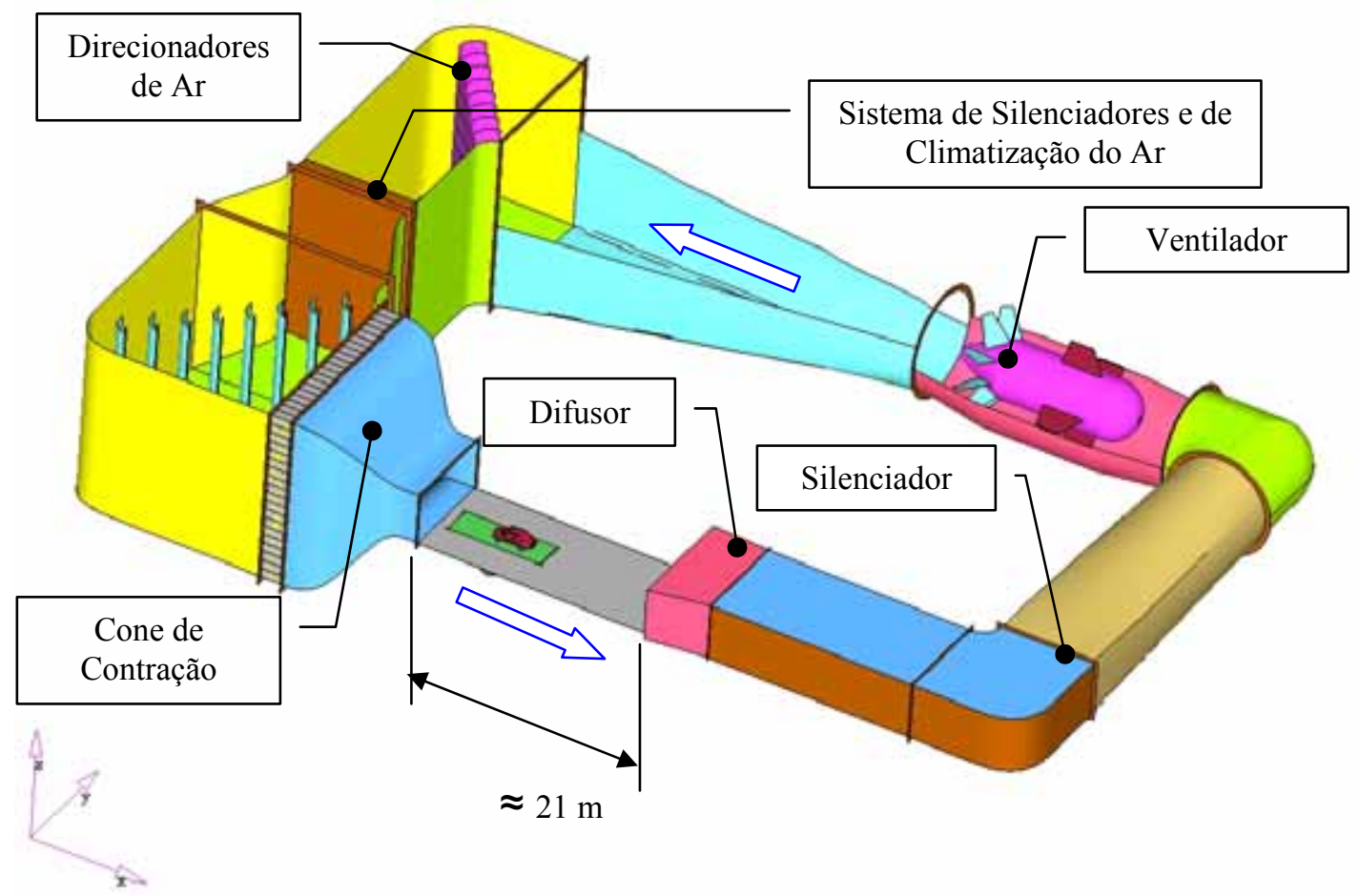

Figura 1.19 - Figura ilustrativa dos componentes internos do túnel de vento de circuito fechado para ensaio aerodinâmico em veículos automotivos.

A seção transversal $\left(\mathrm{A}_{\mathrm{N}}\right)$ e a configuração do túnel têm grande influência nos resultados, pois quanto maior essa área, mais próxima será da condição real. $\mathrm{O}$ fator de bloqueio (figura 1.20) é dado pela razão:

$\varphi=\frac{A}{A_{N}}$

onde A é a área projetada do veículo. 
O bloqueio ocorre quando os campos de escoamento nas regiões perto das paredes do túnel sofrem "contrações" devido à redução da área da passagem do ar.

(a)

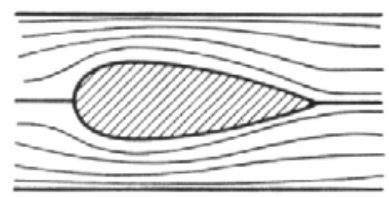

(b)

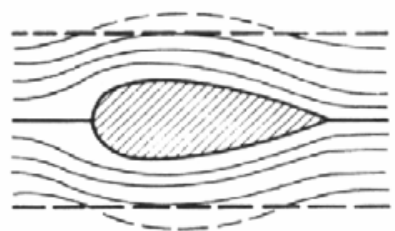

Figura 1.20 - Efeito da fronteira lateral no campo de escoamento: a) efeito de contração em um túnel fechado b) expansão em um túnel aberto.

Segundo Hucho et al (1998), o limite tolerável para teste em veículo automotivo é de $\varphi=0.10$. Neste trabalho, o túnel apresenta área com seção transversal de aproximadamente $56 \mathrm{~m}^{2}$ e a média de área projetada dos veículos de passeio é da ordem de $2 \mathrm{~m}^{2}$, desta forma, o fator de bloqueio de $\varphi=0.035$ encontra-se dentro dos limites aceitáveis.

Como pode ser visto na figura 1.21, para representar a condição aerodinâmica do veículo em movimento, instalou-se uma esteira rolante sob o veículo e um sistema de bomba de sucção do ar na parte frontal da esteira, com o intuito de se minimizar o efeito da camada limite sob os componentes inferiores ao veículo.

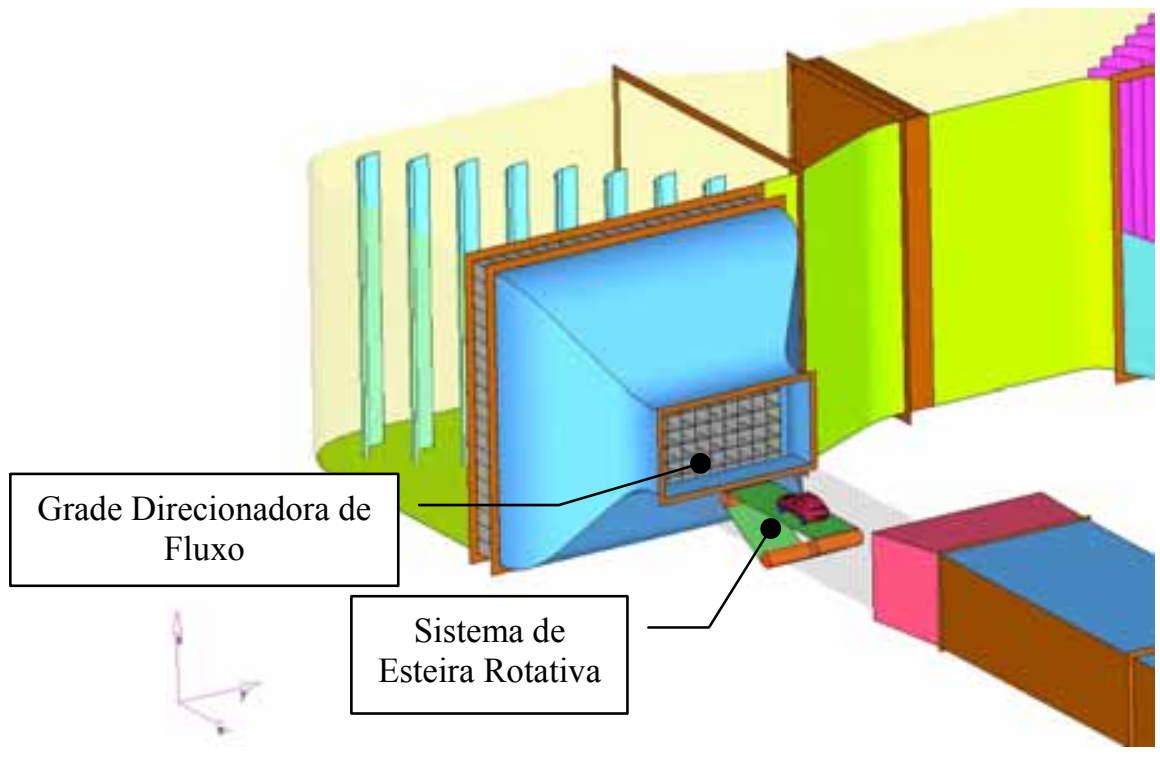

Figura 1.21 - Figura ilustrativa com detalhes do túnel de vento com sistema de esteira móvel.

Estudos feitos pelo Elofsson (2002) e Beauvais (1968) mostram uma diminuição do coeficiente aerodinâmico nos testes em túneis (figura 1.22) com a 
utilização do mecanismo de esteira rolante "Moving Ground" a qual está associado o efeito da roda em movimento "Rotating Wheel", cujas rodas são montadas sob roletes, onde os cilindros são acoplados a um sistema de freio permitindo representar as condições de carga do veículo alterando o torque do motor.

a)

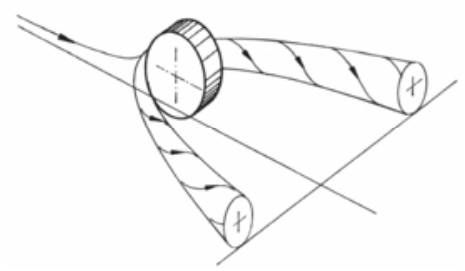

$\omega=0$ b)

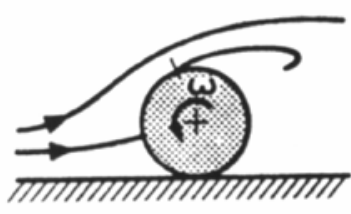

$\omega \neq 0$

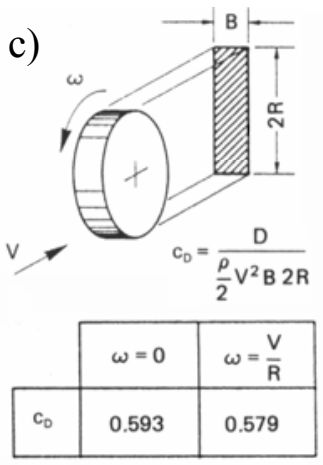

Figura 1.22 - a) Separação de fluxo e formação do vórtice de ferradura para rodas em condição estacionária Elofsson (2002) b) Deslocamento do ponto de estagnação e alteração da esteira de vórtices devido à rotação da roda Cogotti (1983). c) Redução do coeficiente aerodinâmico para roda em movimento Cogotti (1983).

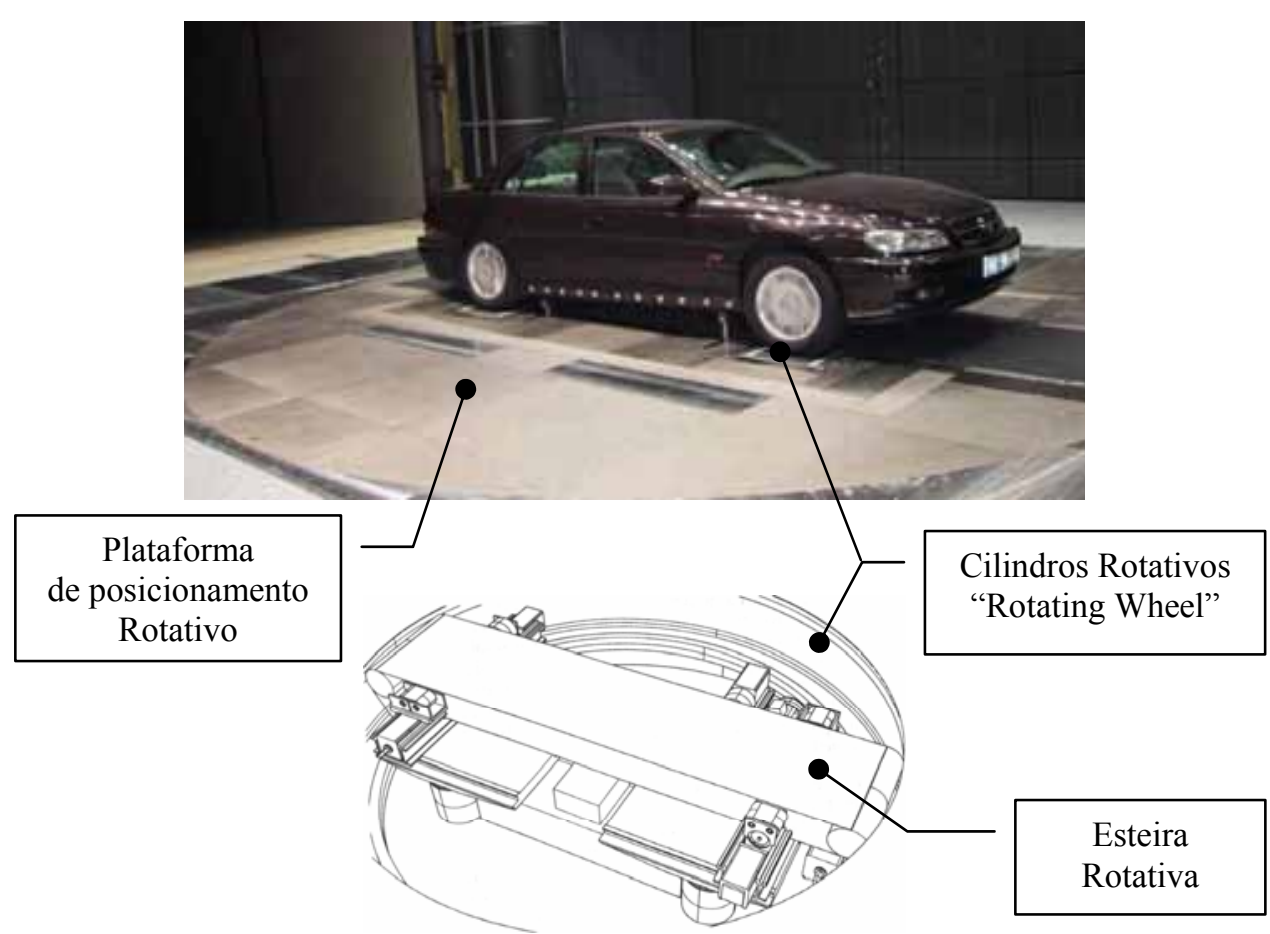

Figura 1.23 - Veículo montado sob sistema de esteira e cilindros rotativos para teste do sistema de arrefecimento. 


\section{CAPÍTULO 2}

\section{REVISÃO BIBLIOGRÁFICA}

Inicialmente os motores veiculares eram resfriados diretamente pelo ar (Sauders,1936), onde os cabeçotes eram aletados para o aumento da área de troca térmica. Com o aumento das potências dos motores surgiu a necessidade de novos meios de arrefecimento e o sistema a ar passou a ser mais utilizado em motores de aeronaves e motocicletas. Em veículos automotivos, face à localização do motor e pelo fato de se encontrar coberto pela carroceria, mostrou-se mais eficiente o sistema de arrefecimento com a utilização da circulação de líquido através do motor, posto que o líquido de arrefecimento apresenta um calor específico maior que o do fluido ar, e conseqüentemente, uma maior troca térmica. O líquido de arrefecimento quente é conduzido ao radiador onde o calor é dissipado ao ambiente.

O sistema de circulação de líquido era inicialmente natural, onde o fluxo era dependente da expansão e contração do líquido na passagem do motor ao radiador. Esse sistema foi utilizado durante pouco tempo, pois o depósito de impurezas nas tubulações restringia a circulação do líquido e também pelo fato que o sistema era ineficiente em condições nas quais o motor era solicitado em sua máxima potência.

O sistema de arrefecimento em veículos exerce um papel fundamental em vários aspectos operacionais. Em um sistema superdimensionado, a temperatura operativa do motor é alterada de modo a resultar em uma combustão incompleta, além do consumo desnecessário de energia por parte dos ventiladores. Já no caso de um sistema subdimensionado, a troca térmica é ineficiente, proporcionando um superaquecimento do motor e conseqüentemente, ocasionado o seu travamento pela perda da camada de lubrificante dos pistões.

Existem muitas literaturas, guias e tabelas para a escolha de tipos de trocadores de calor para um determinado motor, porém uma das melhores fontes de referência para o estudo do sistema de arrefecimento do compartimento do motor e sobre os aspectos da aerodinâmica externa e interna do compartimento do motor consiste na coletânea Huho et al (1998), publicada pela SAE International. 
Mencionada obra trata de diversos assuntos como a redução de ruído aerodinâmico, a otimização e melhorias da estabilidade veicular, além da parte relativa ao sistema de arrefecimento tanto para a cabine quanto para o compartimento do motor. As melhores técnicas de simulações e de medições foram incorporadas nessa coletânea por meio de diversos autores.

Grande número de trabalhos de arrefecimento do motor tem sido publicado pelos fabricantes de veículo por meio de metodologias e procedimentos restritos ou confidenciais e o uso de códigos de programas internos desenvolvidos especificamente para essas finalidades. Devido ao constante desenvolvimento e aperfeiçoamento de métodos e soluções numéricas aplicadas ao CFD, tais programas tornaram-se quase obsoletos face ao elevado custo de manutenção que normalmente é feita por equipes altamente qualificadas.

A solução encontrada pelas empresas foi celebração de parcerias com companhias de desenvolvimento de programas comerciais de CFD, objetivando-se o desenvolvimento de módulos específicos aplicados a um determinado tipo de simulação. Muitos desses módulos já se encontram incorporados e comercializados ao público em geral, como no caso do modelo de trocador de calor e o ventilador utilizado neste trabalho. Dessa forma, os trabalhos recentes já utilizam softwares comerciais de grande popularidade, tais como o FLUENT ${ }^{\circledR}, \operatorname{StarCD}^{\circledR}, \boldsymbol{U H} \boldsymbol{H D}^{\circledR}$, CF $\boldsymbol{X}^{\circledR}$, PAM FLOW $\boldsymbol{W}^{\circledR}$ e outros.

Inicialmente, os estudos de arrefecimento do motor eram predominantemente experimentais como pode ser observado no trabalho de Williams (1985), em que o autor descreve uma metodologia para a melhoria do coeficiente de arrasto e o escoamento de ar no compartimento do motor através de um mapeamento do fluxo de ar nos radiadores por meio de anemômetros e da avaliação da rejeição térmica do motor. O trabalho mostra a influência na abertura da grade no coeficiente aerodinâmico do veículo e no sistema de arrefecimento, onde os resultados mostraram uma variação de 5 a 10\% do valor total do coeficiente aerodinâmico.

Técnicas numéricas foram iniciadas nos anos noventa com a utilização do método de CFD para avaliar o efeito de escoamento e de troca térmica do motor.

Devido ao custo em processamento, a maioria dos trabalhos de simulações com a técnica de volumes finitos dessa época apresentava modelos simplificados e 
com um número limitado de elementos ao redor de 300.000. Novas metodologias de análise foram implementadas para minimizar o tempo de resposta, como por exemplo o trabalho desenvolvido por Li et al (1993) com a utilização de um modelo unidimensional por meio de redes térmicas para a estimativa da temperatura dos componentes do compartimento do motor assim com o líquido de arrefecimento.

Ashmawey et al (1993) analisaram a troca térmica do compartimento do motor do veículo Vectra V6 da OPEL considerando um alto valor de rejeição térmica, com a utilização do método de volumes finitos conjugado com modelos unidimensionais de modo a obter ganhos no tempo de resposta durante as fases do projeto do sistema de arrefecimento. Para avaliar o escoamento do ar dentro do compartimento do motor utilizou-se o programa VINE3D-H $\boldsymbol{H}^{\circledR}$ desenvolvido nos laboratórios de pesquisa da GM na solução das equações de Navier-Stokes (NS) com alto número de Reynols $(\mathrm{k}-\varepsilon)$ e em malha estruturada e que permite a determinação dos coeficientes de troca térmica por condução, convecção e radiação. Uma vez conhecidos estes coeficientes e aliados aos valores de perdas de carga do ar ao longo do compartimento e a distribuição de velocidade nos componentes do motor, estes dados foram, então, transferidos para o $\boldsymbol{C I N D A}^{\circledR}$, na avaliação da distribuição térmica dos componentes. Esse programa foi desenvolvido pela Chrysler Corp. e aperfeiçoado pela Hughes Aircraft, na avaliação térmica de modelos unidimensionais. Resultados mostraram que a proposta, como a inclusão do isolamento acústico do motor, implica em um aumento na temperatura dos componentes adjacentes ao motor na ordem de $65^{\circ} \mathrm{C}$. $\mathrm{O}$ autor atribui esse efeito térmico ao aumento da pressão interna do compartimento, e, consequentemente, a redução do fluxo de ar através no sistema de arrefecimento. $\mathrm{O}$ isolamento acústico impediu a circulação do ar quente resultante da convecção forçada no coletor de escape.

Habchi et al (1994) mostram um estudo de escoamento de ar no compartimento de um veículo de grande porte na categoria de tratores operando em baixa velocidade, em que o efeito de arrefecimento do motor é predominantemente proveniente de um ventilador. Nesse estudo foi utilizada uma malha estruturada para representar o domínio com geometrias simplificadas, onde somente as principais 
partes dos componentes do compartimento foram consideradas no modelo tais como: bloco, filtro de ar, alternador, compressor, direcionador de ar e o ventilador. Diante do custo de processamento, as grades de entradas de ar não foram levadas em consideração. As soluções das equações de NS foram feitas com a utilização do programa $\boldsymbol{R E F L E Q S}{ }^{\circledR}$ desenvolvido pela CFD Research Corporation para área aeroespacial. Resultados de simulações mostram uma grande divergência de valores na ordem de $-17,4 \%$ a $9,7 \%$ no valor da perda de carga do sistema em relação aos medidos em teste por meio do diferencial de pressão estático. Os estudos foram feitos considerando-se 14 tipos de condições de aberturas para a saída do ar dentro do compartimento do motor.

No trabalho de Ecer et al. (1995) utiliza-se também um modelo unidimensional composto por associações de elementos resistivos para representar a perda de carga do escoamento ao longo do compartimento. Nesse estudo, as resistências impostas pelos vários componentes do sistema como a grade, defletor de ar do ventilador e o motor, foram obtidas com o uso de um modelo de elementos finitos 3D com malha estruturada e simplificada, onde foram levantados os coeficientes de perda de carga para várias condições de velocidades do veículo. $\mathrm{O}$ radiador do modelo unidimensional utiliza resistências em séries totalizando na sua face uma matrix de 10x10 células de troca térmica.

Para a validação da metodologia, foram realizados testes em campo com as medições das temperaturas do líquido de arrefecimento do radiador e do mapeamento de temperaturas na face de entrada do ar no radiador com o uso de uma grade contendo 30 termopares. As simulações foram feitas com o uso do programa PASSAGE $^{\circledR}$ / Sysflow, desenvolvida pela TECHNALYSYS e os resultados mostraram uma diferença de 19\% no valor da temperatura do líquido de arrefecimento quando considerada uma velocidade uniforme no radiador. No caso em que a distribuição de velocidade no radiador é considerada com base no modelo de elementos finitos esta diferença é reduzida para 2,2\%.

Trabalho similar com uso da técnica de modelo unidimensional também foi estudado e aperfeiçoado por Mandrusiak e Alkidas (1996) da General Motors, em 
que se incluiu além do modelo do compartimento do motor, o motor, a transmissão, a bomba de água e o termostato para as condições de regime transitório e permanente.

O modelo do motor é interligado por meio dos seguintes submodelos:

1) Sistema de admissão e exaustão: onde se simula a vazão e a troca térmica do ar com o modelo da câmara de combustão;

2) Câmara de combustão: responsável pela fonte térmica do veículo e calculada por meio do coeficiente da média cíclica convectivo do pistão e da variação entre a temperatura do gás e da superfície da câmara. As equações consideram ainda os parâmetros como a rotação do motor, as vazões de ar e de combustível, a razão de compressão e o tempo de avanço da centelha em relação a ponto morto superior da câmara;

3) A cavidade do cilindro representa as regiões de troca térmica do motor com o líquido de arrefecimento;

4) O modelo do pistão considera as interações térmicas entre os gases da câmara de combustão, o óleo do motor e as temperaturas da cavidade do cilindro. A transferência de calor de combustão dos gases no cabeçote do cilindro é modelada através de resistores convectivos obtidos no submodelo da câmara de combustão;

5) O modelo de atrito representa as fontes térmicas devido ao atrito dos componentes tais como, o pistão, o comando de válvulas, a biela e o virabrequim. O modelo é derivativo do programa $\boldsymbol{F L A R E ^ { \circledR }}$ do Centro de Pesquisa de Lubrificação da GM. Esse modelo considera também as fontes térmicas da transmissão compostas pelo conversor de torque e do atrito das engrenagens. Essas fontes térmicas do motor e da transmissão são interligadas através do circuito de arrefecimento composto pela bomba e do termostato. Os resultados mostram uma variação de $\pm 3 \%$ na temperatura do líquido de arrefecimento, porém com uma estimativa exagerada de $10^{\circ} \mathrm{C}$ na temperatura do óleo da transmissão.

Martin e Gilliéron (2001) mostram um interessante estudo para melhorar a eficiência do escoamento de ar nos trocadores de calor do veículo Kangoo, por meio de adição de um pequeno defletor de ar na região inferior ao compartimento do motor.

Esse defletor é projetado de modo a reduzir a perda de energia da separação de vórtices e causa uma queda de pressão estática na região perto da abertura inferior 
do compartimento. Dessa forma, há uma variação de pressão entre a região interior do compartimento e a região exterior, favorecendo assim, o fluxo de ar através do sistema de arrefecimento.

Nobel e Jain (2001) analisaram a distribuição térmica no interior do compartimento do motor de um caminhão através de CFD. Na simulação do sistema de arrefecimento de um caminhão, a técnica de "Multiple Reference Frame" (MRF) foi utilizada para representar o ventilador. O volume do ventilador foi modelado de forma a associar a um sistema de referência local sob a condição de velocidade rotacional. Neste caso, a geometria da pá é muito importante e a sua malha computacional deve ser refinada de modo a poder captar o efeito da pressão e conseqüentemente, a distribuição de velocidade do ar necessária para o sistema de arrefecimento. Esta técnica é muito utilizada em casos onde não se conhece a curva operacional do ventilador.obtida em teste. Neste trabalho foi utilizado um modelo parcial do caminhão onde foram impostas uma vazão e temperatura fixa do líquido de arrefecimento na entrada do radiador de forma a representar a condição térmica do módulo de arrefecimento. Os resultados mostraram uma discrepância de 4\% no valor da rejeição térmica do motor e uma variação de 3\% na temperatura do ar na saída do CAC em relação aos resultados de teste.

No trabalho de Johannessen, Saunders e Sheridan (2002) verifica-se a importância da geometria da grade na avaliação do sistema de arrefecimento veicular. Um tratamento estatístico foi realizado no trabalho com levantamento de 23 configurações de grades para distintas condições operacionais. Nas validações dos modelos, testes foram conduzidos com a utilização de um aparato composto por nove anemômetros instalados na região do radiador, tendo sido verificada a existência de uma boa correlação entre as simulações e os testes realizados, considerando os efeitos de variações numéricas e também as variações nos instrumentos de medição.

Yang et al (2003) mostra que em veículos em baixa velocidade ou parado em marcha lenta, o escoamento do ar no sistema de arrefecimento é causado somente através do acionamento de ventiladores. Em veículos onde não apresentam defletores de ar no sistema de arrefecimento, normalmente levam o aparecimento do efeito da recirculação de ar quente nos trocadores de calor, causando o superaquecimento. 
Nesse caso, o método de avaliação térmica unidimensional apresenta a desvantagem de não permitir a inclusão desse efeito.

Com a crescente capacidade de processamento das máquinas, trabalhos recentes de avaliação térmica já utilizam modelos detalhados de CFD que podem chegar a 5 milhões de elementos com processamento paralelo através da utilização de supercomputadores, os HPCs .

Estudos recentes do sistema de arrefecimento como no trabalho do Jerhamre e Jonson (2004), utilizam modelos completos e detalhados dos veículos como o S80T6 V6 e o V70 2.41, ambos equipados com transmissão automática. Como já visto anteriormente, a transmissão automática favorece o aumento na carga térmica do sistema. Nesse estudo, seis condições de velocidades foram simuladas e testadas em túnel de vento para avaliar a temperatura do líquido de arrefecimento do motor. Os resultados mostram uma diferença de $\pm 4^{\circ} \mathrm{C}$ em relação aos resultados obtidos em túnel de vento e que a vazão mássica de ar aumenta com a elevação da velocidade do veículo. 


\section{CAPÍTULO 3}

\section{DINÂMICA DOS FLUIDOS}

O escoamento de fluidos com ou sem transferência de calor participa de todos os processos de produção de energia, nos fenômenos ambientais, na engenharia de reatores, na aeronáutica e nos projetos de equipamentos térmicos. Para obter a solução desses problemas físicos são necessários modelos matemáticos que representem o escoamento do fluido e o processo da troca térmica. $\mathrm{O}$ escoamento do fluido é causado por ações de forças externas como o gradiente de pressão, a gravidade, as tensões de cisalhamento do fluido, a rotação e a tensão superficial.

A velocidade do fluido afeta as suas propriedades pela variação das forças inerciais e viscosas denotadas pelo número de Reynolds. Em altas velocidades as forças inerciais sobrepõem às forças viscosas resultando em um escoamento instável onde as suas propriedades variam de forma randômica e caótica caracterizando o efeito da turbulência.

As equações que regem o escoamento de um fluido representam expressões matemáticas das leis da conservação da física:

- A massa do fluido é conservada;

- A taxa de variação da quantidade de movimento é igual a soma das forças atuando na partícula fluida;

- A taxa de variação de energia é igual a soma da taxa adicional de calor e a taxa de trabalho realizada na partícula.

\subsection{Equações de Conservação de Massa, Quantidade de Movimento e Energia.}

As equações matemáticas da conservação de massa, quantidade de movimento e energia são desenvolvidas com base em uma partícula fluida, em que a sua estrutura molecular e o seu movimento são ignorados (Versteeg e Malalasekera, 1995). O comportamento do fluido é descrito com base nas propriedades macroscópicas tais como velocidade, pressão, densidade e temperatura, além da parte derivativa do espaço e tempo. As equações que regem o escoamento de um fluido 
representam expressões matemáticas através das leis de física de conservação de massa, força, energia e de estado. Na formulação de conservação geral do transporte, de forma conservativa, é denotada pela expressão:

$\frac{\partial \rho \phi}{\partial t}+\operatorname{div}\left(\rho \phi u_{r}\right)=\operatorname{div}(\Gamma \operatorname{grad} \phi)+S_{\phi}$

Onde:

$u_{r} \quad$ velocidade relativa entre o fluido e a velocidade do sistema de coordenadas

$\begin{array}{ll}\phi & \text { quantidade escalar }(u, v, z, k, \varepsilon, \text { etc. }) \\ \Gamma & \text { coeficiente de difusão } \\ S_{\phi} & \text { termo fonte }\end{array}$

Nota-se que na equação acima a quantidade escalar $\phi$ pode ser representada pela velocidade, temperatura ou mesmo a concentração de componente. O lado esquerdo da equação representa a taxa de variação de $\phi$ no tempo e do termo convectivo, já no lado direito temos o termo difusivo ( $\Gamma$ é o coeficiente de difusão) e o termo fonte $S_{\phi}$. Para a equação da conservação de massa utiliza-se $\phi=1$ e para conservação de momento $\phi=u, v, w$ e $E$ como demonstra na tabela abaixo.

Tabela 3.1 - Equações de Navier-Stokes para um fluido Newtoniano e compressível (Versteeg e Malalasekera, 1995 p24).

\begin{tabular}{|c|l|}
\hline $\begin{array}{c}\text { Equą̧̊o de } \\
\text { Conservação de } \\
\text { Massa }\end{array}$ & $\frac{\partial \rho}{\partial t}+\operatorname{div}(\rho u)=0$, \\
\hline $\begin{array}{c}\text { Quantidade de } \\
\text { Movimento em } x\end{array}$ & $\frac{\partial(\rho u)}{\partial t}+\operatorname{div}(u, \rho u)=-\frac{\partial p}{\partial x}+\operatorname{div}(\mu \operatorname{grad} u)+S_{M:}$ \\
\hline $\begin{array}{c}\text { Quantidade de } \\
\text { Movimento em } y\end{array}$ & $\frac{\partial(\rho v)}{\partial t}+\operatorname{div}(u, \rho v)=-\frac{\partial p}{\partial x}+\operatorname{div}(\mu \operatorname{grad} v)+S_{14}$ \\
\hline $\begin{array}{c}\text { Quantidade de } \\
\text { Movimento em } z\end{array}$ & $\frac{\partial(\rho w)}{\partial t}+\operatorname{div}(u, \rho w)=-\frac{\partial p}{\partial x}+\operatorname{div}(\mu \operatorname{grad} w)+S_{M}$ \\
\hline Energia Irterna & $\frac{\partial(\rho E)}{\partial t}+\operatorname{div}(u, \rho E)=-p \operatorname{div} u,+\operatorname{div}(k, g r a d T)+\Phi+S_{z}$ \\
\hline
\end{tabular}


Onde $\Phi$ é o termo de dissipação viscosa dada por:

$$
\begin{aligned}
& \Phi=\mu\left\{2\left[\left(\frac{\partial u}{\partial x}\right)^{2}+\left(\frac{\partial v}{\partial y}\right)^{2}+\left(\frac{\partial w}{\partial z}\right)^{2}\right]+\left(\frac{\partial u}{\partial y}+\frac{\partial v}{\partial x}\right)^{2}\right. \\
& \left.+\left(\frac{\partial u}{\partial z}+\frac{\partial w}{\partial x}\right)^{2}+\left(\frac{\partial v}{\partial z}+\frac{\partial w}{\partial y}\right)^{2}\right\}+\lambda\left(\operatorname{div} u_{r}\right)^{2}
\end{aligned}
$$

Os efeitos,diante das tensões viscosas da equação de energia, são descritos por uma função de dissipação $\Phi$ não negativa onde os termos elevados ao quadrado representam fontes de energia interna devido ao trabalho de deformação das partículas no movimento e convertido em energia interna ou em forma de calor.

\subsection{Turbulência}

Todo escoamento encontrado na prática da engenharia torna-se instável acima de certo número de Reynolds $\left(U_{c} L / v\right.$, onde $U_{c}$ é a velocidade característica, $L$ é o comprimento do escoamento e $v$ a viscosidade cinemática). O número de Reynolds nos dá uma medida relativa das forças de inércia e das forças viscosas. Para valores de Reynolds abaixo do valor crítico, o escoamento ocorre em um deslizamento de camadas adjacentes de fluido, chamado escoamento laminar. Para números acima do valor crítico, o escoamento se dá de maneira caótica e suas propriedades, como pressão e velocidade, variam no tempo e ao longo das regiões do escoamento.

A transição de um escoamento laminar para turbulento pode ser explicada considerando a estabilidade laminar para pequenas perturbações. Essa transição ocorre em um intervalo chamado de instabilidade hidrodinâmica. Para a engenharia, é suficiente a análise do escoamento laminar $\left(R e<R e_{\text {crit }}\right)$ e do escoamento turbulento plenamente desenvolvido $\left(R e>R e_{c r i t}\right)$, o que faz com que este intervalo de transição $\left(R e_{t r}<R e<R e_{\text {crít }}\right)$ não seja estudado em detalhes em problemas usuais. O outro fator que leva a ignorar essa fase de transição é que não existe uma teoria concreta que a modele de maneira satisfatória.

Os códigos CFD disponíveis ignoram esta fase de transição e classificam o escoamento laminar ou turbulento plenamente desenvolvido.

Ao se analisar o escoamento em um tubo, podemos observar que a região de transição do escoamento laminar para turbulento ocorre no intervalo $2000<\operatorname{Re}<10^{5}$. 
Esse ponto de transição é fortemente afetado por fatores como os gradientes de pressão, níveis de perturbação, rugosidade das paredes e transferência de calor.

O movimento aleatório do escoamento turbulento pode ser decomposto em um valor médio mais uma flutuação e essa média é utilizada para a caracterização do escoamento em suas propriedades de velocidade, pressão e etc.

$u_{r}=\bar{u}_{r}+u_{r}^{\prime}, u=\bar{u}+u^{\prime} \quad ; \quad v=\bar{v}+v^{\prime}$ e $w=\bar{w}+w^{\prime}$

$p=\bar{p}+p^{\prime}$

$\phi=\bar{\phi}+\phi^{\prime}$

O valor médio é calculado por um "ensemble average" (equivalente à média no tempo para situações de regime permanente):

$\bar{u}=\frac{1}{\Delta t} \int_{t 1}^{t 2} u d t ; \bar{v}=\frac{1}{\Delta t} \int_{t 1}^{t 2} v d t \quad e \quad \bar{w}=\frac{1}{\Delta t} \int_{t 1}^{t 2} w d t$

A energia cinética turbulenta $k$ (por unidade de massa) associada com turbulência é definida por:

$k=\frac{1}{2}\left(\overline{u^{\prime 2}}+\overline{v^{\prime 2}}+\overline{w^{\prime 2}}\right)$

Para investigar o efeito da turbulência utilizaremos as equações com composições da média e as suas respectivas flutuações (3.8) nas equações de NS. Com base nas regras de comutação das flutuações demonstradas por Tennekes e Lumley (1972) temos:

$$
\begin{aligned}
& \overline{\operatorname{div} u_{r}}=\operatorname{div} \bar{u}_{r} \quad ; \overline{\frac{\partial u}{\partial t}}=\frac{\partial \bar{u}_{r}}{\partial t} ; \overline{\operatorname{div}\left(u u_{r}\right)}=\operatorname{div}\left(\overline{u u_{r}}\right)+\operatorname{div}\left(\overline{u^{\prime} u^{\prime}}\right) \\
& -\frac{1}{\rho} \frac{\partial p}{\partial x}=-\frac{1}{\rho} \frac{\partial \bar{p}}{\partial x} \quad ; \quad \overline{v \operatorname{div} \operatorname{grad} u}=v \operatorname{div} \operatorname{grad} \bar{u} \cdot
\end{aligned}
$$

Substituindo essas relações na equação na forma de média temporal do momento em $\mathrm{x}, \mathrm{y} \mathrm{e} \mathrm{z} \mathrm{(} 3.2$ a 3.6) e rearranjando os termos, temos as equações de escoamento turbulento para o fluido compressível dada pela tabela 3.2. 
Tabela 3.1 - Equações de escoamento turbulento para fluido compressível (Versteeg e Malalasekera, 1995 p53).

\begin{tabular}{|c|c|}
\hline $\begin{array}{l}\text { Equação da Continuidade } \\
\frac{\partial \rho}{\partial t}+\operatorname{div}\left(\rho \bar{u}_{r}\right)=0\end{array}$ & (3.14) \\
\hline $\begin{array}{l}\text { Equações de Reynolds } \\
\frac{\partial(\rho \bar{u})}{\partial t}+\operatorname{div}\left(\rho \bar{u} \bar{u}_{\gamma}\right)=-\frac{\partial \bar{p}}{\partial x}+\operatorname{div} \mu \operatorname{grad} \bar{u}-\operatorname{div}\left(\rho \overline{u^{\prime} u_{\gamma}}\right)+S_{\text {uk }}\end{array}$ & $(3.15)$ \\
\hline$\frac{\partial(\rho \bar{v})}{\partial t}+\operatorname{div}\left(\rho \bar{v} \bar{u}_{r}\right)=-\frac{\partial \bar{p}}{\partial y}+\operatorname{div} \mu \operatorname{grad} \bar{v}-\operatorname{div}\left(\rho \overline{v u_{r}}\right)+S_{u_{v}}$ & $(3.16)$ \\
\hline$\frac{\partial(\rho \bar{w})}{\partial t}+\operatorname{div}\left(\rho \bar{w} \bar{u}_{r}\right)=-\frac{\partial \bar{p}}{\partial x}+\operatorname{div} \mu \operatorname{grad} \bar{w}-\operatorname{div}\left(\rho \overline{w^{\prime} u_{r}^{\prime}}\right)+S_{v z}$ & $(3.17)$ \\
\hline $\begin{array}{l}\text { Equação de Transporte Escalar } \\
\frac{\partial(\rho \bar{\phi})}{\partial t}+\operatorname{div}\left(\rho \bar{\phi} \bar{u}_{r}\right)=-\operatorname{div}(\Gamma \operatorname{grad} \bar{\phi})-\operatorname{div}\left(\rho \overline{\phi^{\prime} u u_{r}^{\prime}}\right)+S_{\odot}\end{array}$ & $(3.18)$ \\
\hline
\end{tabular}

\subsection{Modelo $k-\varepsilon$}

A modelagem da turbulência é um procedimento computacional utilizado para fechar o sistema de equações do escoamento médio, de forma que os problemas de variações possam ser calculados.

O modelo $k-\varepsilon$. foi desenvolvido por Launder e Spalding (1972) baseado na teoria da existência de uma analogia entre a ação da tensão de Reynolds e da tensão viscosa no escoamento médio. Ambos os termos de tensão aparecem no lado direito da equação de momento, e na lei de Newton da viscosidade, a tensão viscosa é obtida como proporcional à taxa de deformação do elemento fluido. Para um fluido incompressível, temos:

$$
\tau_{i j}=\mu e_{i j}=\mu\left(\frac{\partial u_{i}}{\partial x_{j}}+\frac{\partial u_{j}}{\partial x_{i}}\right)
$$

Para simplificarmos as equações utilizaremos aqui as notações de sufixo onde $\mathrm{i}$ ou $\mathrm{j}=1$ corresponde às direções em $x, j=2$ na direção y e $\mathrm{j}=3$ na direção $z$, como exemplificado abaixo: 
$\tau_{12}=\mu\left(\frac{\partial u_{1}}{\partial x_{2}}+\frac{\partial u_{2}}{\partial x_{1}}\right)$

Boussinesq (1877) propôs a relação entre a tensão de Reynolds e a taxa média de deformação:

$$
\tau_{i j}=-\rho \overline{u_{i}^{\prime} u_{j}^{\prime}}=\mu_{t}\left(\frac{\partial \bar{u}_{i}}{\partial x_{j}}+\frac{\partial \bar{u}_{j}}{\partial x_{i}}\right)
$$

O lado direito da expressão acima é análogo à expressão (3.19), exceto pelo aparecimento do termo viscosidade turbulenta $\mu \mathrm{t}$.

O transporte de calor, massa e outras propriedades escalares são modelados de forma similar. A equação (3.21) mostra que o transporte do momento turbulento é assumido como proporcional à média do gradiente de velocidade. Por analogia, o transporte de um escalar é proporcional ao valor médio da quantidade transportada.

$$
-\rho \overline{u_{i}^{\prime} \phi^{\prime}}=\Gamma_{t} \frac{\partial \bar{\phi}}{\partial x_{i}}
$$

onde $\Gamma_{t}$ é a difusibilidade turbulenta.

O modelo $k-\varepsilon$ assume que a viscosidade turbulenta $\mu_{\mathrm{t}}$ é isotrópica, ou seja, a razão entre a tensão de Reynolds e a taxa de deformação é constante em todas as direções. A energia cinética média e a instantânea são dadas por:

$$
\bar{k}=\frac{1}{2}\left(\bar{u}^{2}+\bar{v}^{2}+\bar{w}^{2}\right) \quad ; \quad k=\frac{1}{2}\left(\overline{u^{\prime 2}}+\overline{v^{\prime 2}}+\overline{w^{\prime 2}}\right) \cdot
$$

A dissipação de energia cinética turbulenta $\varepsilon$ é causada pelo trabalho realizado pelos vórtices de pequenas escalas contra a tensão viscosa. A taxa de dissipação por unidade de massa é de extrema importância no estudo da dinâmica da turbulência e é escrito como: 
$\varepsilon=2 v \overline{e_{i j}^{\prime} \cdot e_{i j}^{\prime}}$

É possível desenvolver equações de transporte similares para todas as propriedades de turbulência, incluindo a taxa de dissipação $\varepsilon$. A equação exata de $\varepsilon$, no entanto, apresenta vários termos desconhecidos. O modelo padrão $k-\varepsilon$ apresenta duas equações, uma para $k$ e outra para $\varepsilon$, que são utilizadas para definir a escala de velocidade $\vartheta$ e a escala de comprimento $\ell$, como seguem:

$$
\vartheta=k^{1 / 2} \quad \ell=\frac{k^{3 / 2}}{\varepsilon}
$$

O modelo de comprimento de mistura assume a viscosidade cinemática turbulenta $\left(\mathrm{m}^{2} / \mathrm{s}\right)$ como um produto da escala de velocidade turbulenta $\vartheta(\mathrm{m} / \mathrm{s})$ pela escala de comprimento $\ell(\mathrm{m})$ :

$$
\mu_{t}=C \vartheta \ell
$$

onde $C_{a}$ é uma constante adimensional.

Logo, a viscosidade turbulenta resulta em:

$$
\mu_{t}=C_{a} \vartheta \ell=\rho C_{\mu} \frac{k^{2}}{\varepsilon}
$$

Os modelos $k$ e $\varepsilon$ são obtidos pelo produto das equações de Reynolds (3.14 a 3.18) pelo respectivo $\bar{u}, \bar{v}$ e $\bar{w}$ e posteriormente a sua soma, obtendo-se:

$$
\begin{aligned}
& \frac{\partial(\rho k)}{\partial t}+\operatorname{div}\left(\rho k \bar{u}_{r}\right)=\operatorname{div}\left[\frac{\mu_{\mathrm{t}}}{\sigma_{\mathrm{k}}} \operatorname{grad} k\right]+2 \mu_{\mathrm{t}} E_{i j} \cdot E_{i j}-\rho \varepsilon \\
& \frac{\partial(\rho \varepsilon)}{\partial t}+\operatorname{div}\left(\rho \varepsilon \bar{u}_{r}\right)=\operatorname{div}\left[\frac{\mu_{t}}{\sigma_{\varepsilon}} \operatorname{grad} \varepsilon\right]+C_{1 \varepsilon} \frac{\varepsilon}{k} 2 \mu_{t} E_{i j} \cdot E_{i j}+ \\
& -C_{2 \varepsilon} \rho \frac{\varepsilon^{2}}{k}
\end{aligned}
$$


As equações (3.28 e 3.29) mostram a taxa de variação e o termo convectivo no lado esquerdo; no lado direito, observam-se o transporte por difusão, a taxa de produção e a taxa de dissipação.

As equações $\boldsymbol{k}-\varepsilon$ padrão apresentam cinco constantes empíricos, $C_{\mu}, \sigma_{k}, \sigma_{\varepsilon}$, $C_{1 \varepsilon}$ e $C_{2 \varepsilon}$ dados por:

Tabela 3.2 - Coeficientes do modelo $k-\varepsilon$ de Turbulência

\begin{tabular}{|c|c|c|c|c|}
\hline$C_{\mu}$ & $\sigma_{k}$ & $\sigma_{\varepsilon}$ & $C_{1 \varepsilon}$ & $C_{2 \varepsilon}$ \\
\hline 0,09 & 1,00 & 1,30 & 1,44 & 1,92 \\
\hline
\end{tabular}

\subsection{Condições de Contorno}

A fig.3.1 exemplifica condições de contorno similar a um teste de um veículo em um túnel de vento onde a geometria foi simplificada por um perfil aerodinâmico.

As equações que modelam $k-\varepsilon$ são do tipo elíptico e em virtude do gradiente de difusão necessitam das seguintes condições de contorno:

- Entrada (1): a distribuição de $\mathrm{k}$ e $\varepsilon$ e as variáveis $\rho, \mu$ e $U_{e}$ precisam ser conhecidas;

- Plano de Simetria (2): $\partial k / \partial n=0$ e $\partial \varepsilon / \partial n=0$

- Escoamento Livre (3): $k=0$ e $\varepsilon=0$

- Parede Sólida (4): a abordagem depende do número de Reynolds com a utilização de função de parede onde será apresentado no próximo item.

- Saída (5): a distribuição de pressão p.

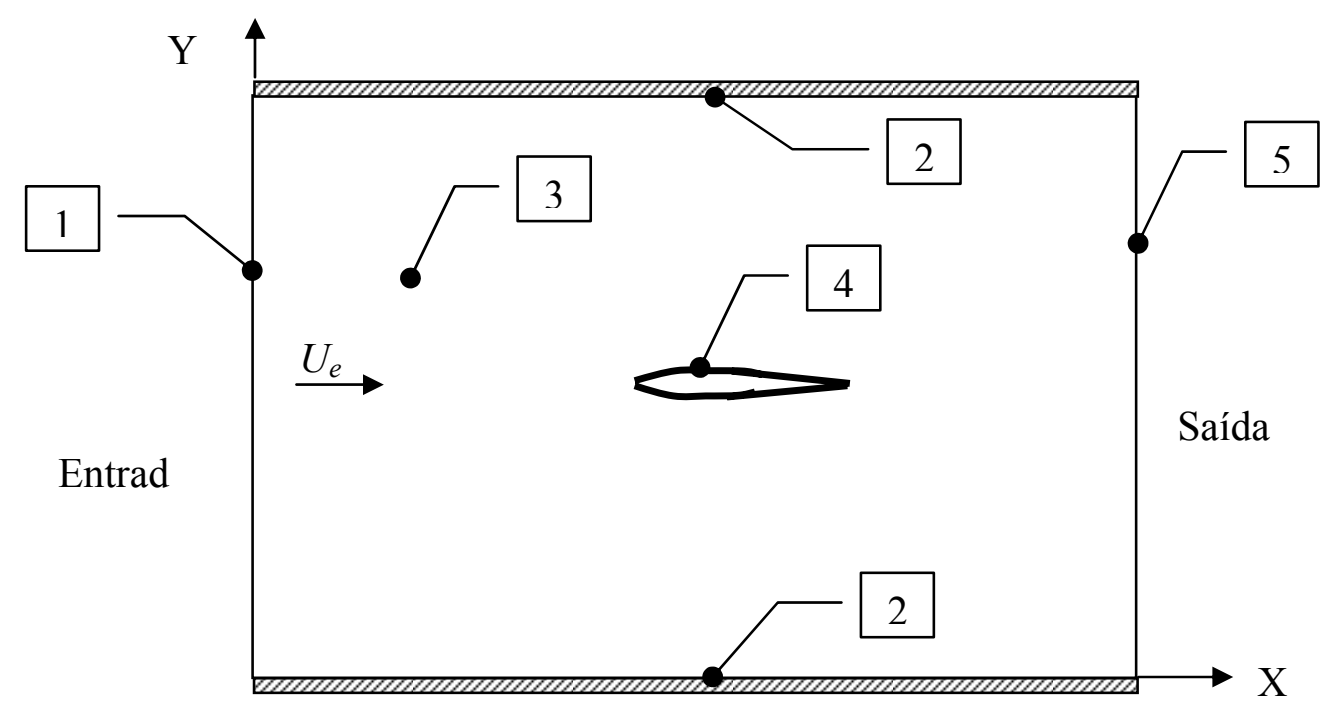

Figura 3.1 - Condições de contornos aplicadas a um perfil de asa no túnel de vento. 
Os parâmetros iniciais de $k$ e $\varepsilon$ são importantes na definição da distribuição da turbulência na região de entrada. Uma das dificuldades em modelos de CFD é a obtenção destes valores, pois dependem de medições ou de dados de literatura.

Uma aproximação pode ser feita na distribuição de $k$ e $\varepsilon$ na entrada é por meio da intensidade turbulenta $T_{i}$ e do comprimento característico do equipamento (equivalente ao raio do tubo) pelo uso das seguintes relações:

$$
\ell=0.07 L \quad k=\frac{3}{2}\left(U_{e} T_{i}\right)^{2} \quad \varepsilon=C_{\mu}^{3 / 4} \frac{k^{3 / 2}}{\ell}
$$

Em túneis de vento, a intensidade turbulenta é dada por:

$$
T_{i}=0.16(R e)^{-1 / 8}
$$

\subsection{Função de Parede}

A estrutura da turbulência possui característica atípica de escoamento próximo a uma parede sólida quando comparada com um escoamento livre. Se analisarmos o número de Reynolds $\left(\operatorname{Re}_{y}=U_{y} / v\right)$ a partir de uma distância $y$ da parede, pode-se verificar que em uma distância y suficientemente longe da parede o efeito das forças inerciais é predominante. Enquanto que, para valores de $y$ próximo à parede, o número de Reynolds tende a diminuir de forma a prevalecer as forças viscosas. A velocidade média da região depende além da distância $y$ da parede, da densidade $\rho$, da viscosidade $\mu$ e da tensão de cisalhamento da parede $\tau_{w}$. As funções de parede são utilizadas como o termo fonte e, juntamente com as equações de momento e de transporte turbulento modificado, para representar o efeito viscoso da parede.

A análise dimensional demonstrada por Schlichting (1979) resulta na seguinte expressão:

$$
u^{+}=\frac{U}{u_{\tau}}=f\left(\frac{\rho u_{\tau} y}{\mu}\right)=f\left(y^{+}\right)
$$


A equação acima é conhecida como lei de parede na qual se apresenta a definição de dois adimensionais importantes, a saber, a velocidade $u^{+}$e $y^{+}$.

Em alto número de Reynolds o modelo padrão $k-\varepsilon$ Launder e Spalding (1972) evita realizar as integrações das equações de NS nas proximidades da parede, porém se utiliza da função de parede com base da lei exponencial para o escoamento próximo a parede. Se $y$ é a coordenada na direção normal à parede, a velocidade média em um ponto $y^{+}$, com $30<y^{+}<60$ (região fora da subcamada viscosa) satisfaz a lei logarítmica:

$u^{+}=\frac{1}{\kappa_{v}} \ln y^{+}+B=\frac{1}{\kappa_{v}} \ln \left(E_{w} y^{+}\right)$

onde $\mathrm{u}^{+}$é a velocidade próxima à parede, $y^{+}$é a distância adimensional dada por $y^{+}=\frac{\rho C_{\mu}^{1 / 4} \kappa_{v}^{1 / 2} y}{\mu}$

onde as constantes empíricas de von Kármám $\kappa_{v}$ e parâmetro de rugosidade da parede $E_{w}$ são dados na tabela abaixo.

Tabela 3.3 - Coeficientes empíricos da função de parede.

\begin{tabular}{|c|c|}
\hline$\kappa_{v}$ & $E_{w}$ \\
\hline 0,42 & 9,793 \\
\hline
\end{tabular}

\subsection{Modelo de Trocador de Calor}

A maioria dos trocadores automotivos é do tipo "escoamento de fluxo cruzado" com fluidos escoando perpendicularmente um em relação ao outro. Um exemplo típico é os trocadores com tubos aletados onde o ar escoa do lado externo através das aletas a qual se denomina fluido não-misturado. Na figura 3.2, o fluido é denominado não-misturado, uma vez que as aletas estão restringidas ao movimento na direção $(\mathrm{y})$ transversal à direção $(\mathrm{x})$ do escoamento principal. 


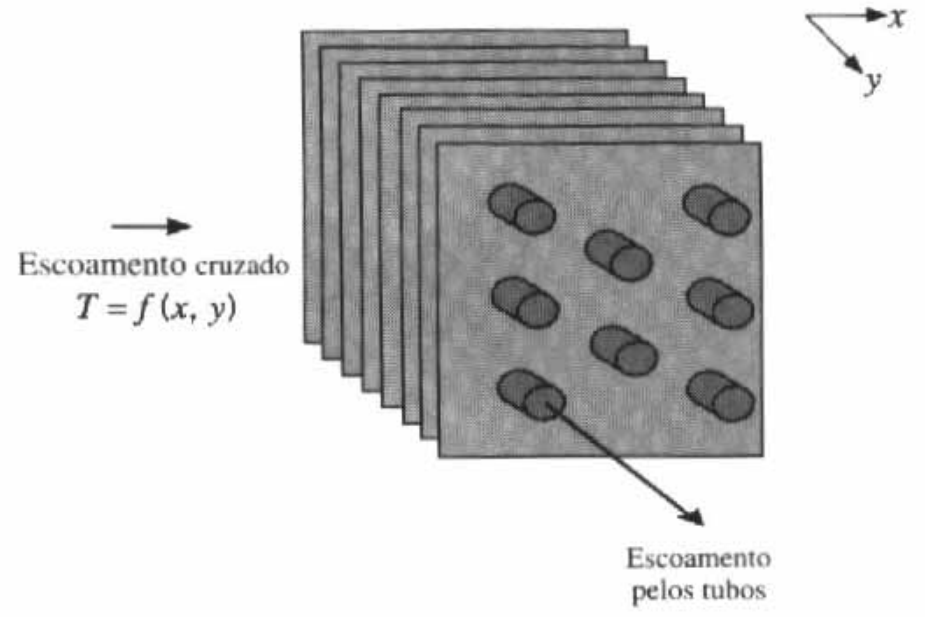

Figura 3.2 - Trocador de calor tipo tubos aletados com os dois fluidos nãomisturados (Incropera e Dewitt,1998).

O método LMDT “Média Logarítmica das Diferenças de Temperatura" é muito utilizado quando as temperaturas de entrada dos fluidos são conhecidas e as temperaturas de saída ou são especificadas ou se determinam com facilidade pelas equações do balanço de energia (Incropera e Dewitt, 1998). Todavia, quando se conhecem somente as temperaturas de entrada, esse método exige um processo iterativo. Nesse caso é preferível usar uma outra abordagem, o método da efetividade-NUT ( $\varepsilon_{f}$-NUT, "Número de Unidade de Transferência de Calor", (Incropera,1998), onde é possível a determinação do coeficiente global de troca térmica de acordo com a disposição do escoamento do trocador do calor.

Esse método foi proposto por Nusselt em 1930 onde foi definida a efetividade do trocador de calor como sendo uma razão da taxa de calor real pelo máximo valor de transferência de calor possível do sistema.

\subsubsection{Modelo de Troca Térmica (Trocador de Fluxo Cruzados)}

A figura 3.3 ilustra um trocador de fluxos cruzados, onde os índices 1 e 2 representam as notações para as linhas de diferentes fluidos do processo. 


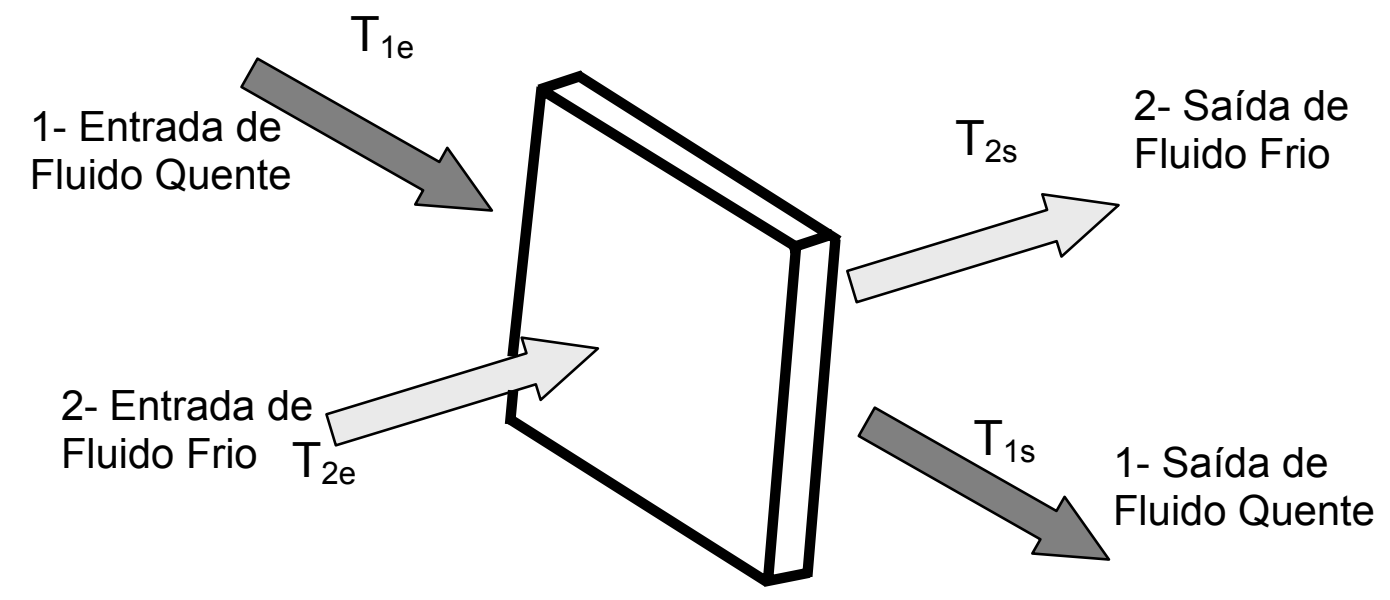

Figura 3.3 - Desenho esquemático do trocador de calor de fluxo cruzado

O valor adimensional da efetividade $\varepsilon_{f}$ do trocador de calor é definido como sendo a razão do calor real transferido pela máxima de transferência possível (Incropera e Dwitt, 1998).

$\varepsilon_{f}=\frac{\dot{Q}_{T C}}{\dot{Q}_{\max }}$

Admitindo-se que o sistema não apresenta vazamento de fluido, perda de energia e que as propriedades do fluido se mantêm constantes, o balanço de calor pode ser escrito como:

$\dot{Q}_{T C}=C_{1}\left(T_{1 e}-T_{1 s}\right)=C_{2}\left(T_{2 e}-T_{2 s}\right)$

Onde o $C$ é definido como a taxa de capacidade calorífica dada por:

$C=\dot{m} \cdot c_{p}$

A máxima troca térmica é dada pelo produto da menor capacidade térmica pela diferença de temperatura de entrada:

$\dot{Q}_{\max }=C_{\min }\left(T_{2 e}-T_{1 e}\right)$ 
Substituindo as equações (3.36 e 3.38) em (3.35), a efetividade do trocador de calor fica:

$\varepsilon_{f}=\frac{C_{1}\left(T_{l e}-T_{1 s}\right)}{C_{\min }\left(T_{2 e}-T_{l e}\right)}$

e analogamente,

$\varepsilon_{f}=\frac{C_{2}\left(T_{2 s}-T_{2 e}\right)}{C_{\text {min }}\left(T_{2 e}-T_{1 e}\right)}$

onde $C_{\min }$ é a menor capacidade térmica:

$C_{\text {min }}=\min \left(C_{1}, C_{2}\right)$

A efetividade pode ser determinada em função da $N U T$, em razão da capacidade térmica e tipo de configuração do trocador de calor.

No caso de radiadores compactos para uso automotivo, os radiadores de tubos aletados em fluxo cruzado não-misturado são os mais utilizados. Segundo Holman (1976), a equação da efetividade para esse tipo de configuração é dada pela expressão:

$\varepsilon_{f}=1-\frac{\exp \left[e^{-N U T \cdot Z \cdot N U T^{-0.22}}-1\right]}{1+Z}$

onde Z é o valor adimensional da capacidade térmica e NUT o valor adimensional da unidade de transferência térmica dados por:

$$
\begin{array}{ll}
Z=\frac{C_{\min }}{C_{\max }} & 0<Z \leq 1 \\
N U T=\frac{K_{t} \cdot A}{C_{\min }} &
\end{array}
$$

A equação (3.42) é exata somente para $Z=1$, mas também pode ter boas aproximações para $0<Z \leq 1$ (Incropera e Dewitt, 1998). Para garantir a convergência da equação (3.42), podemos escrevê-la na forma: 
$\varepsilon_{f}-1+\exp \left[\frac{N U T^{0.22}}{Z}\left(e^{-N U T^{0.78} Z}-1\right)\right]=0$

Para a solução dessa equação foi utilizado o algoritmo numérico de iteração linear. No "apêndice C", foi desenvolvido um programa em TCL para o cálculo da curva de $N U T$, a partir de dados de desempenho de trocadores de calor obtidos por testes físicos.

No caso de condensadores, a capacidade térmica do ar é muito maior que o do fluido refrigerante resultando a razão $Z=C_{\min } / C_{\max }=0$. Nesse caso, o número de unidade de transferência $(N U T)$ é dado por:

$N U T=-\ln \left(1-\varepsilon_{f}\right)$

\subsubsection{Algoritmo de Simulação Numérica para a Determinação da Curva NUT}

Uma vez conhecidas as curvas de rejeição térmica do radiador com variações na vazão de ar e do líquido de arrefecimento, podemos então determinar os valores de NUTs para cada condição através das equações (3.38 a 3.45).

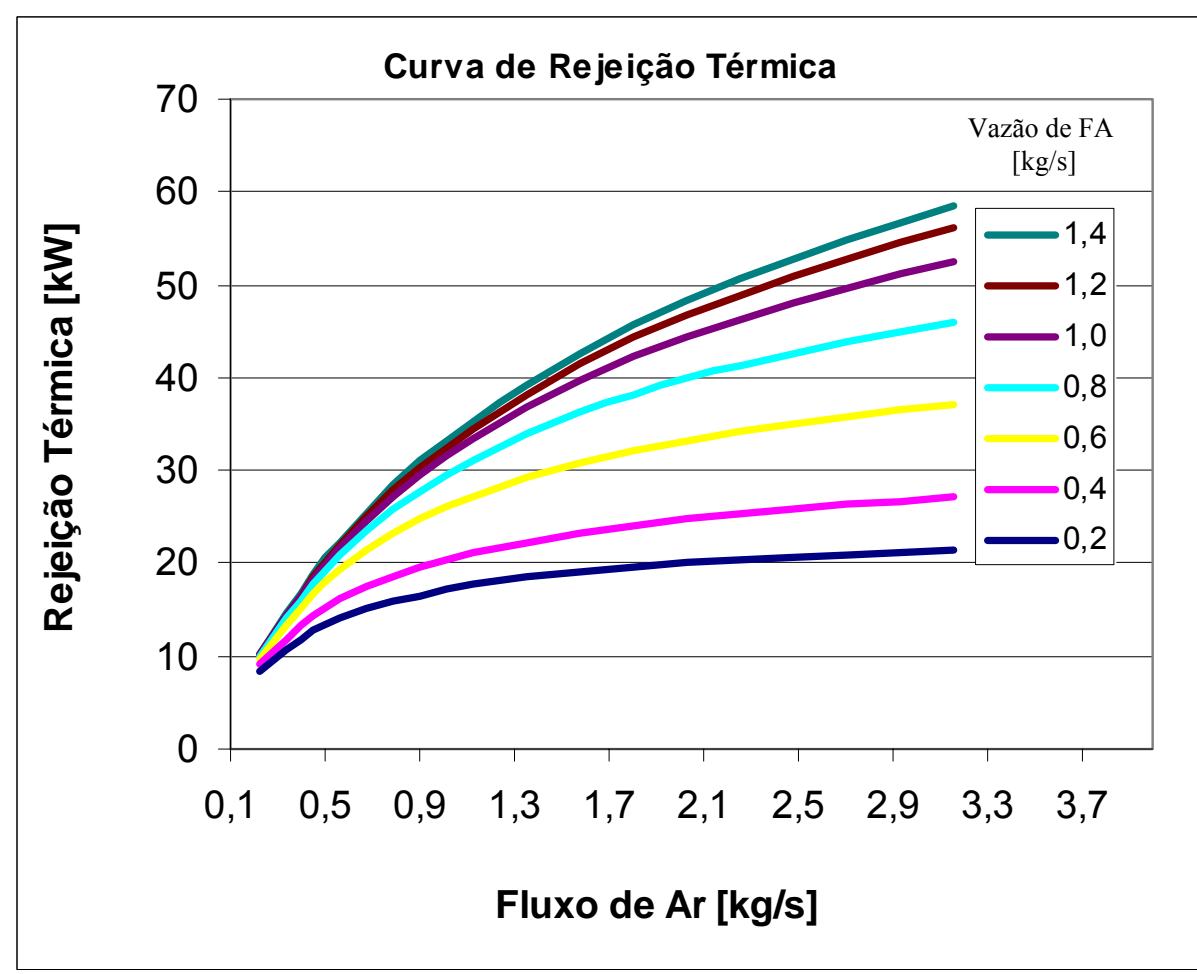

Figura 3.4 - Curva de rejeição térmica do radiador (curva de desempenho). 
Por meio do programa apresentado no "Apêndice C", podemos obter o gráfico de NUT tridimensional do trocador de calor como mostrado abaixo.

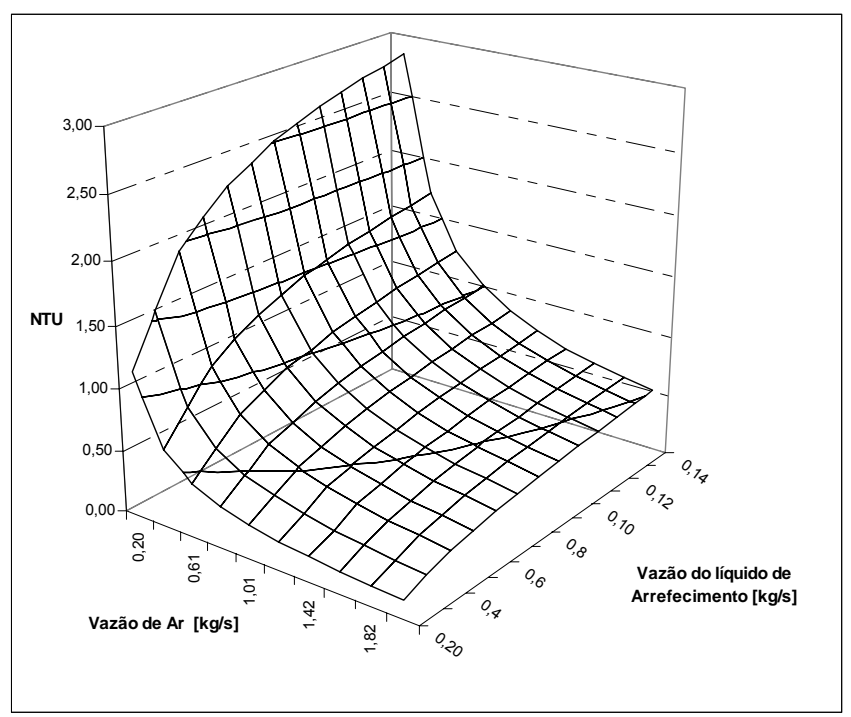

Figura 3.5 - Curva típica da unidade de troca térmica $N U T$ em função das vazões de ar e do líquido de arrefecimento de radiadores.

Em um radiador, o fluido de arrefecimento aquecido escoa de uma extremidade do tanque para o outro, resultando numa variação na rejeição de calor ao longo do trocador. No modelo do trocador de calor considerado, o núcleo do trocador é subdividido em uma matriz de células ou "macros" onde representa o trajeto do fluido. Para representar esse efeito, o modelo de volumes finitos e os trocadores de calor são representados através de elementos hexaédricos divididos em células macroscópicas ou macros, como ilustrados na figura abaixo.

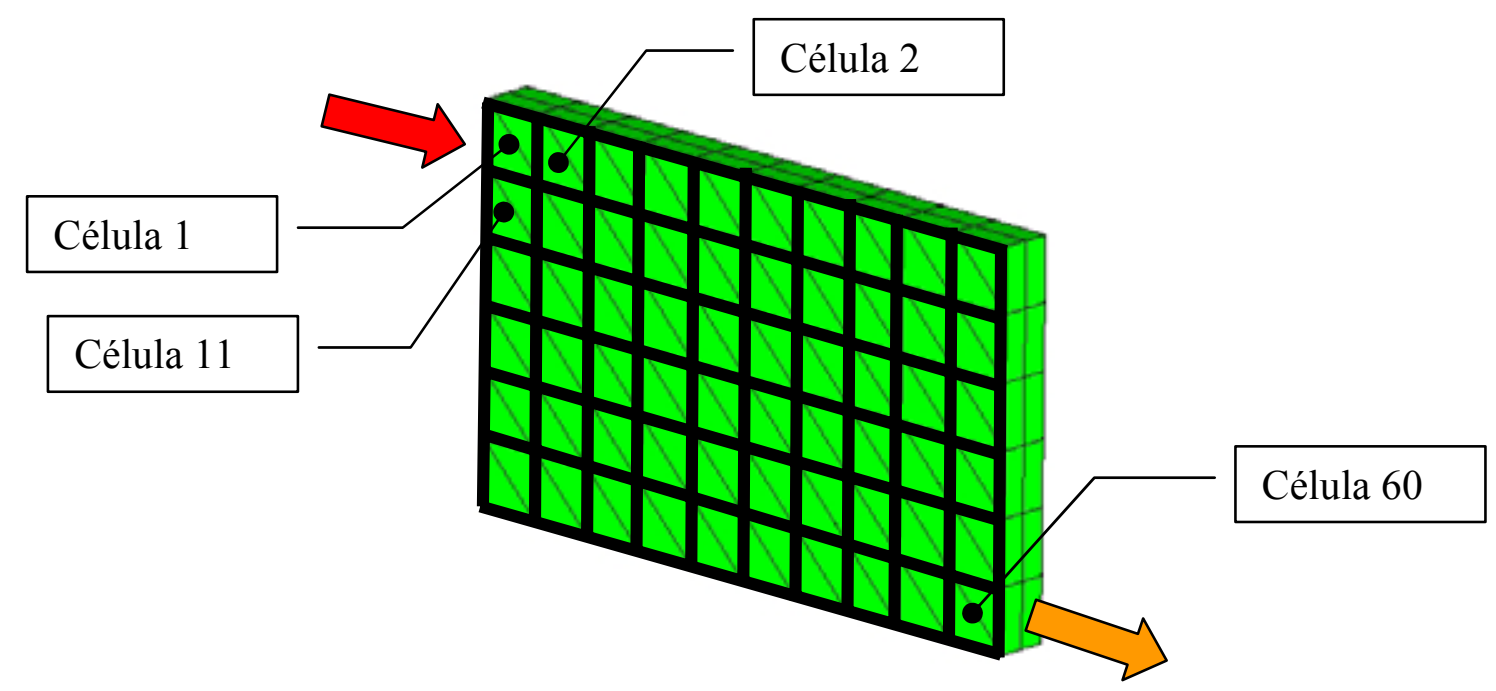

Figura 3.6 - Discretização do núcleo em células de 10 x 6 . 
Desse modo, o fluido de arrefecimento que entra em uma célula realiza a troca térmica com o ar e a rejeição de calor será transferida para a célula subseqüente. Por meio desse procedimento, podemos representar de forma realista o comportamento do trocador de calor onde a efetividade de cada célula é calculada com base na seguinte expressão:

$\varepsilon_{f}=1-\exp \left[\frac{N T U^{0.22}}{Z}\left(e^{-N T U^{0.78} Z}-1\right)\right]$

A rejeição térmica é calculada para cada célula e adicionada com termo fonte na equação de energia.

$\dot{q}_{\text {celula }}=\varepsilon_{f}\left[\left(\dot{m}_{2 e} C p_{2}\right)\left(T_{1 e}-T_{\text {celula }}\right)\right]$

O calor total rejeitado é obtido pelo balanço de energia:

$\dot{q}_{\text {total }}=\sum_{\begin{array}{c}\text { Todas as celulas } \\ \text { do radiador }\end{array}} \dot{q}_{\text {celula }}$

\subsubsection{Modelo de Perda de Carga (Trocador de Fluxo Contracorrente)}

Os modelos de meio poroso são amplamente utilizados em CFD para representar de forma macroscópica a perda de carga de componentes tais como filtros, placas perfuradas, válvulas, etc.

A formulação do meio poroso assume um campo de resistência ortotrópica, em que uma fonte adicional de momento $S_{M i}$ é inserida nas equações da quantidade de movimento 3.15 a 3.17. O termo fonte é composto por dois termos: a perda inercial $I_{i j}$ e a viscosa $V_{i j}$ dada pela equação:

$S_{M i}=-\left(\sum_{j=1}^{3} I_{i j} \frac{1}{2} \rho \cdot v_{m a g} \cdot v_{j}+\sum_{j=1}^{3} V_{i j} \cdot \mu \cdot v_{j}\right)$ 
Onde $S_{M i}$ representa o termo fonte nas direções $\mathrm{x}, \mathrm{y}$ e $\mathrm{z}$ da equação da quantidade de movimento e $I_{i j}$ e $V_{i j}$ são matrizes prescritos na perda de carga. Essa fonte contribui no gradiente de pressão nos elementos do meio poroso, criando uma perda de carga que é proporcional à velocidade do escoamento do elemento.

Para um meio poroso homogêneo podemos simplificar a equação pela permeabilidade $K_{i}$ dado por:

$$
\begin{aligned}
& K_{i}=\alpha_{i}|\vec{v}|+\beta_{i} \\
& \alpha=I_{i j} \frac{1}{2} \rho \\
& \beta=V_{i j} \mu
\end{aligned}
$$

Onde os termos $\alpha_{i}$ e $\beta_{i}$ são coeficientes obtidos experimentalmente. A velocidade do fluido em qualquer seção do meio poroso é calculada pela divisão da vazão volumétrica do fluido pela área total da seção. Dessa forma, o balanço entre a pressão e a força de resistência é dado por:

$$
\frac{\delta p}{\delta \xi_{i}}=-\left(\alpha_{i}|\vec{v}|+\beta_{i}\right) v_{i}
$$

onde:

i representa cada uma das direções mutuamente ortogonais e $v$ a velocidade superficial.

Assim, os coeficientes $\alpha$ e $\beta$ são distintos para cada tipo de configuração de trocadores de calor dependendo do espaçamento dos tubos e das aletas. O ensaio de perda de carga consiste basicamente na obtenção do diferencial de pressão estática entre as faces frontal e posterior do trocador de calor, em uma faixa de velocidade do ar de 0 a $10 \mathrm{~m} / \mathrm{s}$. A vazão e temperatura de entrada do líquido refrigerante assim como a temperatura de entrada do ar foram mantidas com constantes.

A figura 3.7 exemplifica uma curva de perda de carga de um radiador de espessura de $26 \mathrm{~mm}$ com ajuste através de um polinômio quadrático para a obtenção dos coeficientes de perda. 


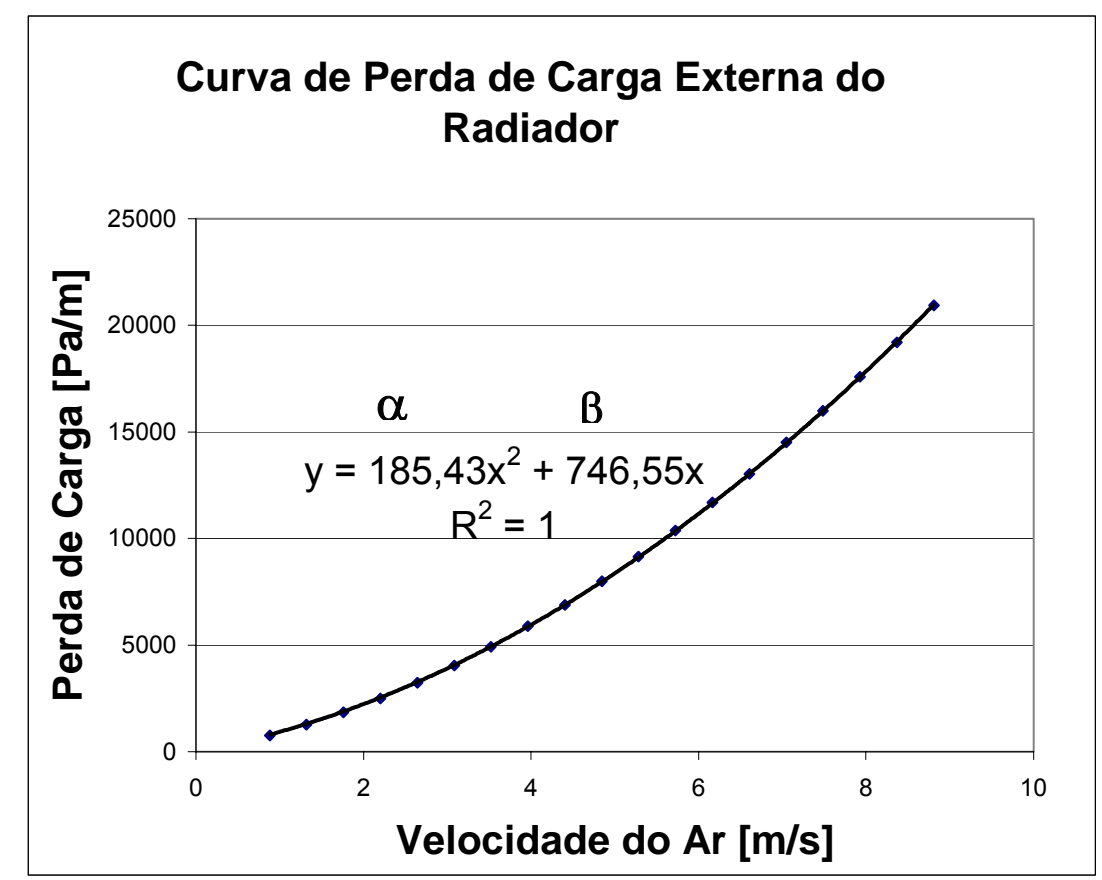

Figura 3.7 - Exemplo de curva de perda de carga externa de um trocador de calor.

Essa expressão possui o mesmo formato da equação do meio poroso (3.54), com coeficientes de permeabilidade $\alpha$ e $\beta$, respectivamente, 185,43 e 746,55. Os coeficientes de perda de cargas podem ser determinados através de equações (3.52) e (3.53), considerando densidade e viscosidade do ar de $38^{\circ} \mathrm{C}$ :

$$
\begin{array}{lll}
I=\frac{2 \alpha}{\rho}=326,8 & \rho\left(38^{\circ} C\right)=1,134 & \mathrm{~kg} / \mathrm{m}^{3} \quad \mathrm{e} \\
V=\frac{\beta}{\mu}=3,94.10^{7} & \mu\left(38^{\circ} \mathrm{C}\right)=1,95.10^{-9} & \mathrm{~kg} / \mathrm{m} . \mathrm{s}
\end{array}
$$

Estes coeficientes são aplicados ao escoamento na direção principal (direção perpendicular à face do radiador). Enquanto para as outras direções é comumente utilizado um fator de 1000 em relação às perdas na direção principal.

\subsection{Modelo do Ventilador}

Como visto no capítulo 1 para veículos em baixa velocidade o efeito "ram" (ver item 1.3 para maiores detalhes) é praticamente nulo, necessitando-se, assim, de uma fonte adicional de fluxo de ar no sistema de arrefecimento o qual é feito através de eletro-ventilador. 
A escolha de um eletro-ventilador axial baseia-se nas suas curvas de desempenho obtidas em testes físicos. Normalmente são caracterizadas por três fatores: a carga ou pressão manométrica, o rendimento e a potência do rotor em função do escoamento.

Usualmente o desempenho de um eletro-ventilador é dado pela variação de pressão $(\Delta p)$ sobre o fluido em função da vazão de ar $(\dot{m})$. Esses parâmetros podem ser adimensionalizados em função do raio do rotor $(R)$ e a velocidade da ponta da pá $\left(U_{\text {tip }}\right)$. Dessa forma, podemos definir o coeficiente de pressão $(\psi)$ dada por:

$$
\psi=\frac{\Delta p}{\frac{\rho_{a r}}{2} U_{t i p}^{2}}
$$

e o coeficiente de velocidade:

$$
r=\frac{\dot{m}}{\pi R^{2} U_{t i p}^{2}}
$$

Estes adimensionais são tais que $\Psi=\Psi(Y)$. Para esse dado formato de pá, a relação será válida para vários tamanhos e velocidades de ventiladores. Isso reflete a insensibilidade não depende do fluxo ao número de Reynolds, isto é, tanto a velocidade quanto a pressão adimensionalizada são predominantemente controladas pelas forças inerciais e pelas condições de contornos impostos, elas são insensitivas a efeito viscoso.

O modelo do ventilador considera a adição de fontes de quantidade de movimento às equações de transporte através de sub-rotinas ou UDFs "UserDefined-Functions". Nesse caso, é necessária a obtenção das curvas de desempenho do ventilador por meio de testes experimentais.

Neste método, a força aerodinâmica que o ventilador exerce sobre o escoamento de ar é representada pelo aumento de pressão através do ventilador dada pela seguinte expressão:

$$
\Delta p=\sum_{n=1}^{N} f_{n} U^{n-1}
$$


Onde $\Delta p$ é a variação de pressão, $f_{n}$ são os coeficientes de pressão e $U$ é a velocidade fluido local perpendicular à face do ventilador. A figura 3.8 mostra uma curva característica típica de um ventilador axial.

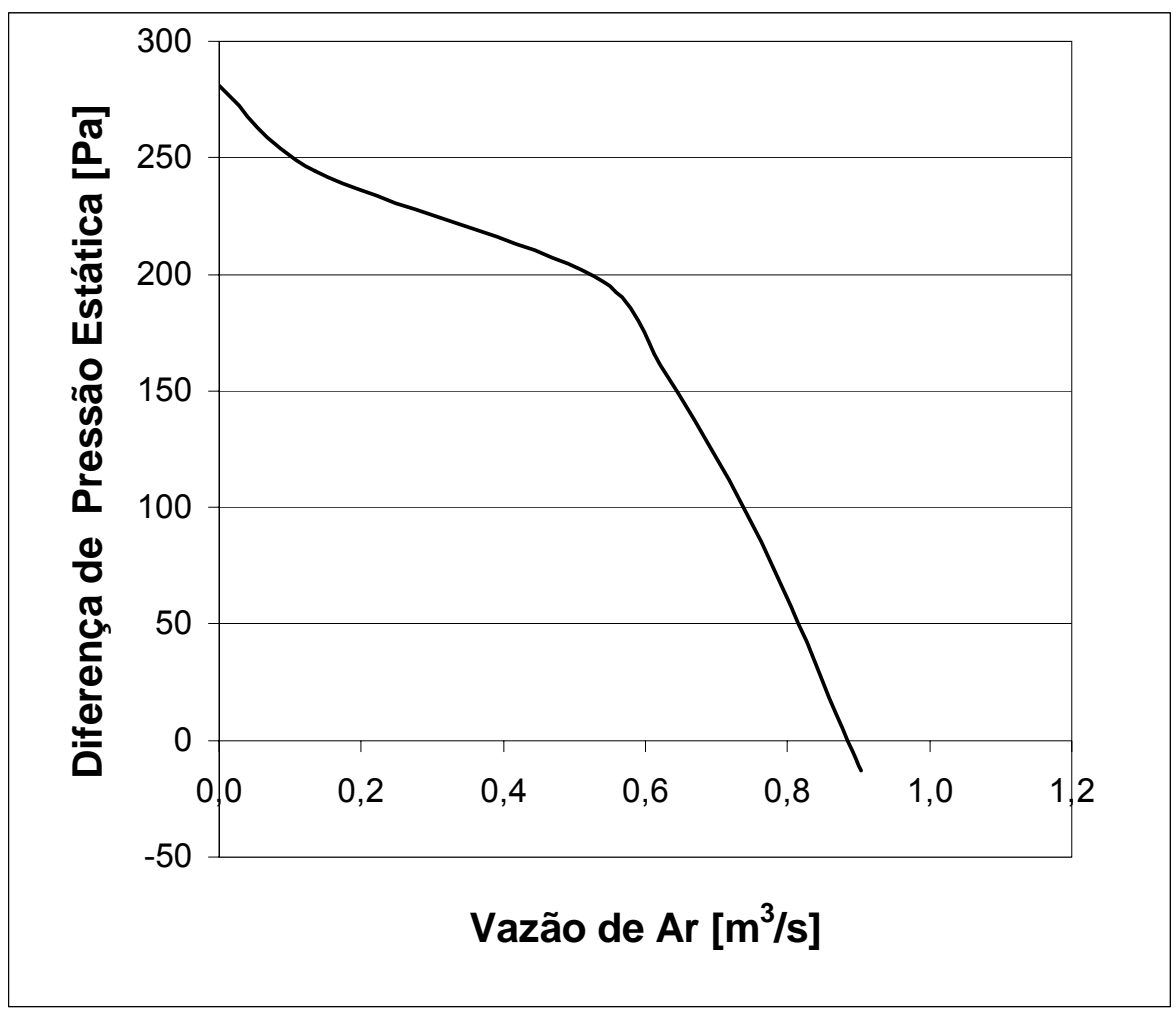

Figura 3.8 - Curva característica de um ventilador automotivo.

Tipicamente, a curva característica de um ventilador é levantada para duas condições de rotações correspondentes a baixa e alta voltagem. No caso em que o ensaio for realizado em rotações diferentes ao de operação, será necessário fazer uma interpolação ou extrapolação dos valores existentes. Essa aproximação pode ser feita utilizando a "Lei Universal dos Ventiladores" (Joergensen, 1961), dada pelas equações:

$$
\begin{aligned}
& \frac{p_{1}}{p_{2}}=\frac{\rho_{1} N_{1}^{2} D_{1}^{2}}{\rho_{2} N_{2}^{2} D_{2}^{2}} \\
& \frac{\dot{m}_{1}}{\dot{m}_{2}}=\frac{N_{1} D_{1}^{3}}{N_{2} D_{2}^{3}}
\end{aligned}
$$


Para um mesmo ventilador, as equações acima não levam em consideração o efeito do diâmetro $D$.

No apêndice $D$ mostra a sub-rotina $U D F$ denominada "fan.f" utilizada para representar o efeito do ventilador a partir da curva de desempenho do ventilador obtido por meio de teste físico. Esse modelo considera os componentes de velocidade radial e tangencial "swirl" (Takara, 2003). 


\section{CAPÍTULO 4}

\section{SIMULAÇÃO COMPUTACIONAL}

O fenômeno da dinâmica de fluídos é descrito pelas equações diferenciais parciais, que podem ser resolvidas analiticamente ou numericamente de acordo com a complexidade do problema. Em situações onde as geometrias do problema são complexas, a aproximação numérica é a mais utilizada. A simulação numérica consagrada baseia-se no método de volumes finitos (MVF) com a utilização de malha não estruturada pelo método das medianas e funções semelhantes às utilizadas no Método de Volumes Finitos Patankar (1972).

\subsection{Método dos Volumes Finitos}

O método de volumes finitos (MVF) (Spalding, 1972; Patankar e Spalding, 1972) que visa a solução numérica das equações de Navier Stokes e de problemas convectivos-difusivos mostrou-se bastante competitiva em relação aos métodos de diferenças finitas (MDF) e de elementos finitos (MEF).

As soluções numéricas obtidas por meio de técnicas do MVF (Patankar,1975) ou do MDF (Cebecci, 1981) apresentam problemas de erros numéricos chamados de falsa difusão e dispersão numérica.

A difusão numérica ocorre quando a função de interpolação utilizada na discretização das equações difere da solução exata. Várias funções de interpolação foram desenvolvidas levando os diferentes esquemas que visam minimizar os efeitos da falsa difusão dentre elas o método "Upwind" de segunda ordem utilizado neste trabalho.

No método dos volumes finitos (MVF) o domínio em estudo é subdividido em volumes elementares ou células computacionais, para as quais as equações de transporte escalar (3.37) são integradas no espaço e no tempo.

$$
\frac{\partial \rho \phi}{\partial t}+\operatorname{div}(\rho u \phi)=\operatorname{div}(\Gamma \operatorname{grad} \phi)+S_{\phi}
$$


A equação 4.1 pode ser generalizada na seguinte forma:

$$
\frac{\partial(\rho \phi)}{\partial t}+\operatorname{div}(\rho \vec{u} \phi-\Gamma \operatorname{grad} \phi)=S_{\phi}
$$

onde:

$$
\begin{array}{ll}
\rho: & \text { densidade } \\
\vec{u}: & \text { velocidade média } \\
\phi: & \text { propriedade transportada } \\
\Gamma: & \text { coeficiente de difusividade }
\end{array}
$$

A forma integral desta equação escrita para um volume $V$, delimitado por uma superfície e em regime permanente é dada por:

$$
\int_{V_{c}} \operatorname{div}\left(\rho \phi u_{r}\right) d V-\int_{V_{c}} \operatorname{div}(\Gamma \operatorname{grad} \phi) d V=\int_{V_{c}} S_{\phi} \cdot d V
$$

De acordo com o teorema do divergente temos:

$$
\oint\left(\rho \phi u_{r}\right) d \vec{A}-\oint(\Gamma \operatorname{grad} \phi) d \vec{A}=\int_{V_{c}} S_{\phi} \cdot d V
$$

Aplicando esta equação para cada volume de controle ou célula, no domínio computacional, obteremos:

$$
\sum_{f}^{N_{\text {faces }}}\left(\rho_{f} u_{r f} \phi_{f}\right) \vec{A}_{f}=\sum_{f}^{N_{\text {faces }}} \Gamma(\operatorname{grad} \phi)_{n} \cdot \vec{A}_{f}+S_{\phi} V
$$

Onde:
$N_{\text {faces }}$ :
é o número de faces de cada célula
$\phi_{f}:$ valor da propriedade $\phi$ convectada através da face $f$
$S_{\phi}:$ termo fonte 


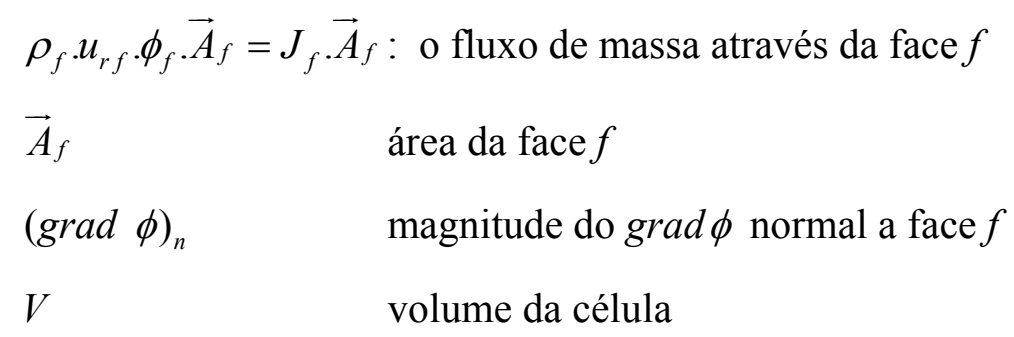

Esta equação é aplicada em cada célula computacional, onde os valores das propriedades escalares são armazenados no ponto central da célula $\left(\mathrm{C}_{0} \mathrm{e}\right.$ $\mathrm{C}_{1}$ da figura 4.1) e interpolados para cada face da célula. $\mathrm{O}$ esquema de diferenças centradas é utilizado na convecção, sendo que este esquema não leva em consideração a direção do escoamento. Para suprir esta deficiência, utiliza-se o esquema de "Upwind", onde o valor de $\phi_{f}$ é tomado na célula a montante, relativa à direção normal da velocidade do escoamento.

O código FLUENT ${ }^{\circledR}$ utiliza como padrão o gradiente de célula centrada ("Upwind" de primeira ordem) onde o valor $\bar{\phi}_{f}$ baseia se na média dos valores das células $\mathrm{C}_{0}$ e C1 (figura 4.1).

$\bar{\phi}_{f}=\frac{\phi_{C 0}+\phi_{C 1}}{2}$

Aqui, os valores são calculados pela média de $\phi$ de duas células adjacentes a face. Esse gradiente é limitado de modo que não produzam máximos ou mínimos, (Fluent 6.1 User's Guide, 2003).

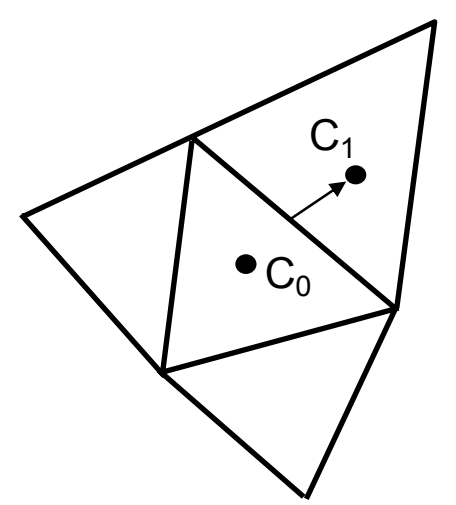

Figura 4.1 - Volume de Controle para ilustrar a discretização das equações do transporte escalar. 
Neste trabalho optou-se pelo esquema de segunda ordem de forma a obter maior precisão nos resultados.

No esquema "Upwind" de segunda ordem, as quantidades escalares nas faces da célula são computadas com a utilização do método linear de reconstrução multidimensional. Nesta aproximação, a alta ordem de precisão é alcançada nas faces através da utilização da expansão da série de Taylor. Nesse esquema, a quantidade escalar é calculada utilizando-se a seguinte expressão:

$\phi_{f}=\phi+\operatorname{grad} \phi . \Delta \vec{s}$

onde:

$\phi_{f}: \quad \quad$ valor escalar de $\mathrm{f}$ da célula centrada a jusante

$\operatorname{grad} \phi: \quad$ gradiente da célula centrada a jusante

$\Delta \vec{s}: \quad \quad$ Vetor deslocamento do centróide da célula a jusante em relação ao centróide da face.

Esta equação (4.7) necessita do valor do gradiente de $\phi$ em cada célula. Este gradiente é calculado utilizando o teorema do divergente, que escrito na forma numérica resulta em:

$$
\nabla \phi=\frac{1}{V} \sum_{f}^{N_{\text {faces }}} \bar{\phi}_{f} \vec{A}
$$

\subsection{Equações Aproximadas na Forma Linear}

A equação (4.5) contém a variável $\phi$ como incógnita no centro da célula assim como nas células adjacentes, portanto, a forma dessa equação é não-linear em relação a essas variáveis. Uma forma linear da equação (4.5) pode ser escrita da seguinte forma:

$a_{p} \phi=\sum_{n b} a_{n b} \phi_{n b}+b$ 
Onde os índices " $n b$ " que se referem às células vizinhas a " $a_{p}$ " e " $a_{n b}$ " são os coeficientes lineares de “ $\phi$ ” " $\phi_{n b}$ ”. O número de células vizinhas depende da topologia dos pontos nodais que tipicamente será igual ao número de faces da célula. A equação (4.8) é escrita para cada célula do modelo, formando um sistema de equações algébricas, cuja matriz dos coeficientes é uma matriz esparsa. Na solução desta matriz, utiliza-se o método de sub-relaxação para o controle da variação de $\phi$ durante o processo iterativo. De forma simplificada, o novo valor $\phi_{\text {novo }}$ de uma célula irá depender do seu valor na iteração anterior, $\phi_{\text {anterior }}$ e de um coeficiente de subrelaxação $\alpha_{r}$ como segue na equação abaixo:

$$
\phi_{\text {novo }}=\phi_{\text {antigo }}+\alpha_{r} \cdot\left(\phi_{\text {novo }}-\phi_{\text {antigo }}\right)
$$

\subsection{Acoplamento Pressão-Velocidade}

O algoritmo de solução numérica utilizada neste trabalho é o método segregado, onde as equações são resolvidas sequencialmente. Como as equações que governam o fenômeno são não-lineares, várias iterações devem ser feitas até a convergência da solução seguindo as seguintes etapas:

1- As propriedades do fluido são atualizadas com base na solução anterior.

2- As equações de momento em u,v e w são resolvidas uma de cada vez utilizando-se o valor atual da pressão e fluxo de massa na face para a atualização do campo de velocidade.

3 - Quando a velocidade obtida na etapa 2 não satisfaz as condições de continuidade, correções na pressão devem ser feitas de modo a garantir a convergência.

4 - Cálculo das quantidades escalares como a energia, $\mathrm{k}$, e $\varepsilon$.

5 - Verificação da convergência. 


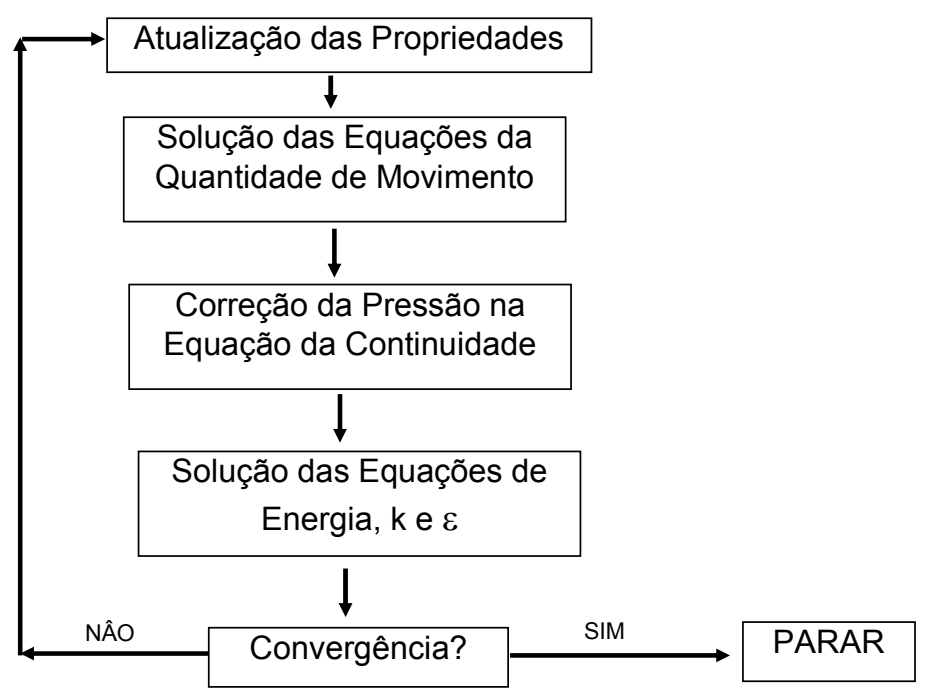

Figura 4.2 - Algoritmo do Método de Solução Segregado.

Como pode ser visto, a pressão irá desempenhar um papel crucial nas equações da continuidade, mesmo que não esteja explícita a influência na equação da continuidade. O algoritmo SIMPLE (Semi-Implicit Method for Pressure Linked Equations), originalmente desenvolvido por Patankar e Spalding (1972), é essencialmente um algoritmo de tentativa e correção para o cálculo da pressão nas células computacionais.

O algoritmo inicia com a utilização do campo de pressão $p^{*}$ para a solução do campo de velocidade $u^{*}$ ou de fluxo dado por:

$J_{f}^{*}=\hat{J}_{f}^{*}+d_{f} \cdot\left(p_{c 0}^{*}-p_{c 1}^{*}\right)$

Onde :

$J_{f}^{*}: \quad \quad$ é a função de fluxo de massa $\rho . u^{*}$ através da face $f$

$d_{f}$ : $\quad$ função da razão da área da célula em relação aos coeficientes lineares " $a_{p} "$

Para satisfazer a condição de continuidade, a função de correção da pressão $J_{f}^{\prime}$ é introduzida na função de fluxo $J_{f}^{*}$ resultando em uma função de fluxo corrigida dada por: 
$J_{f}=J_{f}^{*}+J_{f}^{\prime}$

Onde a função de correção é dada por:

$J_{f}^{\prime}=d_{f} \cdot\left(p_{c 0}^{\prime}-p_{c 1}^{\prime}\right)$

$p^{\prime} \quad$ pressão de correção

O algoritmo SIMPLE substitui as equações de correções de fluxo (equações $4.12 \mathrm{e}$ 4.13) dentro da equação de continuidade (4.9):

$a_{p} \cdot p^{\prime}=\sum_{n b} a_{n b} p_{n b}^{\prime}+b$

Onde o termo fonte b é o fluxo de massa através da célula computacional

$b=\sum_{f}^{N_{\text {faces }}} J_{f}^{*} A_{f}$

A equação da pressão de correção (4.14) é resolvida através de iterações até a convergência. Neste processo computacional, a equação de correção de pressão está sujeita à divergência no resultado, portanto, é necessário um processo de sobrerelaxação $\alpha_{p}$ nas correções dos valores de pressão e de fluxo, da seguinte forma:

$$
\begin{aligned}
& p=p^{*}+\alpha_{p} \cdot p^{\prime} \\
& J_{f}=J_{f}^{*}+d_{f} \cdot\left(p_{c 0}^{\prime}-p_{c 1}^{\prime}\right)
\end{aligned}
$$




\subsection{Método de Geração de Malha}

Neste trabalho, os processos de geração de malha foram feitos com base nos arquivos de CAD (Computer Aided Design) onde se apresentam todos os detalhes geométricos do veículo. O programa utilizado foi o Unigraphics ${ }^{\circledR}$, segundo o qual as superfícies geométricas de cada componente foram convertidas no formato universal IGES. Este tipo de formato é muito utilizado para a comunicação entre diferentes tipos de códigos de $\mathrm{CAD} / \mathrm{CAE} / \mathrm{CAM}$.

As etapas de geração de malha foram feitas com base nas seguintes fases:

- Geração de malha superficial (2D);

- Geração de malha volumétrica (3D).

\subsubsection{Malha Superficial 2D}

Com base nas superfícies geradas pelo software de CAD UG, a geração de malha superficial com elementos triangulares foi feita com base no software Hypermesh $^{\circledR}$ o qual utiliza o método "Advancing Front".

Este algoritmo de geração de malha baseia-se no seguinte algoritmo:

1- Discretização da fronteira (perímetro) da superfície em número de partes $\left(N_{s}\right)$ através dos comprimentos mínimos estabelecidos pelo usuário $\left(\delta_{m}\right)$;

$$
\begin{aligned}
& \Lambda_{s}=\int_{0}^{l} \frac{1}{\delta_{m}} d l \\
& N_{s}=a b s\left(\Lambda_{s}\right)
\end{aligned}
$$

2- Para cada segmento da fronteira, criar elementos triangulares até o fechamento do perímetro (vide figura 4.1).

3- Considerar o novo domínio a fronteira dos elementos anteriores.

4- Proceder as etapas 2 e 3 até o preenchimento da superfície com todos os elementos.

5- Correção dos elementos com a maximização dos menores ângulos dos elementos triangulares através do algoritmo de suavização "smoothing" onde os nós são reposicionados para ter a melhor qualidade. 

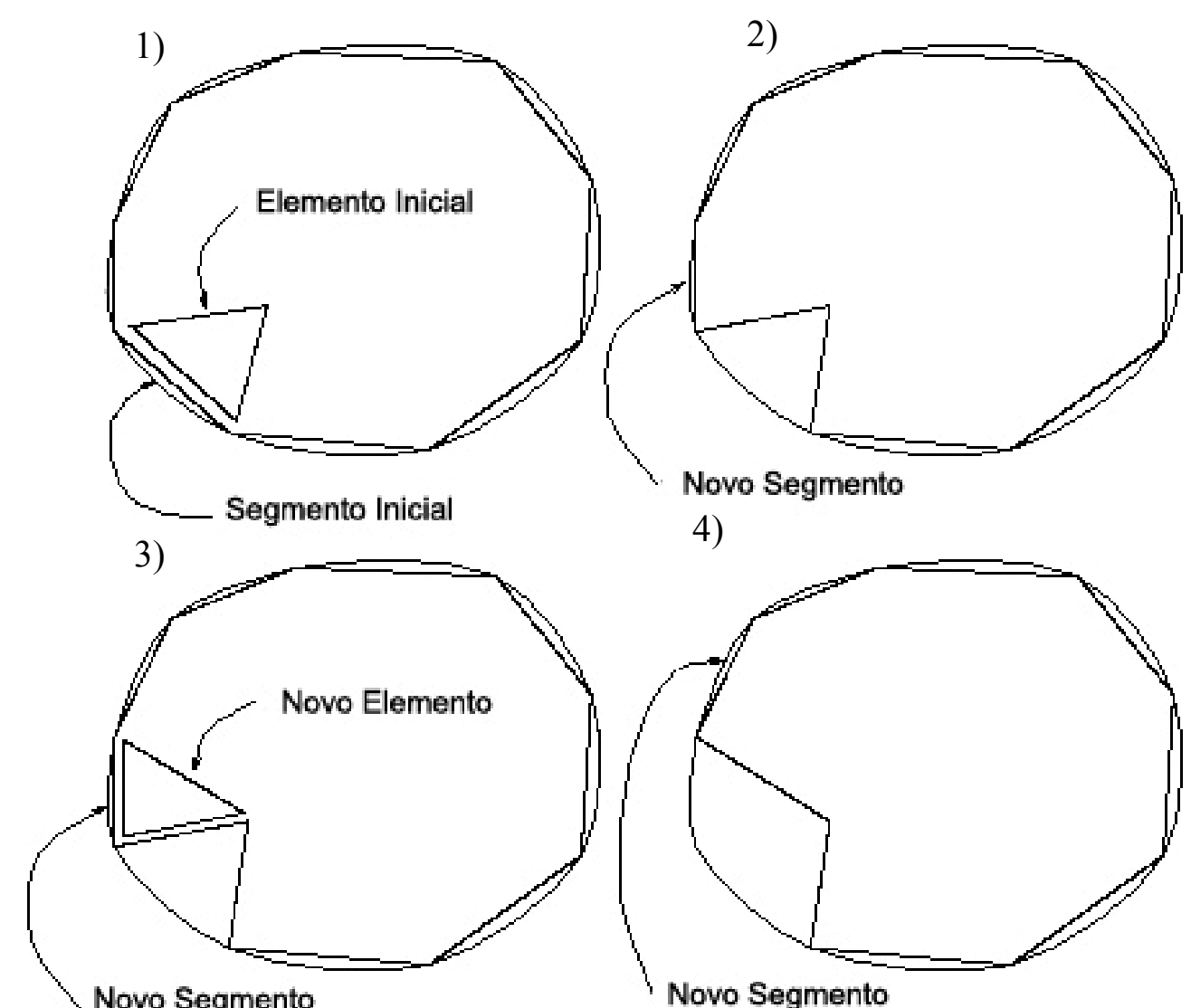

Novo Segmento

4)

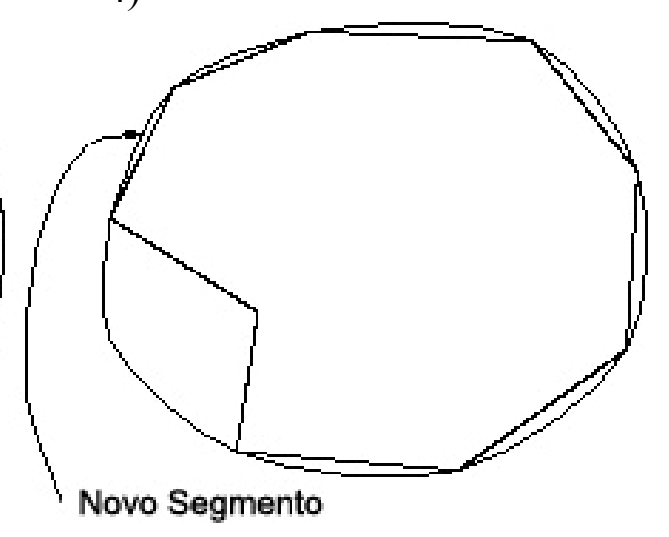

Figura 4.1 - Etapas de geração de malha 2D pelo algoritmo "Advancing Front".

A qualidade dos elementos da discretização da fronteira é muito importante, especialmente para a geração da malha volumétrica, pois uma triangularização de baixa qualidade pode resultar em malha volumétrica de mesma qualidade. Uma forma para garantir a qualidade dos elementos é a utilização das seguintes condições para as arestas adjacentes de modo a encontrar a posição inicial C1 (ver Fig. 4.2):

$$
\delta_{I}= \begin{cases}0.55 A B & \delta_{m}<0.55 A B \\ \delta_{m} & 0.55 A B<\delta_{m}<2 A B \\ 2 A B & 2 A B<\delta_{m}\end{cases}
$$

Esta condição garante que nenhum elemento tenha distorções excessivas durante o processo de triangularização. 


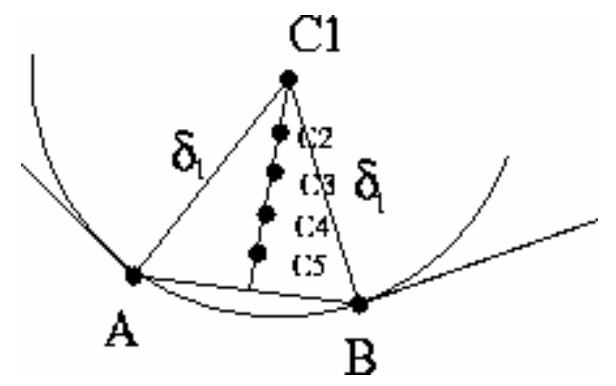

Figura 4.2 - Criação do Novo elemento, escolha inicial.

Uma forma de medir a qualidade dos elementos 2D é o angulo de distorção "skew". Este ângulo é calculado da seguinte forma: primeiramente é obtido para cada nó o menor dos ângulos (denominado de $\alpha_{\min }$ ) entre o vetor que liga o nó ao ponto médio da aresta oposta e o vetor que liga os dois pontos médios adjacentes a este nó. O ângulo de "skew" é a diferença do ângulo de $90^{\circ}$ com o menor ângulo encontrado.

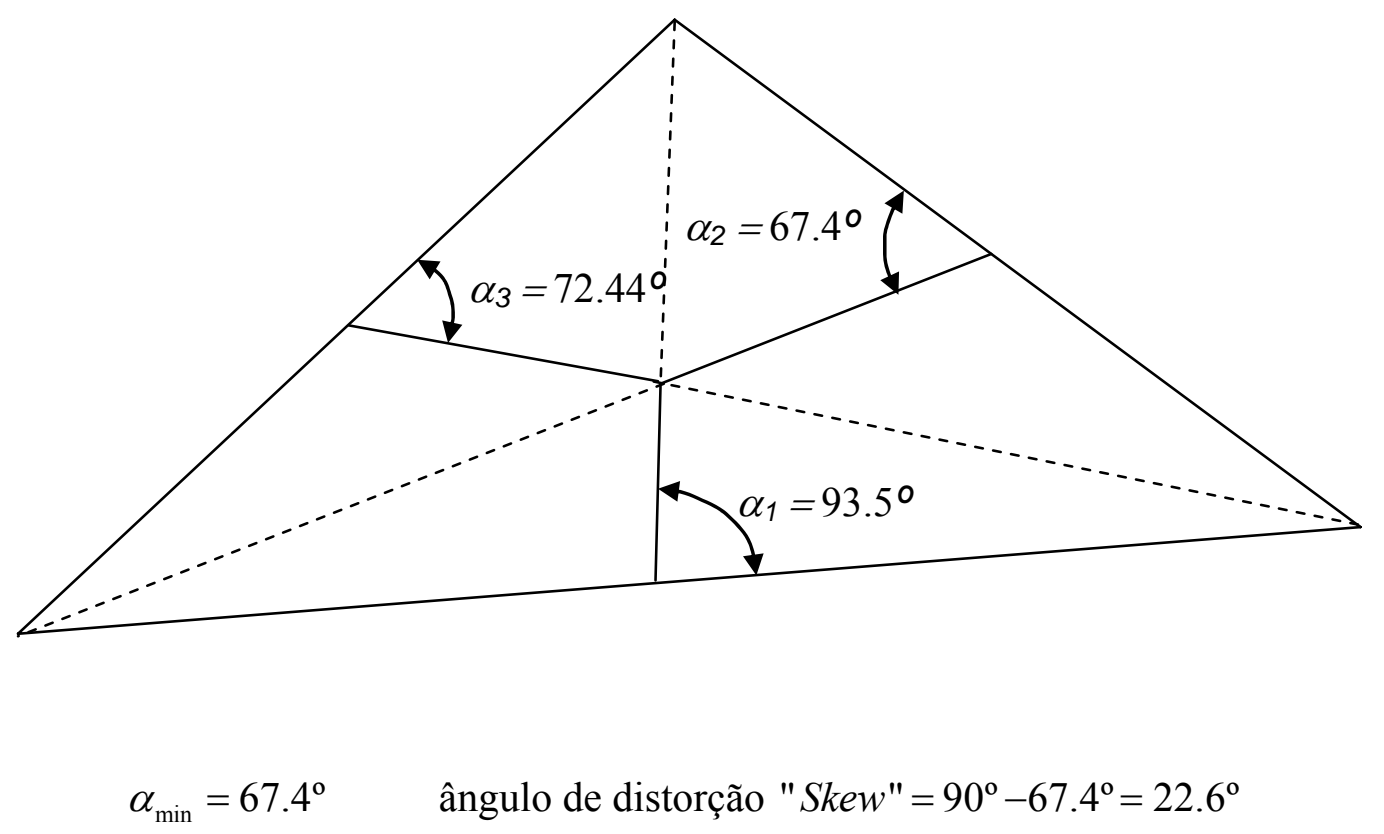

Figura 4.3 - Exemplo de um elemento com ângulo de distorção "skew" de $22.6^{\circ}$. 


\subsubsection{Malha Volumétrica 3D}

O método mais comum de geração de malha tetraédrica não estruturada a partir de uma superfície triangularizada é o método de "Delaunay". Este método preserva as faces triangulares da superfície até o término do processo de geração de malha. Numa malha Delaunay, para cada célula existe uma esfera que a contém, passando por todos os nós que definem esta célula. Uma malha é Delaunay quando não existe nenhum nó no interior destas esferas.

O algoritmo de geração de uma malha Delaunay funciona da seguinte forma: dada uma malha Delaunay existente, um nó pode ser inserido pela remoção de todas as células que contêm este novo nó em suas esferas, e conectando este novo nó às faces do contorno da cavidade resultante.

Em uma malha 2D o algoritmo de "Triangularização de Delaunay" tende a maximizar o mínimo ângulo do triangulo o que é um requisito para uma boa qualidade do elemento. Porém, isto não ocorre para o processo de malha volumétrica diante da complexidade das geometrias e a disposição dos elementos triangulares, de modo que a otimização dos ângulos dos elementos podem se perder, resultando em elementos de baixa qualidade.

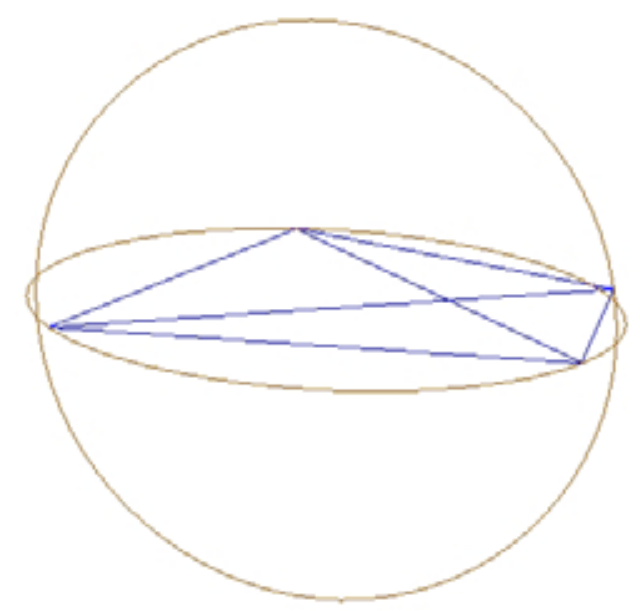

a)

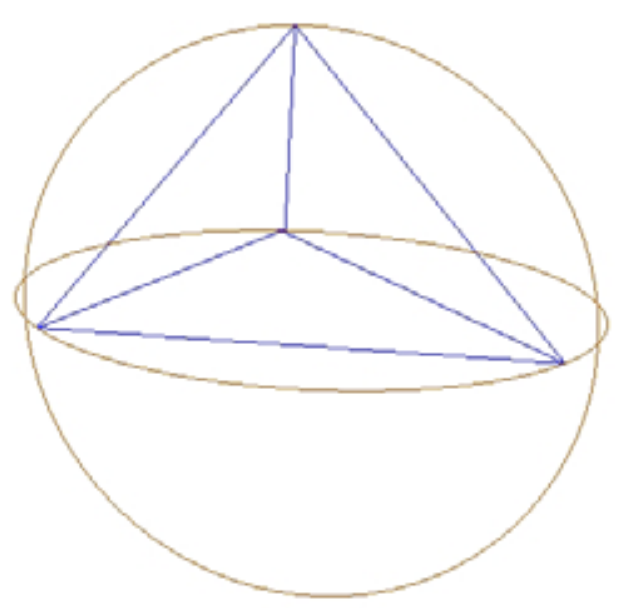

b)

Figura 4.4 - a) Tetraedro de baixa qualidade; b) Tetraedro de ótima qualidade. 
A convergência numérica está intrinsecamente ligada à qualidade dos elementos, desta forma é necessária uma verificação prévia da qualidade da malha tetraédrica gerada.

A qualidade da malha volumétrica é medida pelo "Skewness". Este parâmetro é dado por:

skewness $=\frac{\text { tamanho_ótimo }- \text { tamanho_célula }}{\text { tamanho_ótimo }}$

Sendo tamanho_ótimo o tamanho do elemento cujas faces são compostos por elementos triangulares eqüiláteros.

O "Skewness" varia de 0 a 1 , sendo 0 o valor ótimo. Segundo TGrid ${ }^{\circledR}$, recomenda-se a utilização de um "skewness" de até 0.96 .

A escolha de uma malha é fortemente influenciada pelo desempenho e precisão dos resultados da simulação. O desempenho depende do número de elementos a serem processados, ou seja, quanto maior a área coberta por cada elemento da malha, menos elementos serão necessários e consequentemente, mais rápida será a simulação. A precisão nos resultados da simulação está relacionada tanto com o formato quanto ao tamanho dos elementos.

Diferente do desempenho, quanto menores forem os elementos, mais precisos serão os resultados, o que leva à conclusão de que os formatos dos elementos também influenciam a precisão, sendo que geralmente, elementos mais próximos dos eqüiláteros são preferidos. Como foi possível observar, desempenho e precisão são requisitos conflitantes e geralmente é necessário fazer uma ponderação entre eles. Para um determinado grupo de aplicações, o melhor compromisso entre desempenho e precisão é obtido com elementos refinados em regiões de separação de vórtices. $\mathrm{O}$ refino da malha possibilita assim "captar" os vórtices de pequenas escalas.

No capítulo seguinte será apresentado um estudo de influência no refino da malha da grade de um veículo na vazão de ar no radiador, isto porque, um refino extremo de todos os componentes do modelo, além de elevar o custo de processamento, inviabiliza o estudo de propostas devido ao tempo de resposta. 


\section{CAPÍTULO 5}

\section{VALIDAÇÃO E VERIFICAÇÃO DOS MODELOS NUMÉRICOS}

A ferramenta de simulação numérica do sistema de arrefecimento automotivo nada mais é que um "interpolador" de dados, cuja precisão dos resultados depende basicamente dos seguintes aspectos:

\section{A) Modelos numéricos eficientes na representação do trocador de calor e do ventilador:}

Os modelos numéricos do trocador de calor e ventilador devem ser capazes de representar o efeito da perda de carga externa do ar através do seu núcleo. No caso do trocador de calor, além da perda de carga, o modelo numérico deverá também ser capaz de representar o processo de troca térmica do líquido de arrefecimento com o ar externo.

\section{B) Grau de refinamento da malha volumétrica:}

Sabe-se que no método de volumes finitos, os resultados tendem a serem mais próximos ao analítico, na medida em que os tamanhos dos elementos de discretização tendem a zero. Porém, como já foi salientada em capítulos anteriores, essa prática ainda não é viável face à limitação de custo de processamento. Dessa forma, deve-se buscar um equilíbrio de modo a obter o menor tempo em respostas sem o comprometimento na qualidade dos resultados.

\section{C) Conhecimento das condições de contorno:}

O conhecimento e a correta utilização das condições de contorno são essenciais para se obter uma simulação confiável. Neste trabalho, as condições de contorno foram obtidas por meio de testes em túneis de vento.

\section{D) A representatividade das propriedades dos materiais:}

Este trabalho considera a interação térmica do motor e o fluido de arrefecimento. As propriedades dos fluidos sofrem variações de acordo com a variação da temperatura. Dessa forma, a utilização adequada das propriedades do 
fluido deve ser relevante. Neste trabalho foram feitas correções das propriedades do fluido como o uso de gráficos obtidos em literatura (vide apêndice B).

Devemos lembrar que os resultados desses testes físicos dependem do grau de aferição dos equipamentos de medição assim como no grau de estabilidade do regime durante a coleta de dados. Como os testes de arrefecimento de um veículo envolvem muitas variáveis, é de se esperar que testes, utilizando o mesmo procedimento, podem resultar em pequenas discrepâncias nos resultados.

\subsection{Validação de Modelo Numérico do Sistema de Arrefecimento}

\subsubsection{Trocador de Calor}

Como visto no item 3.6, as curvas de desempenho de trocadores de calor são obtidas por meio de testes físicos, sendo que cada trocador de calor dependendo das configurações como número de aletas e tubos, resultam em curvas distintas de perda de carga externa do ar e da rejeição térmica.

$\mathrm{O}$ conceito de validação utilizado neste capítulo refere-se à capacidade do método numérico de poder simular os mesmos efeitos de troca térmica e perda de carga do componente para um determinado valor de vazão de ar previamente obtido em testes físicos.

É por meio das validações dos subcomponentes principais do sistema de arrefecimento (Trocador de Calor e Ventilador) que se pode garantir a confiabilidade dos resultados obtidos em um modelo de um veículo.

A validação do trocador de calor é feita com a utilização de um modelo de câmara dupla, onde o trocador de calor é posicionado na parte central e separado por uma parede como ilustrado na figura 4.1. 


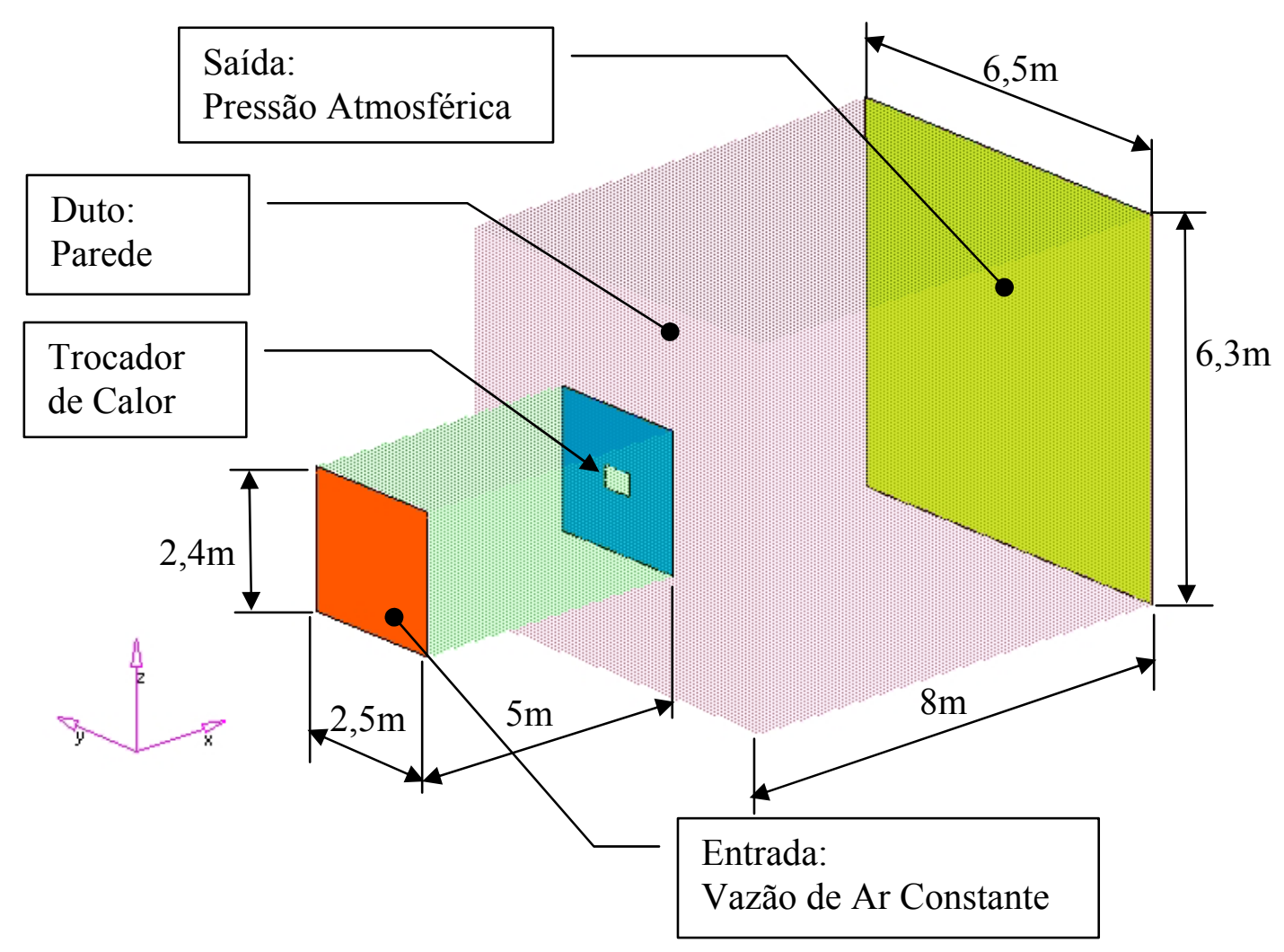

Figura 5.1 - Condições de contorno da câmara para validação do trocador de calor.

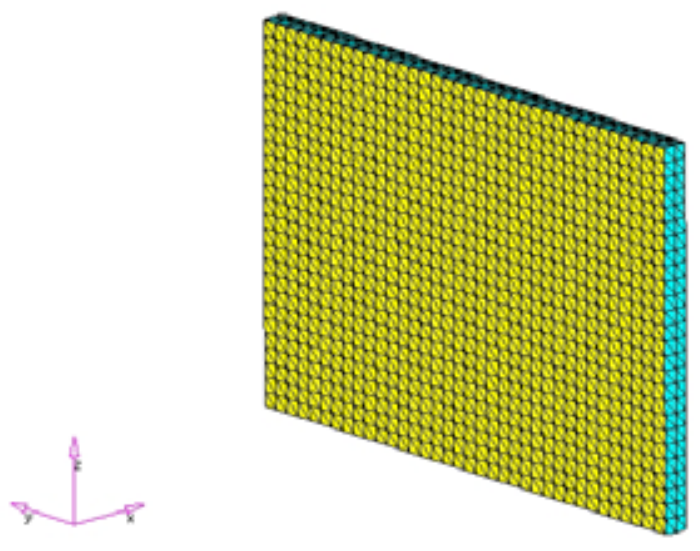

Figura 5.2 - Modelo do trocador de calor contendo 36 x 26 células.

Para a simulação da perda de carga externa do ar através do núcleo do trocador de calor, inicialmente foram calculados os coeficientes de perda de carga com base na curva de pressão do ar obtido em teste físico e com o uso do procedimento descrito no item 3.6.2: 


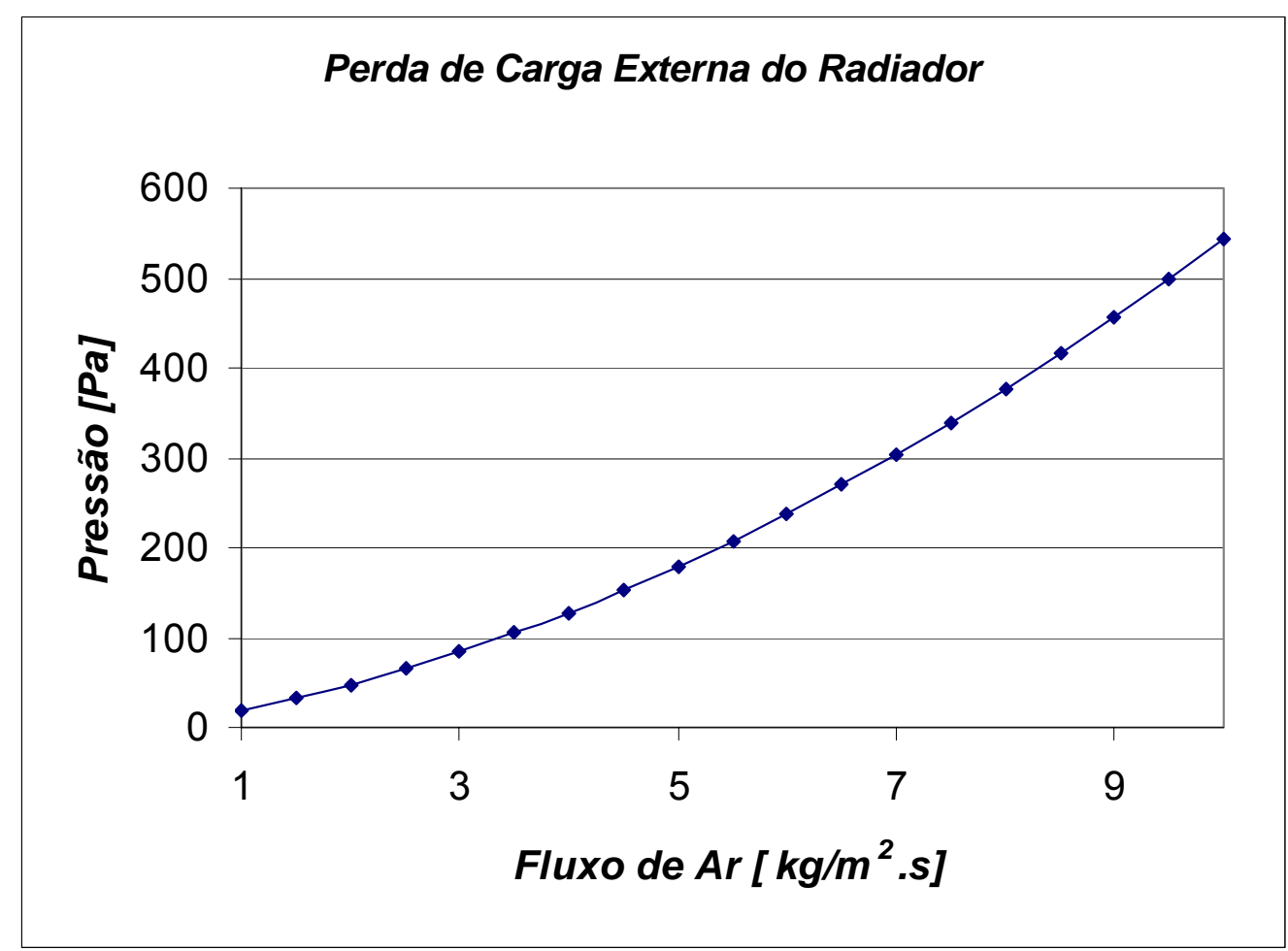

Figura 5.3 - Curva típica de Perda de carga externa do ar obtida em teste.

Utilizando-se as equações (3.52) e (3.53) obtêm-se as perdas de carga do trocador de calor.

Perda de carga viscosa:

$V=\frac{\beta}{\mu}=3,94 \cdot 10^{7}$ $\mu\left(38^{\circ} \mathrm{C}\right)=1,95.10^{-9} \quad[\mathrm{~kg} / \mathrm{m.s}]$

Perda de carga inercial:

$I=\frac{2 \alpha}{\rho}=326,8$

As simulações foram consideradas em regime permanente, utilizando-se o modelo $k-\varepsilon$ com o método de integração de primeira ordem e função de parede padrão. Para cada variação do valor de vazão de ar na entrada do duto, obteve-se o diferencial de pressão na entrada e na saída das câmaras. A figura 5.4 mostra a comparação das curvas de perda de carga entre o teste físico e a simulação numérica. 


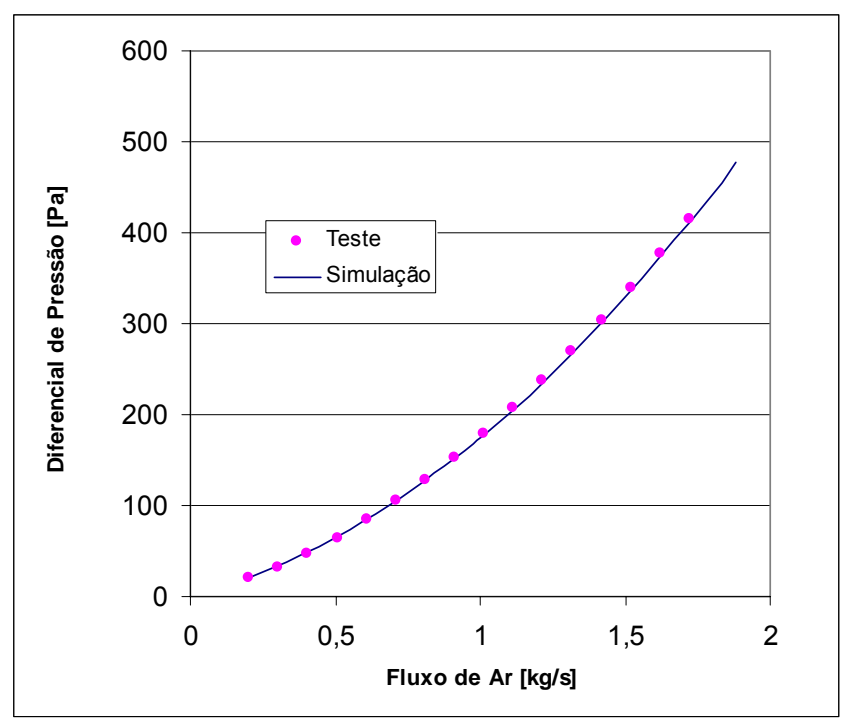

Figura 5.4 - Curva comparativa de perda de carga entre teste e simulação numérica.

Para o caso da rejeição térmica foram calculadas as curvas de NUT a partir das curvas de desempenho térmico obtidas em testes (figura 5.5), com a utilização do procedimento descrito no item 3.6.1 e do programa do apêndice C.

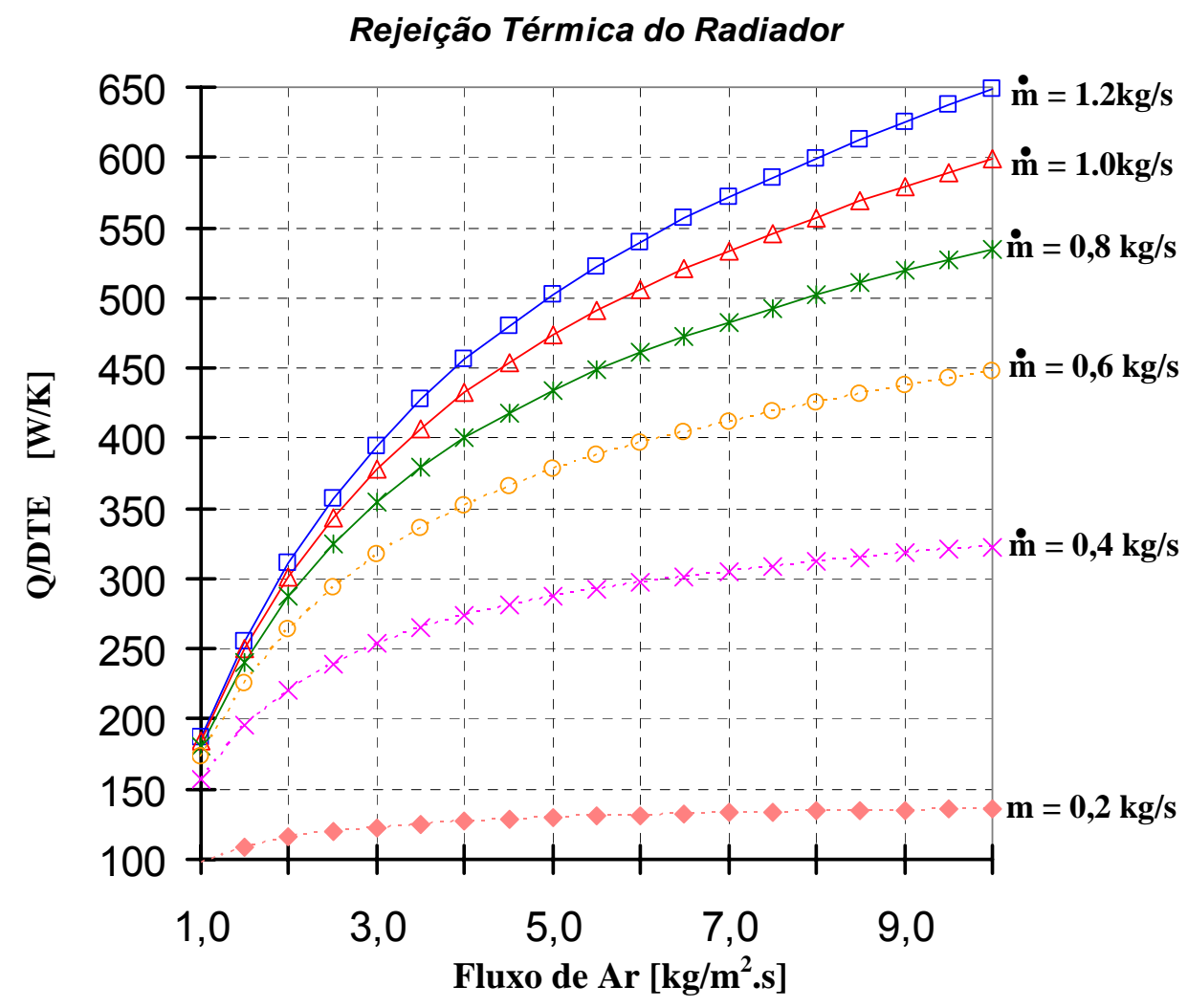

Figura 5.5 - Curvas típicas de rejeição térmica de um radiador. 


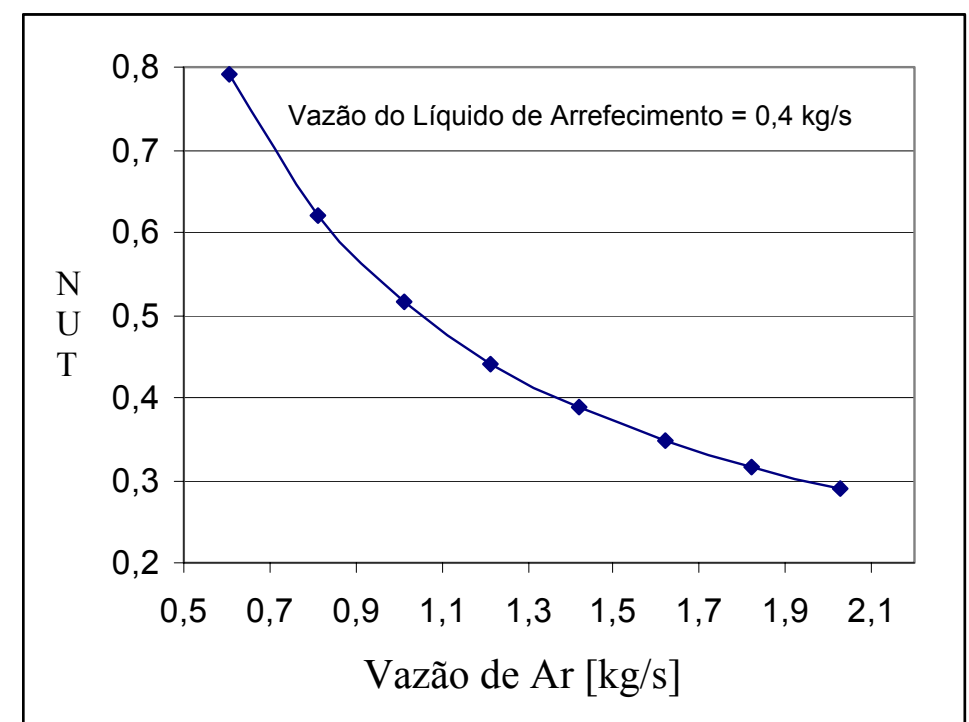

Figura 5.6 - Curva de NUT para vazão do líquido de arrefecimento de $0.4 \mathrm{~kg} / \mathrm{s}$.

As simulações foram consideradas em regime permanente, tendo-se utilizado o modelo $k-\varepsilon$ com o método de integração de primeira ordem "Upwind" e função de parede padrão. Com base nos dados do teste, a variação da temperatura do ar atmosférico e do líquido de arrefecimento na entrada do radiador foi fixada em $50^{\circ} \mathrm{C}$. Para cada variação do valor de vazão de ar na entrada do duto, obteve-se o calor rejeitado pelo trocador de calor. A figura 5.7 mostra a comparação das curvas de rejeição de calor entre o teste físico e a simulação numérica. 


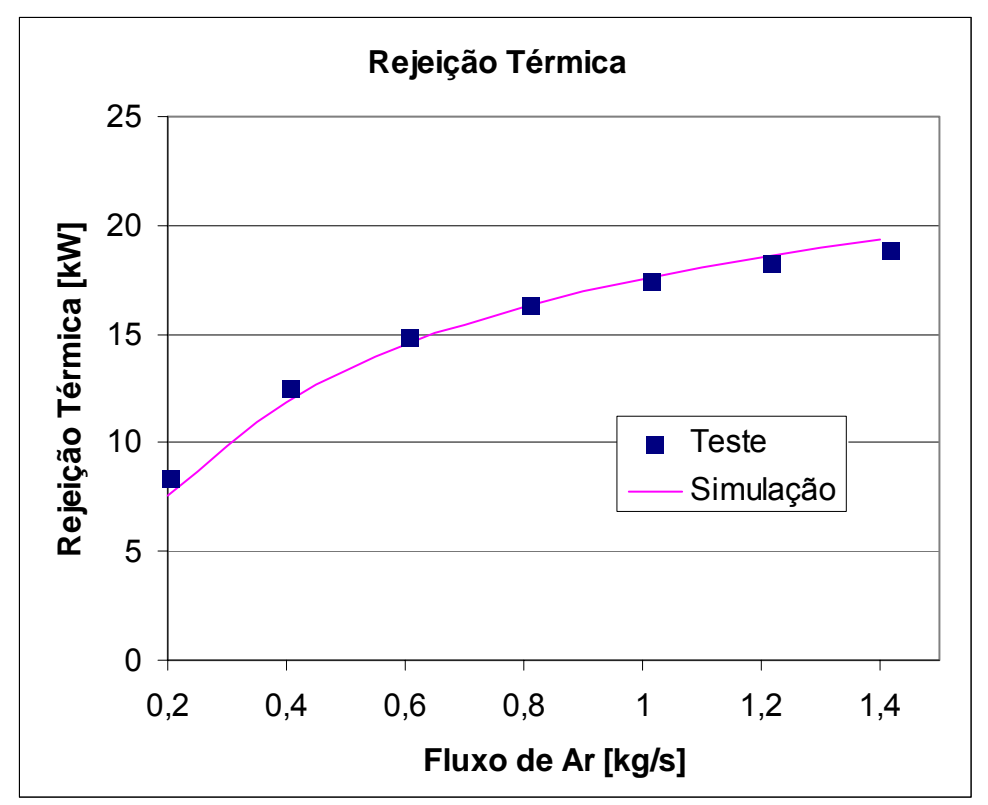

Figura 5.7 - Curva comparativa de rejeição térmica entre teste físico e simulação numérica.

\subsubsection{Ventilador}

Existem, basicamente, duas formas de representar o ventilador nas simulações de CFD. A primeira delas é considerar que a malha volumétrica do ventilador está em rotação sob uma determinada velocidade angular constante. Esse método é denominado de Rotating Reference Frame Method o qual considera as forças centrífugas e de Coriolis nas equações de quantidade de movimento. Ele é muito utilizado no estudo de redução de ruídos em pás de ventiladores como mostrado no trabalho desenvolvido por Suzuki e Soya (2005).

Quando se conhece a curva de desempenho do ventilador, a segunda alternativa que utiliza a curva pressão como fonte nas equações de transporte é mais a mais indicada (método utilizado neste trabalho).

A validação do modelo do ventilador consiste na utilização de um duto circular de $34 \mathrm{~cm}$ de diâmetro e $2 \mathrm{~m}$ de comprimento. $\mathrm{O}$ ventilador foi posicionado na região central como mostra na figura abaixo. 


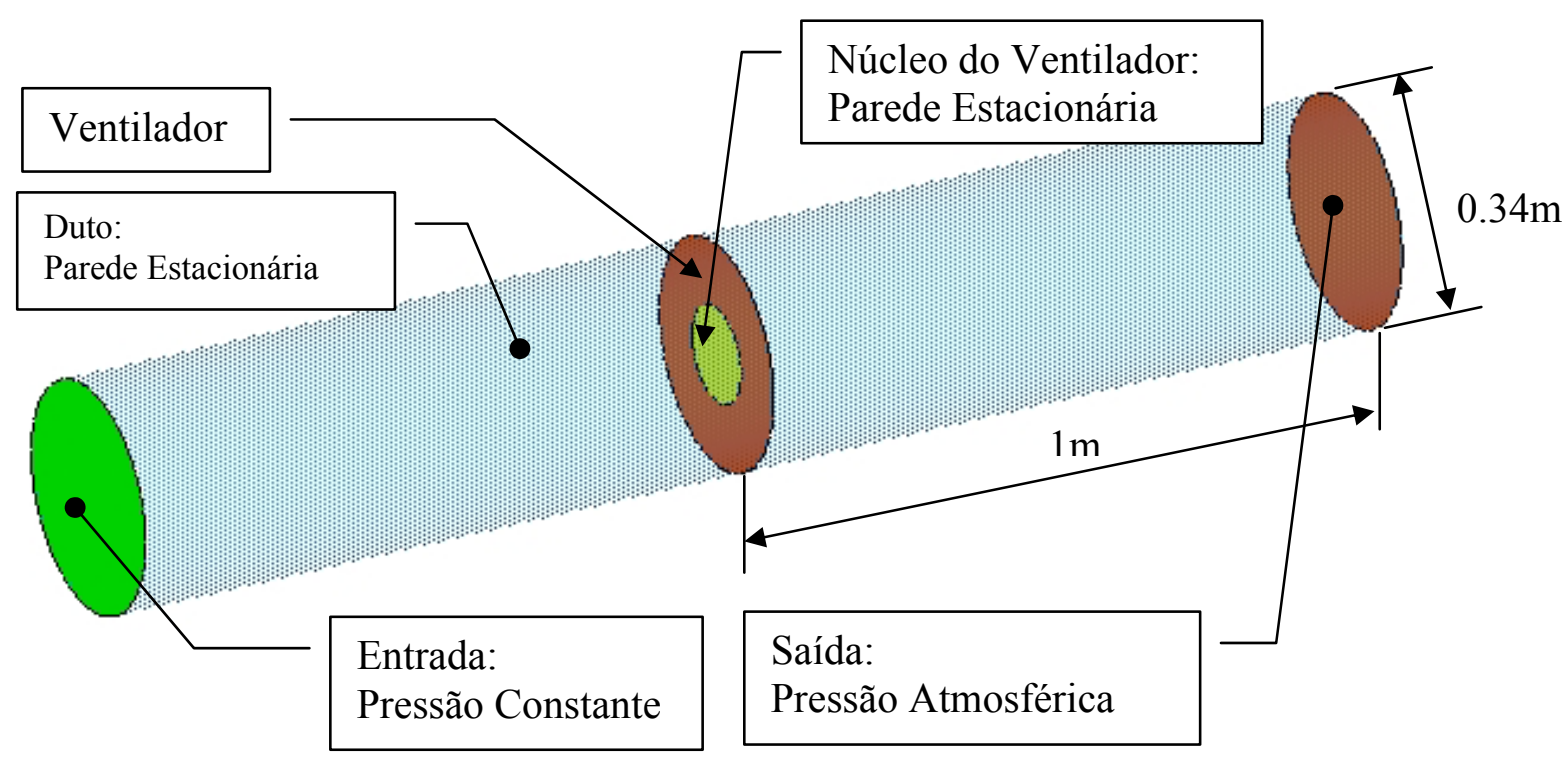

Figura 5.8 - Condições de contorno do duto para validação do ventilador.

A validação do modelo do ventilador foi feita com base no trabalho de graduação de Takara (2003) onde considera o modelo $k$ - $\varepsilon$ com método de integração de primeira ordem "Upwind" e função de parede padrão. Para cada variação do valor da pressão na entrada do duto, obteve-se o valor da vazão de ar pelo ventilador.

A figura. 5.9 mostra a comparação das curvas de diferencial de pressão do teste físico e da simulação numérica.

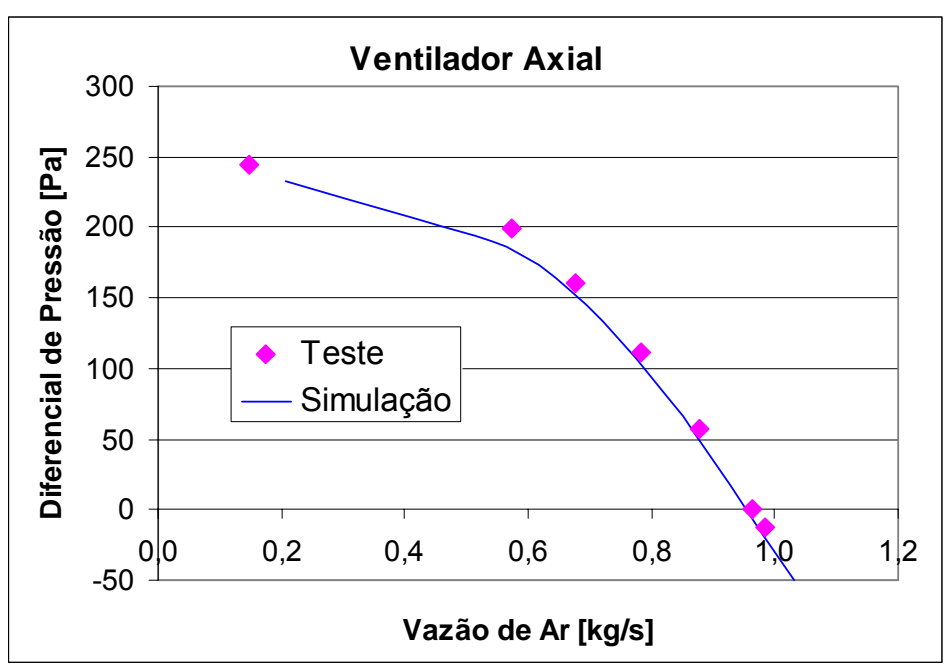

Figura 5.9 - Curva comparativa de perda de carga entre teste e simulação numérica.

As figuras 5.10 mostra as linhas de corrente no ventilador onde o efeito do "swirl" é considerando. Enquanto na figura 5.11 mostra o contorno de velocidade na região após o ventilador. 


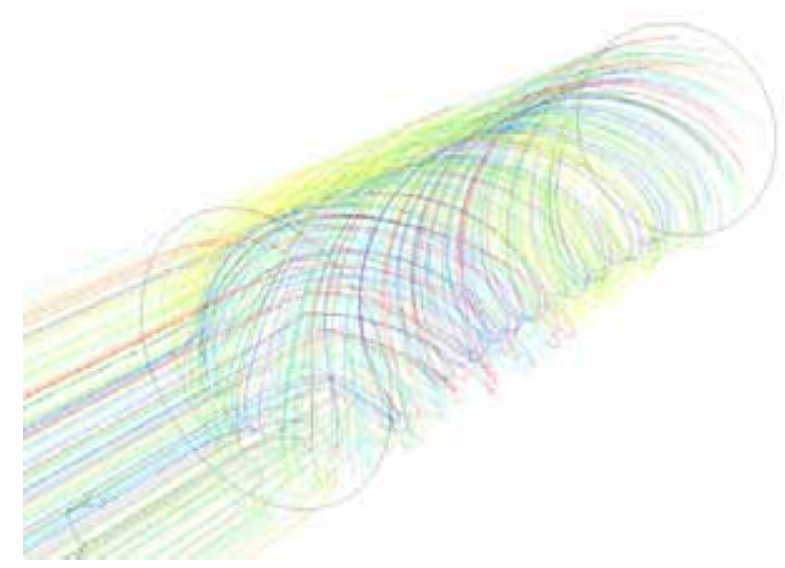

Figura 5.10 - Linhas de corrente mostrando o efeito "swirl".

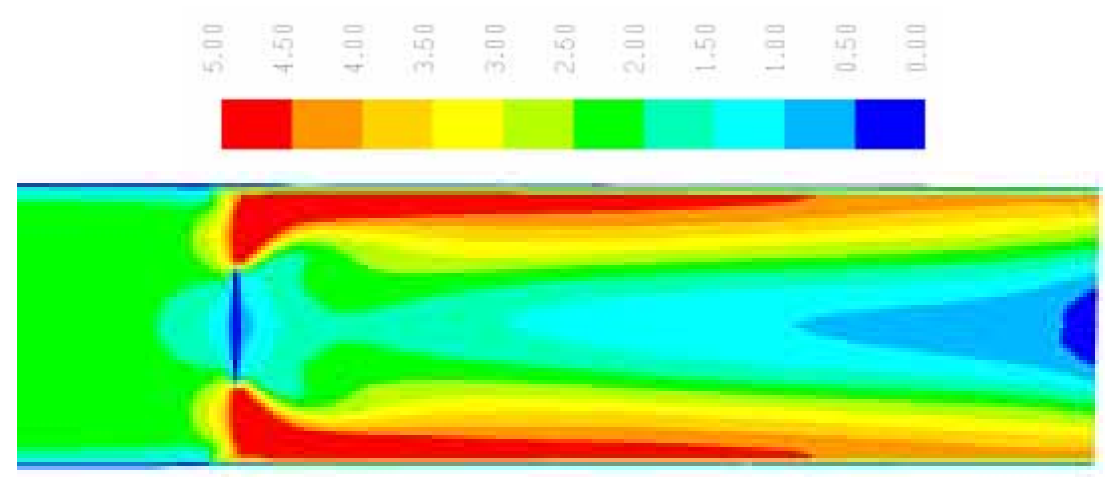

Figura 5.11 - Distribuição de velocidade [m/s] no plano central longitudinal.

\subsubsection{Conclusões Preliminares das Validações Numéricas dos Itens Isolados do Sistema de Arrefecimento.}

Os resultados das simulações numéricas do trocador de calor e do ventilador mostraram boa concordância tais como os valores obtidos em testes físicos. No caso do radiador, obteve-se variações menores que $2 \%$ na validação da perda de carga, enquanto que para a troca térmica este valor é de $4 \%$. No caso do ventilador, a variação máxima foi de $6 \%$ na condição de vazão de ar de $0,55 \mathrm{~kg} / \mathrm{s}$, enquanto que para outras condições esta variação foi menor que 3\%. Dessa análise, pode-se concluir que os modelos numéricos são eficientes na representação das condições operacionais de um sistema de arrefecimento, podendo ser incorporados em um modelo de um veículo para avaliar a temperatura do líquido de arrefecimento. 


\subsection{Estudo da Influência de Malha no Fluxo de Ar no Compartimento do Motor (Veículo A)}

A eficiência de um sistema de arrefecimento de um veículo depende basicamente da quantidade de ar e a sua temperatura que entram pelas grades para o processo de troca térmica com o calor gerado pelo motor.

Estudos feitos por Hucho et al (1998) mostram que o escoamento de ar pelo compartimento do motor em um veículo em alta velocidade é movido pelo efeito "ram" que é o diferencial de pressão gerada entre a grade inferior e a região posterior ao protetor de cárter.

O fluxo de ar através da grade gera separação do escoamento caracterizando a ocorrência do fenônemo de desprendimento de vórtices.

Esses fatores nos levam a indicativa da relevância na discretização da grade de forma a obter valores confiáveis de vazões de ar nos trocadores de calor.

$\mathrm{O}$ estudo da influência de malha da grade foi feito com o uso de um veículo de passeio, aqui denotado como o Veículo A.

\subsubsection{Modelo do Veículo A}

Esse modelo foi gerado a partir de superfícies geométricas de modelos em CAD, tendo a malha triangularizada gerada com o uso do método Advancing Front (ver item 4.3.1). As regiões em que podem ocorrer elevados gradientes, assim como as regiões com possibilidades de ocorrências de separação de escoamento e as regiões adjacentes ao sistema de arrefecimento, foram refinadas.

A grade superior foi modelada com elementos de tamanho $10 \mathrm{~mm}$, enquanto na região inferior da abertura na região do pára-choque foi inicialmente modelada com elementos de tamanho $20 \mathrm{~mm}$. O estudo de refino de malha será aplicado a esta região de modo a obter valores de vazões de ar mais próximas à condição real de operação dos trocadores de calor.

No sistema de arrefecimento, a malha foi modelada com elementos triangulares variando de 5 a $10 \mathrm{~mm}$. Já para os componentes do motor e a estrutura da 
carroceria foram modeladas com elementos variando de 10 a $25 \mathrm{~mm}$. Com o intuito de se reduzir o número de elementos com altos valores de "skewness", a transição da malha foi feita de forma suave, evitando-se também a variação brusca do tamanho de elementos de componentes adjacentes. Normalmente, regiões como frestas ou "gaps", além de gerar elementos volumétricos de baixa qualidade, podem resultar em escoamentos com alta velocidade ("spikes”), prejudicando a convergência da solução. Para evitar esta prejudicialidade, a forma encontrada foi o uso do critério de eliminação das frestas para valores inferiores a $3 \mathrm{~mm}$. Durante a modelagem, procurou-se obedecer a qualidade dos elementos com ângulo de skew máximo de $70^{\circ}$.

Em relação aos componentes internos, via de regra, devem ser incluídos todos os componentes com dimensões acima de 50mm. Dessa forma, não devem participar os componentes tais como os cabos elétricos, linhas de combustíveis e de freio, abraçadeiras e pequenos suportes.

É importante a consideração de componentes que afetam a restrição de ar pelo compartimento, Sabe-se que, na condição de baixa velocidade, o sistema de arrefecimento é operado pelo ventilador, criando uma pressão positiva dentro do compartimento e o ar quente tenderá a retornar para a região da grade, a qual apresenta menor pressão estática, caracterizando o efeito da recirculação e que é prejudicial ao sistema de arrefecimento. No caso em que os componentes agregados ao motor não forem considerados, o ar escoará com maior facilidade para a região inferior, mascarando o efeito da recirculação. 


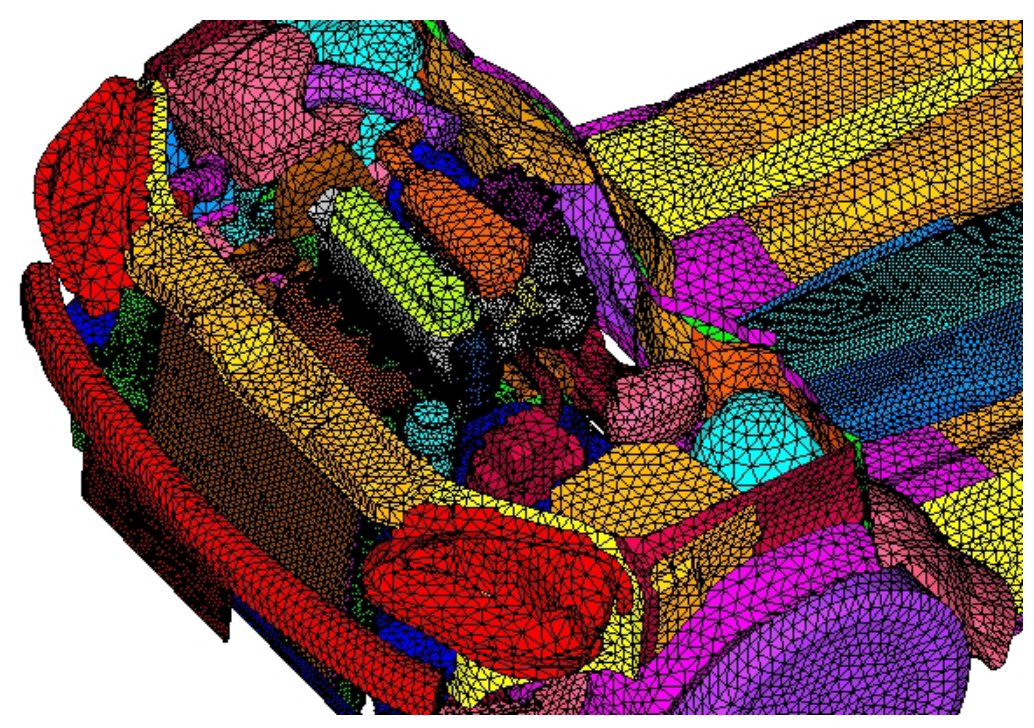

Figura 5.12 - Malha triangular do compartimento do motor do Veículo A.

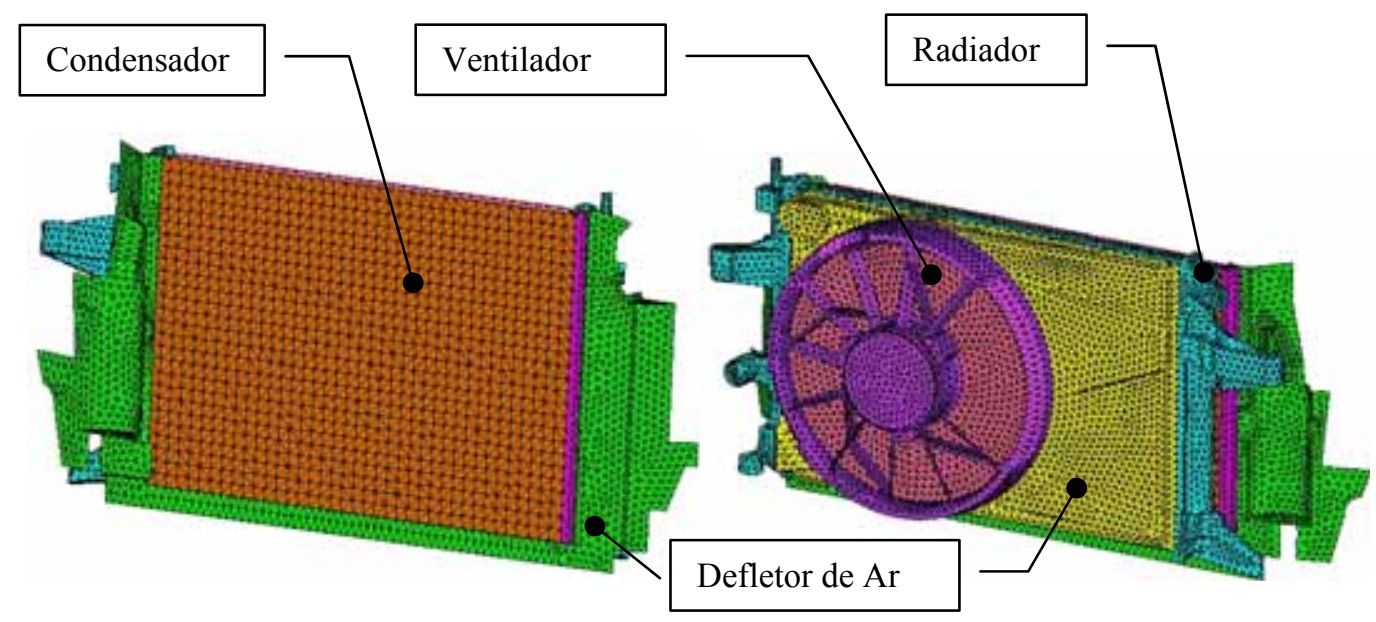

a) Vista Frontal

b) Vista Traseira

Figura 5.13 - Malha triangular do sistema de arrefecimento (CRFM).

A malha superficial triangular servirá como uma "fronteira" para o processo de geração da malha volumétrica.

A geração de malha volumétrica não estruturada foi feita com base no método de Delauney (ver item 4.3.2). Várias iterações foram realizadas com alteração da malha triangular até a obtenção da qualidade de malha volumétrica com skewness inferior ao 0,96 . 


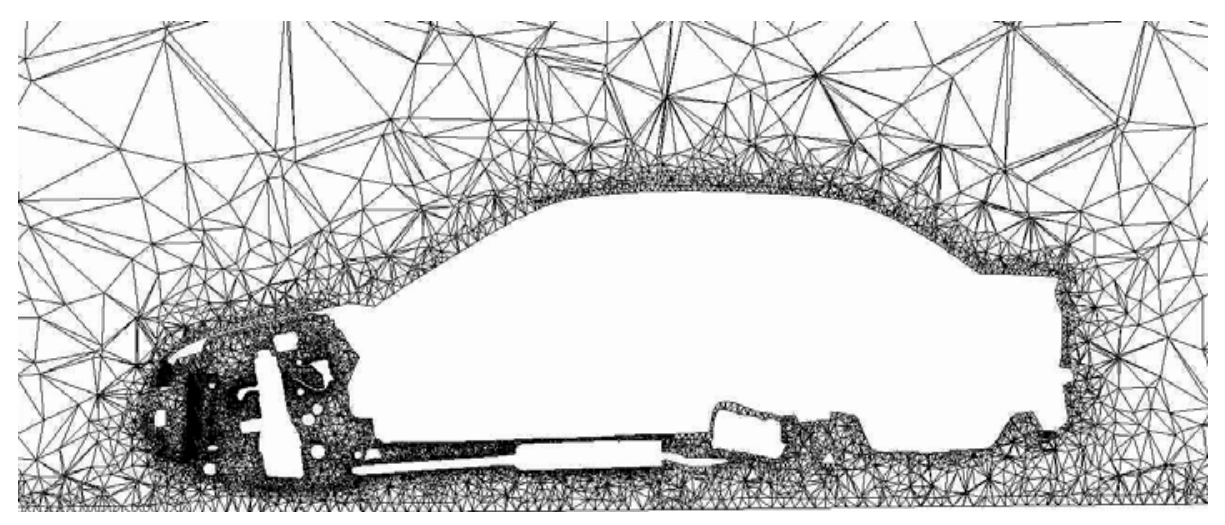

Figura 5.14 - Malha volumétrica do veículo A (corte no plano central na longitudinal).

\subsubsection{Condições de Contorno}

As condições de contornos aplicadas ao modelo numérico são similares às condições do veículo testado em túnel de vento, como ilustrado na figura 5.15. As dimensões do túnel assim como o posicionamento e a inclinação do veículo foram respeitadas.

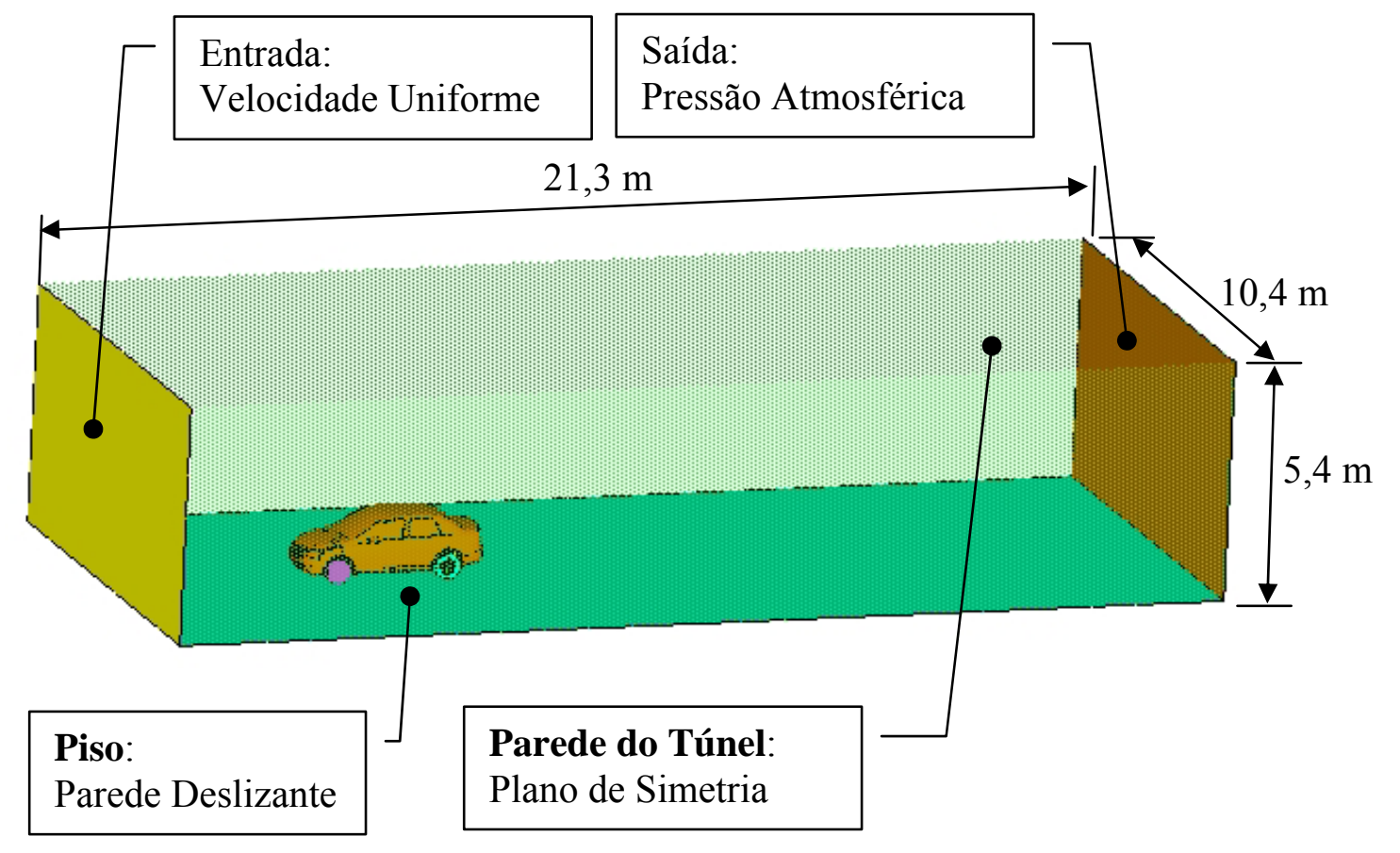

Figura 5.15 - Condições de contorno do túnel de vento. 
Para avaliar o efeito de malha da grade no escoamento de ar no trocador de calor foi considerada a velocidade do veículo de $100 \mathrm{~km} / \mathrm{h}$, pois a esta velocidade, o efeito de separação do escoamento será mais intenso.

No plano de entrada do túnel, além da velocidade, serão necessários a especificação do valor da densidade e os valores de turbulência. A densidade do ar foi mantida constante a $38^{\circ} \mathrm{C}$, pois simulações desse tipo ocorrem para baixo número de Mach.

Escoamentos turbulentos em dutos geram altos níveis de turbulência e devem ser consideradas no domínio da fronteira do volume de controle. Valores de intensidade de turbulência fora da realidade física podem contaminar os resultados da simulação, além de impedir a convergência da solução.

Em situações em que os perfis de velocidade na entrada do túnel não são completamente conhecidos, a alternativa é a utilização das quantidades turbulentas na entrada como: a intensidade turbulenta, viscosidade turbulenta, diâmetro hidráulico ou da escala de comprimento de turbulência.

A intensidade turbulenta $I$, é definida como a razão das flutuações de velocidades pela velocidade média de entrada.

$I=\frac{u^{\prime}}{U}=\frac{(2 / 3 \cdot k)^{1 / 2}}{U}$

onde

u' ....... a flutuação de velocidade

$k$....... a energia cinética dada por $: k=\frac{1}{2}\left(\overline{u^{\prime 2}}+\overline{v^{\prime 2}}+\overline{w^{\prime 2}}\right)$

U........ módulo da velocidade média na entrada

De acordo com os resultados de túnel de vento, os valores da intensidade turbulenta utilizada neste trabalho foram: $\mathrm{I}=0.6 \%$ e diâmetro hidráulico $(\mathrm{Dh}) \mathrm{de} 7 \mathrm{~m}$ (Kuzmanov, 1993).

Para o piso do túnel, foi considerado a condição de parede deslizante de forma a representar o sistema de esteira rotativa do túnel (ver figura 1.23), com a redução do efeito da camada limite.

Tanto as paredes laterais quanto ao teto do túnel foram considerados como sendo planos de simetrias, devido às seguintes razões: 
1) Como a seção transversal do túnel $A_{N}$ é muito maior que a área projetada do veículo A, a razão de bloqueio $\varphi$ será menor que 0,05 Hucho et al (1988), o que significa que o efeito da camada limite da parede do túnel tem pouca influência no escoamento.

$\varphi=\frac{A}{A_{N}}=\frac{2,03}{56,16}=0,036$

2) A segunda razão refere-se ao tempo de processamento, pois com a utilização de planos de simetria não será necessário resolver as equações das funções de parede.

Já no caso das paredes do veículo, foram definidas como paredes estacionárias com a condição de aderência, utilizando a função padrão de parede “Standard Wall Function”. O solver utiliza a formulação de Launder e Spalding (1972) para a resolução da turbulência na parede (ver item 3.5). No caso, para a determinação das forças reativas nas paredes, assim como o efeito da camada limite para os coeficientes de convecção, haverá a necessidade de um refinamento para que resulte em um $\mathrm{y}^{+}$dentro da faixa da lei logarítmica.

Como este trabalho trata somente da troca térmica entre o ar e os trocadores de calor através do método "NUT" e não importando com as interações térmicas do motor e com os componentes adjacentes, o refino para se obter um $\mathrm{y}^{+}$na camada logarítmica, como demonstrado na equação 3.34, não será de grande relevância. A consideração do efeito da camada limite é necessária quando se deseja estudar o efeito da temperatura dos componentes do compartimento devido à troca térmica com o radiador e com o bloco, pois o efeito da camada limite tem influência no cálculo dos coeficientes de troca térmica.

Nas simulações, o veículo foi considerado em regime permanente. Para a resolução das equações de Navier-Stokes para o escoamento incompressível, isotérmico e turbulento, foi utilizado o código FLUENT ${ }^{\circledR}$ com o uso do modelo de turbulência $\mathrm{k}-\varepsilon$. O modelo $\mathrm{k}-\varepsilon$. tem sido muito utilizado para simulações de fluxo de ar através de compartimento do motor como pode ser visto nos trabalhos do (Ashmawey et al., 1993), (Nobel e Jain, 2001) e (Jerhamre e Jonson , 2004).

O método "SIMPLE" foi utilizado para o acoplamento velocidade-pressão e esquema de discretização "Upwind" de segunda ordem (ver capítulo 4). 


\subsubsection{Resultados do Estudo da Influência de Malha da Grade no Fluxo de Ar no Compartimento do Motor (Veículo A)}

Como já foi mencionado anteriormente, a região do pára-choque é caracterizada por apresentar ponto de estagnação do ar (região de alta pressão) o que favorece o escoamento do ar para o interior do compartimento. Na região da grade ocorre o efeito de desprendimento de vórtices. Dessa forma, o estudo de malha deve ser considerado para representar possíveis regiões de recirculações além de obter uma distribuição de velocidade nos trocadores de calor mais próxima da condição real de operação.

Para o estudo da influência da malha da grade no fluxo de ar no radiador, foram utilizados três níveis de refino de malha do pára choque: 20,10 e $5 \mathrm{~mm}$.
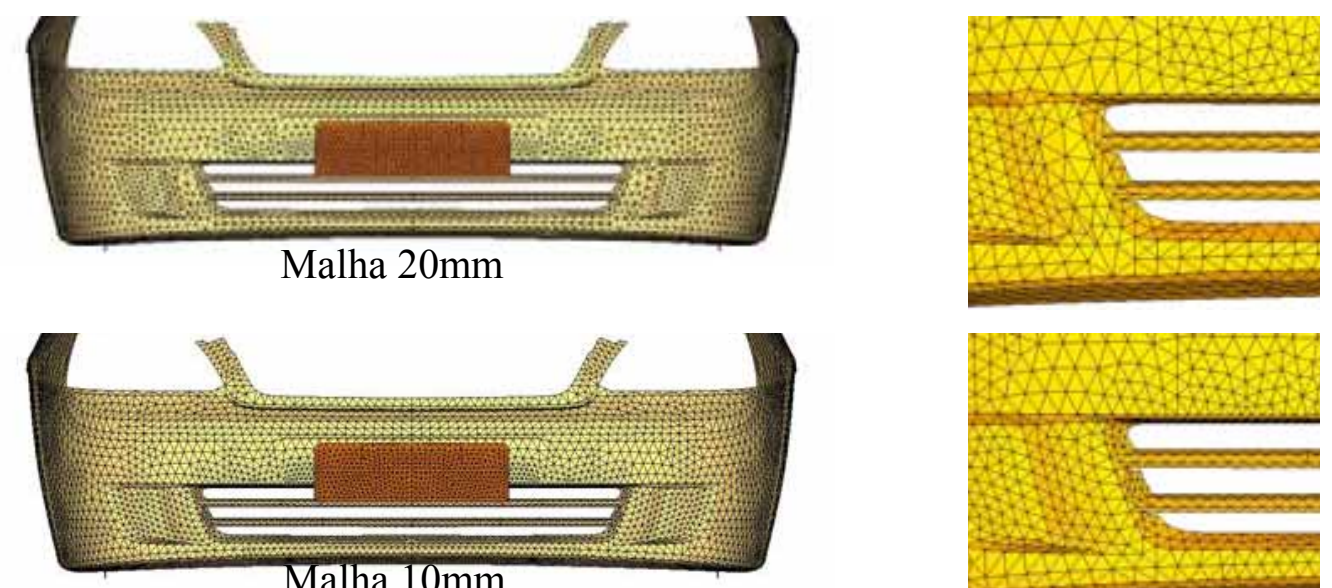

Malha 10mm

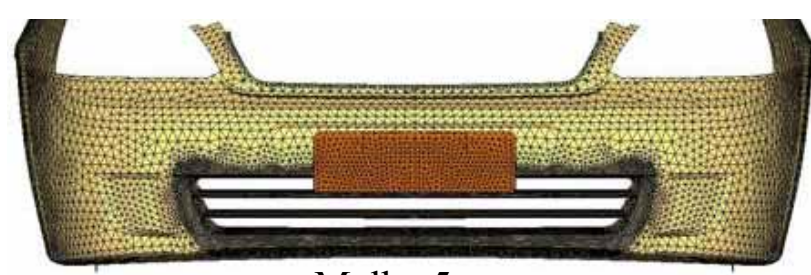

Malha $5 \mathrm{~mm}$
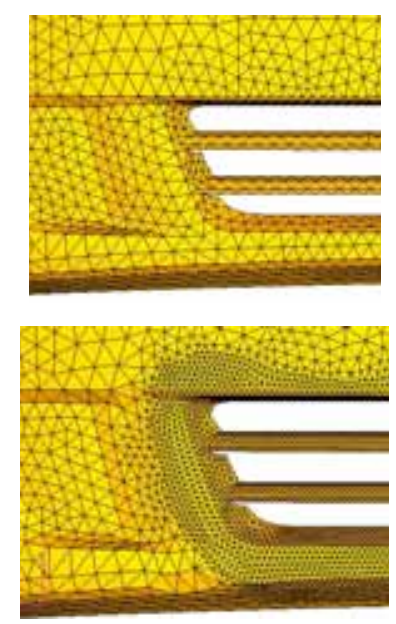

Figura 5.16 - Níveis de refino de malha superficial da grade do pára-choque.

Devido ao tamanho dos modelos ( 1,5 milhões de elementos ) foi necessário a utilização de processamento em paralelo por meio de quatro processadores ou “clusters" em um super computador "HPC" IBM Regatta P655 equipado com 16Gb de memória e com sistema operacional UNIX. 

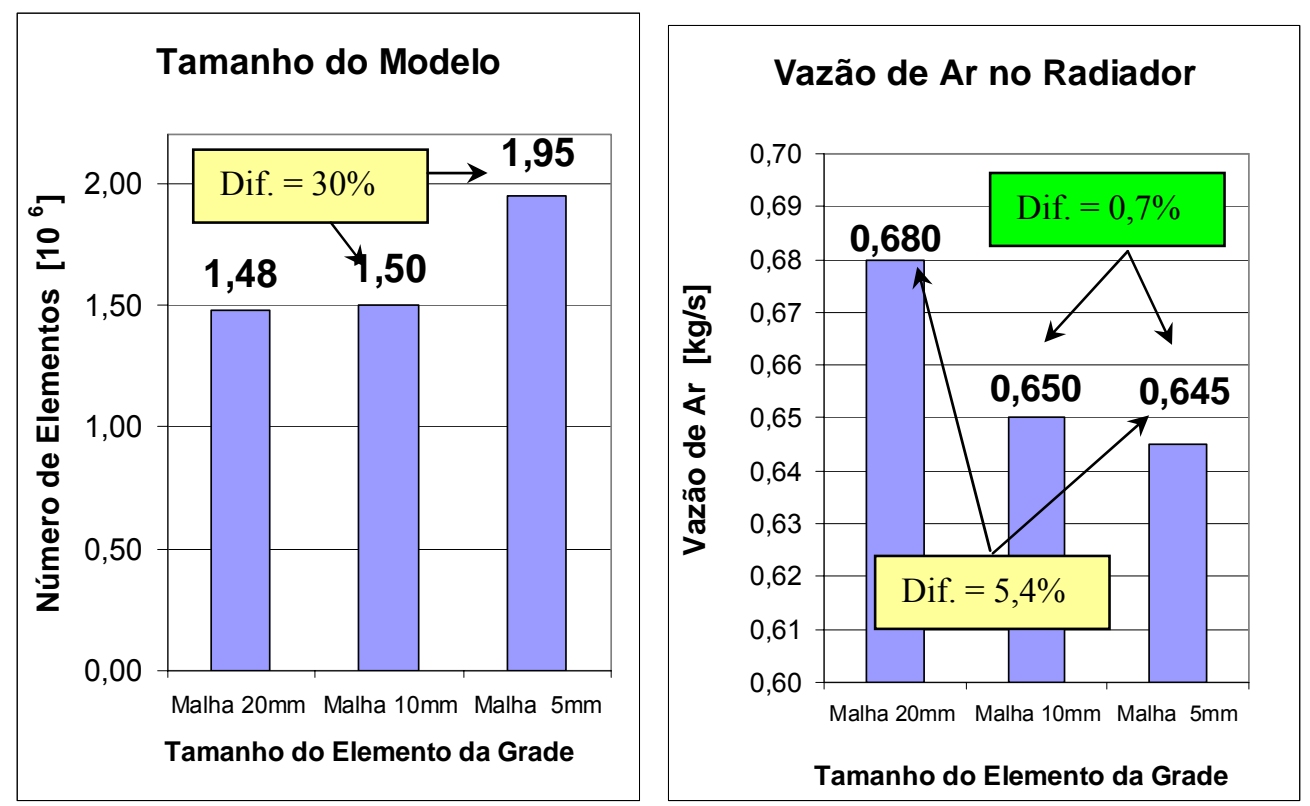

Figura 5.17 - Estudo da Influência de malha da grade no fluxo de ar no radiador. a) Tamanho do modelo. b) Vazão de ar no radiador.
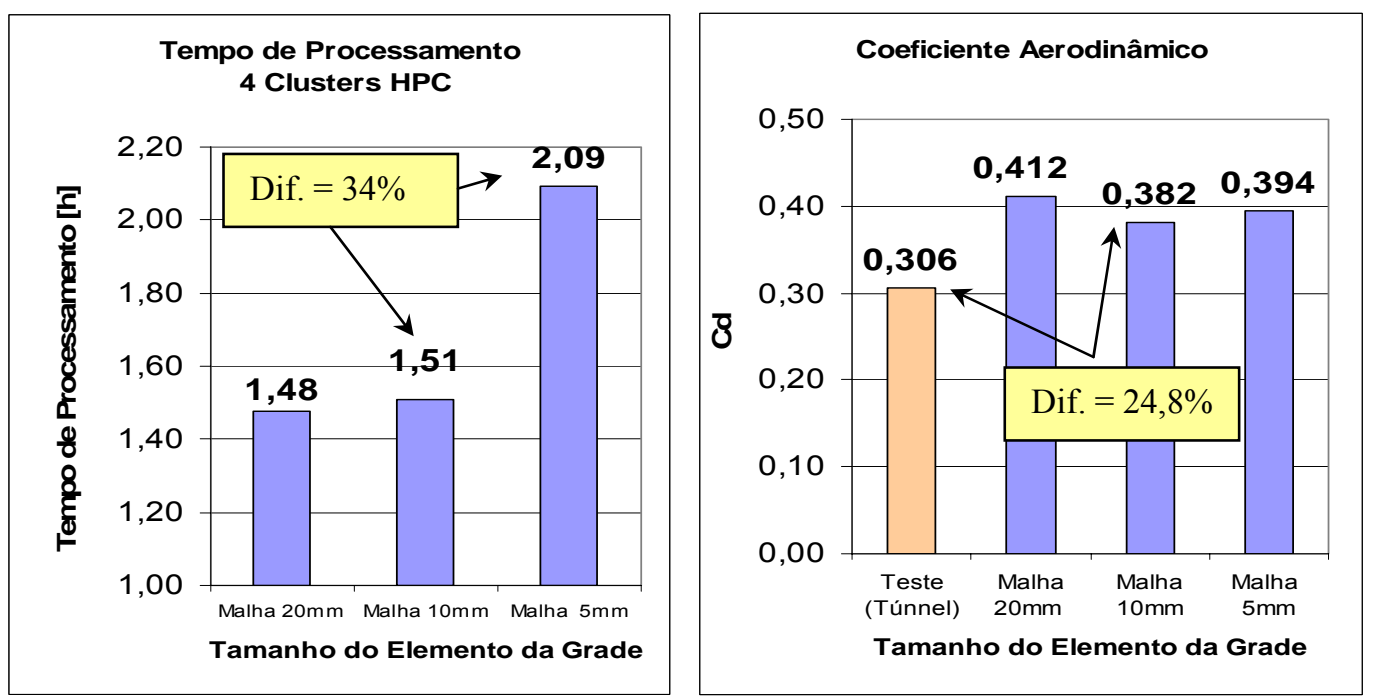

Figura 5.18 - Estudo da Influência de malha da grade no fluxo de ar no radiador. a) Tempo de processamento. b) Coeficiente aerodinâmico.

Como pode ser observado nos gráficos da figura 5.17, existe somente uma pequena diferença de $0,7 \%$ na vazão de ar no radiador entre os modelos com tamanho de elemento de malha da grade de 10 e $5 \mathrm{~mm}$. Porém, em relação ao tempo de processamento, a malha de tamanho $5 \mathrm{~mm}$ requer $34 \%$ a mais no tempo da malha de $10 \mathrm{~mm}$. 
Como este trabalho está focado na precisão dos resultados e também no tempo de resposta, podemos, assim, concluir que o modelo com a malha da grade de $10 \mathrm{~mm}$ é o mais indicado para o estudo do sistema de arrefecimento do motor.
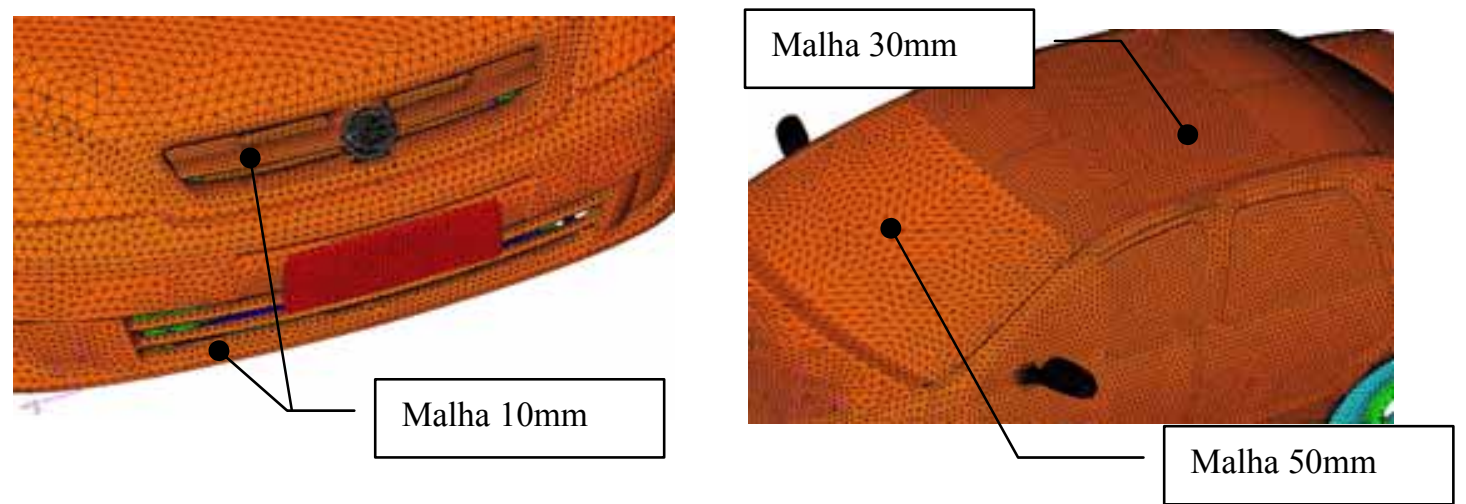

Figura 5.19 - Modelo do veículo A como refinamento de malha $10 \mathrm{~mm}$ na região da grade.

\subsubsection{Estudo da Influência de Malha Externa no Fluxo de Ar no Trocador de Calor (Veículo A)}

As discrepâncias nos resultados dos coeficientes aerodinâmicos $(\mathrm{Cd})$ podem ser atribuídas, basicamente, pelo grau de refino da malha externa do veículo influenciando assim as forças viscosas sobre o veículo.

$\mathrm{O}$ coeficiente aerodinâmico está relacionado com a força de resistência $\mathrm{F}$ do veículo.

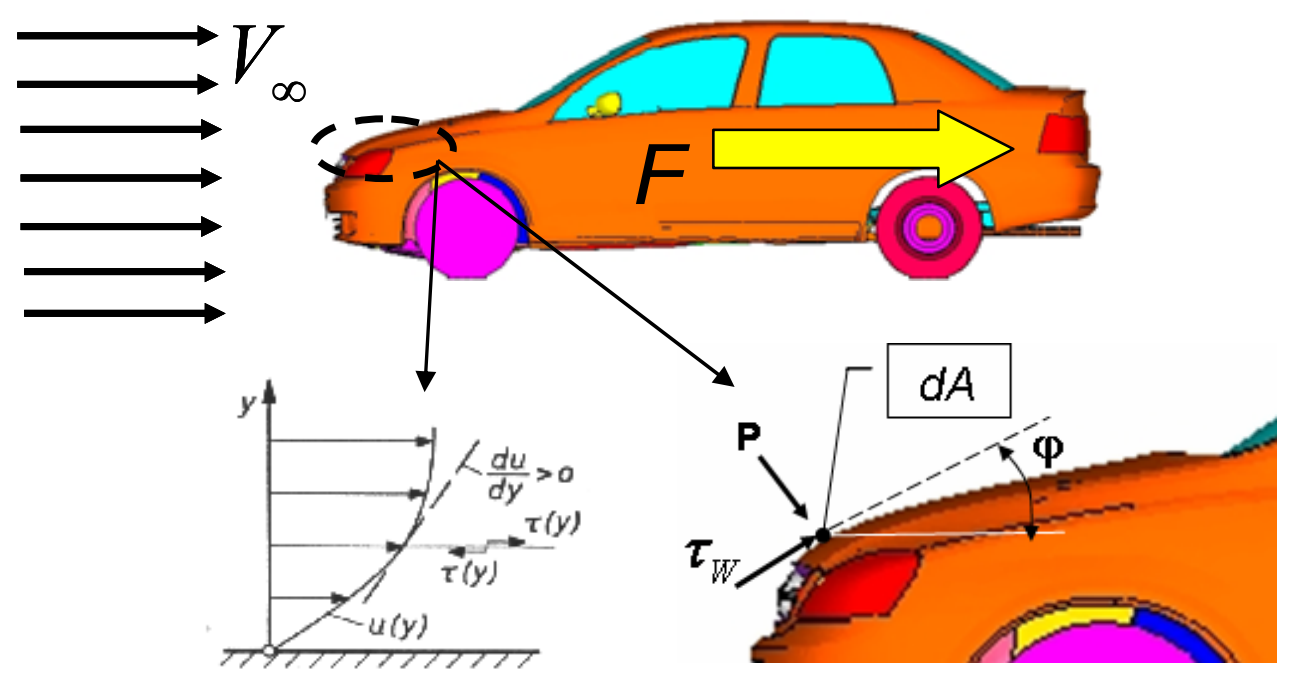

Figura 5.20 - Efeito das forças viscosas sob a superfície do veículo. 
Essa força é ocasionada devida às tensões de cisalhamento e do efeito de pressão nas regiões próximo às paredes.

$$
\begin{aligned}
& F=\int \tau_{w} \cdot \cos \varphi d A+\int p \sin \varphi d A \\
& \tau_{w}=\mu\left(\frac{\partial u}{\partial x}\right)_{w} \\
& C_{d}=\frac{F}{\frac{\rho}{2} U_{\infty}^{2} A_{f}}
\end{aligned}
$$

Como foi visto no item 3.5, a função de parede tem a finalidade de interligar a solução das variáveis da parede com as do escoamento livre e está associado aos adimensionais $u^{+}$e $y^{+}$(vide equações 3.33 e 3.34 ).

No $\boldsymbol{F L U E N \boldsymbol { T } ^ { \Theta }}$ a função de parede padrão é baseada nas propostas de Launder e Spalding (1972) em que a lei logarítmica é válida para o limite $30<y^{+}<500$.

Uma análise de sensibilidade do coeficiente aerodinâmico do modelo do "veículo A" com malha da grade de $10 \mathrm{~mm}$ mostra que a estrutura externa do veículo e as rodas têm uma grande influência no valor final do coeficiente aerodinâmico $(C d)$, como ilustra no gráfico abaixo.

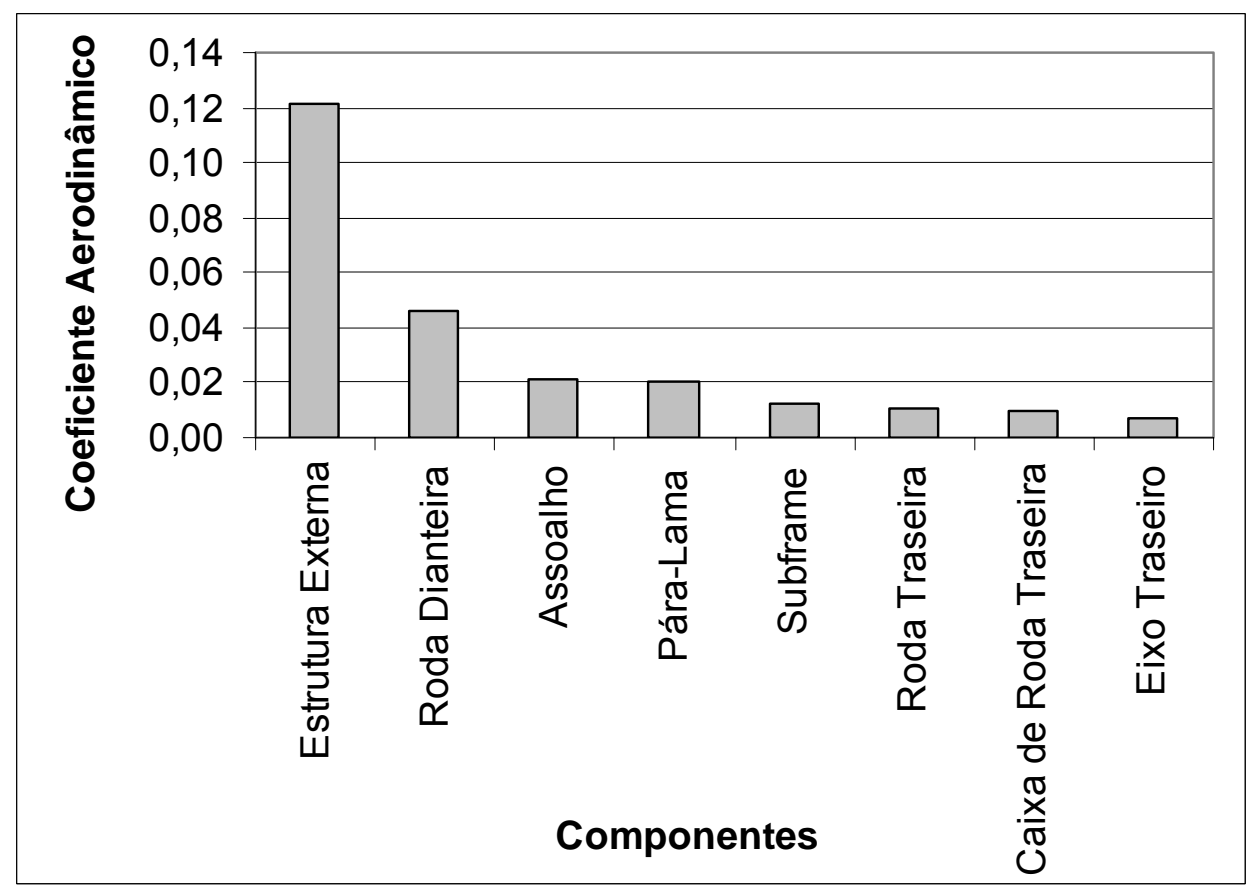

Figura 5.21 - Gráfico de contribuição dos principais componentes no coeficiente aerodinâmico 
Com base na avaliação do gráfico de contribuição do coeficiente aerodinâmico, as seguintes modificações foram consideradas:

- Refinamento somente da malha externa do veículo com redução do tamanho do elemento de 50 a $30 \mathrm{~mm}$ para 15 a $8 \mathrm{~mm}$. Cuidados foram tomados para que este refino não abrangesse as regiões das grades, pois isto poderia comprometer a base comparativa do fluxo de ar no compartimento do motor;

- Detalhamento das rodas com a inclusão da condição de parede deslizante para simular o efeito da rotação da roda.

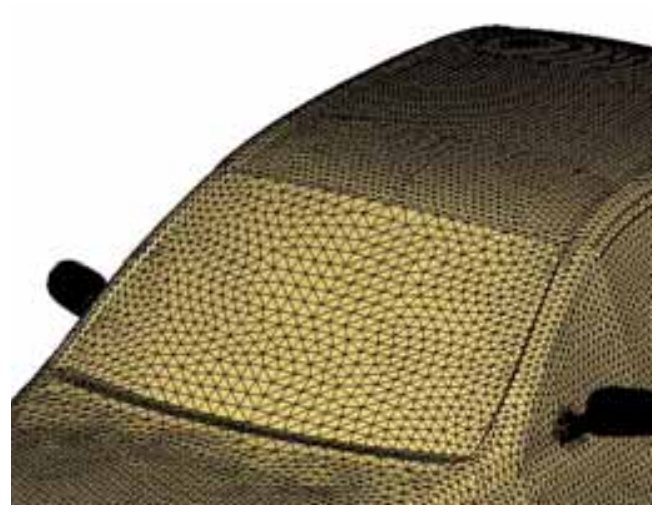

a) Modelo Inicial

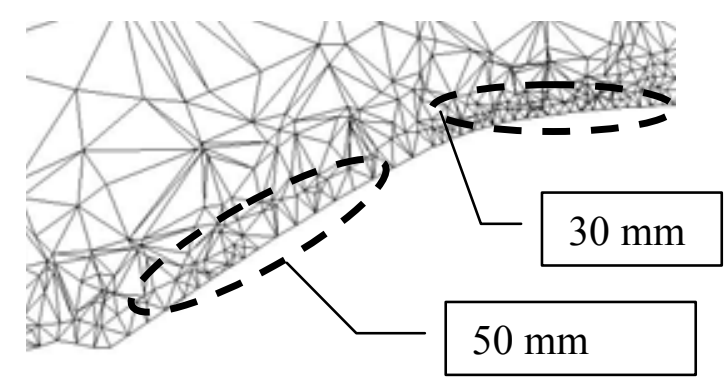

c) Modelo Inicial (Seção Longitudinal Y00).

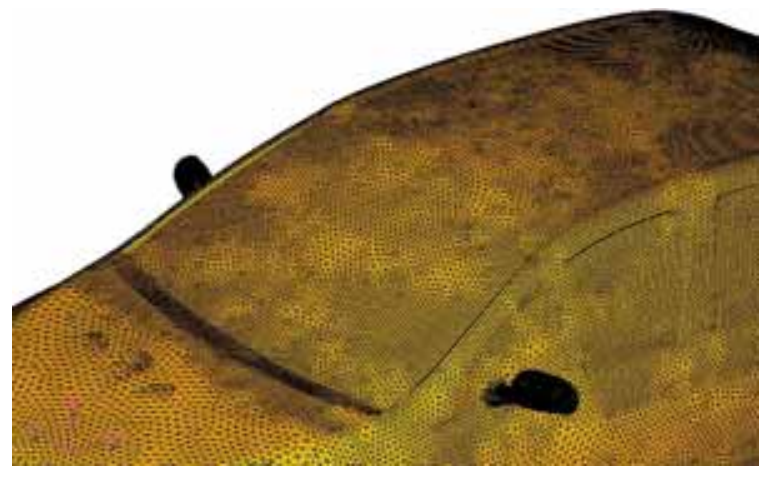

b) Modelo Refinado

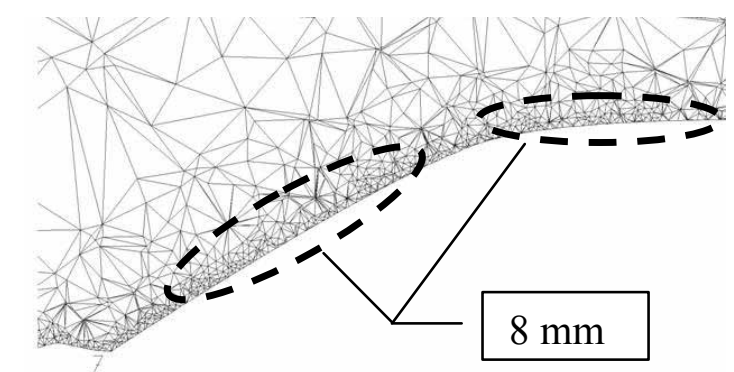

d) Modelo Refinado.

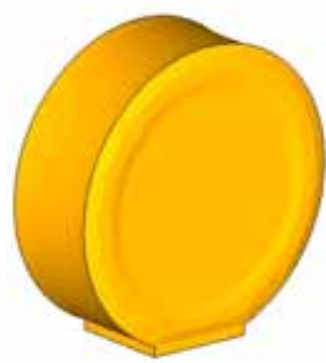

e) Modelo Inicial (Roda Simplificada).

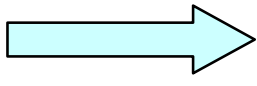

$\omega=0$

f) Modelo Refinado (Roda com Parede Deslizante)

Figura 5.22 - Refinamento da malha externa do veículo A e consideração das rodas em detalhes com a condição de parede deslizante . 


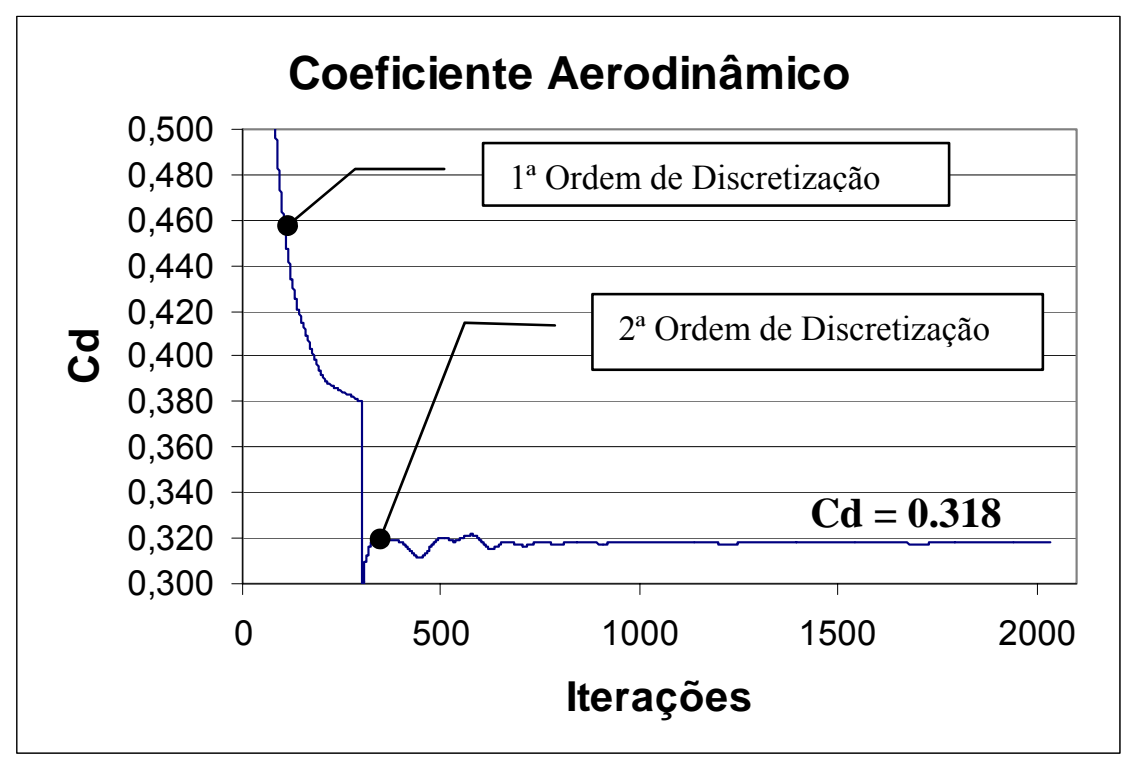

Figura 5.23 - Gráfico de convergência do coeficiente aerodinâmico para diferentes ordens de discretização.

Para garantir a convergência, inicialmente foi utilizado a discretização de primeira ordem e posteriormente alterado para a segunda ordem (ver item 4.1) como pode ser visto no gráfico de convergência da fig. 5.23.

Com a alteração da malha externa do veículo e considerando o efeito da roda em movimento, o coeficiente aerodinâmico do veículo alterou de 0,382 para 0,318 representando uma redução de $20,1 \%$ no valor total. Isso comprova a influência da camada limite no coeficiente aerodinâmico como mostra por meio da comparação do valor do adimensional $y^{+}$na figura 5.24.

Em teste em túnel de vento do veículo, o valor do coeficiente aerodinâmico obtido foi $0.306^{4}$, o que corresponde uma variação de $3.9 \%$ em relação à simulação.

Nos estudos feitos por Elofsson (2002) e Cogotti (1983) observam-se a separação do escoamento em uma roda estacionária com a formação de vórtice de ferradura, enquanto que para a roda em movimento, a formação do vórtice é localizada predominantemente na região superior. Esses efeitos foram comprovados nas simulações (figura 5.25) através de visualizações das trajetórias das partículas, com a utilização do software de pós-processamento, o EnSight ${ }^{\circledR}$. Podemos verificar através da figura 5.26 que a região do pára-choque é caracterizada pela presença da

\footnotetext{
${ }^{4} \mathrm{Cd}=0,306$ valor obtido com base nos arquivos internos da GMB.
} 
região de estagnação do ar, o que favorece o efeito do escoamento do ar para o compartimento do motor (efeito "ram").
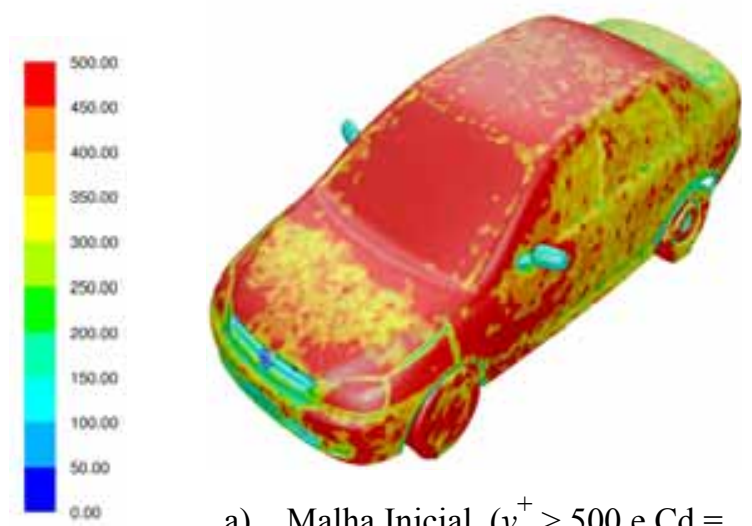

a) Malha Inicial $\left(y^{+}>500 \mathrm{e} \mathrm{Cd}=\right.$ $0,382)$.

$\mathrm{N}^{\mathrm{o}}$ de Elementos $\approx 1,5 \mathrm{E} 6$.

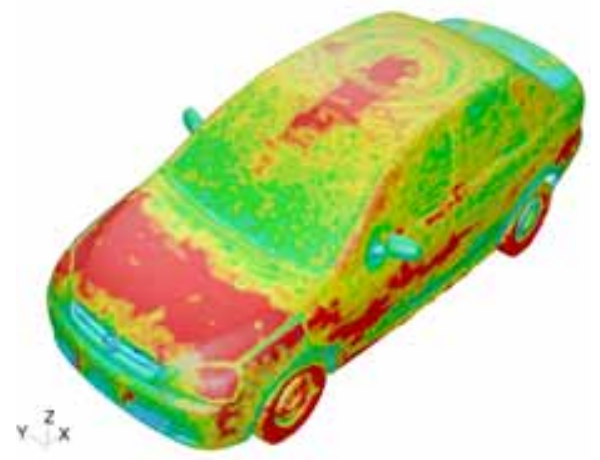

b) Malha Refinada $(\mathrm{Cd}=0,318)$.

$\mathrm{N}^{\mathrm{o}}$ de Elementos $\approx 2,55 \mathrm{E} 6$.

Cd Experimental (Túnel) $=0,306$ (Diferença $=\mathbf{3 , 9 2} \%$ )

Figura 5.24 - Contorno de $y^{+}$na superfície da carroceria do veículo.
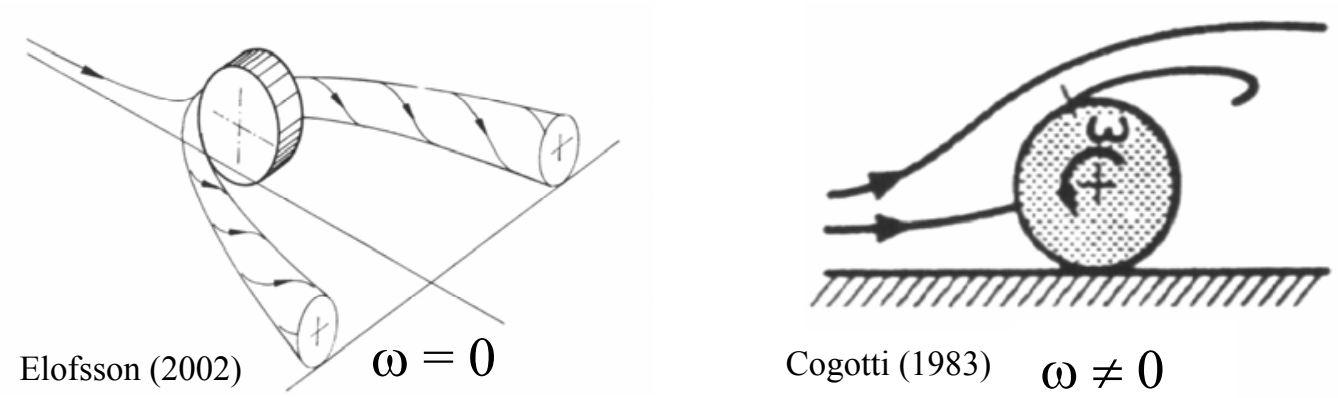

$$
\omega=0
$$

Cogotti (1983) $\quad \omega \neq 0$

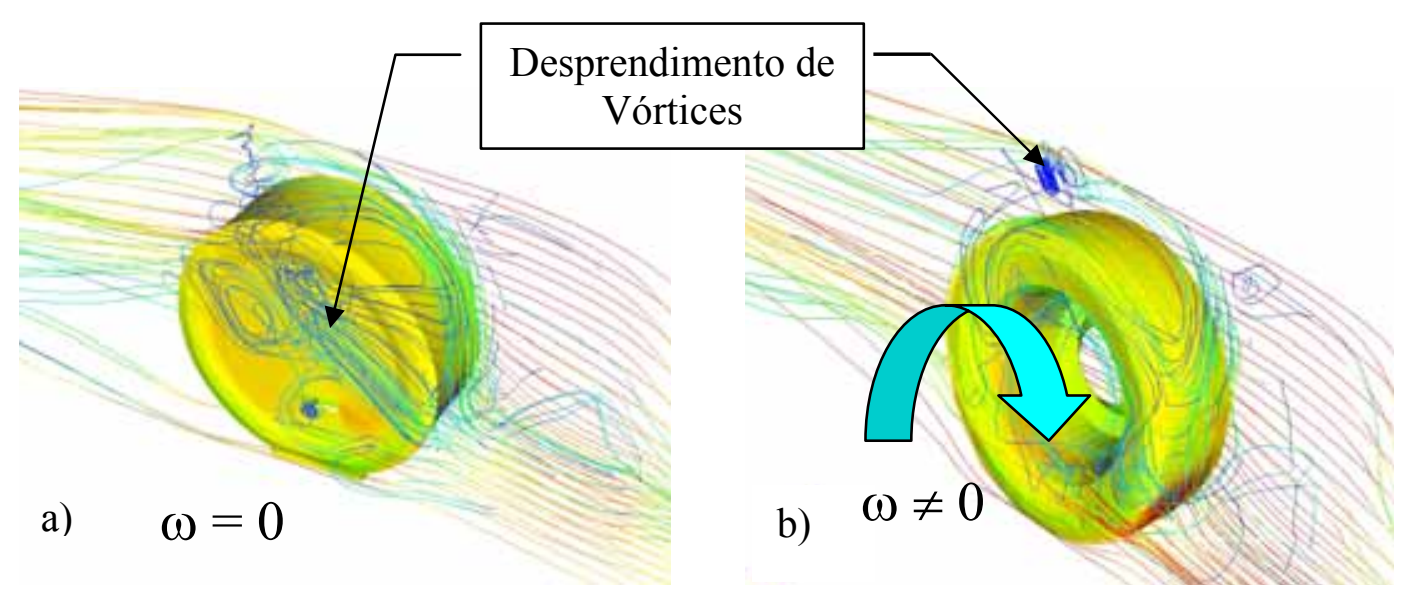

Figura 5.25 - a) Linha de corrente sob roda estacionária com formação do vórtice ferradura. b) Linha de corrente sob roda em movimento resultando o desprendimento de vórtice na região superior. 

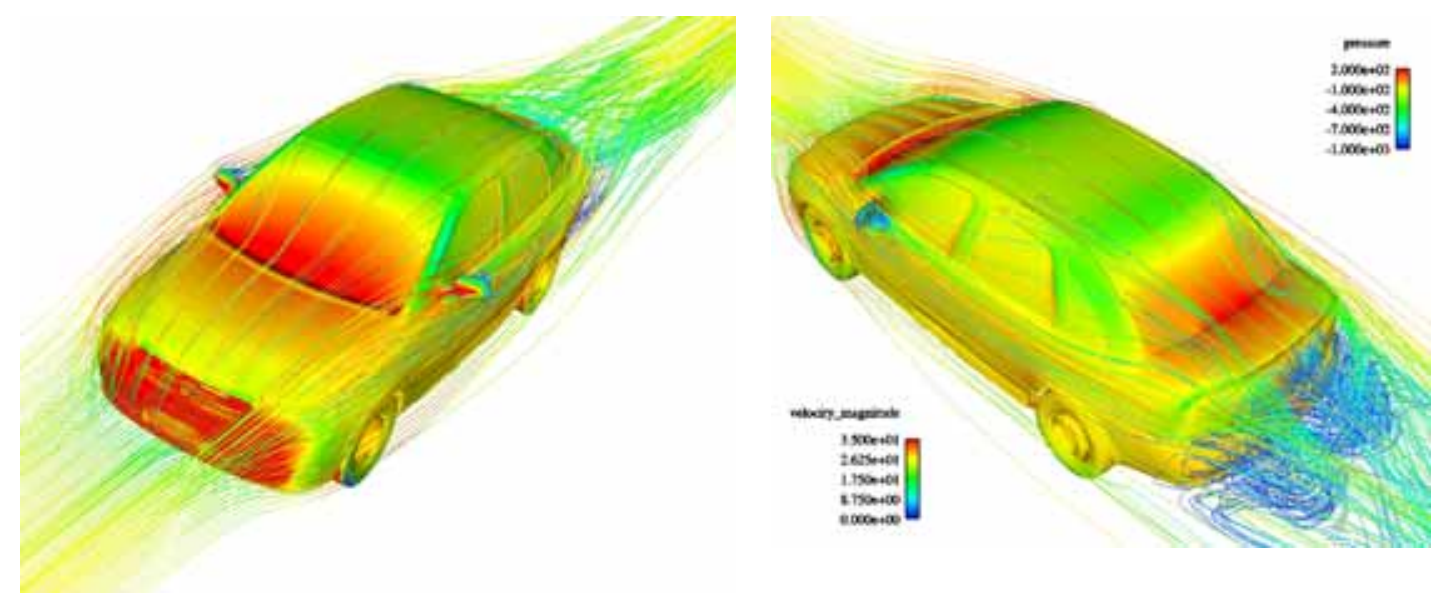

Figura 5.26 - Distribuição de pressão na superfície e linhas de corrente com contorno de velocidade no veículo completo.
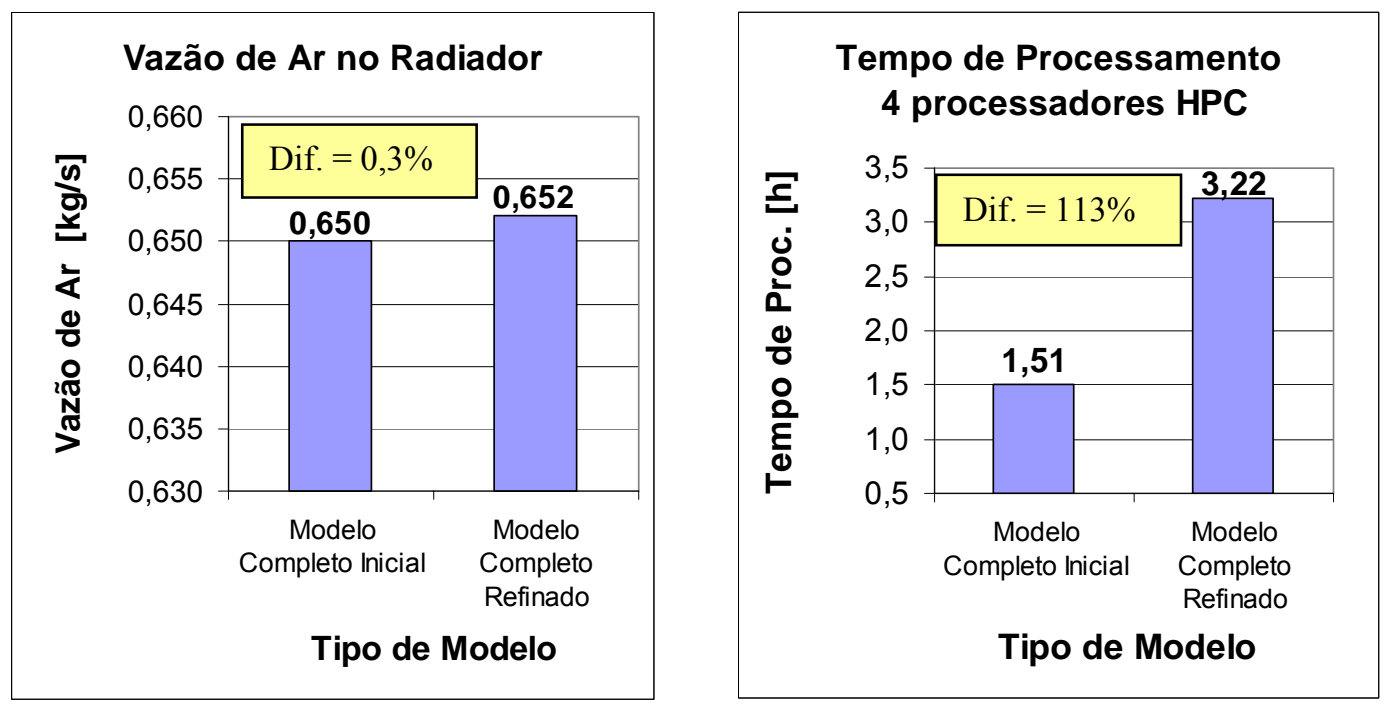

Figura 5.27 - Gráfico comparativo da vazão de ar no trocador de calor e do tempo de processamento.

Podemos observar por meio do gráfico da figura 5.27 que o refino da malha para se obter um valor de $C_{d}$ próximo ao valor de teste em túnel, não apresenta alteração significativa do valor do fluxo de ar no trocador de calor. Porém, o tempo de processamento se eleva em $113 \%$, o que não justifica a utilização desse modelo para o estudo de troca térmica do compartimento. 


\subsection{Estudo da Influência do Modelo Simplificado no Fluxo de Ar no Trocador de Calor do Veículo A}

No item anterior, a malha volumétrica do veículo A completo é da ordem de $1,5 \times 10^{6}$ elementos, a qual requer um tempo de processamento elevado de 3,22h. Nesse momento ainda não consideramos as equações de energia e as quatro condições de cargas para as simulações do sistema de arrefecimento o que implicará em ainda mais o aumento no tempo de resposta.

Simplificações podem ser feitas no modelo de modo a não comprometer a vazão de ar nos trocadores de calor, pois uma malha exageradamente refinada inviabilizará a metodologia devido ao elevado tempo e custo de processamento.

Estudos feitos por Ramesh (1998) mostram que a exclusão da região traseira do veículo (após o pilar central) não afeta o escoamento nos trocadores de calor. Como não apresentam discrepâncias significativas entre os modelos completos com e sem refino da malha externa (ver figura 5.27), podemos utilizar o modelo inicial (ver fig. 5.22a) para o estudo da simplificação com o intuito na redução do tempo de resposta.

As simplificações baseiam-se na exclusão da malha da região traseira do veículo na seção transversal, após o pilar central e dos espelhos retrovisores laterais externos, como ilustrado na figura abaixo.

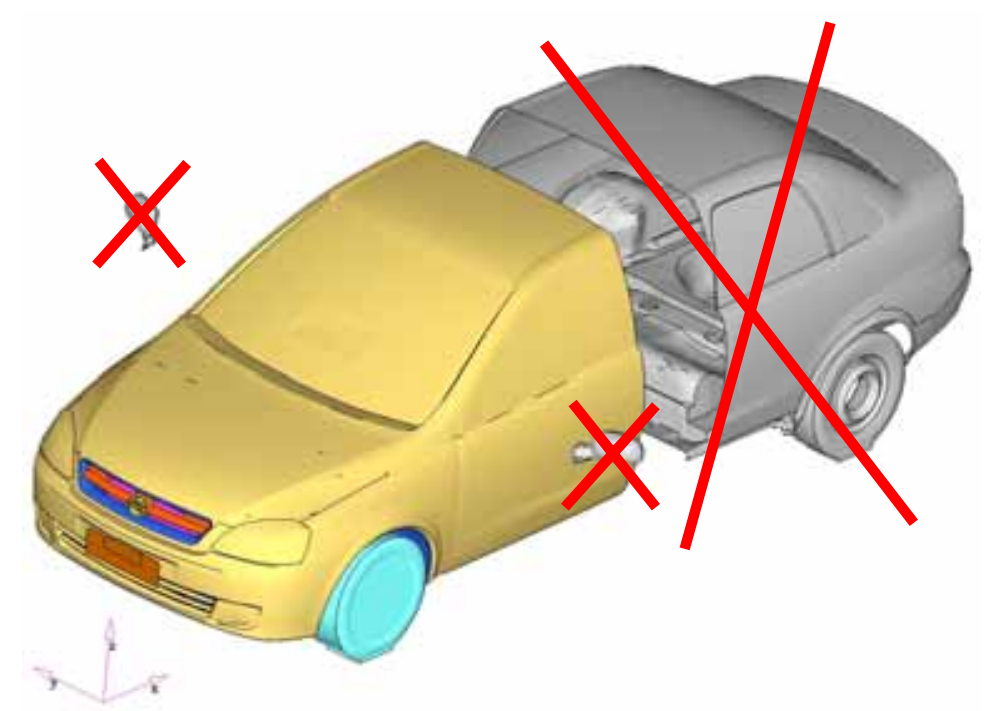

Figura 5.28 - Simplificações no modelo com a exclusão da parte traseira e os retrovisores laterais do veículo. 
O modelo parcial foi simulado com a utilização das mesmas condições de contornos aplicadas ao modelo completo como descritos no item 5.2.2.

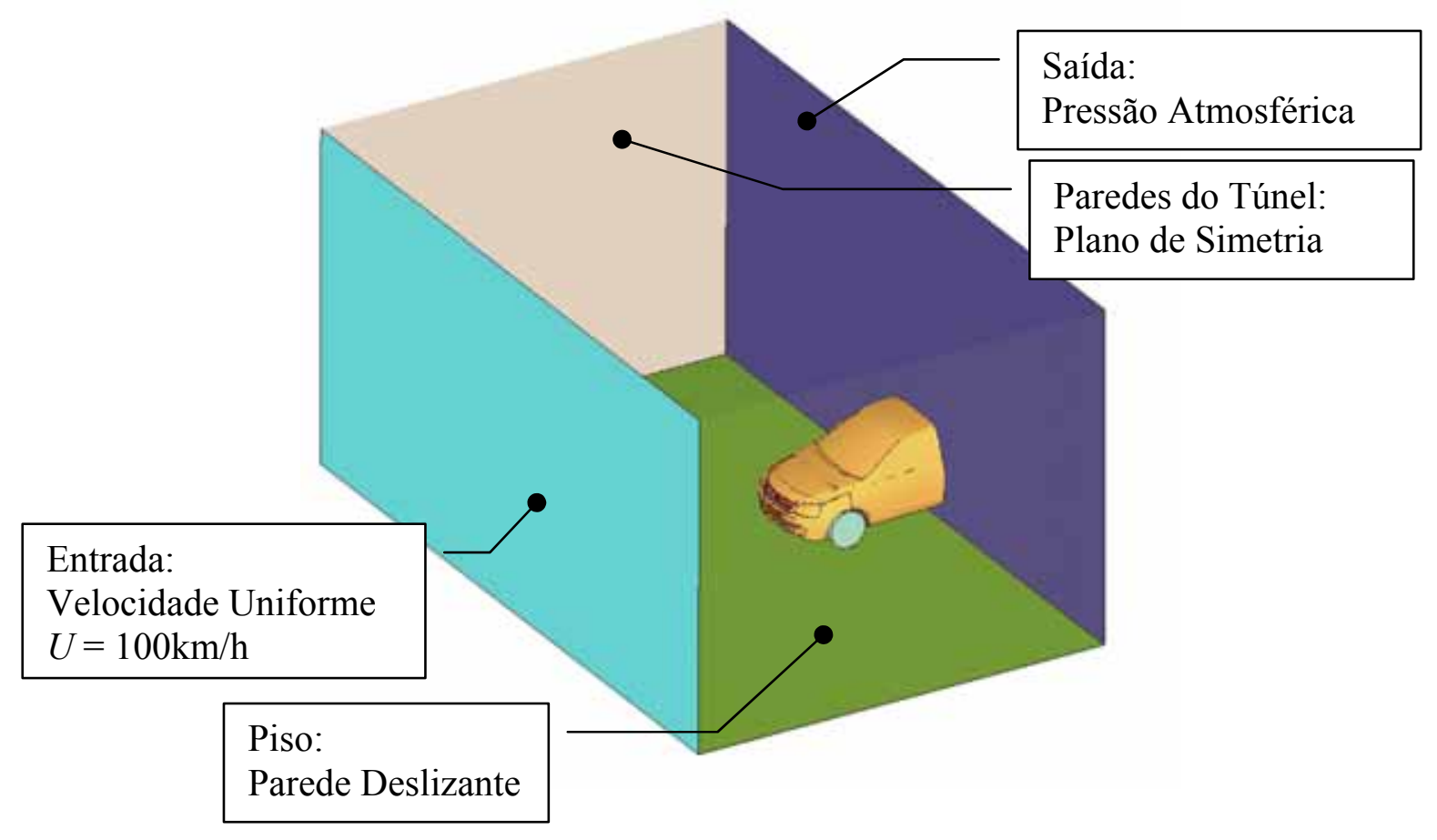

Figura 5.29 - Condições de contorno do modelo parcial simplificado.
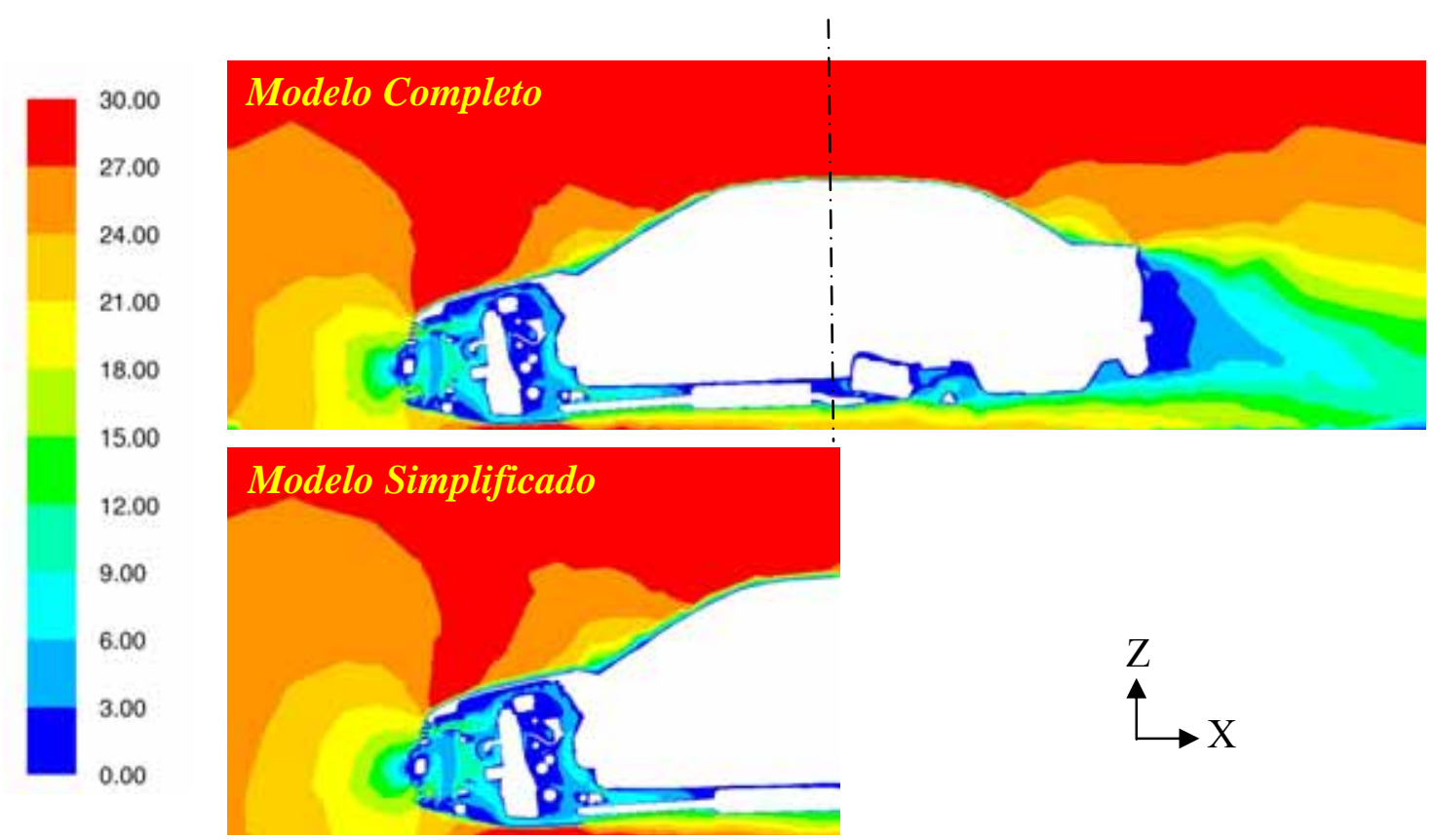

Figura 5.30 - Contorno de velocidade $[\mathrm{m} / \mathrm{s}]$ entre o modelo completo e modelo parcial (plano $\mathrm{Y}=00$ ). 

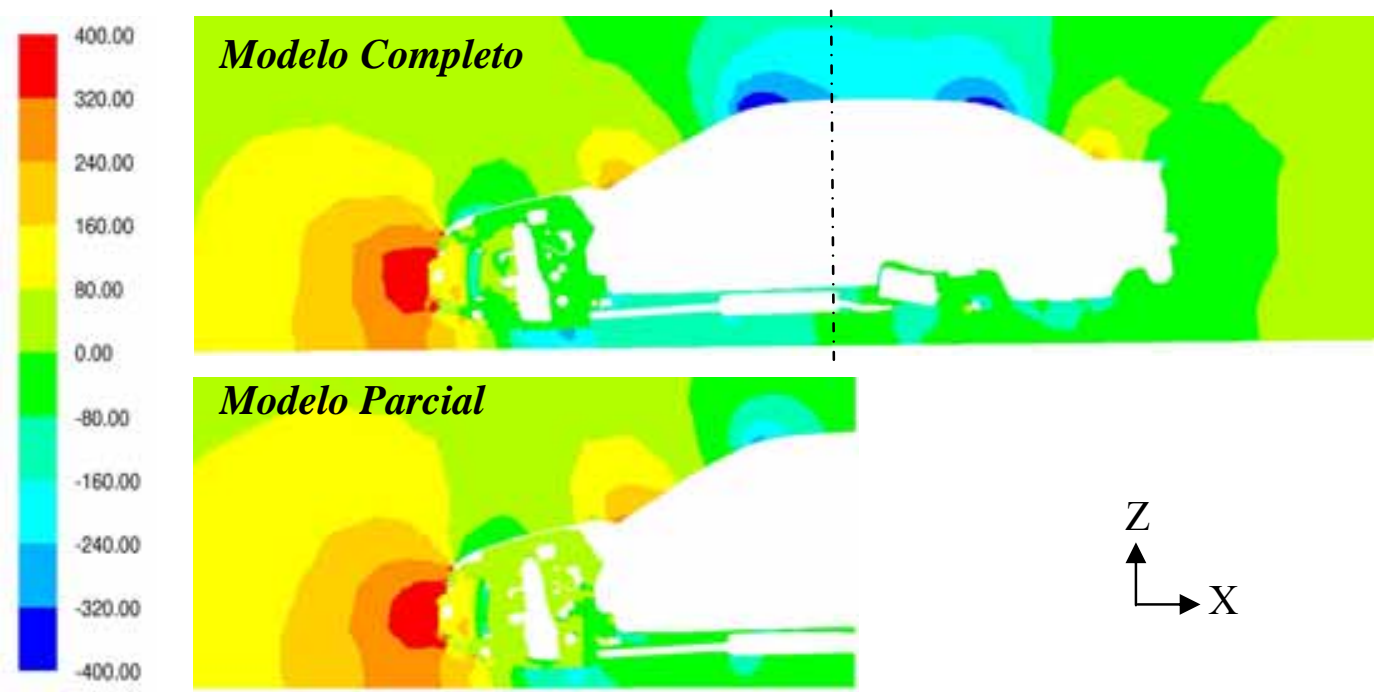

Figura 5.31 - Contorno de pressão $[\mathrm{Pa}]$ entre o modelo completo e o modelo parcial (plano $\mathrm{Y}=00$ ).

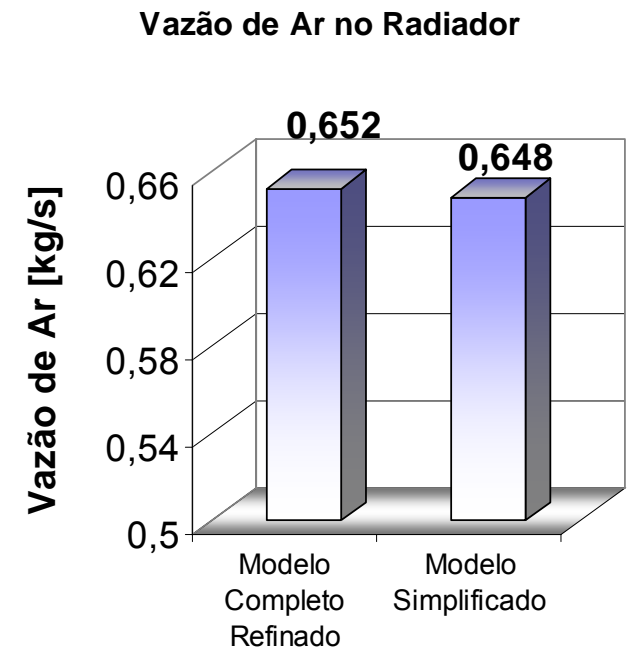

Tipos de Modelo

\section{Tempo de Processamento}

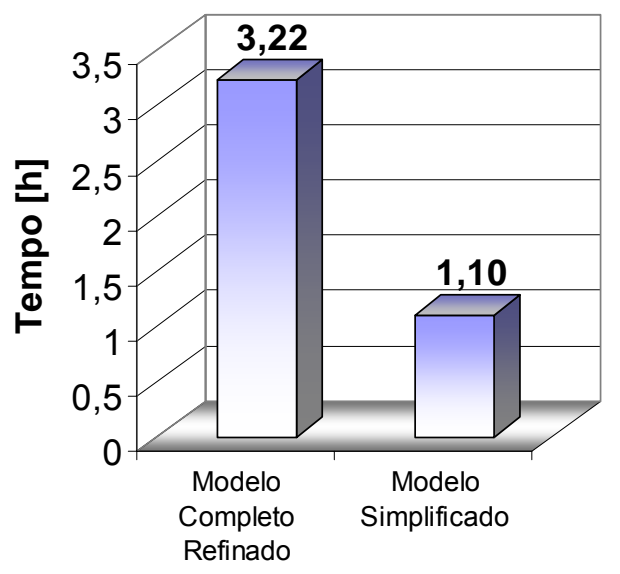

Tipos de Modelo

Diferença $=-292 \%$

Figura 5.32 - Gráfico comparativo da vazão de ar no trocador de calor e do tempo de processamento. 


\subsection{Conclusões Preliminares do Estudo de Refinamento de Malha}

Os resultados mostram que o refino da malha na região da grade altera o valor da vazão do ar no compartimento do motor, e isso pode acarretar em discrepância nos resultados da temperatura em simulações de troca térmica. Por outro lado, o refinamento da malha externa não apresenta grande contribuição na variação da vazão de ar no compartimento do motor. O refino da malha externa é importante no estudo da estabilidade do veículo, pois uma malha externa refinada permite discretizar a camada limite e, conseqüentemente, a determinação das forças viscosas perto das superfícies. Isso foi comprovado com o cálculo do coeficiente aerodinâmico obtendo uma diferença de apenas $1,2 \%$ em relação ao valor obtido em teste em túnel.

O modelo parcial simplificado apresentou uma pequena discrepância no fluxo de ar $(0,6 \%)$ em comparação ao modelo completo e refinado, o que comprovou uma similaridade com os estudos feitos por Ramesh (1998).

Em simulações do sistema de arrefecimento serão necessárias as avaliações de quatro tipos de condições de contorno. A utilização de um modelo completo é praticamente inviável, pois, como visto neste estudo, o tempo de resposta para uma determinada proposta irá consumir mais de doze horas em processamento.

A utilização do modelo parcial simplificado reduz o tempo de processamento em 292\%, sem alteração significativa do valor da vazão de ar no compartimento.

Este trabalho está focado somente na troca térmica do ar com o radiador, o qual está localizado longe da influência da camada limite das paredes. No caso de estudo de distribuição térmica nos componentes do compartimento do motor, o efeito da camada limite nos componentes internos ao compartimento, deverá ser considerado para o cálculo dos coeficientes de troca térmica. 


\section{CAPÍTULO 6}

\section{RESULTADOS}

Neste capítulo serão apresentados os resultados das simulações do sistema de arrefecimento com a inclusão do efeito térmico das equações de Navier Stokes e equação da energia, na avaliação da temperatura de entrada do líquido de arrefecimento no radiador. É através desta temperatura que se permite avaliar se um sistema de arrefecimento atende ou não os requisitos de projeto, posto que um sistema de arrefecimento ineficiente irá resultar em uma temperatura acima da operativa ocasionando a perda do líquido e superaquecimento do motor.

Inicialmente, a validação do modelo será aplicada ao "Veículo A", ou seja, o mesmo utilizado no trabalho para o estudo de simplificação de malha (vide figura 5.29). Este veículo foi testado em túnel de vento sob quatro condições distintas:

a) Veículo com carga parcial (pedal do acelerador não está acionado ao máximo), na $2^{\mathrm{a}}$ marcha e com velocidade de $20 \mathrm{~km} / \mathrm{h}$ equivalente ao transporte de um "trailer" sob uma rampa com inclinação de seis graus. Essa condição é considerada crítica devido a alto valor de rejeição térmica liberado pelo motor, porém com baixo valor de vazão de ar para a troca térmica.

b) Veículo em média velocidade $80 \mathrm{~km} / \mathrm{h}$ e com máxima aceleração. Essa condição representa a condição de máximo torque do motor.

c) Veículo em velocidade de $100 \mathrm{~km} / \mathrm{h}$ e com máxima aceleração. Essa é a condição que exige maior potência do motor.

d) Veículo em máxima velocidade $160 \mathrm{~km} / \mathrm{h}$. Essa condição representa a condição de máxima rejeição de calor do motor.

Durante a realização do teste foram monitorados os parâmetros tais como a velocidade do ar no túnel, as temperaturas do líquido de arrefecimento do radiador, 
as rotações do motor e do ventilador e as temperaturas ao longo da linha de escape. Todos estes dados servirão como condições de contornos para os modelos de CFD.

Os valores das temperaturas de entrada do líquido no radiador simulado serão confrontados com os resultados obtidos em teste em túnel.

No estudo de validação seguinte, aplica-se para um veículo de médio porte da família de "Pick-Up", o qual denominaremos como "Veículo B”. Esse veículo opera com combustível diesel, a qual requer uma alta taxa de compressão do motor e consequentemente, a liberação de uma elevada carga térmica. Para a dissipação desta energia, o veículo está equipado com três ventiladores, dois eletros-ventiladores posicionados na parte frontal do condensador e outro na parte posterior ao radiador, operando acoplada à árvore de manivela do motor.

Para atender às legislações ambientais, este veículo foi equipado com um trocador de ar comumente denominado de CAC "Charge Air Cooler", que tem a função de resfriar o ar de admissão em alta pressão direcionado para o bloco do motor. Desta forma, isto elevará a eficiência do motor e, consequentemente, a redução do nível de emissões do gás poluente devido a uma queima completa do combustível.

No caso de um veículo diesel somente três condições críticas serão necessárias para avaliar o sistema de arrefecimento.

a) Veículo em máximo torque;

b) Veículo em média velocidade e máxima aceleração;

c) Veículo em máxima potência.

Para a validação da metodologia foi utilizado um terceiro veículo de médio porte, denominado aqui de "Veículo C". Este veículo utiliza o mesmo motor e transmissão do "Veículo A", porém com um sistema de arrefecimento completamente distinto. As mesmas rejeições térmicas do veículo A foram aplicadas no "Veículo C". No caso do "Veículo C", os resultados foram comparados com testes feitos em pista circular no Campo de Prova da General Motors do Brasil, situado em Indaiatuba SP. 
Conforme já foi mencionado em capítulos anteriores, os procedimentos em simulações utilizaram diferentes tipos de softwares, como ilustrado no fluxo de atividades da figura abaixo.

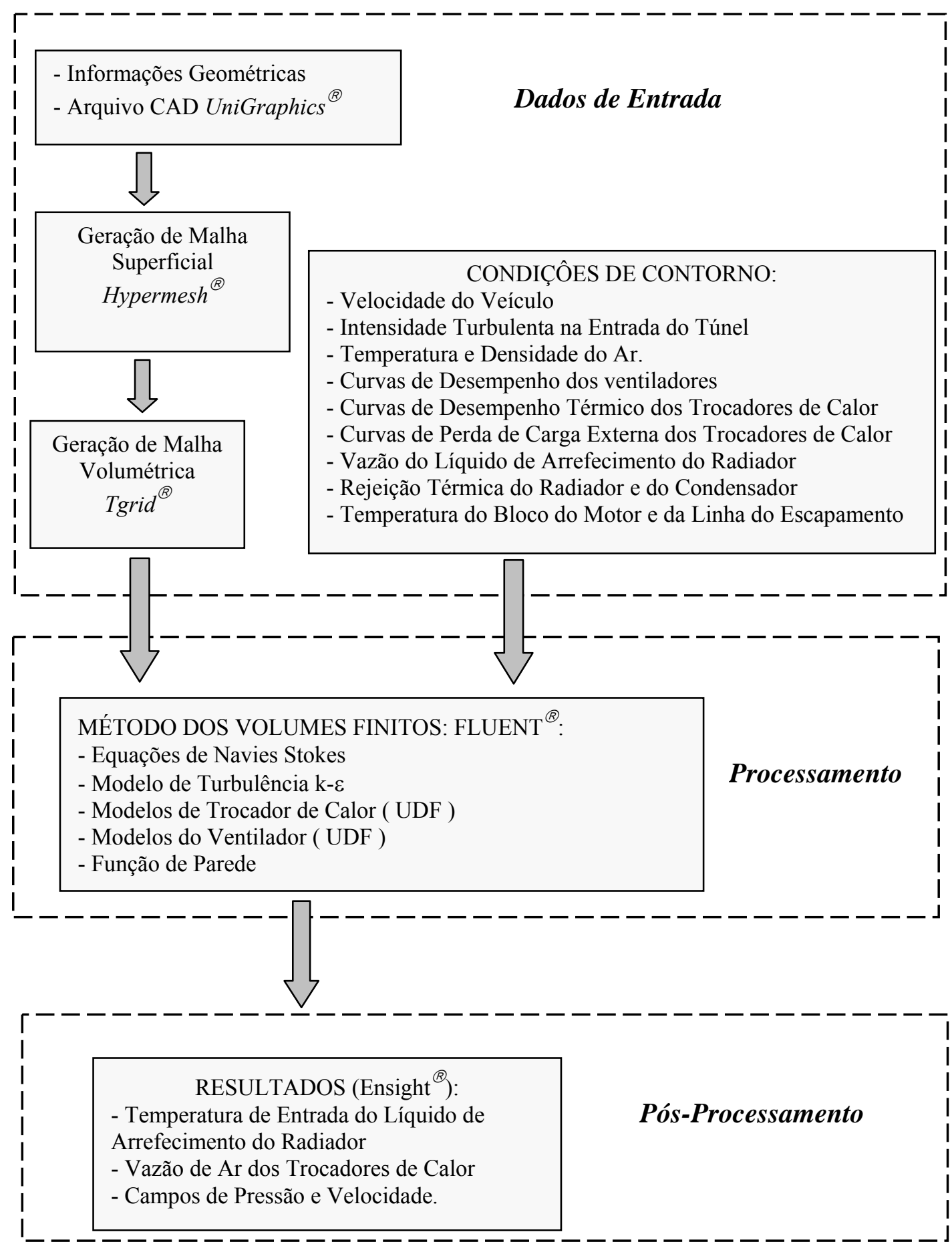

Figura 6.1 - Procedimento de Simulação CFD. 


\subsection{Validação do Veículo A.}

Para a validação do veículo A foi utilizado o mesmo veículo do estudo de refino de malha do item 5.3 como mostrado na figura 5.29. Este veículo apresenta o módulo de arrefecimento composto por um eletro-ventilador de $300 \mathrm{~W}$ de potência, que "puxa" o ar através dos trocadores de calor, como ilustrado na vista explodida da figura 6.3. Este módulo apresenta também os direcionadores de ar para evitar que o ar frio (essencial para a troca térmica) escoe através das regiões de baixa perda de carga.

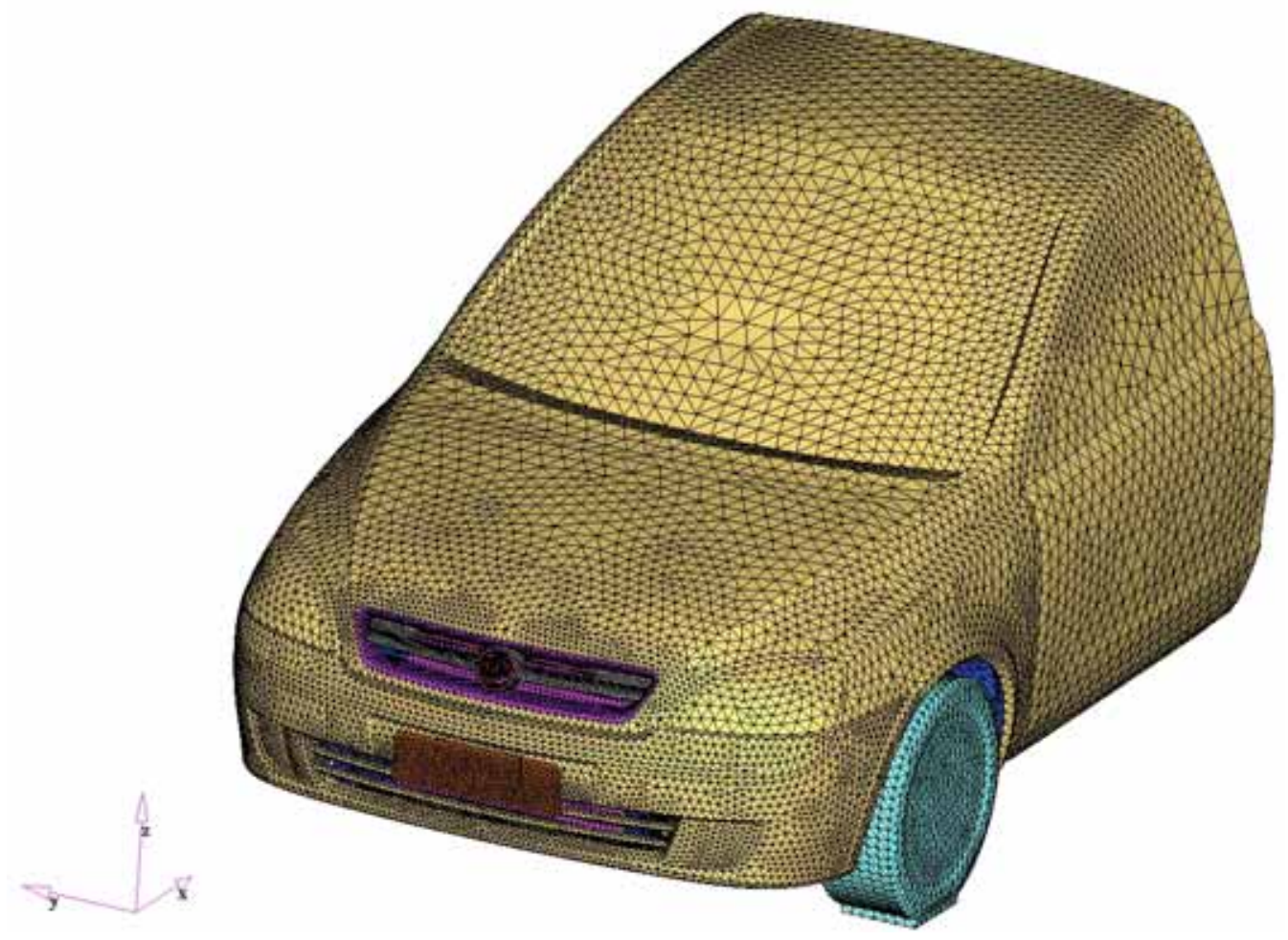

Figura 6.2 - Modelo do Veículo A. 


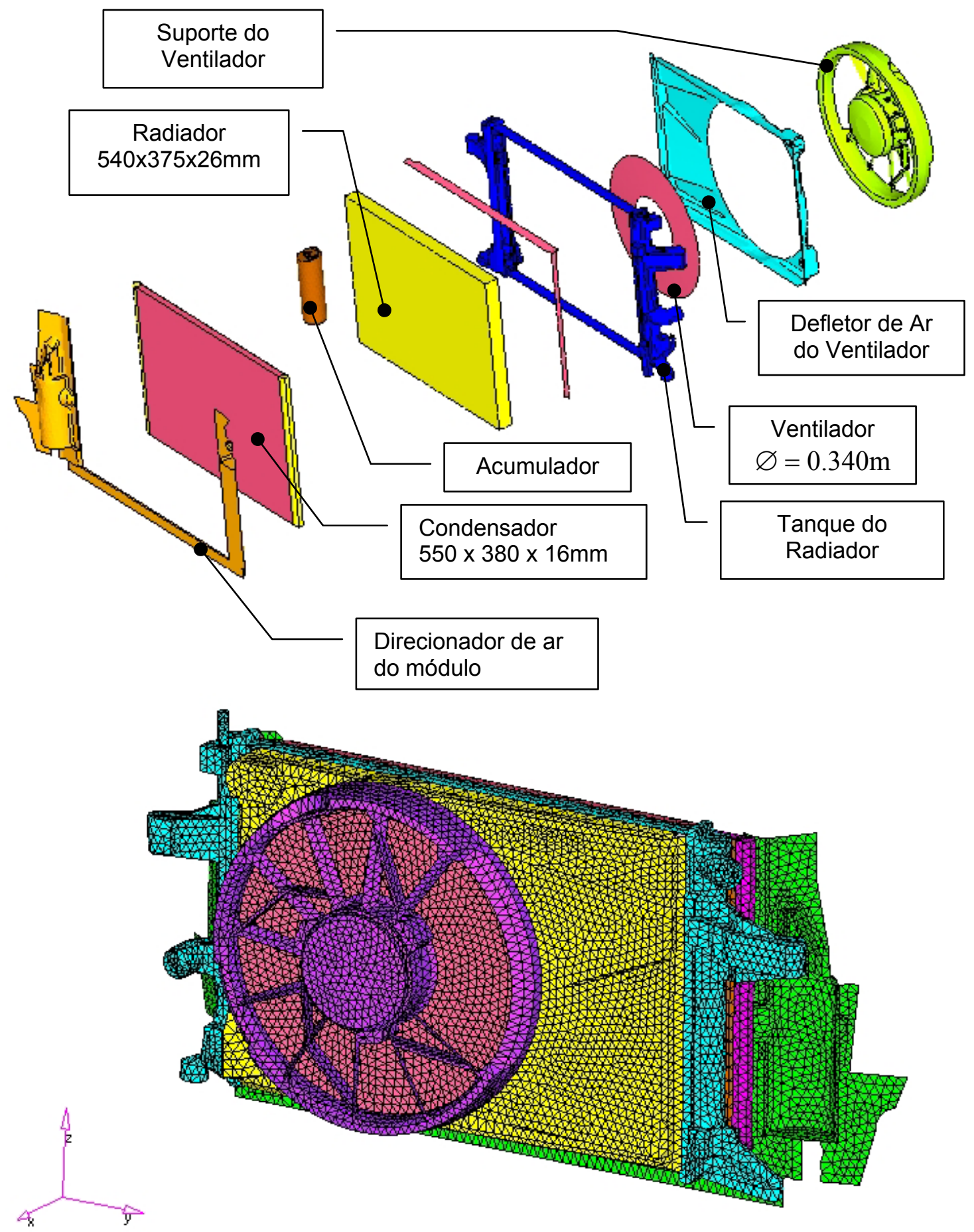

Figura 6.3 - Sistema de Arrefecimento do Modelo A

As condições de contorno do veículo foram obtidas com base nos testes do sistema de arrefecimento em túnel de vento da GMNA para a certificação do veículo. Os dados foram coletados com o veículo na condição de regime permanente para as quatro condições consideradas críticas para o sistema de arrefecimento. 
Tabela 6.1 - Dados obtidos em túnel de vento e utilizado como condições de contorno no modelo CFD do veículo A.

\begin{tabular}{|c|c|c|c|c|c|c|}
\cline { 4 - 7 } \multicolumn{2}{|c}{} & $20 \mathrm{~km} / \mathrm{h}$ & $80 \mathrm{~km} / \mathrm{h}$ & $100 \mathrm{~km} / \mathrm{h}$ & $160 \mathrm{~km} / \mathrm{h}$ \\
\hline Carga & Unidade & Incerteza & $6 \%$ Rampa & Max.Torque. & Max.Acel. & Max.Veloc. \\
\hline Marcha & - & - & $2^{\mathrm{a}}$ & $4^{\mathrm{a}}$ & $4^{\mathrm{a}}$ & $5^{\mathrm{a}}$ \\
\hline Tipo de Freon & - & - & $134-\mathrm{A}$ & $134-\mathrm{A}$ & $134-\mathrm{A}$ & $134-\mathrm{A}$ \\
\hline Radiação Solar & - & - & Ligada & Ligada & Ligada & Ligada \\
\hline Temp. Ambiente & ${ }^{\circ} \mathrm{C}$ & $\pm 0,4$ & 37,9 & 37,8 & 37,9 & 37,8 \\
\hline Velocidade do Veículo & $\mathrm{km} / \mathrm{h}$ & \pm 1 & 20,0 & 81,3 & 100,3 & 139,4 \\
\hline Torque do Dinamometro & $\mathrm{N} . \mathrm{m}$ & \pm 5 & 686 & 777 & 701 & 488 \\
\hline Rotação do Motor & $\mathrm{rpm}$ & \pm 10 & 1510 & 2951 & 3623 & 4008 \\
\hline Rotação do Ventilador & $\mathrm{rpm}$ & \pm 10 & 2945 & 2954 & 2960 & 2966 \\
\hline $\begin{array}{c}\text { Vazão do Líquido de Arref. do } \\
\text { Radiador }\end{array}$ & $\mathrm{I} / \mathrm{min}$ & $\pm 0,5$ & 27,5 & 55,0 & 67,5 & 74,0 \\
\hline $\begin{array}{c}\text { Rotação do Compressor } \\
\text { Pressão na Entrada do } \\
\text { Compressor - P1 }\end{array}$ & $\mathrm{rpm}$ & \pm 10 & 2040 & 3991 & 4900 & 5423 \\
\hline $\begin{array}{c}\text { Temperatura na Entrada do } \\
\text { Compressor - T1 }\end{array}$ & ${ }^{\circ} \mathrm{C}$ & $\pm 0,8$ & 24,5 & 19,5 & 19,2 & 19,4 \\
\hline $\begin{array}{c}\text { Pressão na Saída do } \\
\text { Compressor - P2 }\end{array}$ & $\mathrm{kPa}$ & \pm 2 & 2188 & 1833 & 1802 & 1691 \\
\hline $\begin{array}{c}\text { Temperatura na Saída do } \\
\text { Compressor - T2 }\end{array}$ & ${ }^{\circ} \mathrm{C}$ & $\pm 0,8$ & 139,0 & 126,1 & 127,4 & 127,6 \\
\hline $\begin{array}{c}\text { Pressão na Entrada do } \\
\text { Condensador - P3 }\end{array}$ & $\mathrm{kPa}$ & \pm 2 & 2162 & 1797 & 1761 & 1646 \\
\hline $\begin{array}{c}\text { Temperatura na Entrada do } \\
\text { Condensador - T3 }\end{array}$ & ${ }^{\circ} \mathrm{C}$ & $\pm 0,8$ & 137,0 & 125,0 & 126,4 & 124,1 \\
\hline $\begin{array}{c}\text { Pressão na Saída do } \\
\text { Condensador - P4 }\end{array}$ & $\mathrm{kPa}$ & \pm 2 & 2114 & 1739 & 1703 & 1584 \\
\hline $\begin{array}{c}\text { Temperatura na Saída do } \\
\text { Condensador - T4 }\end{array}$ & ${ }^{\circ} \mathrm{C}$ & $\pm 0,8$ & 62,7 & 50,2 & 49,0 & 47,0 \\
\hline $\begin{array}{c}\text { Pressão na Saída do } \\
\text { Evaporador - P6 }\end{array}$ & $\mathrm{kPa}$ & \pm 2 & 338 & 243 & 234 & 228 \\
\hline $\begin{array}{c}\text { Temperatura na Saída do } \\
\text { Evaporador - T6 }\end{array}$ & ${ }^{\circ} \mathrm{C}$ & $\pm 0,8$ & 17,4 & 8,7 & 7,7 & 6,9 \\
\hline
\end{tabular}

Os pontos 1 a 6 da fig. 6.4 representam os pontos do circuito de refrigeração do sistema de ar condicionado do veículo A. Desta forma, podemos determinar a rejeição térmica do condensador através da equação 1.3 nos pontos 3 e 4 . 

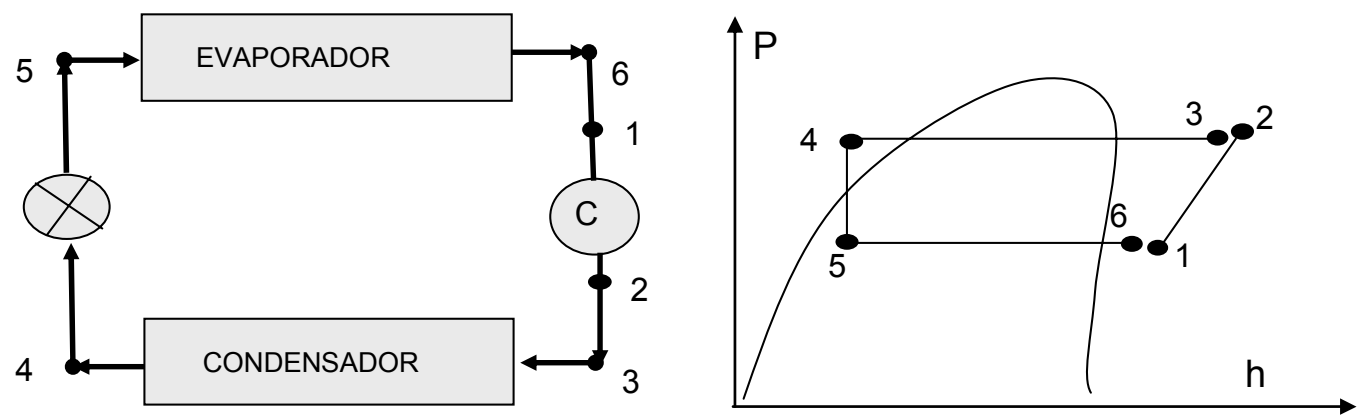

Figura 6.4 - Pontos instrumentados do circuito de refrigeração do veículo A.

Para a determinação da rejeição térmica do condensador foi utilizado o diagrama do freon R134a anexo no apêndice B.

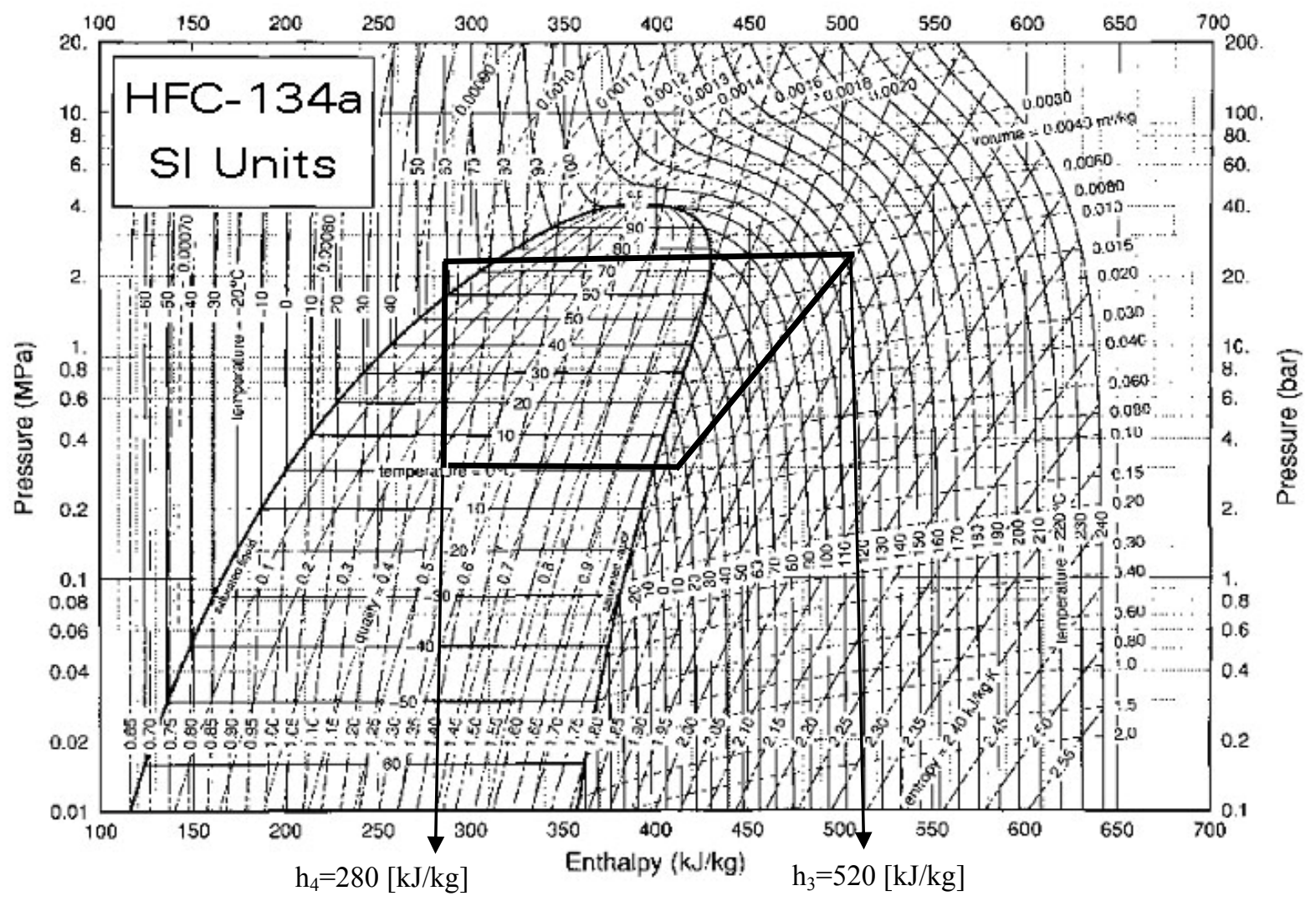

Figura 6.5 - Diagrama R134a para o cálculo da carga térmica do condensador na condição de $20 \mathrm{~km} / \mathrm{h}$.

A carga térmica do condensador a $20 \mathrm{~km} / \mathrm{h}$ é dada por:

$Q_{c}=\dot{m}_{r} .\left(h_{3}-h_{4}\right)=0,03 \cdot(520-280)$

$Q_{c}=7,2 \mathrm{~kW}$ 
Aplicando a equação (1.3) para todos os casos de carregamento têm-se os valores de rejeição térmica do condensador, como mostrado na tabela abaixo.

Tabela 6.2 - Cálculo da Rejeição Térmica do Condensador do Veículo A.

\begin{tabular}{|c|c|c|c|c|c|}
\cline { 2 - 6 } \multicolumn{1}{c|}{} & Unidade & $20 \mathrm{~km} / \mathrm{h}$ & $80 \mathrm{~km} / \mathrm{h}$ & $100 \mathrm{~km} / \mathrm{h}$ & $160 \mathrm{~km} / \mathrm{h}$ \\
\hline$h_{3}$ & $\mathrm{~kJ} / \mathrm{kg}$ & 490 & 500 & 501 & 495 \\
\hline$h_{4}$ & $\mathrm{~kJ} / \mathrm{kg}$ & 250 & 270 & 275 & 258 \\
\hline$\Delta h$ & $\mathrm{~kJ} / \mathrm{kg}$ & 240 & 230 & 226 & 237 \\
\hline$\dot{m}_{r}$ & $\mathrm{~kg} / \mathrm{s}$ & 0,03 & 0,03 & 0,03 & 0,03 \\
\hline$\dot{Q} c$ & $\mathrm{~kW}$ & 7,2 & 6,9 & 6,8 & 7,1 \\
\hline
\end{tabular}

As rejeições térmicas do radiador foram calculadas a partir de dados de túnel, com a utilização da seguinte equação:

$$
\dot{Q}_{r}=\dot{m}_{r} \cdot c p \cdot \Delta T
$$

Onde o valor do calor específico do fluido de arrefecimento do radiador foi obtido com base na curva do "apêndice B" para solução com 50\% de etilenoglicol.

Tabela 6.3 - Cálculo da Rejeição Térmica do Radiador do Veículo A.

\begin{tabular}{|c|c|c|c|c|c|}
\cline { 2 - 6 } \multicolumn{2}{|c|}{} & $20 \mathrm{~km} / \mathrm{h}$ & $80 \mathrm{~km} / \mathrm{h}$ & $100 \mathrm{~km} / \mathrm{h}$ & $160 \mathrm{~km} / \mathrm{h}$ \\
\hline $\begin{array}{c}\text { Diferencial de Temperatura do } \\
\text { Líquido de Arrefecimento do } \\
\text { Radiador } \Delta T\end{array}$ & ${ }^{\circ} \mathrm{C}$ & 6,5 & 6,3 & 5,9 & 5,9 \\
\hline $\begin{array}{c}c_{p} \text { do Fluido de Arrefecimento } \\
\left(110^{\circ} \mathrm{C}\right)^{*}\end{array}$ & $\mathrm{~J} / \mathrm{kg} . \mathrm{K}$ & 3625 & 3625 & 3625 & 3625 \\
\hline$\dot{Q}_{r}$ & $\mathrm{~kW}$ & 11,6 & 22,7 & 26,0 & 28,5 \\
\hline
\end{tabular}

(*) Ver tabela do "Apêndice A" (solução com 50\% Etilenoglicol). 
As simulações consideram também, as fontes térmicas provenientes do bloco do motor e da linha de escapamento, para o efeito da convecção forçada do ar dentro do compartimento do motor. As temperaturas médias foram obtidas em testes físicos, através de termopares instalados ao longo da linha, como mostra na figura abaixo.

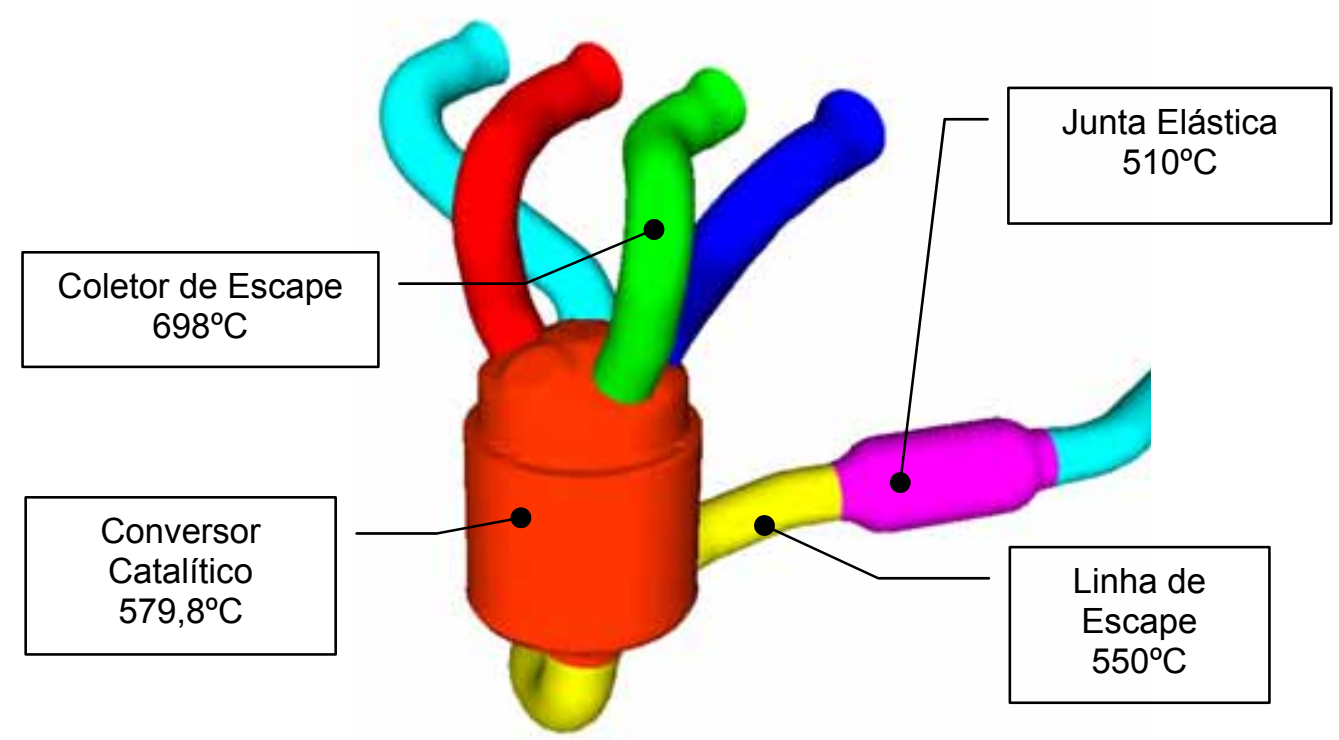

Figura 6.6 - Distribuição térmica da linha de escapamento obtido em teste físico.

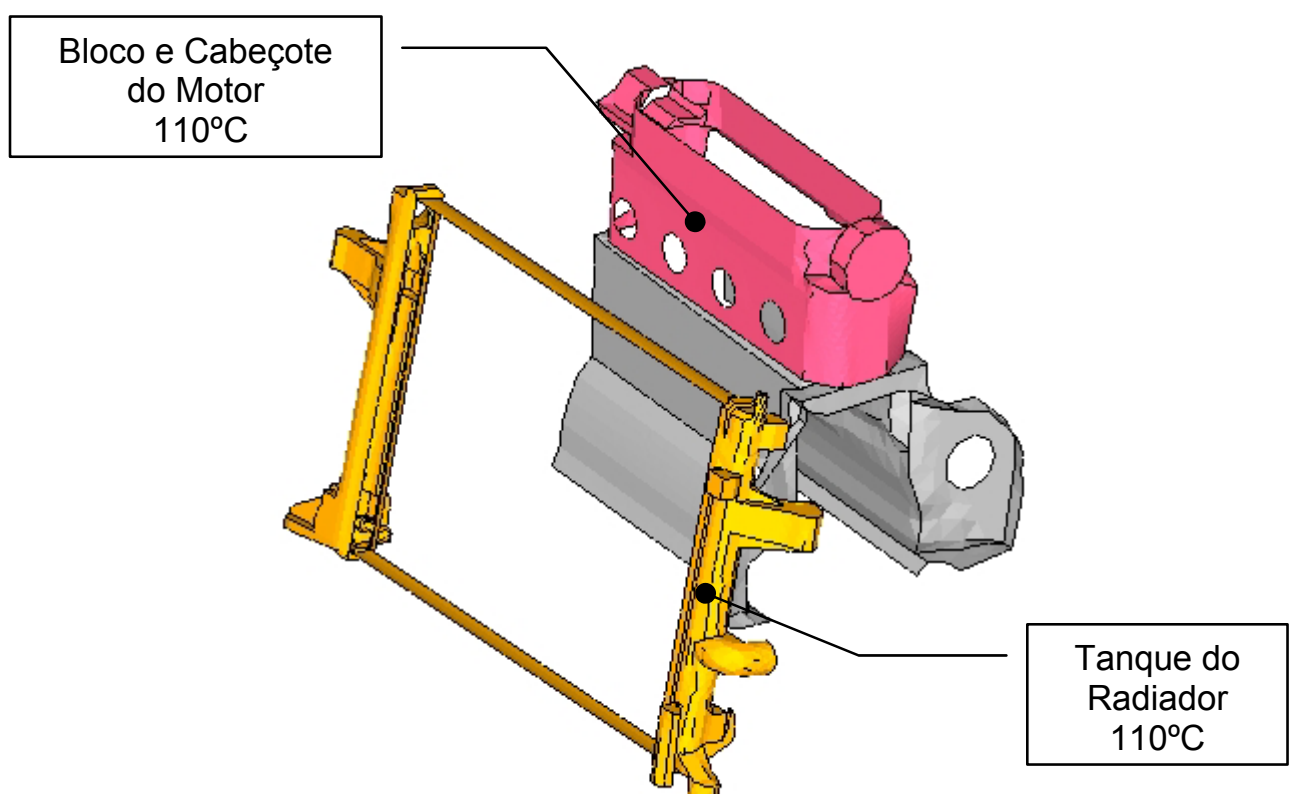

Figura 6.7 - Distribuição térmica do bloco do motor obtido em teste físico. 
Tabela 64 - Resultados da Simulação do Veículo A.

\begin{tabular}{|c|c|c|c|c|}
\cline { 2 - 5 } \multicolumn{1}{c|}{} & $20 \mathrm{~km} / \mathrm{h}$ & $80 \mathrm{~km} / \mathrm{h}$ & $100 \mathrm{~km} / \mathrm{h}$ & $160 \mathrm{~km} / \mathrm{h}$ \\
\hline Vazão de Ar no Radiador [kg/s] & 0,55 & 0,60 & 0,65 & 0,80 \\
\hline $\begin{array}{c}\text { Temperatura média do Ar na } \\
\left.\text { Entrada do Radiador [ }{ }^{\circ} \mathrm{C}\right]\end{array}$ & 71,8 & 59,6 & 59,9 & 57,5 \\
\hline $\begin{array}{c}\text { Temperatura média do Ar na } \\
\text { Saída do Radiador }\left[{ }^{\circ} \mathrm{C}\right]\end{array}$ & 88,8 & 85,8 & 87,2 & 80,0 \\
\hline $\begin{array}{c}\text { Vazão de Ar no Condensador } \\
{[\mathrm{kg} / \mathrm{s}]}\end{array}$ & 0,49 & 0,66 & 0,74 & 0,99 \\
\hline $\begin{array}{c}\text { Temperatura média do Ar na } \\
\left.\text { Entrada do Condensador [ }{ }^{\circ} \mathrm{C}\right]\end{array}$ & 58,0 & 44,1 & 43,6 & 42,7 \\
\hline $\begin{array}{c}\text { Temperatura média do Ar na } \\
\left.\text { Saída do Condensador [ }{ }^{\circ} \mathrm{C}\right]\end{array}$ & 67,6 & 49,3 & 48,4 & 46,8 \\
\hline Vazão de Ar no Ventilador [kg/s] & 0,55 & 0,60 & 0,65 & 0,80 \\
\hline
\end{tabular}

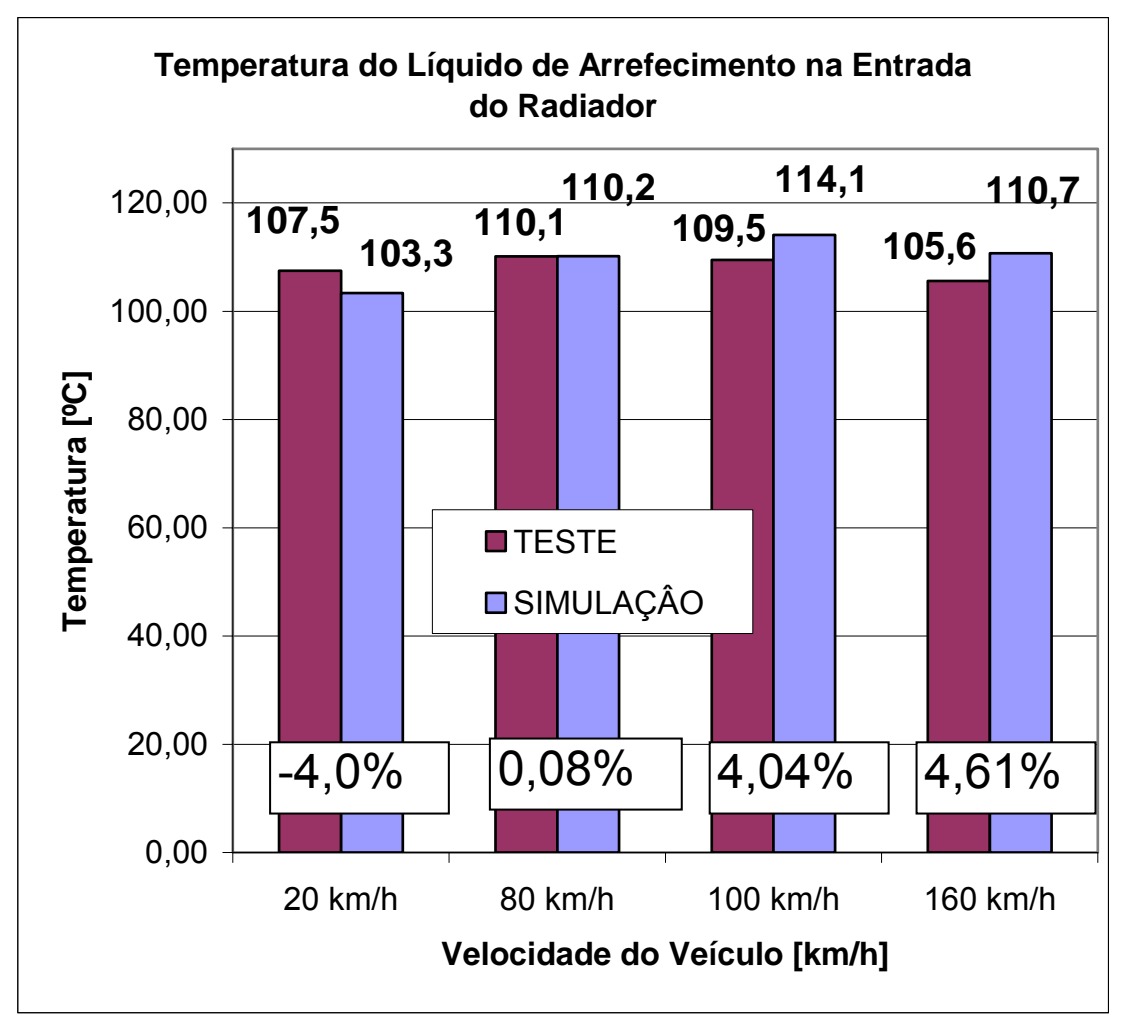

Figura 6.8 - Gráfico comparativo da temperatura do líquido de arrefecimento na entrada do radiador (Veículo A). 


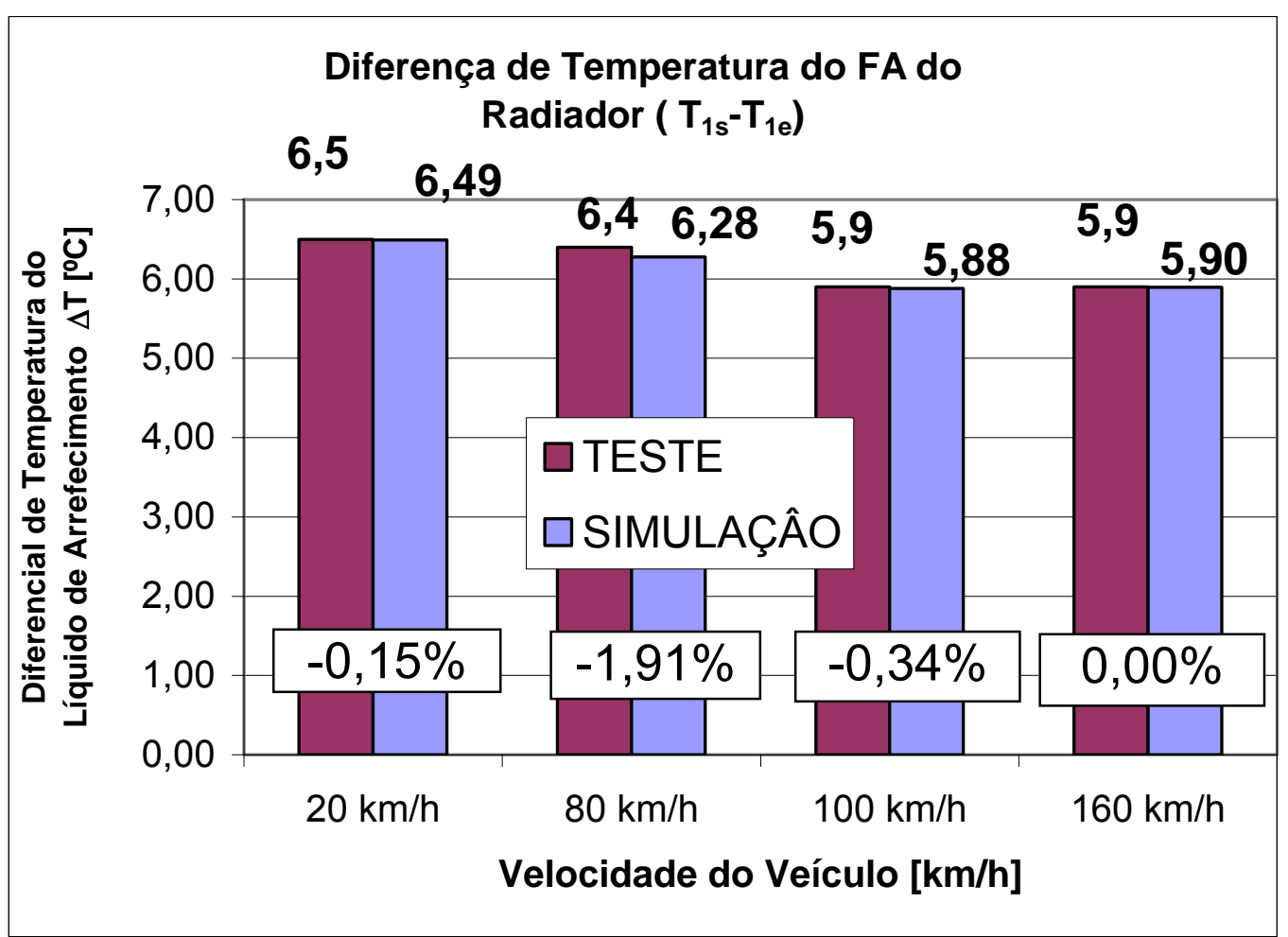

Figura 6.9 - Diferença de temperatura do líquido de arrefecimento na entrada $\left(\mathrm{T}_{1 \mathrm{e}}\right)$ e saída $\left(\mathrm{T}_{1 \mathrm{~s}}\right)$ do radiador (Veículo $\left.\mathrm{A}\right)$.

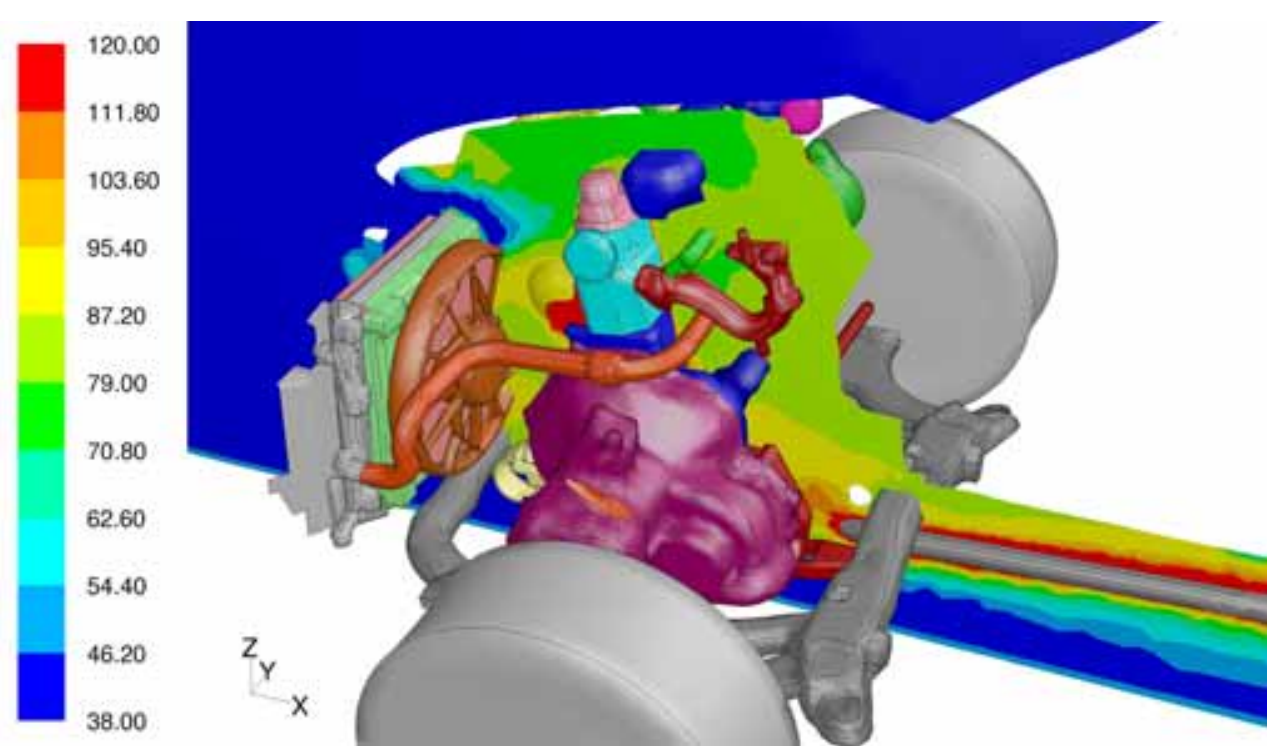

Figura 6.10 - Distribuição térmica da seção transversal do Veículo A. 


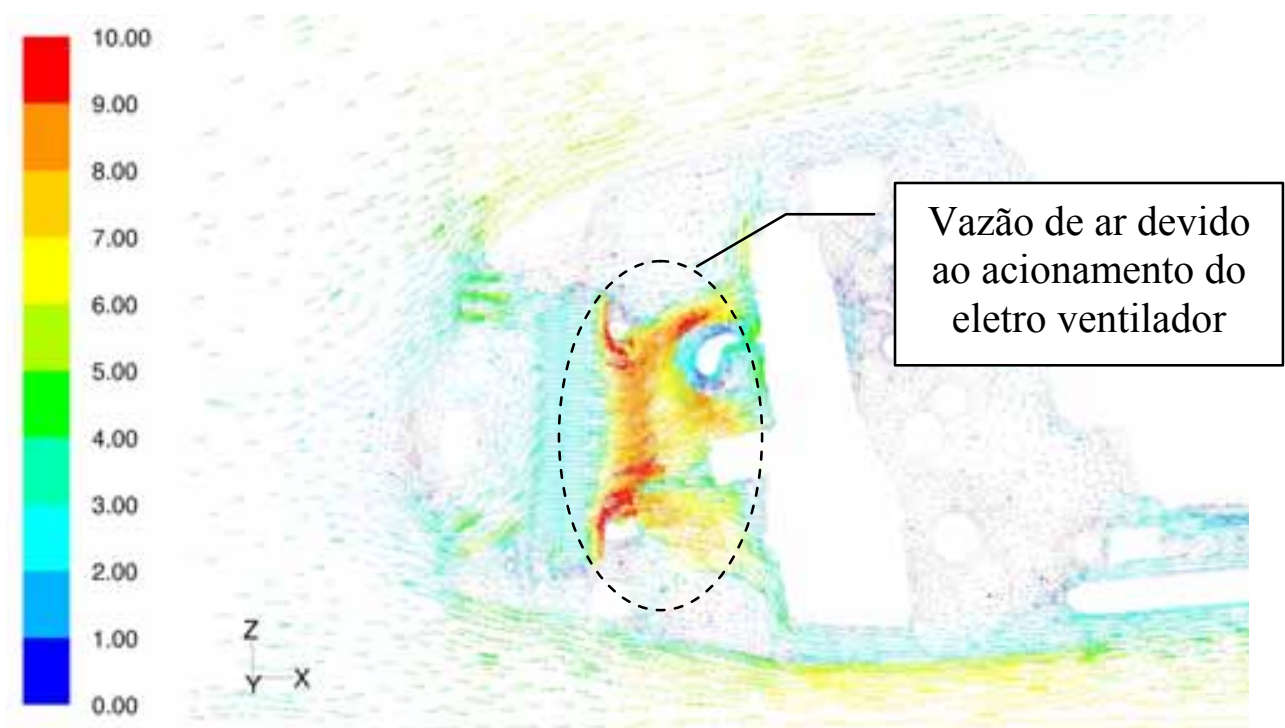

Figura 6.11 - Vetor de velocidade na seção longitudinal ( $Y=00$ ) para a condição de $20 \mathrm{~km} / \mathrm{h}$.

A figura 6.11 mostra a distribuição de velocidade no plano central longitudinal para a condição de baixa velocidade $(20 \mathrm{~km} / \mathrm{h})$. Diante da ausência do efeito "ram", a vazão de ar nos trocadores de calor é suprida pelo eletro ventilador localizado na região posterior ao radiador. A presença dos direcionadores laterais de ar (fig. 6.3) evita o efeito da recirculação que geralmente ocorrem na região superior e inferior ao módulo de arrefecimento.

\subsection{Validação do Veículo B}

Para a segunda validação foi utilizado um veículo "Pick-Up” (figura 6.12), equipado com motor diesel 2.8L (figura 6.13). Devido à elevada potência do motor, este veículo foi equipado com três ventiladores para garantir a remoção do calor gerado pelo motor diesel. Além do sistema de arrefecimento normal (condensador e radiador), este veículo está equipado também com um trocador de ar ou CAC (figura 6.14). A necessidade desse trocador é atribuída pelo fato que, com a redução da temperatura da mistura ar combustível, possibilita uma maior quantidade da mistura dentro da câmara de combustão e consequentemente o aumento da eficiência. Do mesmo modo, com a redução da temperatura do ar de entrada, evita-se em muitos casos o fenômeno de auto-ignição da mistura ar-combustível que prejudica o desempenho do motor. 


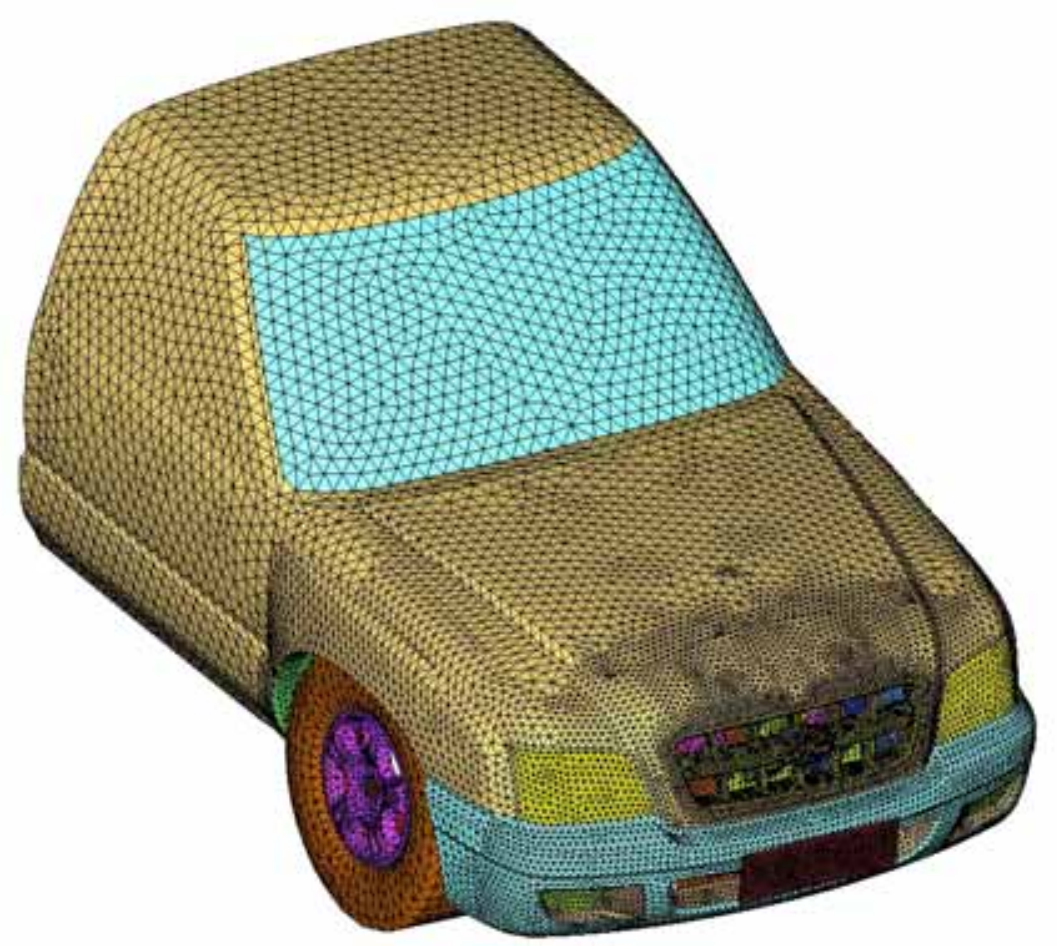

Figura 6.12 - Malha superficial do veículo B.

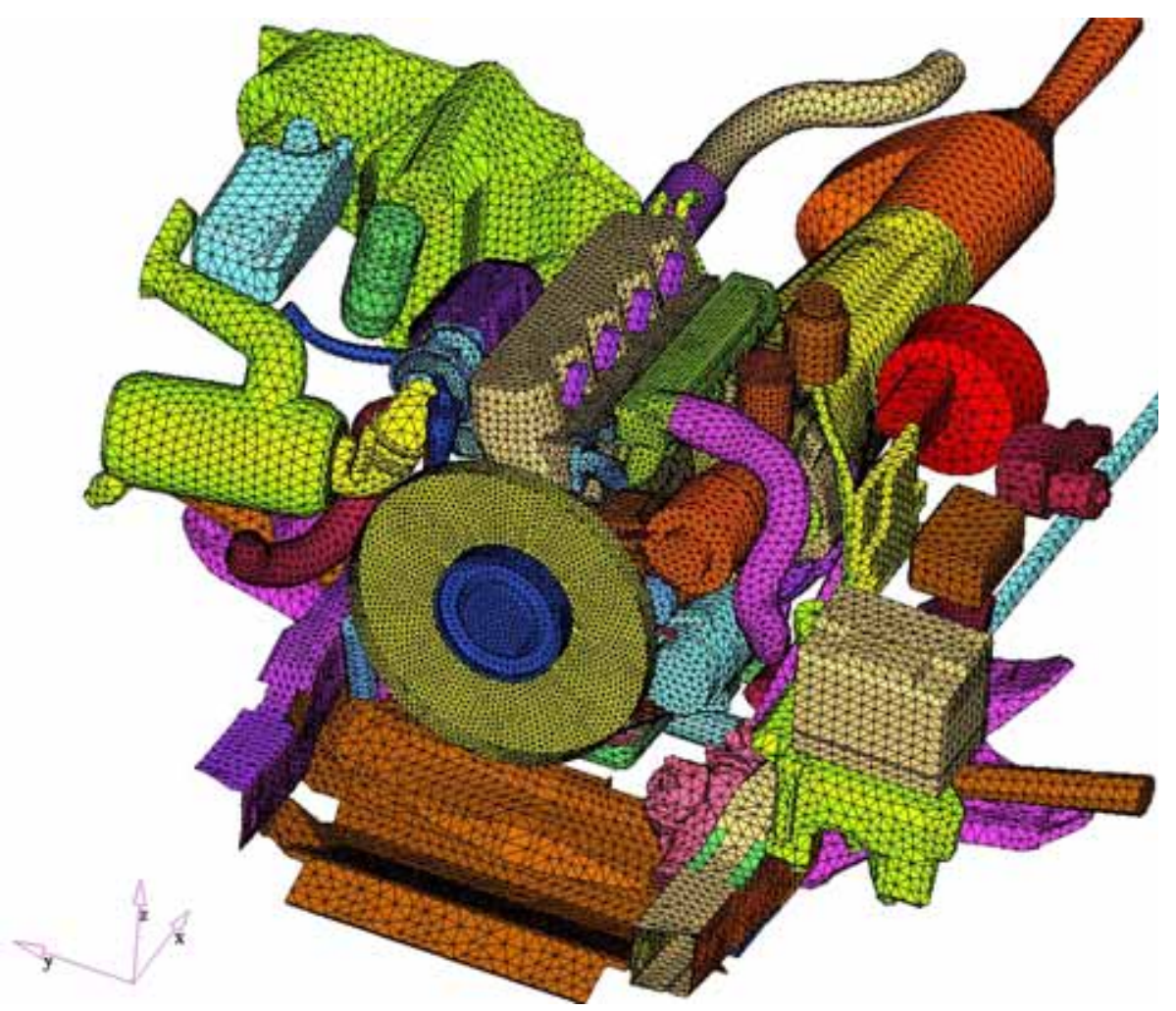

Figura 6.13 - Malha superficial dos componentes do motor. 


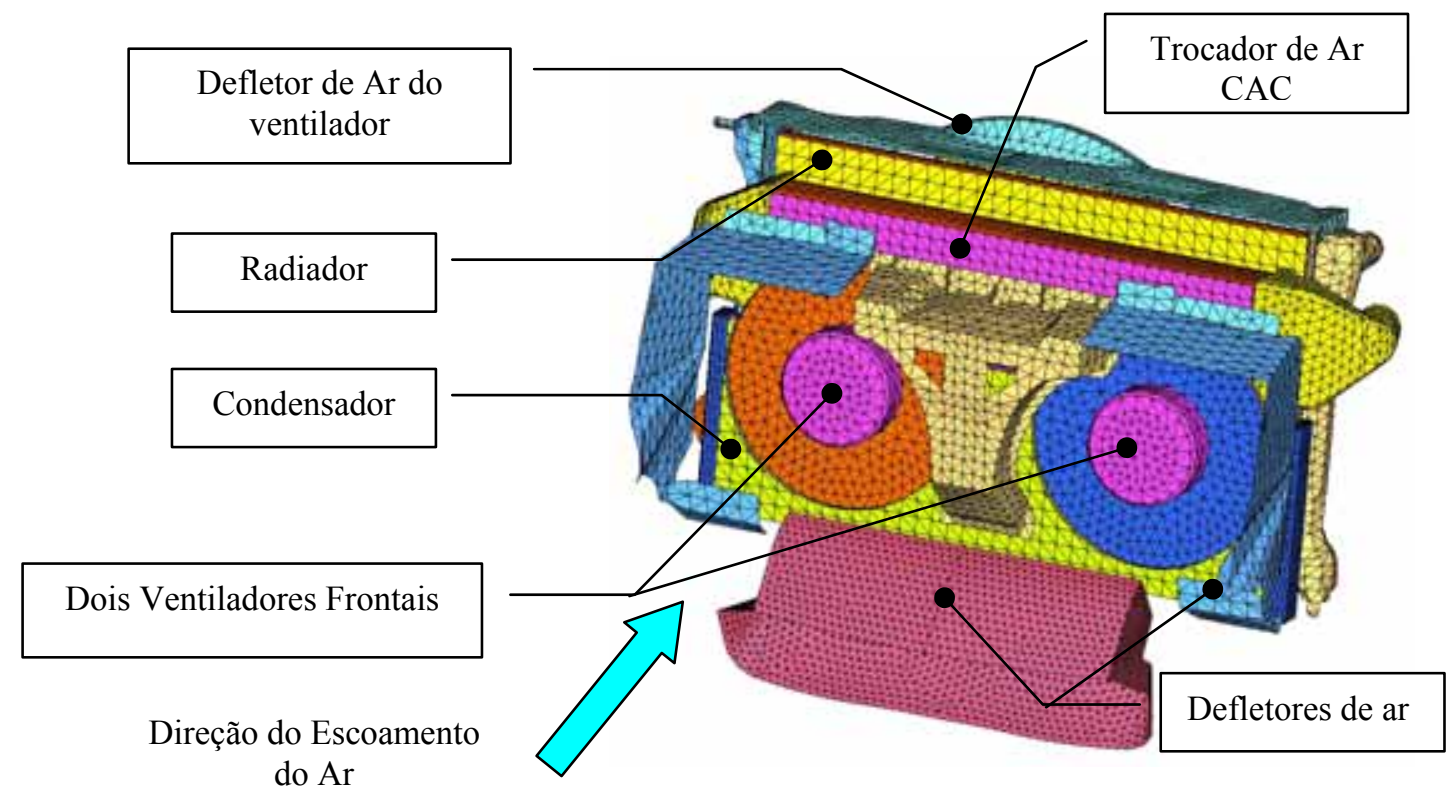

Figura 6.14 - Modelo do sistema de arrefecimento do veículo B.

As cargas térmicas dos componentes do motor (condições de contornos) foram obtidas através de testes físicos considerando uma temperatura média como ilustra na figura 6.15 .

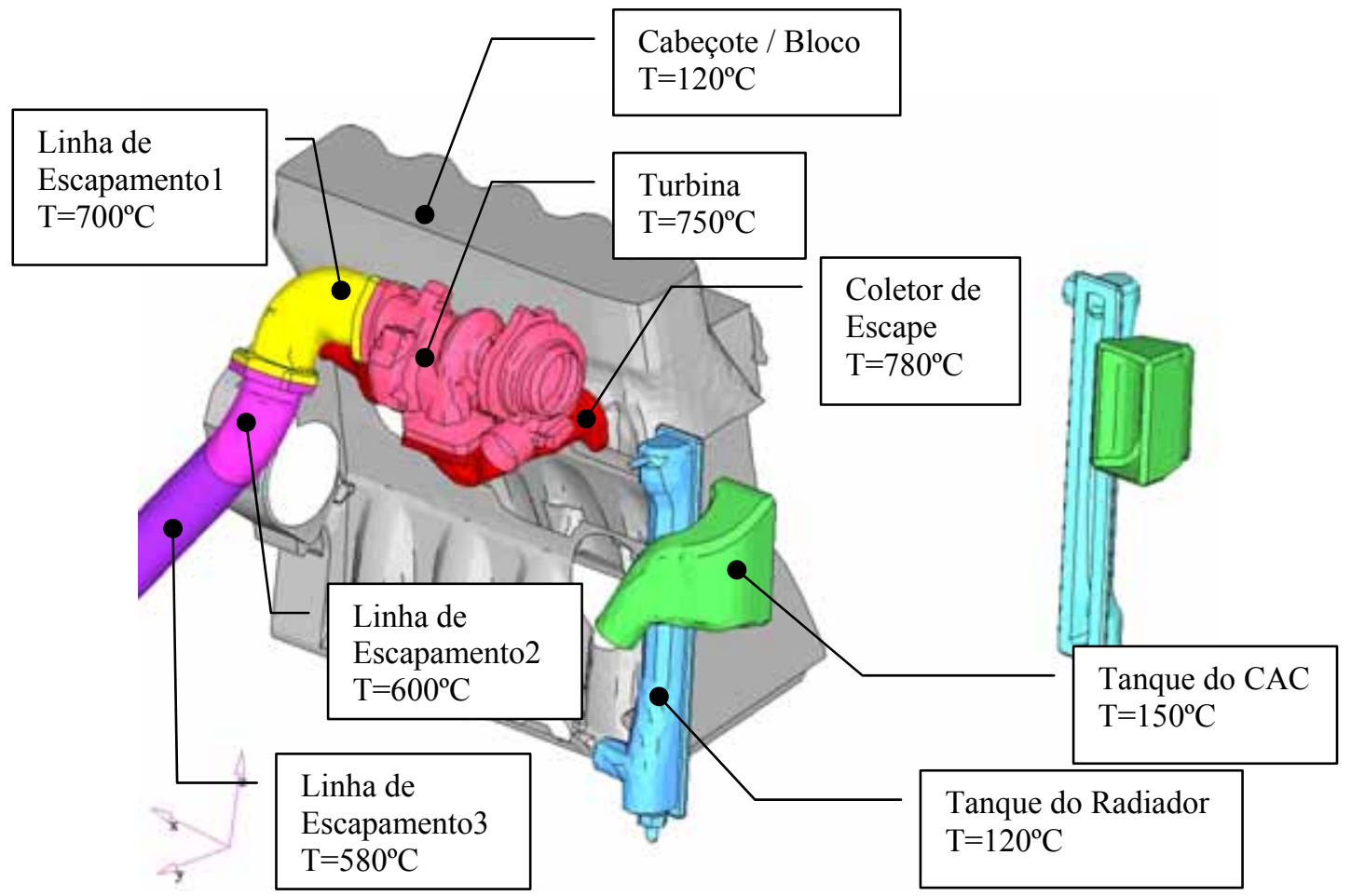

Figura 6.15 - Distribuição térmica da linha de escapamento e do bloco obtidos em teste físico. 
A tabela 6.5 mostra os resultados obtidos em teste de túnel de vento e utilizado como condições de contornos na validação do modelo do "veículo B". Na simulação do (CAC), a temperatura do ar na entrada do trocador foi mantida constante de acordo para cada condição operacional do veículo.

Tabela 6.5 - Dados obtidos em túnel de vento e utilizado como condições de contorno no modelo CFD do veículo B.

\begin{tabular}{|c|c|c|c|c|c|}
\hline & Unidade & Incerteza & Max. Torque & $\begin{array}{c}\text { 80kph } \\
\text { Máxima } \\
\text { Aceleração }\end{array}$ & $\begin{array}{c}\text { Max. } \\
\text { Potência }\end{array}$ \\
\hline Velocidade do Veículo & & & $52 \mathrm{~km} / \mathrm{h}$ & $80 \mathrm{~km} / \mathrm{h}$ & $156 \mathrm{~km} / \mathrm{h}$ \\
\hline Marcha & - & - & $4^{a}$ & $4^{a}$ & $5^{a}$ \\
\hline Radiação Solar & - & - & Ligada & Ligada & Ligada \\
\hline Tipo de Freon & - & - & $134 \mathrm{~A}$ & $134 \mathrm{~A}$ & $134 \mathrm{~A}$ \\
\hline Umidade do $\mathrm{Ar}$ & $\%$ & $\pm 0,2$ & 39,3 & 39,8 & 41,5 \\
\hline Temperatura Ambiente & ${ }^{\circ} \mathrm{C}$ & $\pm 0,4$ & 37,9 & 37,9 & 37,8 \\
\hline Rotação dos Ventiladores & rpm & \pm 10 & 2909 & 2944 & 3044 \\
\hline Rotação do Visco Ventilador & $\mathrm{rpm}$ & \pm 10 & 1970 & 2938 & 3583 \\
\hline Rotação do Motor & rpm & \pm 10 & 1796 & 2742 & 3742 \\
\hline Torque do Motor & N.m & \pm 5 & 1599 & 1505 & 692 \\
\hline Vazão do Líquido interno do Radiador & $\mathrm{I} / \mathrm{min}$ & $\pm 0,5$ & 76,6 & 118,6 & 163,8 \\
\hline Variação da Temperatura do Líquido de Arref. & ${ }^{\circ} \mathrm{C}$ & $\pm 0,8$ & 6,6 & 5,6 & 5,5 \\
\hline Temperatura do ar interno na entrada do CAC & ${ }^{\circ} \mathrm{C}$ & $\pm 0,8$ & 191,5 & 203,8 & 190,9 \\
\hline Vazão de ar interno do CAC & $\mathrm{kg} / \mathrm{s}$ & - & 0,07 & 0,10 & 0,13 \\
\hline Vazão de HFC134a no Condensador & $\mathrm{kg} / \mathrm{s}$ & - & 0,03 & 0,03 & 0,03 \\
\hline Temperatura na Saída do Compressor - T2 & ${ }^{\circ} \mathrm{C}$ & $\pm 0,8$ & 102,6 & 95,8 & 104,8 \\
\hline Temperatura na Entrada do Condensador - T3 & ${ }^{\circ} \mathrm{C}$ & $\pm 0,8$ & 101,7 & 108,5 & 103,4 \\
\hline Temperatura na Saída do Condensador - T4 & ${ }^{\circ} \mathrm{C}$ & $\pm 0,8$ & 65,9 & 62,8 & 66,3 \\
\hline Temperatura na Entrada do Evaporador - T5 & ${ }^{\circ} \mathrm{C}$ & $\pm 0,8$ & 17,6 & 28,4 & 20,3 \\
\hline Temperatura na Saída do Evaporador - T6 & ${ }^{\circ} \mathrm{C}$ & $\pm 0,8$ & 8,1 & 8,7 & 8,6 \\
\hline Temperatura na Entrada do Compressor - T1 & ${ }^{\circ} \mathrm{C}$ & $\pm 0,8$ & 6,7 & 8,5 & 9,2 \\
\hline Pressão na Saída do Compressor - P2 & $\mathrm{kPa}$ & \pm 2 & 2161 & 2192 & 2162 \\
\hline Pressão na Entrada do Condensador - P3 & $\mathrm{kPa}$ & \pm 2 & 2150 & 2171 & 2144 \\
\hline Pressão na Saída do Condensador - P4 & $\mathrm{kPa}$ & \pm 2 & 2133 & 2158 & 2129 \\
\hline Pressão na Saída do Evaporador - P6 & $\mathrm{kPa}$ & \pm 2 & 291 & 288 & 294 \\
\hline Pressão na Entrada do Compressor - P1 & $\mathrm{kPa}$ & \pm 2 & 267 & 249 & 268 \\
\hline Rejeição Térmica do Condensador - $\dot{Q}_{C}$ & $\mathrm{~kW}$ & - & 5,3 & 5,3 & 5,2 \\
\hline Rejeição Térmica do Radiador $-\dot{Q}_{R}$ & $\mathrm{~kW}$ & - & 30,7 & 42,8 & 57,8 \\
\hline
\end{tabular}


Tabela 6.6 - Resultados da Simulação do Veículo B.

\begin{tabular}{|c|c|c|c|c|c|}
\hline & Unidade & $52 \mathrm{~km} / \mathrm{h}$ & $80 \mathrm{~km} / \mathrm{h}$ & $156 \mathrm{~km} / \mathrm{h}$ & Incerteza \\
\hline $\begin{array}{c}\text { Temperatura de entrada do líquido do } \\
\text { Radiador }\end{array}$ & ${ }^{\circ} \mathrm{C}$ & 113,3 & 115,0 & 110,8 & $\pm 0,8$ \\
\hline $\begin{array}{l}\text { Temperatura de saída do líquido do } \\
\text { Radiador }\end{array}$ & ${ }^{\circ} \mathrm{C}$ & 106,9 & 109,6 & 105,4 & $\pm 0,8$ \\
\hline Vazão de ar externo do Radiador & $\mathrm{kg} / \mathrm{s}$ & 0,9 & 1,2 & 1,7 & $\pm 0,1$ \\
\hline $\begin{array}{l}\text { Temperatura média de entrada do ar } \\
\text { externo do Radiador }\end{array}$ & ${ }^{\circ} \mathrm{C}$ & 64,0 & 62,5 & 58,0 & $\pm 0,8$ \\
\hline $\begin{array}{c}\text { Temperatura média de saída do ar } \\
\text { externo do Radiador }\end{array}$ & ${ }^{\circ} \mathrm{C}$ & 87,9 & 89,4 & 83,4 & $\pm 0,8$ \\
\hline Vazão de Ar externo do Condensador & $\mathrm{kg} / \mathrm{s}$ & 0,6 & 0,8 & 1,3 & $\pm 0,1$ \\
\hline $\begin{array}{c}\text { Temperatura média de entrada do ar } \\
\text { do Condensador }\end{array}$ & ${ }^{\circ} \mathrm{C}$ & 40,4 & 39,5 & 38,8 & $\pm 0,8$ \\
\hline $\begin{array}{l}\text { Temperatura média de saída do ar do } \\
\text { Condensador }\end{array}$ & ${ }^{\circ} \mathrm{C}$ & 47,5 & 44,9 & 42,0 & $\pm 0,8$ \\
\hline Vazão de Ar externo do CAC & $\mathrm{kg} / \mathrm{s}$ & 0,1 & 0,2 & 0,4 & $\pm 0,1$ \\
\hline $\begin{array}{c}\text { Temperatura média de entrada do ar } \\
\text { externo do CAC }\end{array}$ & ${ }^{\circ} \mathrm{C}$ & 46,8 & 45,3 & 42,8 & $\pm 0,8$ \\
\hline $\begin{array}{l}\text { Temperatura de saída do ar externo } \\
\text { do CAC }\end{array}$ & ${ }^{\circ} \mathrm{C}$ & 89,2 & 84,8 & 71,6 & $\pm 0,8$ \\
\hline $\begin{array}{l}\text { Temperatura de saída do ar interno } \\
\text { do CAC }\end{array}$ & ${ }^{\circ} \mathrm{C}$ & 74,6 & 99,0 & 91,8 & $\pm 0,8$ \\
\hline
\end{tabular}

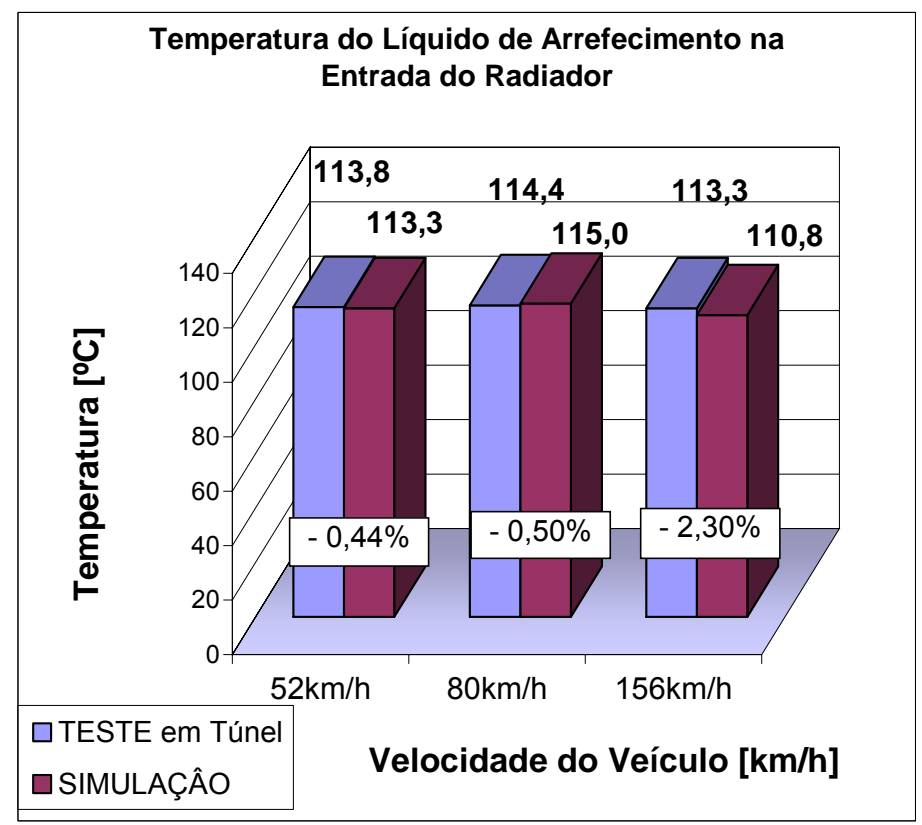

Figura 6.16 - Gráfico comparativo da temperatura do líquido de arrefecimento na entrada do radiador (Veículo B). 


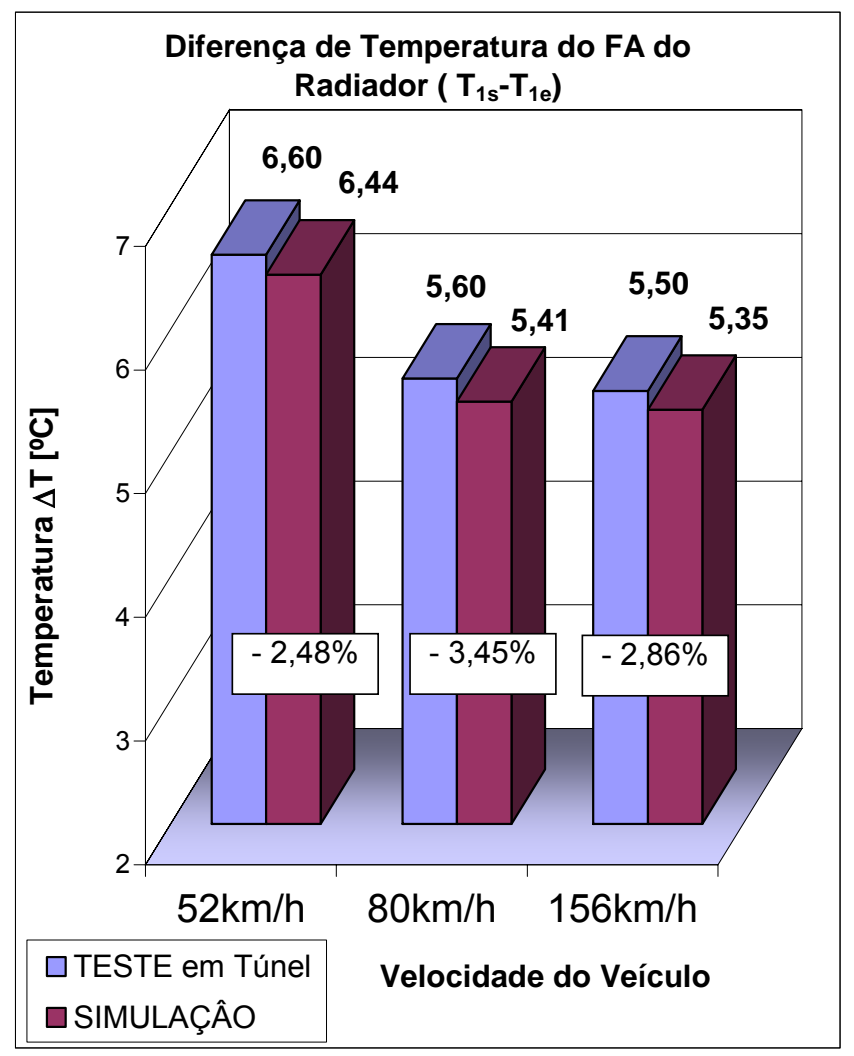

Figura 6.17 - Diferença de temperatura do líquido de arrefecimento na entrada e saída do radiador (Veículo B).

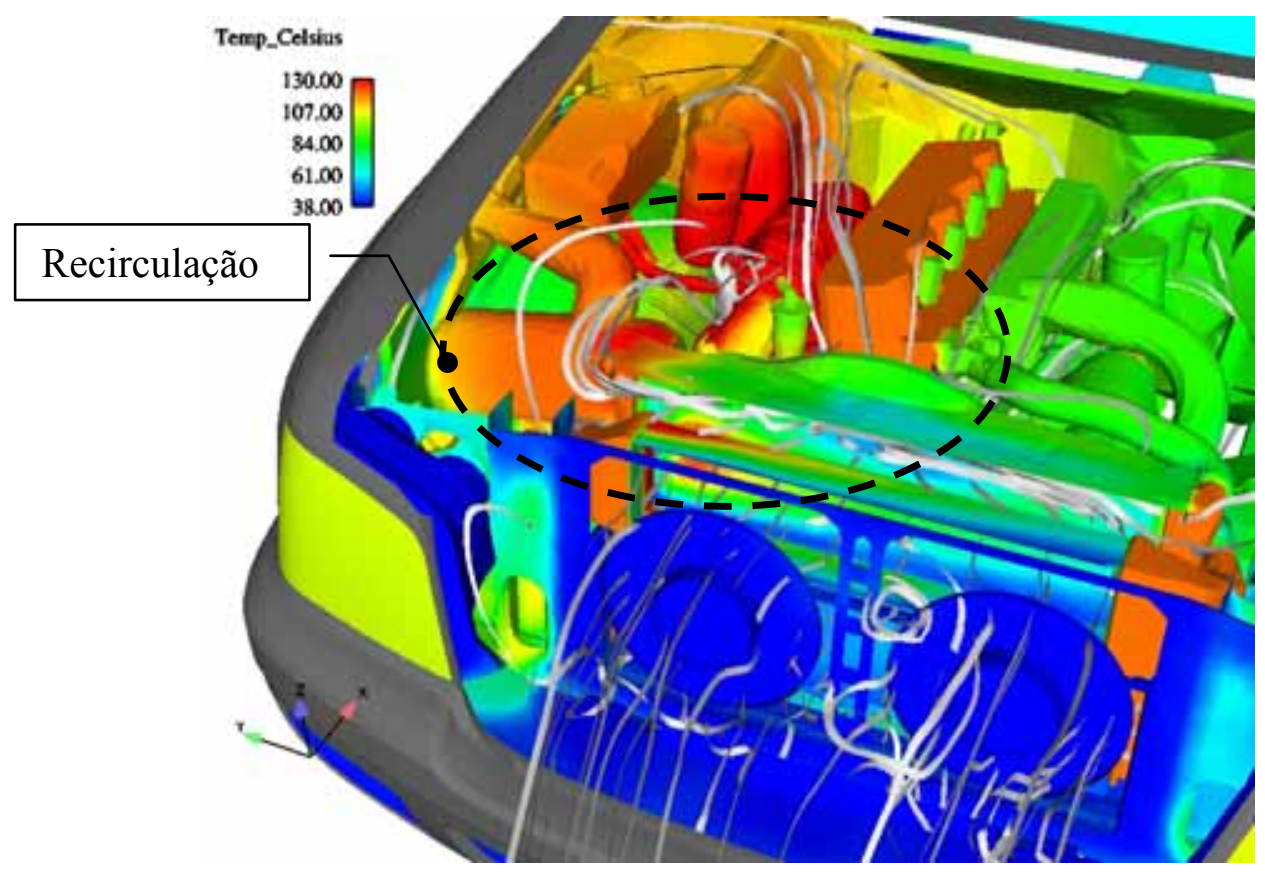

Figura 618 - Distribuição térmica do compartimento do motor com linhas de trajetórias de partículas. 


\subsection{Validação da Metodologia (Veículo C)}

Para a validação desta metodologia foi utilizado um veículo C com o mesmo motor e transmissão do veículo $\mathrm{A}$, porém equipado com um novo sistema de arrefecimento. Este sistema permite a inclusão de um trocador de ar na parte superior para o caso em que a motorização a diesel for utilizada (figura 6.20a).

Para um aproveitamento mais eficiente do ar frio, defletores de ar foram instalados nas partes laterais e na inferior do sistema de arrefecimento como ilustrado na figura abaixo. As condições de refino de malha superficial foram feitas seguindo os mesmos procedimentos já descritos para os modelos A e B. Como este veículo utiliza a mesma motorização do veículo $\mathrm{A}$, os valores de rejeições térmicas assim como as temperaturas médias da linha de escapamento do veículo A foram mantidas para o modelo $\mathrm{C}$.

Para a validação do procedimento, este veículo foi instrumentado e testado sobre uma pista circular do Campo de Provas da General Motors do Brasil localizada em Indaiatuba (SP), destacando-se que foram utilizadas as mesmas condições de operação do veículo A, diferenciando-se somente no valor da temperatura ambiente.

Para simular as condições de carga de rampa sob a inclinação de seis graus, um "trailer" equipado com sistema de frenagem hidráulico foi utilizado para impor cargas devido à inclinação em que o veículo é submetido.

Cuidados foram tomados para que os sinais fossem coletados sob condições próximas às de regime permanente do veículo. Assim como nos procedimentos utilizados em túneis de vento, no teste em pista o ventilador também foi acionado na máxima rotação para todas as condições de teste do veículo. 


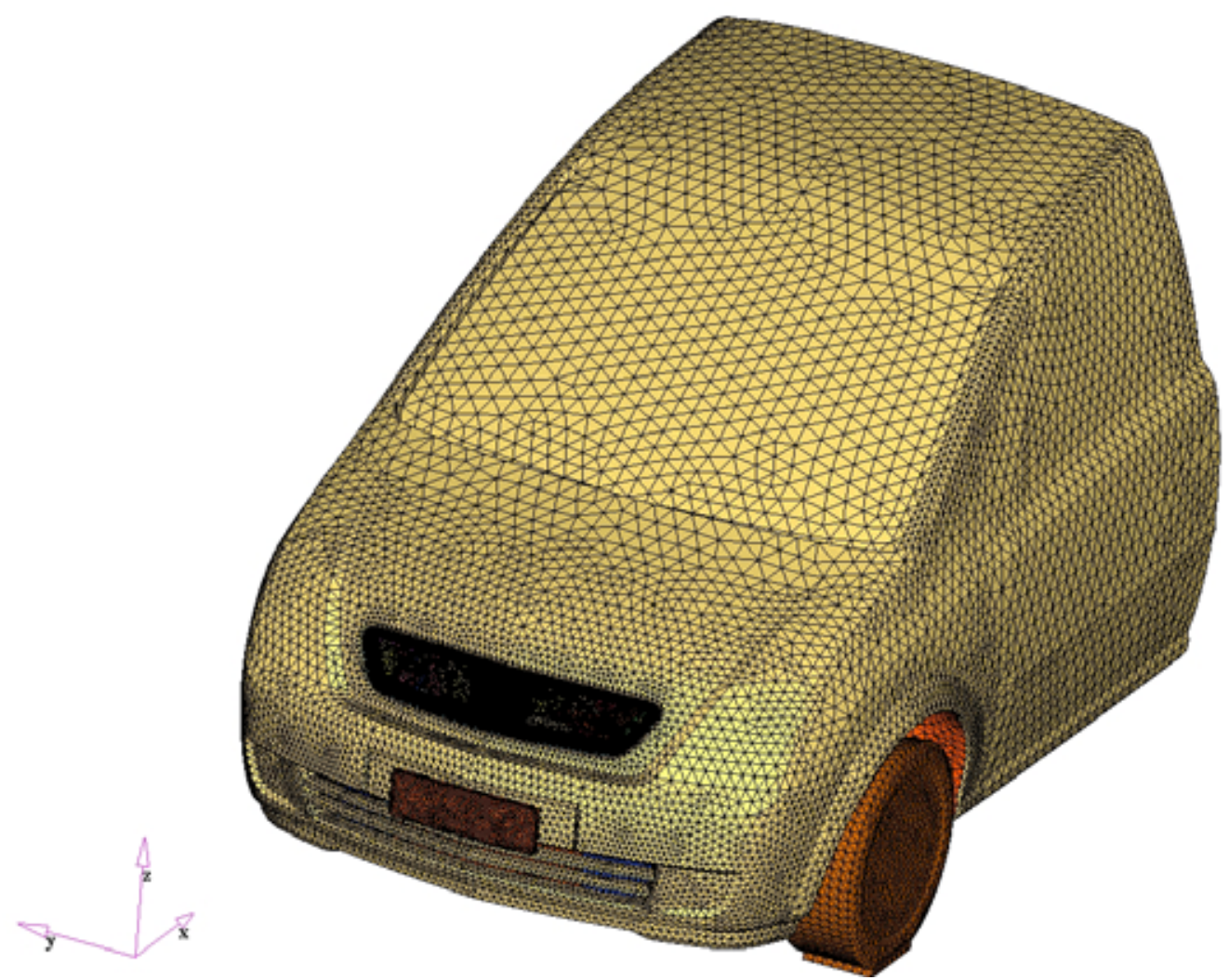

Figura 6.19 - Modelo do Veículo C.

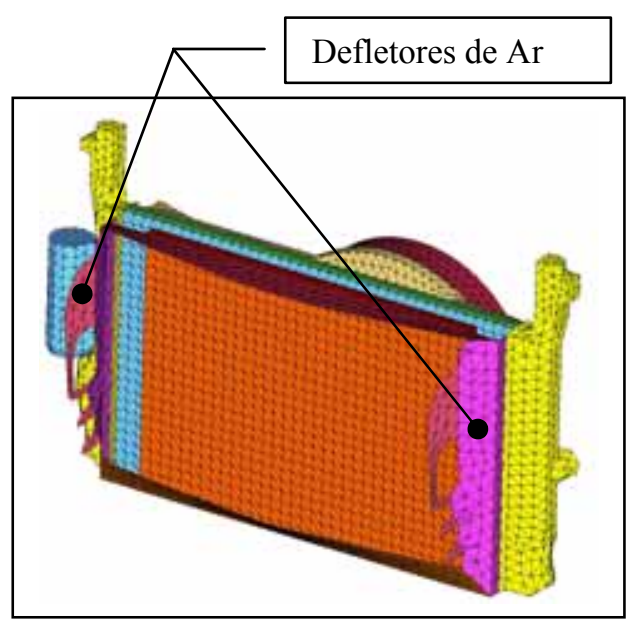

a)

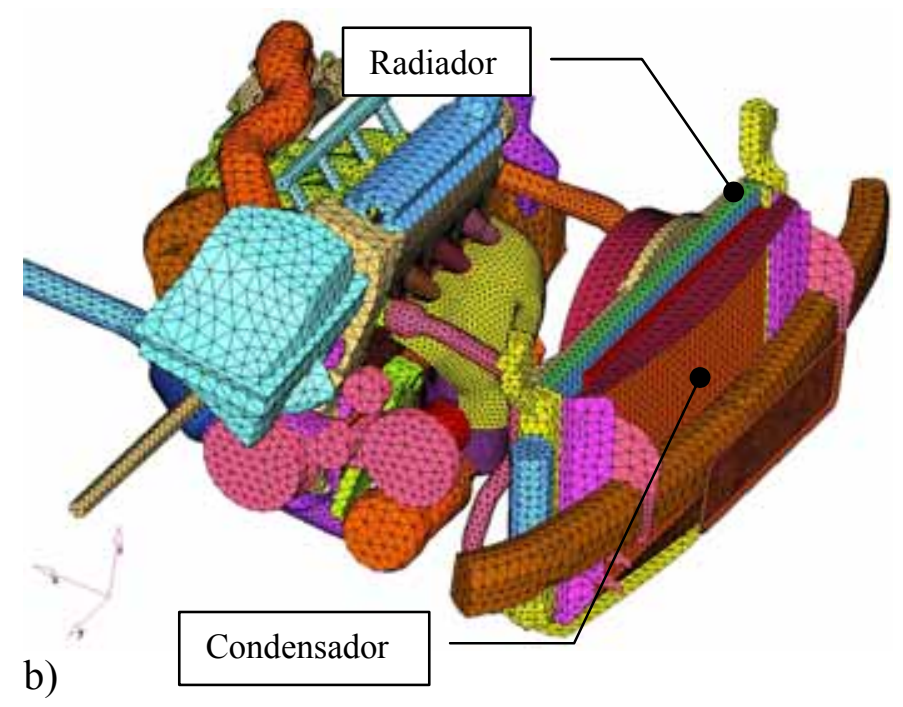

b)

Figura 6.20 - a) Modelo do sistema de arrefecimento do veículo C. b) Motor do veículo A montado sob o veículo $\mathrm{C}$. 


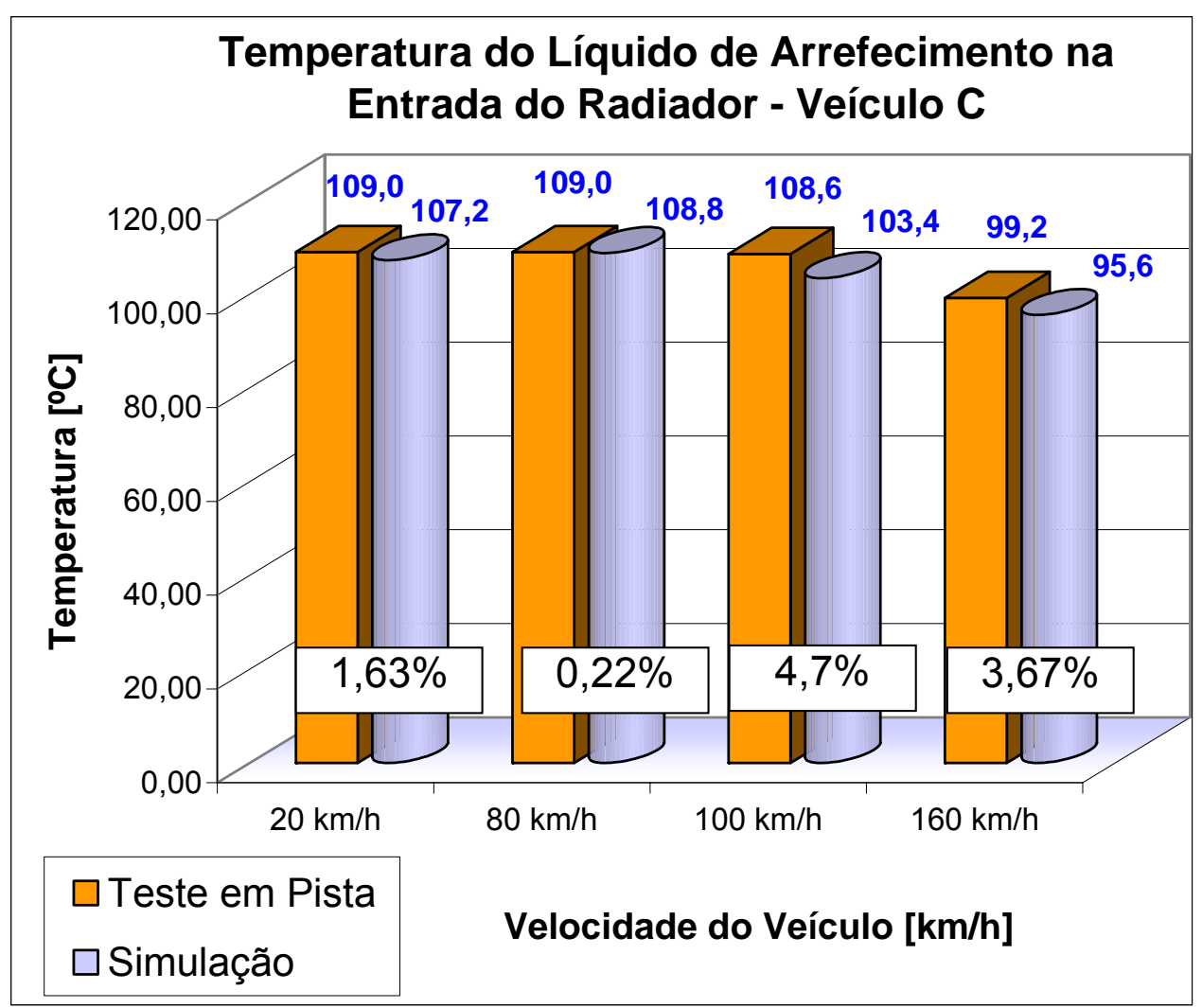

Figura 6.21 - Temperatura do líquido de arrefecimento na entrada do radiador (Veículo C).

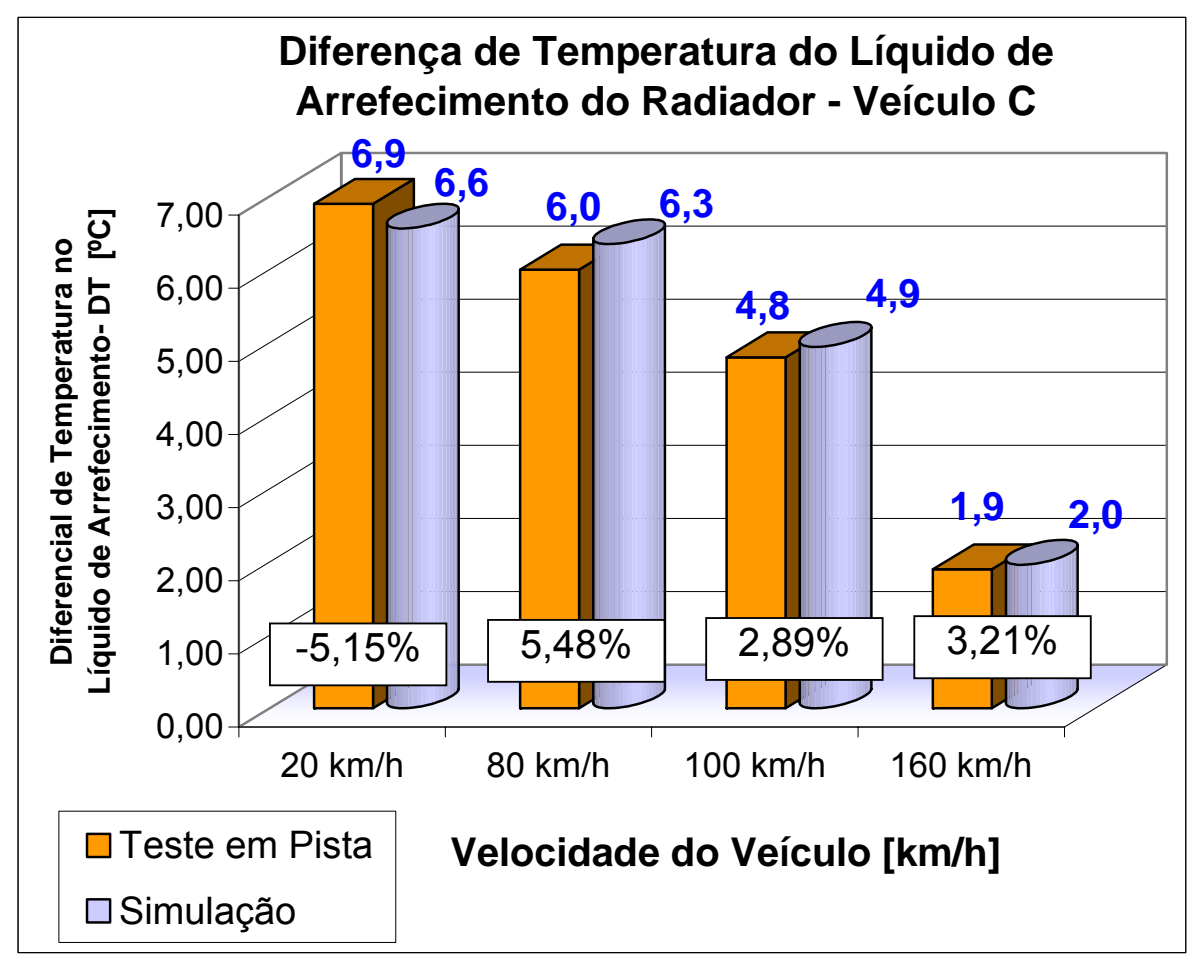

Figura 6.22 - Diferença de temperatura do líquido de arrefecimento na entrada e saída do radiador (Veículo C). 


\section{CAPÍTULO 7}

\subsection{Conclusão}

O modelo numérico de trocador de calor e do ventilador do código $\boldsymbol{F L U E N T}^{\circledR}$ mostrou ser eficiente na determinação da perda de carga e da rejeição térmica. Os resultados das simulações de validações dos modelos numéricos mostraram baixa discrepância em relação aos resultados obtidos em testes experimentais como podem ser vistos pelas figuras 5.4, 5.7 e 5.9.

No estudo do refino de malha em que se utilizou um veículo completo, os resultados mostram que o refino da malha na região da grade de $20 \mathrm{~mm}$ para $10 \mathrm{~mm}$ alteram o valor da vazão do ar no compartimento do motor na ordem de $-4,6 \%$, enquanto que, para o refino da malha externa do veículo não houve alteração significativa na vazão de ar dentro do compartimento (- 0,3\%). Este estudo mostrou que o refino da malha externa do veículo melhora somente o valor do coeficiente aerodinâmico, mostrando uma diferença de 1,3\% com relação ao valor obtido em teste de túnel de vento, porém o tempo de processamento eleva em 113\% totalizando 3,22h utilizando 4 processadores na HPC.

A simplificação do modelo com a exclusão dos retrovisores laterais e da região posterior à coluna central do teto do veículo implica em uma redução no tempo de processamento em $292 \%$ sem afetar o valor do fluxo de ar dentro do compartimento essencial para a troca térmica, como mostrado nos estudo feito por Ramesh (1998).

A metodologia de simulação considerando a troca térmica aplicado ao veículo apontou uma diferença $\pm 5 \%$ no valor da temperatura de entrada do líquido de arrefecimento do radiador em relação aos valores obtidos em testes de túnel de vento, enquanto que, para o veículo B a diferença foi de $\pm 3 \%$. Estas discrepâncias podem ser atribuídas aos seguintes fatores:

- Na construção do modelo de volumes finitos, detalhes como as tubulações do sistema de ar condicionado, assim como os cabos elétricos e pequenos componentes da parte frontal ao sistema de arrefecimento não foram levados em consideração. 
- Para a simplificação da metodologia de cálculo para o veículo em baixo número de Mach, os modelos consideram a densidade do ar constante com base na temperatura ambiente. Nas regiões com temperaturas elevadas. como na passagem de ar através do radiador, a densidade do ar é reduzida resultando em alterações no fluxo de massa e, conseqüentemente, afetam as temperaturas do líquido de arrefecimento.

A validação da metodologia com o uso do veículo $\mathrm{C}$ mostrou uma discrepância menor que $6 \%$ nos resultados em relação aos testes físicos em pista circular. Como pode ser observado as temperaturas do líquido do radiador simulado são menores que os de teste. Esta diferença pode ser atribuída ao fato de que o veículo $\mathrm{C}$ apresenta uma massa total superior ao veículo A. Para manter as condições do "veículo A" será necessário um acréscimo nas rotações do motor e conseqüentemente, haverá um aumento também nos valores de rejeições térmicas, as quais não foram consideradas no modelo.

Uma das vantagens da simulação numérica do sistema de arrefecimento do motor é permitir a visualização do escoamento e a distribuição térmica do motor, além de identificar o efeito indesejável da recirculação do ar quente nos trocadores de calor como pode ser visto na figura 6.16.

Os objetivos deste trabalho foram atingidos e a metodologia de simulação apresentou uma discrepância inferior a 5\% no valor da temperatura do líquido de arrefecimento em relação ao teste em pista, o que é satisfatório para estudos de propostas de melhoria na fase inicial de projeto. Demonstrou-se ainda que o uso da metodologia reduz o tempo de resposta em mais de $200 \%$ quando comparada ao processo tradicional. 


\subsection{Recomendações para trabalhos posteriores}

Visando o aprimoramento da metodologia, segue abaixo algumas das recomendações que serão úteis em trabalhos posteriores:

- Implementação da função densidade com a variação da temperatura nos cálculos de troca térmica.

- Implementação de uma bancada de teste térmico do motor. A metodologia apresentada neste trabalho é útil quando se conhecem as curvas de rejeições térmicas do motor valores obtidos através de testes em túnel de vento. Em situações onde se deseja avaliar o sistema de arrefecimento com a utilização de um motor não validado, será necessário o levantamento das rejeições térmicas, assim como a vazão do líquido de arrefecimento deste motor para as condições críticas do veículo.

- Desenvolvimento de uma metodologia para avaliar o sistema de arrefecimento em condição de "soak" veículo parado e com motor desligado (em regime trasitório). Imagine-se uma situação onde o veículo está solicitado ao máximo torque (subida de serra), e em um determinado instante, é obrigado a parar devido um congestionamento. Diante disso, a inércia térmica do motor irá aumentar a temperatura do líquido de arrefecimento em um curto espaço de tempo. Nessa situação, um sistema de arrefecimento ineficiente irá apresentar vazamento do líquido mesmo com o ventilador ligado. 


\section{REFERÊNCIAS BIBLIOGRÁFICAS}

ASHMAWEY, M.; BERNEBURG, H.; HARTUNG, W.; WERNER, F., A numerical evaluation of the thermal effect of the new V6 engine on the underhood environment of the 1993 Opel Vectra, SAE paper 930295, Society of Automotive Engineers, 1993.

ASHRAE 85, ASHRAE Handbook 1985 Fundamentals; SI-Edition, Atlanta, GA, 1985.

ÁVILA, J. A., Ar Condicionado Automotivo: Caracterização e Avanços Tecnológicos, Trabalho de conclusão de Mestrado Profissionalizante em Engenharia Mecânica Automotiva, Escola Politécnica da Universidade de São Paulo, São Paulo, 2002 .

BEAUVIS, F. N.; TIGNOR, S. C.; TURNER, T. R., Problems of Ground Simulation in Automotive Aerodynamics, SAE Paper, 680121, Society of Automotive Engineers, Warrendale, Pa., 1968.

BUCHHEIM, R.; LEIE, B.; LÜCHOFF, H. J., Der neue Audi 100 - Ein Beispiel für konsequente aerodynamishe Personenwangen-Entwicklung, ATZ, Vol.85, 1983.

CEBECCI, T.; Hirsh, R.S.; Keller, H. B.; Williams, P. G., Studies of Numerical Methods for the Plane Navier-Stokes Equations, Comp. Meth. in App. Mech and Eng., Vol. 27, 1981.

COGOTTI, A.; Ground Effect Simulation for Full Scale Cars in the Pininfarina Wind Tunnel, SAE Paper, 950996, Society of Automotive Engineers, Warrendale, Pa., 1995. 
CROOK, R. F., 14 Rules for Improving Engine Cooling System Capability in

High-Performance, NARSA (National Automotive Radiator Association).

Disponível em: $<$ http://www.arrowheadradiator.com/

14_rules_for_improving_engine_cooling_system_capability_in_high-

performance_automobiles.htm., Acesso em 16 de Setembro de 2005.

ECER, A.; TOKSOY, C.; RUBEK, V.; HALL, R.; GEZMISOGLU, G.; PAGliarulO, V.; CARUSO, S.; AZZALI, J., Air Flow and Heat Transfer Analysis of an Automotive Engine Radiator to Calculate Air-to-Boil Temperature, SAE Paper, No 951015, Society of Automotive Engineers, 1995.

ELOFSSON, P.; BANNISTER, M., Drag Reduction Mechanisms Due to Moving Ground and Wheel Rotation in the Passenger Cars, SAE Paper, $N^{\circ}$ 2002-01-0531, Society of Automotive Engineers, 2002.

EMMELMANN, H. J.; BERNEBUR, H., Aerodynamic Drag and Engine Cooling Confliting Goals, Internal Report Opel, 1990.

FLUENT 6.1., User's Guide, Fluent Inc., 2003.

HABCHI, S. D.; HO, S. Y.; ELDER, J.; SINGH, S., Airflow and Thermal Analysis of Underhood Engine Enclosures, SAE Paper, N ${ }^{\circ}$ 940316, Society of Automotive Engineers, 1994.

HENNER, M.; LEVASSEUR, A.; Moreau S., Detailed CFD Modeling of Engine Cooling and Fan Systems Airflow, SAE Paper, N 2003-01-0615, Society of Automotive Engineers, 2003.

HOLMAN, J. P., Heat Transfer, 4th Ed., McGraw-Hill Book Co., New York, NY, 1976. 
HUCHO, W. H.; AHMED, S. R.; BAYER, B. E.; CALliSTER, J. R.; EMMELMANN, H. J.; FLEGL, H.; GEORGE, A. R.;GILHAUS, A.; HOFFMANN, R.; HUMMEL, D.; KOHL, W. R.; MAYER, G., Aerodynamics of Road Vehicles, From Fluid Mechanics of Vehicle Engineering $4^{\text {th }}$ Edition 1998, SAE International.

Hypermesh 7.0 User's manual Altair Computing, Inc., 2004.

INCROPERA, F. P.; DEWITT D. P., Fundamentos de Transferência de Calor e de Massa, $4^{\text {rd }}$ edição, Rio de Janeiro, LTC - Livros Técnicos e Científicos Editora S. A, 1998.

JERHAMRE, A; JONSON, A., Development and Validation of Coolant Temperature and Cooling Air Flow CFD Simulations at Volvo Cars, SAE Paper, No 2004-010051, Society of Automotive Engineers, 2004.

JOHANNESSEN, K.; SAUNDERS, J.; SHERIDAN, J.; NICLASEN, D., Experimental Assessment of CFD Predictions of Fascia Performance, SAE Paper, $\mathrm{N}^{\mathrm{o}}$ 2002-01-0570, Society of Automotive Engineers, 2002.

KAYS, W. M.; LONDON, A. L., Compact Heat Exchangers, $3^{\text {rd }}$ Edition. McGraw Hill Book Company, 1984.

KAYS, W. M.; CRAWFORD, M. E., Convective Heat and Mass Transfer, $3^{\text {rd }}$ Edition. McGraw Hill Book Company, 1993.

KELLY, K. B.; PROVENCHER, L. G.; SCHENKEL, F. K., The General Motors Engineering Staff Aerodynamics Laboratory - A full Scale Automotive Wind Tunnel, SAE Paper, No 820371, Society of Automotive Engineers, 1982.

KUZMANOV, T.; HARRIS, C. R., Hot Wire Velocity and Turbulence Data Acquisition at General Motors Aerodynamics Laboratory, GM Internal Report, 1993. 
LAKSHMIKANTHA, M. G., Computer Aided Aerodynamic Design of Radiator Fans, SAE Paper, No 1999-01-0644, Society of Automotive Engineers, 1999.

LAUNDER, B. E.; SPALDING, D. B., Lectures in Mathematical Models of Turbulence, Academic Press, London, England, 1972.

LAURENCE, V., Simulação do Escoamento de Ar Através do Compartimento do Motor de um Veículo de Passeio, Dissertação apresentada à Escola Politécnica da Universidade de São Paulo para a obtenção do Título de Mestre em Engenharia, São Paulo, 2003.

LOHMANN, D., Aeroacustic Optimization of Blade Geometry, DLRNachrichten, 1995.

MAES, J. P.; ARMSTRONG, R., Antifreeze and Coolant, Texaco Corp., Vol 78, 1992.

MARTIN, W.; GILLIÉRON, P., Itegration of Fluid Flow Modelling in the Vehicles Renault Development Process. SAE papers, SAE 2001-01-0700,2001

MERCER, A. D., Corrosion Inhibition of Engine Coolants, Corrosion Protection and Finishing Techniques, The Institution of Mechanical Engineers, Automotive Division, International Seminar, 1995.

NISHIMURA, Y. T.; ABE, T.; TAKAMITSU, J., Prediction of the Airflow Through Automotive, SAE Paper, No 932889, Society of Automotive Engineers, 1993.

NOBEL, P. T., JAIN K., A Multi-Dimensional Approach to Truck Underhood Thermal Management, SAE Paper, $N^{0}$ 2001-01-2785, Society of Automotive Engineers, 2001. 
PATANKAR, S. V., Numerical Prediction of Tree-Dimensional Flows, in Studies in Convection: Theory Measurement and Applications. Academic Press, London, Vol.1, 1975.

PATANKAR, S. V.; SPALDING, D. B., A calculation Procedure for Heat, Mass and Momentum Transfer in Tree-dimensional Parabolic Flows", Int. J. Heat Mass Trasnfer, Vol.15, 1972.

RAMESH, A; HYTOPOUlOS, E.; KUMAR, K.; SUN, R. L., The Effect of Boundary and Geometry Simplification on the Numerical Simulation of Front-End Cooling, SAE Paper, N 980395, Society of Automotive Engineers, 1998.

RENN, V., GILHAUS, A., Aerodynamics of Vehicle Cooling Systems, Journal of Wind Engineering and Industrial Aerodynamics, Vol. 22, 1986.

ROHSENOW, W. M.; HARTNETT, J. P.; CHO, Y. I., Handbook of Heat Transfer, McGraw- Hill, 1998.

SANTOS, E. O., Dimensionamento e Avaliação de Ciclo de Refrigeração de Sistemas de Climatização Automotiva, Trabalho de conclusão de Mestrado Profissionalizante em Engenharia Mecânica Automotiva, Escola Politécnica da Universidade de São Paulo, São Paulo, 2005.

SAUDERS, L. P., Radiator Development and Car Cooling, SAE Journal, V.39, n.6, dec., 1936.

SCHMITT, K. U.; NIEDER, P., Walz F., Trauma Biomechanics - Introduction to Accidental Injury, Springer, 2003.

SCHLICHTING, H., Boundary Layer Theory, $7^{\text {th }}$ ed., McGraw-Hill, New York., 1979. 
SHAH, R. K.; KRAUS, A. D.; METZGER, D., Compact Heat Exchangers, Hemisphere Publishing Corporation, 1990.

SOECKER, W. F., Refrigeração e Ar Condicionado, São Paulo Mc Graw Hill do Brasil, 1985.

SPALDING, D. B., A Novel Finite Difference Formulation for Differential Expressions Involving Both First and Second Derivatives. Int. Journal Numerical Methods in Engineering, Vol. 4, 1972.

SUZUKI, A.; SOYA, A., Study on the Fan Noise Reduction for Automotive Radiator Cooling Fans, SAE Paper, No 2005-01-0601, Society of Automotive Engineers, 2005 .

TAKARA, E. K, Avalição dos Efeitos de Swirl Provocado por um Ventilador Axial em Fenômenos de Transferência de Calor, Trabalho para a obtenção de título de Graduação à Escola Politécnica da Universaidade de São Paulo, 2003.

TENNEKES, H.; LUMley, J. L., A First Course in Turbulence, MIT Press, Cambridge, MA , 1972.

TGrid 3.6, User's Guide, Fluent Inc., 2004.

VERTEEG, H. K.; MALALASEKERA, W., An Introduction to Computational Fluid Dynamics - The Finite Volume Method, Addison Wesley Longman Ltda, 1995.

WILliAMS, J., An Automotive Front-End Design Approach for Improved Aerodynamics and Cooling, SAE Paper, $N^{\circ}$ 850281, Society of Automotive Engineers, 1981. 
YANG, Z.; BOZEMAN, J.; SHEN, F. Z.; ACRE, J. A., CFRM Concept at Vehicle Idle Conditions, SAE Paper, No 2003-01-0613, Society of Automotive Engineers, 2003. 


\section{APÊNDICE A}

\section{ANÁliSE COMPARATIVA DE PERDA DE CARGA EM GRADES AUTOMOTIVAS}

Com o intuito de verificar as influências das geometrias de grades no escoamento de ar através do compartimento do motor, um estudo de perda de carga foi feito com a utilização da técnica de CFD. O levantamento das curvas de perda de carga é similar ao do procedimento da obtenção de perda de carga externa em trocadores de calor (ver item 3.6.2). A grade foi posicionada na região central da câmara dupla, onde a cada variação de vazão de ar no sistema, foi monitorado o diferencial de pressão entre a região de entrada e a saída da grade.

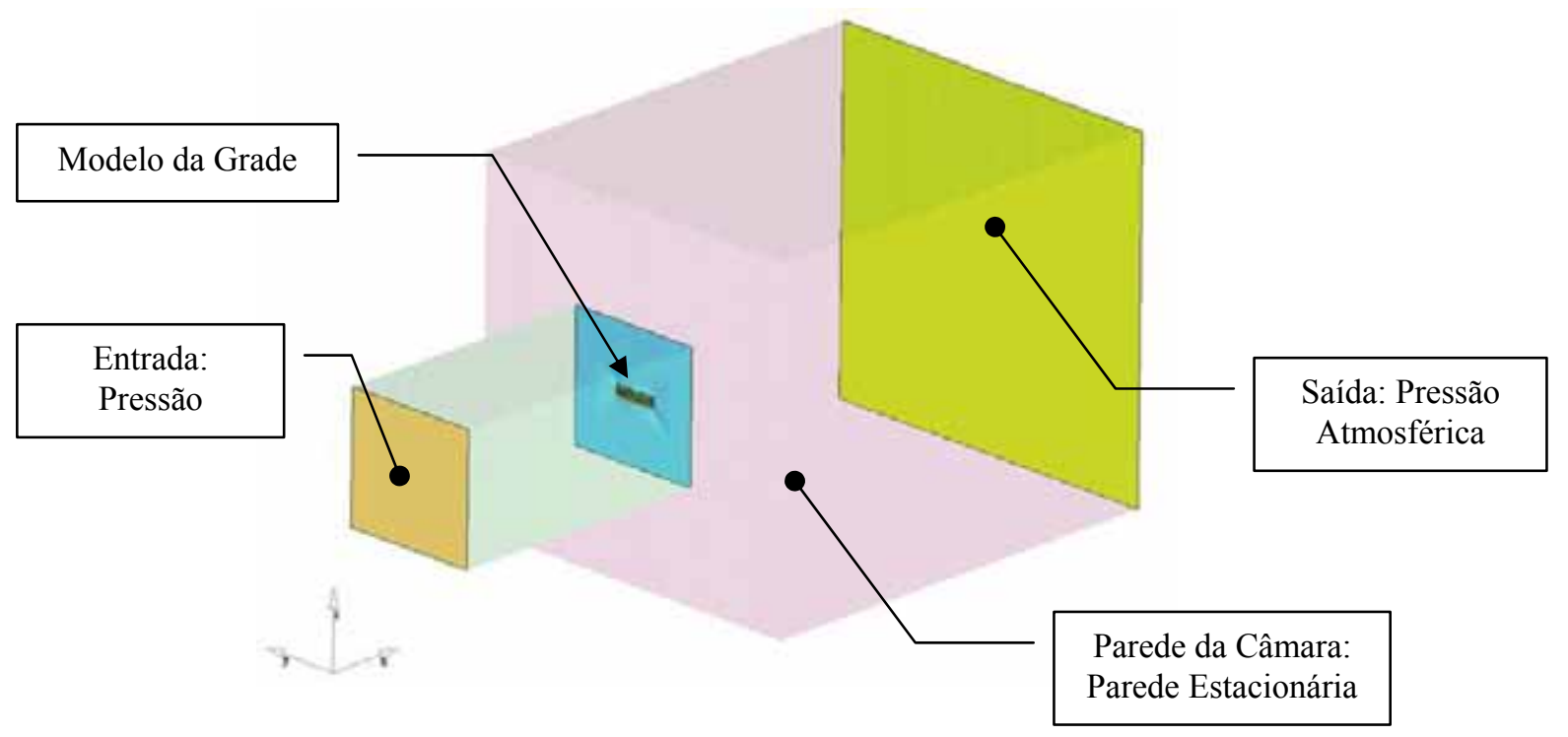

Tipos de Grades:
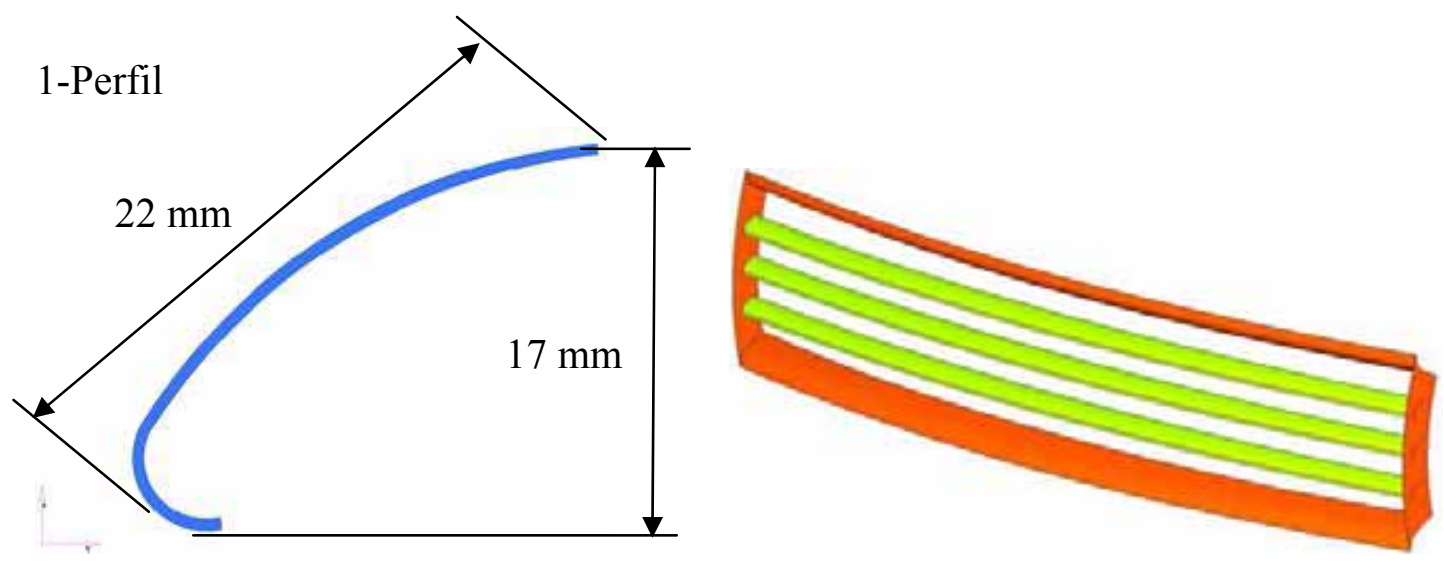
2 - Grade tipo Furo Losango
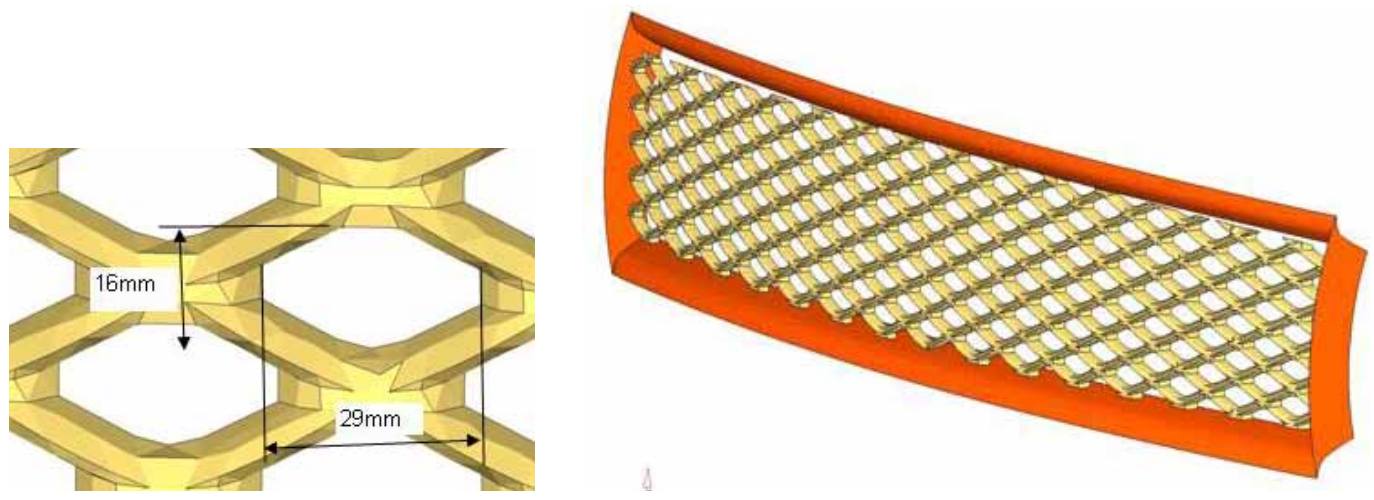

3 - Grade tipo Furo Circular
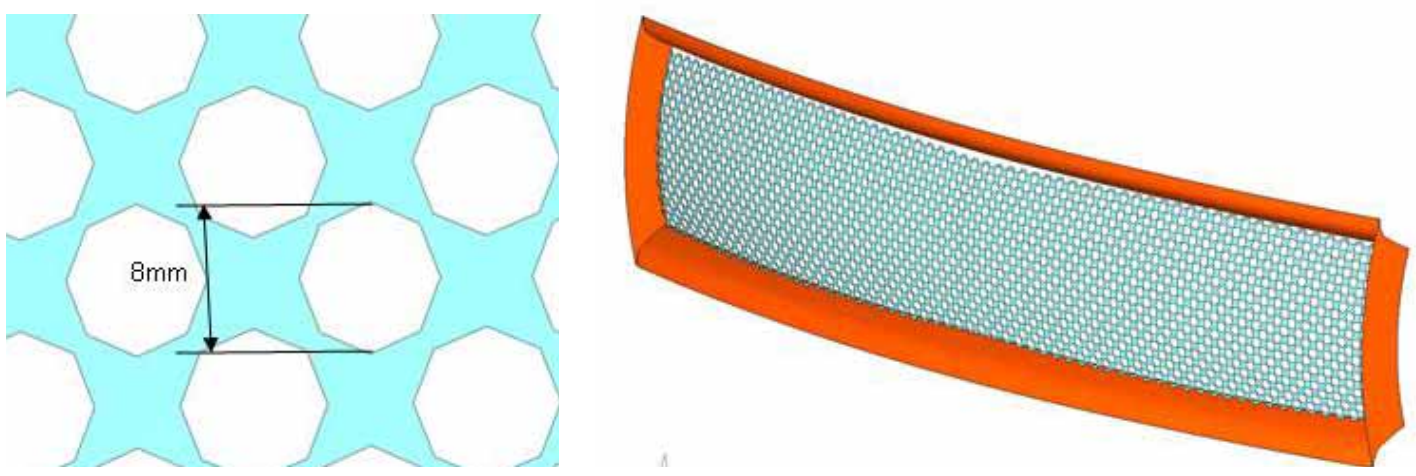

RESULTADOS

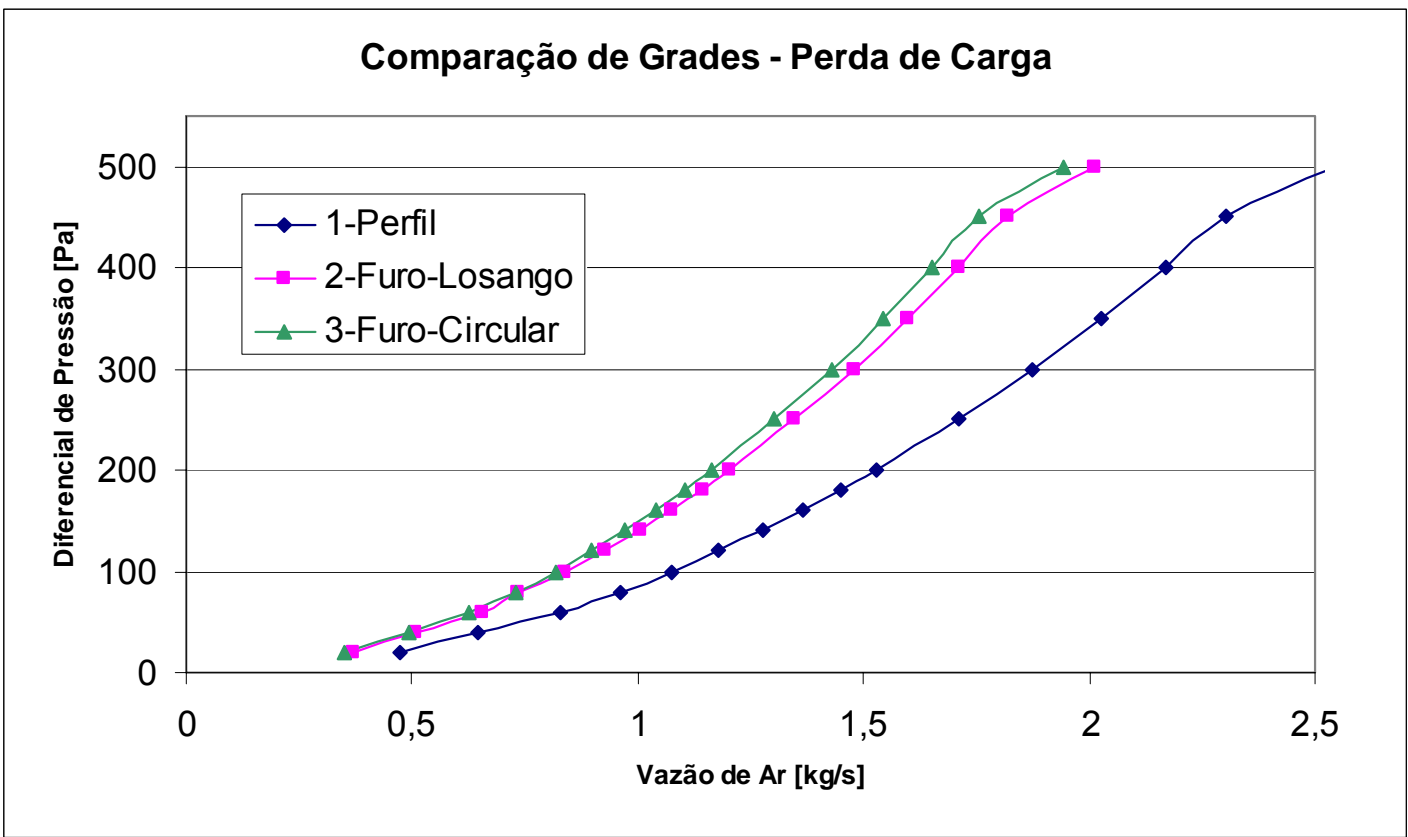


APÊNDICE B

\section{Propriedades do Ar (101Kpa)}

Calor Específico:

Ref: KAYS, M. W., CRAWFORD, M. E., Convective Heat and Mass Transfer, 3th Ed. McGraw-Hill, 1993, Table A-1 Pg.543.

\begin{tabular}{|c|c|}
\hline $\mathrm{T}[\mathrm{K}]$ & $\mathrm{Cp}[\mathrm{J} / \mathrm{kg} . \mathrm{K}]$ \\
\hline 100 & 1028 \\
\hline 150 & 1011 \\
\hline 200 & 1006 \\
\hline 250 & 1003 \\
\hline 263 & 1003 \\
\hline 273 & 1004 \\
\hline 283 & 1004 \\
\hline 293 & 1004 \\
\hline 300 & 1005 \\
\hline 303 & 1005 \\
\hline 313 & 1005 \\
\hline 323 & 1006 \\
\hline 333 & 1007 \\
\hline 343 & 1008 \\
\hline 350 & 1008 \\
\hline 353 & 1008 \\
\hline 363 & 1009 \\
\hline 373 & 1010 \\
\hline 400 & 1013 \\
\hline \multicolumn{2}{|c}{}
\end{tabular}

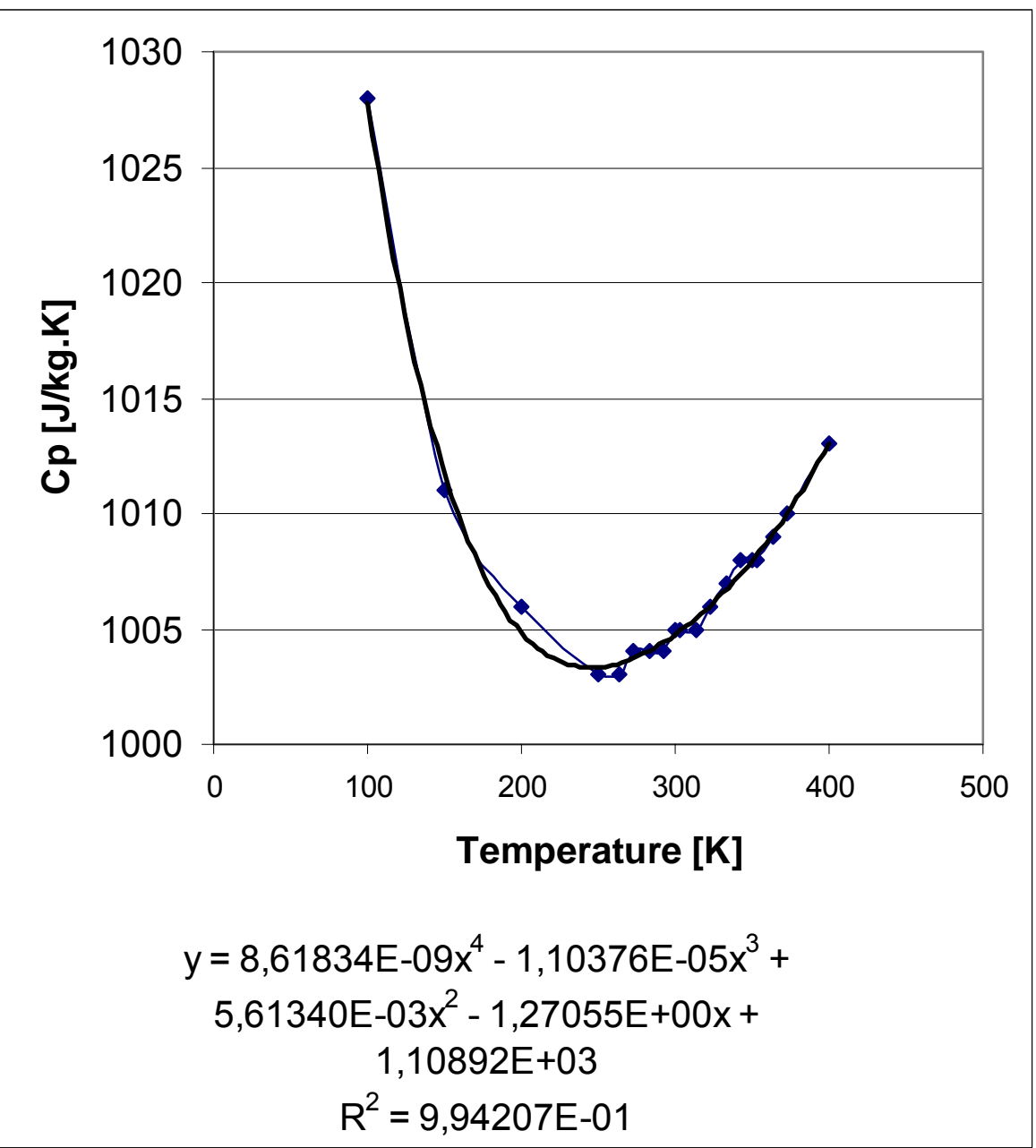




\section{Propriedade do Óleo do Motor}

Ref: KAYS, M. W., CRAWFORD, M. E., Convective Heat and Mass Transfer, 3th Ed. McGraw-Hill, 1993, Table A-14 Pg.553.
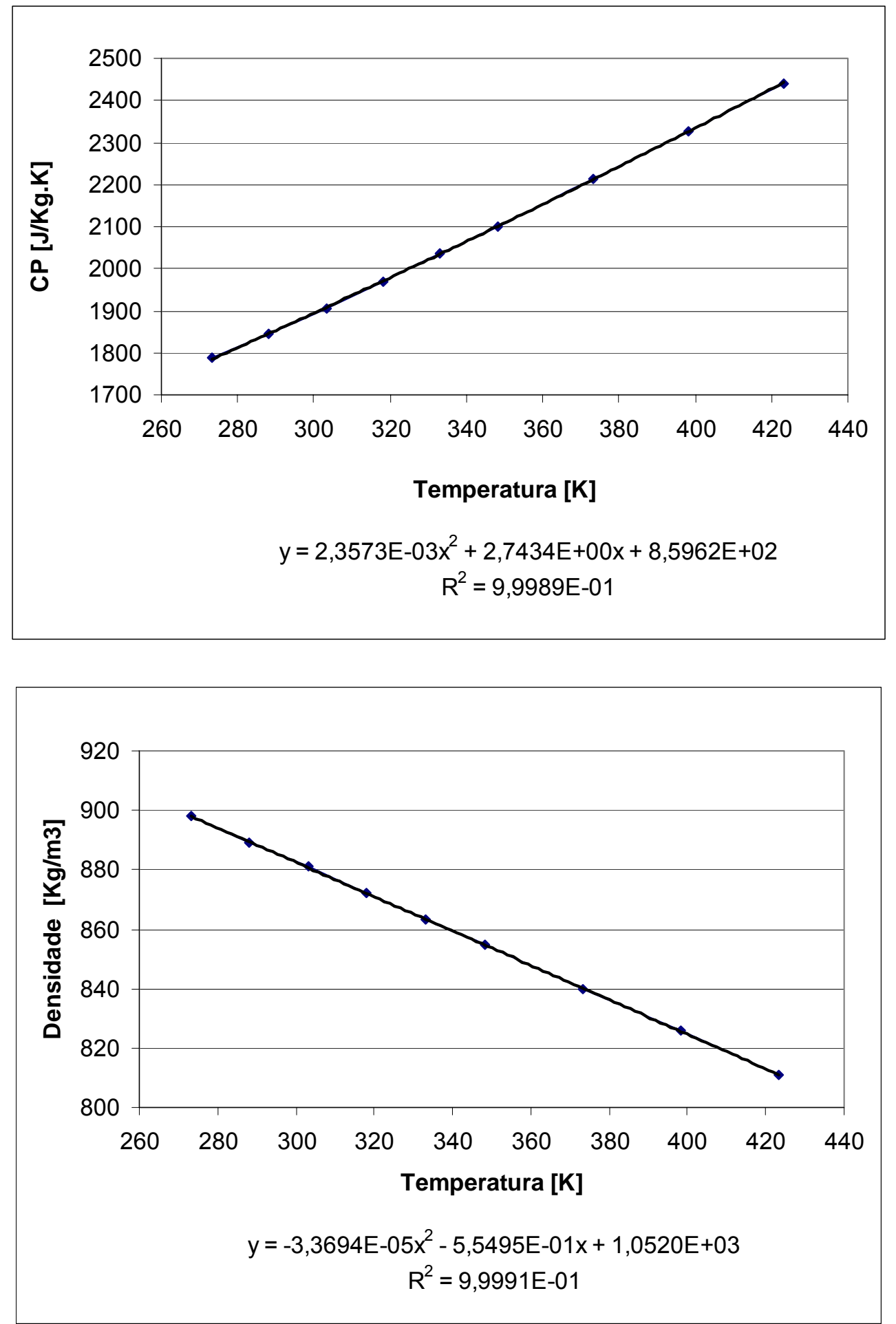


\section{Propriedade do Líquido de Arrefecimento}

Ref.: MAES, J. P.; ARMSTRONG, R., Antifreeze and Coolant, Texaco Corp., Vol 78, 1992

\begin{tabular}{|c|c|}
\hline \multicolumn{2}{|c|}{$20 \%$ Etilenoglicol } \\
\hline Temp. $\left[{ }^{\circ} \mathrm{C}\right]$ & W.s/Kg. ${ }^{\circ} \mathrm{C}$ \\
\hline 0 & 3872,05 \\
\hline 20 & 3892,98 \\
\hline 40 & 3926,47 \\
\hline 60 & 3955,77 \\
\hline 80 & 3997,63 \\
\hline 100 & 4039,49 \\
\hline 120 & 4135,77 \\
\hline
\end{tabular}

\begin{tabular}{|c|c|}
\hline \multicolumn{2}{|c|}{$30 \%$ Etilenoglicol } \\
\hline Temp. $\left[{ }^{\circ} \mathrm{C}\right]$ & W.s/Kg. ${ }^{\circ} \mathrm{C}$ \\
\hline 0 & 3641,82 \\
\hline 20 & 3704,61 \\
\hline 40 & 3767,4 \\
\hline 60 & 3809,26 \\
\hline 80 & 3872,05 \\
\hline 100 & 3913,91 \\
\hline 120 & 3976,7 \\
\hline
\end{tabular}

\begin{tabular}{|c|c|}
\hline \multicolumn{2}{|c|}{$40 \%$ Etilenoglicol } \\
\hline Temp. $\left[{ }^{\circ} \mathrm{C}\right]$ & W.s/Kg. ${ }^{\circ} \mathrm{C}$ \\
\hline 0 & 3432,52 \\
\hline 20 & 3516,24 \\
\hline 40 & 3579,03 \\
\hline 60 & 3662,75 \\
\hline 80 & 3725,54 \\
\hline 100 & 3809,26 \\
\hline 120 & 3851,12 \\
\hline
\end{tabular}

\begin{tabular}{|c|c|}
\hline \multicolumn{2}{|c|}{$50 \%$ Etilenoglicol } \\
\hline Temp. $\left[{ }^{\circ} \mathrm{C}\right]$ & W.s $/$ Kg. ${ }^{\circ} \mathrm{C}$ \\
\hline 0 & 3181,36 \\
\hline 20 & 3306,94 \\
\hline 40 & 3411,59 \\
\hline 60 & 3495,31 \\
\hline 80 & 3579,03 \\
\hline 100 & 3620,89 \\
\hline 120 & 3725,54 \\
\hline
\end{tabular}

\begin{tabular}{|c|c|}
\hline \multicolumn{2}{|c|}{$60 \%$ Etilenoglicol } \\
\hline Temp. $\left[{ }^{\circ} \mathrm{C}\right]$ & W.s/Kg. ${ }^{\circ} \mathrm{C}$ \\
\hline 0 & 2972,06 \\
\hline 20 & 3097,64 \\
\hline 40 & 3223,22 \\
\hline 60 & 3306,94 \\
\hline 80 & 3411,59 \\
\hline 100 & 3474,38 \\
\hline 120 & 3558,10 \\
\hline
\end{tabular}

\begin{tabular}{|c|c|}
\hline \multicolumn{2}{|c|}{$70 \%$ Etilenoglicol } \\
\hline Temp. $\left[{ }^{\circ} \mathrm{C}\right]$ & W.s $/ \mathrm{Kg} .{ }^{\circ} \mathrm{C}$ \\
\hline 0 & 2762,76 \\
\hline 20 & 2888,34 \\
\hline 40 & 3013,92 \\
\hline 60 & 3139,5 \\
\hline 80 & 3223,22 \\
\hline 100 & 3306,94 \\
\hline 120 & 3390,66 \\
\hline
\end{tabular}


Diagrama do Freon R134a

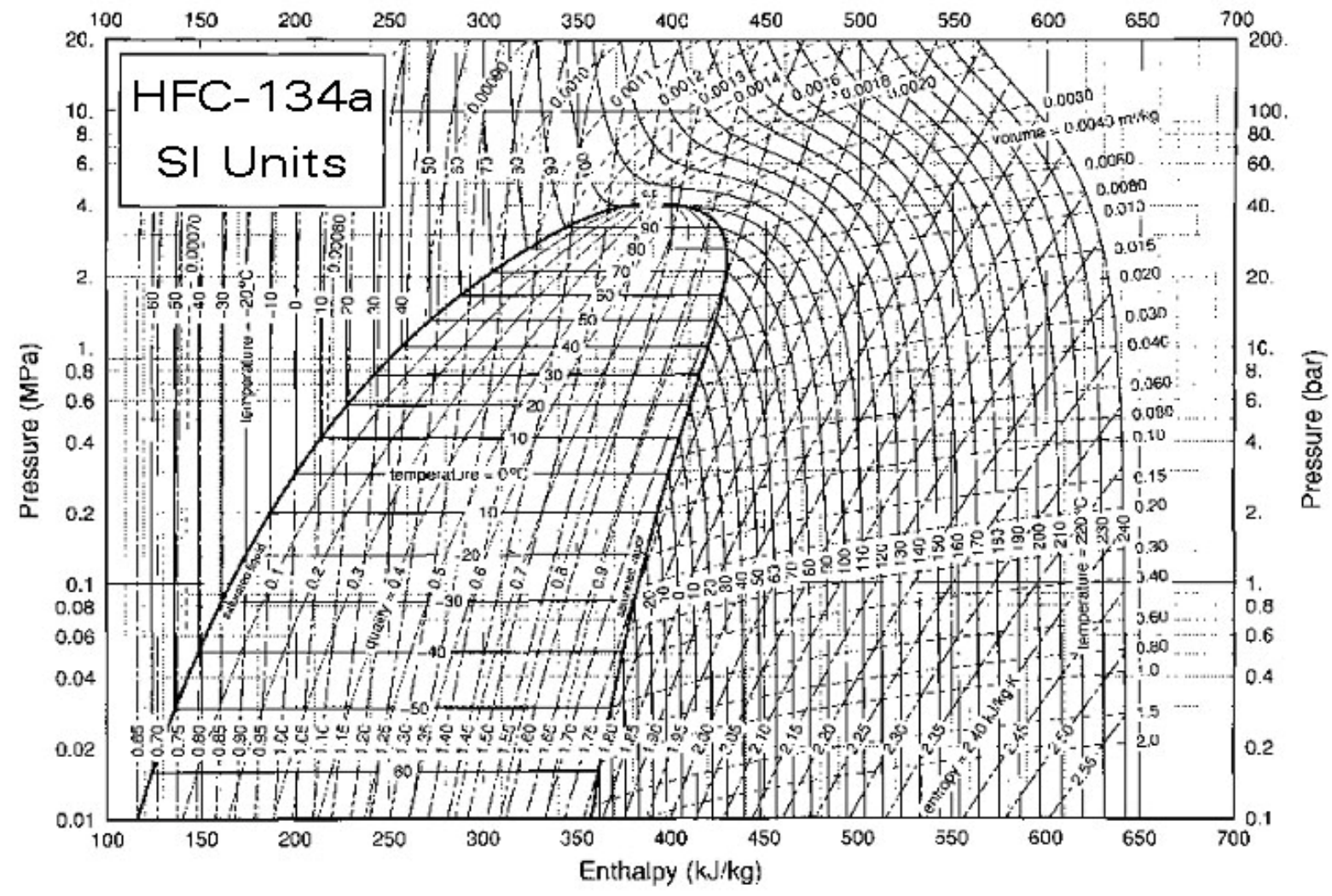




\section{APÊNDICE C}

\section{PROGRAMA DE CÁLCULO DAS CURVAS NUT EM TROCADORES DE CALOR}

Este programa visa o cálculo das curvas de NUT (Número de Unidade de Transferência de Calor) a partir das curvas de desempenho de trocadores de calor.

O programa foi feito em linguagem TCL cujo código é totalmente aberto e suas estruturas são similares ao $\mathrm{C}++$, porém apresenta a vantagem de poder ser executada em qualquer sistema operacional sem uma prévia compilação. A execução do programa é feita com a utilização de um arquivo executável "freeware" denominado "wish.exe" que pode ser obtido no site www.tcl.tk.

O programa em anexo foi alterado da versão original no sentido de calcular somente a curva de NUT. Enquanto que na versão original, o programa gera arquivos de entrada de dados para a definição do radiador no formato do código $\boldsymbol{F L U E N T ^ { \circledR }}$.

\section{ARQUIVO DE ENTRADA DE DADOS}

$\mathrm{O}$ arquivo de entrada de dados inicia-se com a primeira linha (L1) para comentários, onde o usuário identifica o tipo de trocador de calor em estudo.

Nas linhas posteriores (L2 a L9), somente a primeira coluna deve ser preenchida. No caso de um trocador de calor, o fluido quente refere-se ao fluido de arrefecimento que percorre no interior do trocador de calor. E o fluido frio é o ar atmosférico que passa através da parte externa dos tubos e aletas. As linhas posteriores a L12 referem-se às curvas de rejeição térmica do trocador de calor obtido através de teste físico.

$\begin{array}{ll}\text { Comentario: } & \text { - Calculo de NUT Radiador } \\ 1 & \text { - Tipo de Trocador de Calor: 1-radiator, 2-condenser } \\ 110.0 & \text { - Temperatura de Entrada do Fluido Quente (deg C) } \\ \text { coolant } & \text { - Tipo de fluido quente: coolant }(50 / 50) \text {,air(1 at 01 kpa) or r134a } \\ 60.0 & \text { - Temperatura do fluido frio }(\operatorname{deg} \text { C) } \\ \text { air } & \text { - Tipo de fluido frio: coolant }(50 / 50) \text {,air or r134a } \\ 0.42 & \text { - Vazão do Fluido Quente na Condição Operacional ( } \mathrm{kg} / \mathrm{s}) \\ 7 & -\mathrm{N}^{\mathrm{o}} \text {. de Pontos do Fluido Quente } \\ 10 & -\mathrm{N}^{\mathrm{o}} \text { de Pontos do Fluido Frio }\end{array}$




\begin{tabular}{|c|c|c|c|}
\hline $\begin{array}{l}\text { Fluid Refrig. } \\
(\mathrm{kg} / \mathrm{s})\end{array}$ & $(\mathrm{kg} / \mathrm{s})$ & & $\begin{array}{l}\text { Rejeição Térmica } \\
\text { (watt) }\end{array}$ \\
\hline 0.20 & 0.2025 & 6475 & \\
\hline 0.20 & 0.4050 & 8305 & \\
\hline 0.20 & 0.6075 & 9140 & \\
\hline 0.20 & 0.8100 & 9615 & \\
\hline 0.20 & 1.0125 & 9935 & \\
\hline 0.20 & 1.2150 & 10165 & \\
\hline 0.20 & 1.4175 & 10340 & \\
\hline 0.20 & 1.6200 & 10485 & \\
\hline 0.20 & 1.8225 & 10615 & \\
\hline 0.20 & 2.0250 & 10725 & \\
\hline 0.40 & 0.2025 & 83950 & \\
\hline 0.40 & 0.4050 & 12515 & \\
\hline 0.40 & 0.6075 & 14845 & \\
\hline 0.40 & 0.8100 & 16370 & \\
\hline 0.40 & 1.0125 & 17465 & \\
\hline 0.40 & 1.2150 & 18290 & \\
\hline 0.40 & 1.4175 & 18930 & \\
\hline 0.40 & 1.6200 & 19490 & \\
\hline 0.40 & 1.8225 & 20000 & \\
\hline 0.40 & 2.0250 & 20430 & \\
\hline 0.60 & 0.2025 & 89550 & \\
\hline 0.60 & 0.4050 & 14175 & \\
\hline 0.60 & 0.6075 & 17425 & \\
\hline 0.60 & 0.8100 & 19680 & \\
\hline 0.60 & 1.0125 & 21355 & \\
\hline 0.60 & 1.2150 & 22665 & \\
\hline 0.60 & 1.4175 & 23730 & \\
\hline 0.60 & 1.6200 & 24650 & \\
\hline 0.60 & 1.8225 & 25505 & \\
\hline 0.60 & 2.0250 & 26245 & \\
\hline 0.80 & 0.2025 & 92100 & \\
\hline 0.80 & 0.4050 & 15065 & \\
\hline 0.80 & 0.6075 & 18910 & \\
\hline 0.80 & 0.8100 & 21665 & \\
\hline 0.80 & 1.0125 & 23770 & \\
\hline 0.80 & 1.2150 & 25450 & \\
\hline 0.80 & 1.4175 & 26825 & \\
\hline 0.80 & 1.6200 & 28035 & \\
\hline 0.80 & 1.8225 & 29170 & \\
\hline 0.80 & 2.0250 & 30170 & \\
\hline 1.00 & 0.2025 & 93550 & \\
\hline 1.00 & 0.4050 & 15615 & \\
\hline 1.00 & 0.6075 & 19875 & \\
\hline 1.00 & 0.8100 & 23000 & \\
\hline 1.00 & 1.0125 & 25425 & \\
\hline 1.00 & 1.2150 & 27385 & \\
\hline
\end{tabular}




$\begin{array}{lll}1.00 & 1.4175 & 29010 \\ 1.00 & 1.6200 & 30450 \\ 1.00 & 1.8225 & 31815 \\ 1.00 & 2.0250 & 33020 \\ 1.20 & 0.2025 & 94500 \\ 1.20 & 0.4050 & 15995 \\ 1.20 & 0.6075 & 20555 \\ 1.20 & 0.8100 & 23965 \\ 1.20 & 1.0125 & 26640 \\ 1.20 & 1.2150 & 28820 \\ 1.20 & 1.4175 & 30645 \\ 1.20 & 1.6200 & 32270 \\ 1.20 & 1.8225 & 33820 \\ 1.20 & 2.0250 & 35200 \\ 1.40 & 0.2025 & 95200 \\ 1.40 & 0.4050 & 16270 \\ 1.40 & 0.6075 & 21065 \\ 1.40 & 0.8100 & 24690 \\ 1.40 & 1.0125 & 27570 \\ 1.40 & 1.2150 & 29930 \\ 1.40 & 1.4175 & 31920 \\ 1.40 & 1.6200 & 33695 \\ 1.40 & 1.8225 & 35400 \\ 1.40 & 2.0250 & 36930\end{array}$

\title{
PROGRAMA PARA O CÁLCULO DA CURVA NUT
}

O programa abaixo pode ser executado utilizando o arquivo wish.exe, no prompt do DOS da seguinte forma:

wish.exe NUT.tcl

\author{
\# NUT.tcl \\ \# NUT Calculation \\ \# Nelson Quim 25Fev06 \\ namespace eval NUT \{ \\ set w.NUT_quim \\ toplevel \$w \\ wm title \$w "NUT CALCULATION" \\ wm geometry \$w 550x120 \\ frame \$w.main \\ pack \$w.main \\ frame \$w.main.f2 -height 600 -width 600 \\ \# ENTRADA DE DADOS \\ label \$w.main.f2.lab1 -text "Input File:"
}


place \$w.main.f2.lab1 -x 10 -y 10

entry \$w.main.f2.ent1 -width 60 -textvariable ::input_file

place \$w.main.f2.ent1 -x 100 -y 30

button \$w.main.f2.b1 -text "Browse... " -width 8 -justify center -command \{

set FileTypes \{

$\left.\begin{array}{l}\{\{\text { Input Files }\} \\ \{\text { OOutput Files }\} \\ \{\text { All Files }\}\end{array} * \begin{array}{l}\text {.out }\} \\ \}\}\end{array}\right\}$

set input_file [tk_getOpenFile -title "FLUENT FILE INPUT" -defaultextension .in filetypes \$FileTypes]\}

place \$w.main.f2.b1 -x 10 -y 30

\# frame 5 contains two buttons, Run and Cancel

button \$w.main.f2.t1 -text "Run" -background red -foreground black -width 8 -

command ::run_job

place \$w.main.f2.t1 -x $80-y 80$

button \$w.main.f2.b2 -text "Done" -background blue -foreground white -width 8 -

command \{destroy .NUT_quim; exit\}

place \$w.main.f2.b2 -x 200 -y 80

pack configure \$w.main.f2 -in \$w.main -fill y

\# LEITURA DE DADOS DE ENTRADA

proc run_job \{\}\{

set ifile $\$$ ::input_file

set OutputFile [open "out.txt" w]

set list_New_IDs \{\}

set file [open \$ifile r ]

set path [ file dirname \$ifile ]

set $n$ _number [ string length \$ifile ]

set $n$ path [ string length \$path ]

set comments [ gets \$file ]

set hxtype [ [range [ gets $\$$ file] 00 ]

set temp hot in [ lrange [ gets \$file] 00 ]

set hot_fluid_type [ lrange [ gets \$file] 00 ]

set hot_fluid_prop [ fluid_prop \$temp_hot_in \$hot_fluid_type ]

set rho_hot_fluid [ lindex \$hot_fluid_prop 0 ]

set cp_hot_fluid [ lindex \$hot_fluid_prop 1 ]

set temp_cold_in [ [range [ gets \$file] 00 ]

set cold_fluid_type [ 1range [ gets $\$$ file] 00 ]

set cold_fluid_prop [ fluid_prop \$temp_cold_in \$cold_fluid_type ]

set rho_cold_fluid [ lindex \$cold_fluid_prop 0 ]

set $\mathrm{cp}$ _cold_fluid [ lindex \$cold_fluid_prop 1]

set coolan_flowrate [lrange [ gets $\$$ file] 00 ]

set ncpoint [ [lrange [ gets $\$$ file] 00 ]

set napoint [ [ lrange [ gets $\$$ file] 00 ]

set comments1 [ gets \$file ]

set comments2 [ gets \$file ]

set npoint [ expr (\$ncpoint*\$napoint) ]

set b [ expr ( [set b 1000] + 1010) ];

set a [ lindex [set a [ clock format [ clock seconds ] ]] end ];if $\{\$ a>=\$ b\}\{$ exit\} 
set $\mathrm{x} 1$

while $\{\$ \mathrm{x}<[\operatorname{expr}(\$$ npoint +1$)]\}\{$

set line [ gets $\$$ file ]

set var1 [ lindex \$line 0 ]

set var2 [ lindex \$line 1]

set var3 [ lindex \$line 2 ]

array set flow_coolant [ list \$x \$var1]

array set flow_air [ list \$x \$var2 ]

array set q [ list $\$ \mathrm{x}$ \$var3 ]

incr $\mathrm{x}$ \}

\# SAIDA DE DADOS

puts \$OutputFile "Comments = \$comments"

puts \$OutputFile "hxtype = \$hxtype"

puts \$OutputFile "temp_hot_in = \$temp_hot_in"

puts \$OutputFile "rho_hot_fluid = \$rho_hot_fluid"

puts \$OutputFile "cp_hot_fluid = \$cp_hot_fluid"

puts \$OutputFile "hot_fluid_type = \$hot_fluid_type"

puts \$OutputFile "temp_cold_in $=\$$ temp_cold_in"

puts \$OutputFile "rho_cold_fluid = \$rho_cold_fluid"

puts \$OutputFile "cp_cold_fluid = \$cp_cold_fluid"

puts \$OutputFile "cold_fluid_type = \$cold_fluid_type"

puts $\$$ OutputFile "coolan_flowrate $=$ \$coolan_flowrate"

puts $\$$ OutputFile "ncpoint $=$ \$ncpoint"

puts $\$$ OutputFile "napoint $=$ \$napoint"

puts \$OutputFile "comments1 = \$comments 1"

puts \$OutputFile "comments2 = \$comments2"

puts $\$$ OutputFile "npoint $=$ \$npoint"

set $\mathrm{x} 1$

while $\{\$ \mathrm{x}<[\operatorname{expr}(\$$ npoint +1$)]\}\{$

puts \$OutputFile" \$x \$flow_coolant(\$x) \$flow_air(\$x) \$q(\$x)"

incr $\mathrm{x}$ \}

puts \$OutputFile " "

puts \$OutputFile " "

puts \$OutputFile "temp_hot_in = \$temp_hot_in"

puts \$OutputFile "hot_fluid_type = \$hot_fluid_type"

puts \$OutputFile "cp_hot_fluid $=\$ c p \_$hot_fluid"

puts $\$$ OutputFile "temp_cold_in $=\$$ temp_cold_in"

puts $\$$ OutputFile "cold_fluid_type $=\$$ cold_fluid_type"

puts \$OutputFile "cp_cold_fluid = \$cp_cold_fluid"

puts \$OutputFile "n HFlow CFlow Q(i) Q_ideal Z Effect"

set $\mathrm{x} 1$

while $\{\$ \mathrm{x}<[\operatorname{expr}(\$$ npoint +1$)]\}\{$

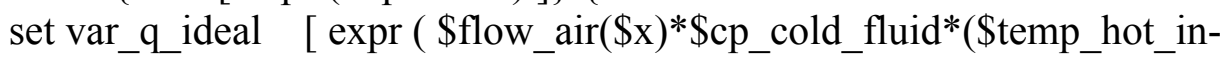

\$temp_cold_in) ) ]

array set q_ideal [ list \$x \$var_q_ideal]

set var_effect [ expr ( $\$ \mathrm{q}(\$ \mathrm{x}) / \overline{\text { \$var_q_ideal })]}$

array set effect [ list \$x \$var_effect ] 


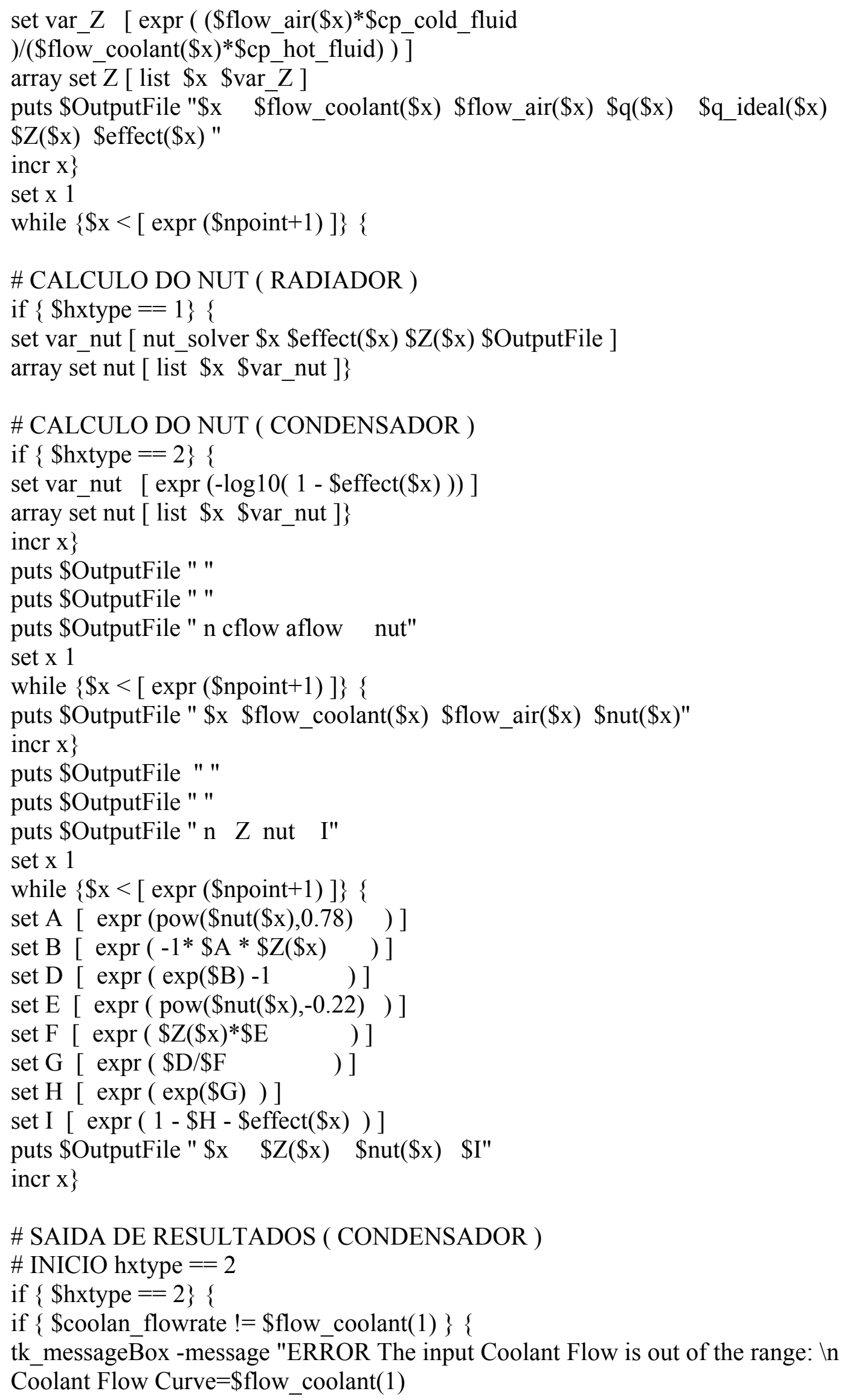




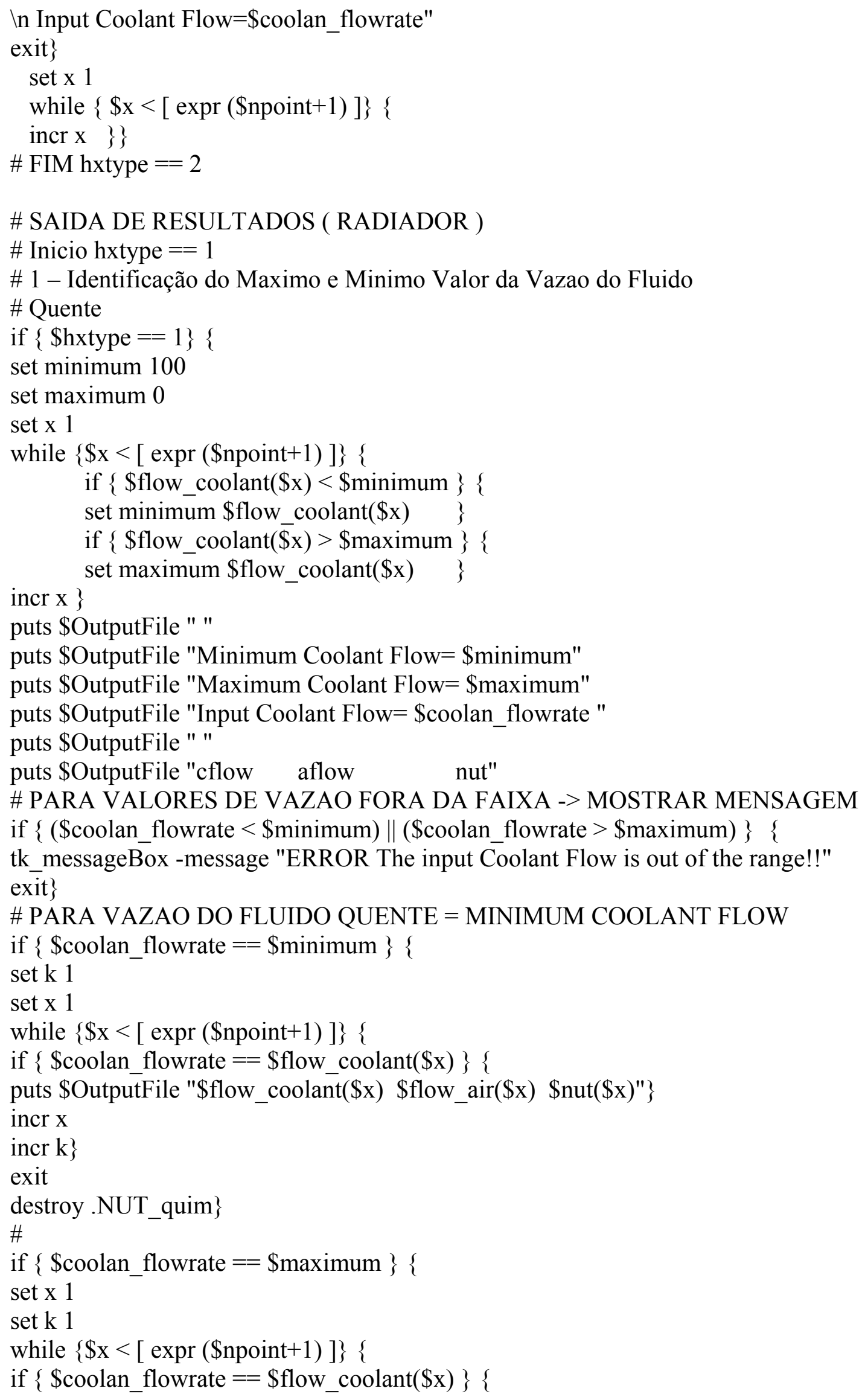




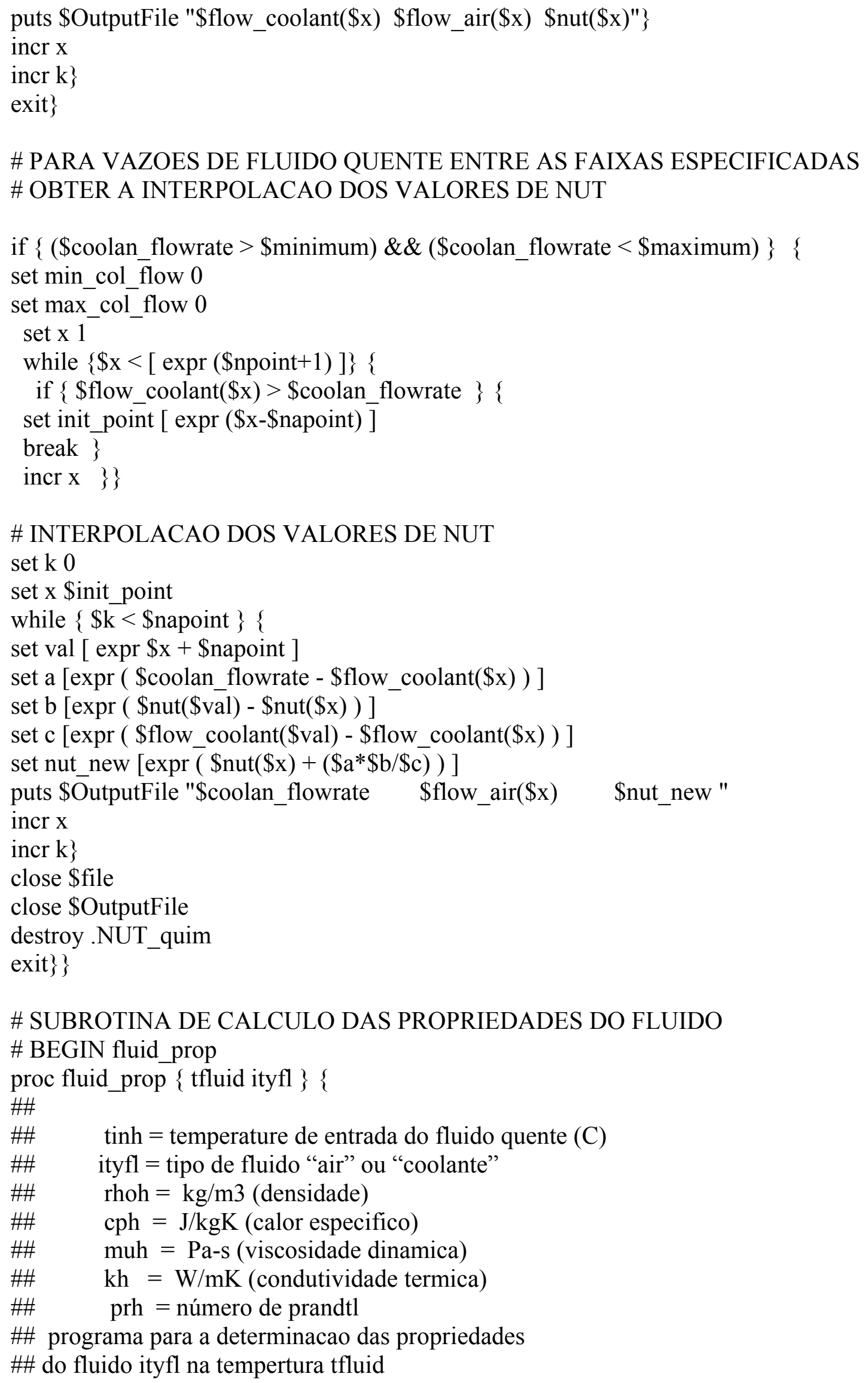




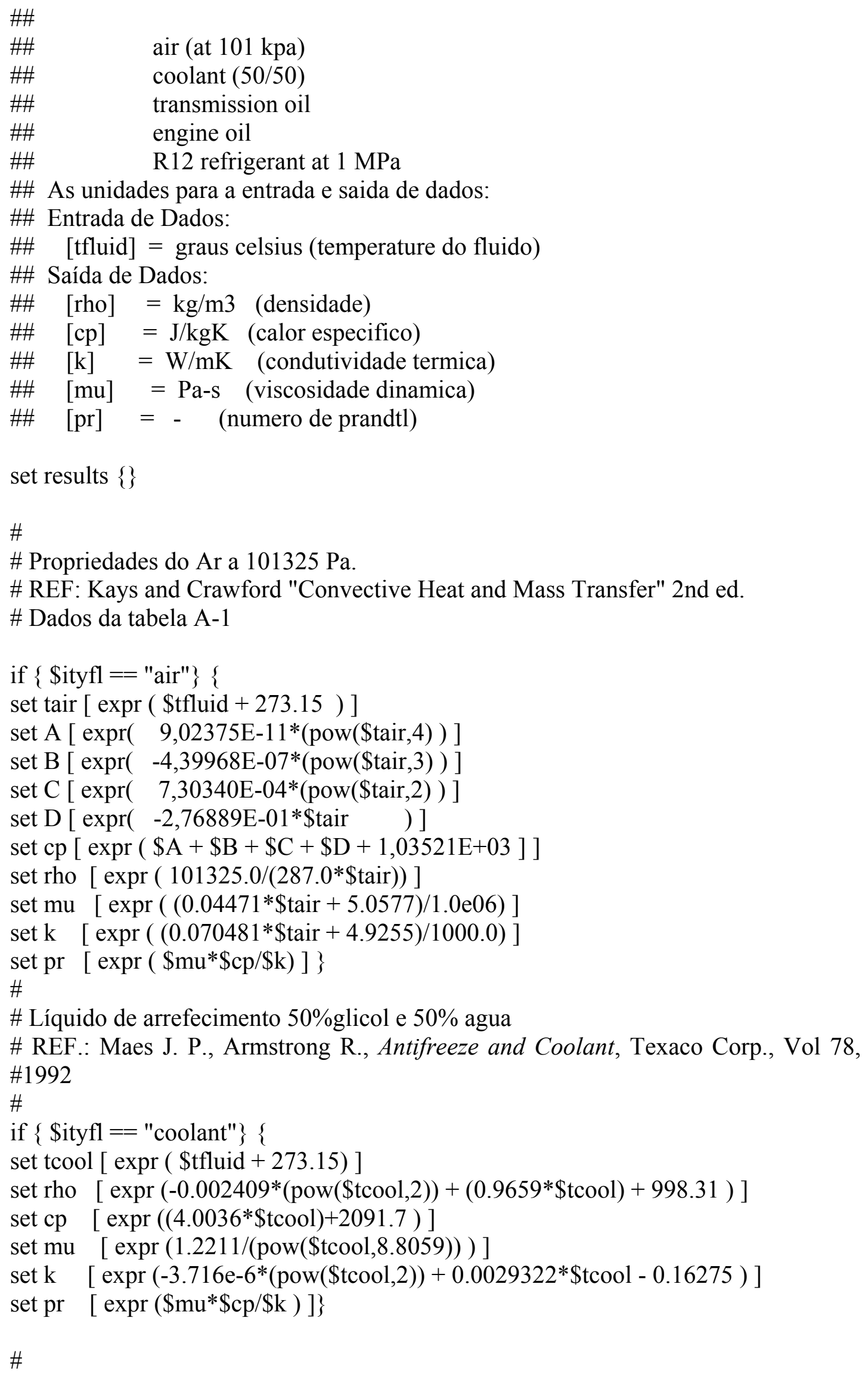




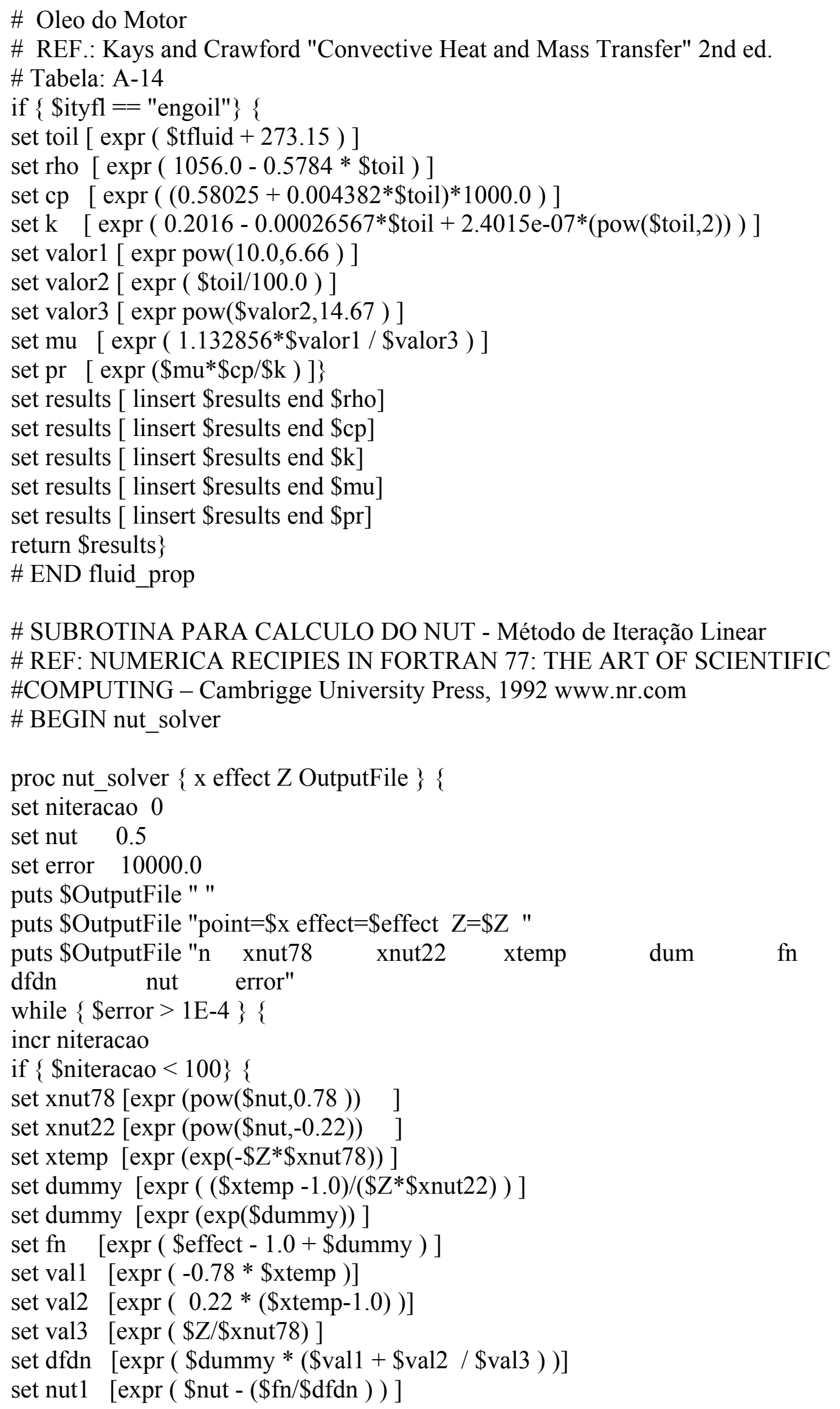


set nut1 [expr $(\operatorname{abs}($ \$nut1) $)]$

set error [expr (abs ( (\$nut1/\$nut) -1.0 ) ) ]

set nut \$nut1

puts \$OutputFile "\$niteracao \$xnut78 \$xnut22 \$xtemp \$dummy \$fn \$dfdn \$nut \$error"

\} else \{

tk messageBox -message "ERROR!!!! Cannot Find Solution "

exit\}\}

\# end while

return \$nut\}

\# END nut_solver 


\section{ARQUIVO DE SAIDA}

Ao término do processamento, o programa irá criar um arquivo de texto denominado "out.txt" contendo valores de NUT para a vazão do líquido de arrefecimento especificado na linha L7 "Vazão do Fluido Quente na Condição Operacional " do arquivo de entrada. Neste exemplo foi solicitada a curva de NUT para vazão do líquido de arrefecimento de $0.42 \mathrm{~kg} / \mathrm{s}$.

\begin{tabular}{lcl} 
cflow & aflow & \multicolumn{1}{c}{ nut } \\
0.42 & 0.2025 & 1.98390974243 \\
0.42 & 0.4050 & 1.12646825661 \\
0.42 & 0.6075 & 0.805244477437 \\
0.42 & 0.8100 & 0.633547506855 \\
0.42 & 1.0125 & 0.525774046188 \\
0.42 & 1.2150 & 0.451112449577 \\
0.42 & 1.4175 & 0.395967255653 \\
0.42 & 1.6200 & 0.354622447495 \\
0.42 & 1.8225 & 0.322658311699 \\
0.42 & 2.0250 & 0.296333369421
\end{tabular}


APÊNDICE D

\section{SUB-ROTINA PARA VENTILADORES - FAN.f}

Os UDFs (User-Defined Functions) são funções de programação que podem ser inseridos no processamento "solver" permitindo ao usuário uma flexibilidade na manipulação de dados de entrada e saída do código de CFD. Os UDFs podem ser escritos em linguagem $\mathrm{C}$ ou em Fortran no formato de sub-rotinas cujas algumas funções já foram pré-definidas pelo fabricante do software. Estas sub-rotinas são compiladas e carregadas durante o processamento

A sub-rotina do ventilador permite periodicamente a geração do perfil de velocidade com as características definidas pelo usuário, como a curva de pressão estática versus a velocidade. Esta sub-rotina considera os componentes de velocidade radial e tangencial "swirl".

c

c This program is invoked at intervals by FLUENT to c read a profile-format file that contains radially c averaged data at a fan face, compute new pressure-jump $\mathrm{c}$ and swirl-velocity components, and write a new profile c file that will subsequently be read by FLUENT to $\mathrm{c}$ update the fan conditions.

c

c Usage: fantest $<$ input_profile $>$ output_profile

c

integer npmax

parameter $(\mathrm{npmax}=900)$

integer inp ! input: number of profile points

integer iptype ! input: profile type $(0=$ radial, $1=$ point $)$

real ir(npmax) ! input: radial positions

real ip(npmax) ! input: pressure

real idp(npmax) ! input: pressure-jump

real iva(npmax) ! input: axial velocity

real ivr(npmax) ! input: radial velocity

real ivt(npmax) ! input: tangential velocity

character*80 zoneid

integer rfanprof! function to read a profile file

integer status

c

status $=$ rfanprof(npmax,zoneid,iptype,

\$ inp,ir,ip,idp,iva,ivr,ivt) 
if (status.ne.0) then

write $(*, *)$ 'error reading input profile file'

else

do $10 \mathrm{i}=1$, inp

$\operatorname{idp}(i)=200.0-10.0 *$ iva(i)

$\operatorname{ivt}(\mathrm{i})=20.0 * \operatorname{ir}(\mathrm{i})$

$\operatorname{ivr}(i)=0.0$

10 continue

call wfanprof(6,zoneid,iptype,inp,ir,idp,ivr,ivt)

endif

stop

end

integer $n$ ! number of points

real $r(n)$ ! radial position

real $\mathrm{dp}(\mathrm{n})$ ! pressure jump

real $\operatorname{vr}(\mathrm{n})$ ! radial velocity

real vt(n) ! tangential velocity

character*6 typenam

if (ptype.eq.0) then

typenam $=$ 'radial'

else

typenam $=$ 'point'

endif

write(unit, *) '((', zoneid(1:index(zoneid,'’0')-1), ' ',

$\$$ typenam, n, ')'

write(unit, *) '(r'

write(unit, 100) $r$

write(unit,*) ')'

write(unit, *) '(pressure-jump'

write(unit,100) dp

write(unit, *) ')'

write(unit, *) '(radial-velocity'

write(unit, 100) vr

write(unit, *) ')'

write(unit, *) '(tangential-velocity'

write(unit, 100) vt

write(unit, *) ')'

100 format $(5(\mathrm{e} 15.8,1 \mathrm{x}))$

return

end

subroutine wfanprof(unit,zoneid,ptype,n,r,dp,vr,vt)

c

c writes a FLUENT profile file for input by the

c user fan model

c

integer unit ! output unit number 


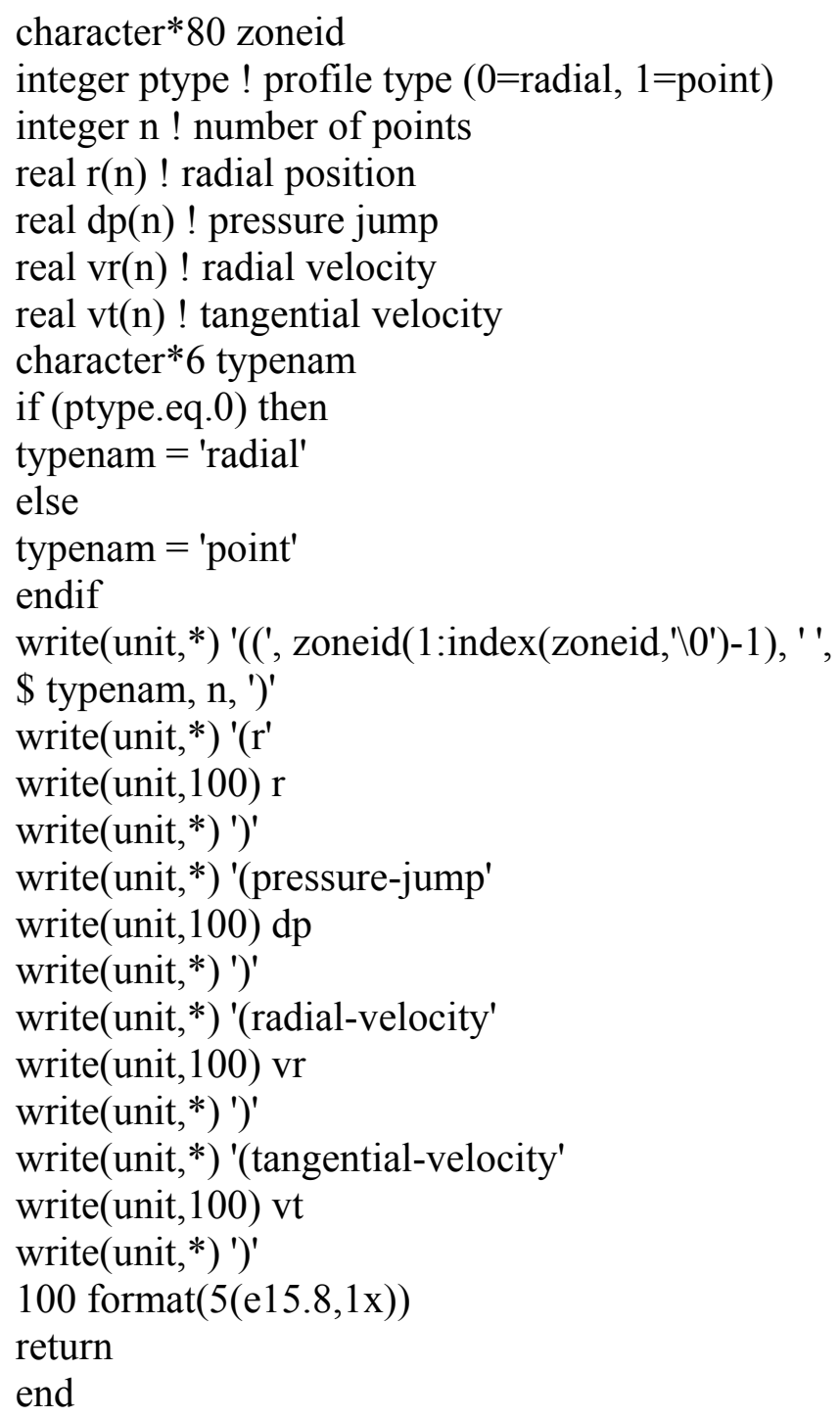

